\title{
Heterogeneous reactions of mineral dust aerosol: implications for tropospheric oxidation capacity
}

\author{
Mingjin Tang ${ }^{1}$, Xin Huang ${ }^{2}$, Keding Lu$^{3}$, Maofa Ge ${ }^{4}$, Yongjie Li ${ }^{5}$, Peng Cheng ${ }^{6}$, Tong Zhu $^{3}$, Aijun Ding ${ }^{2}$, \\ Yuanhang Zhang ${ }^{3}$, Sasho Gligorovski ${ }^{1}$, Wei Song ${ }^{1}$, Xiang Ding ${ }^{1}$, Xinhui Bi ${ }^{1}$, and Xinming Wang ${ }^{1,7}$ \\ ${ }^{1}$ State Key Laboratory of Organic Geochemistry and Guangdong Key Laboratory of Environmental Protection and Resources \\ Utilization, Guangzhou Institute of Geochemistry, Chinese Academy of Sciences, Guangzhou, China \\ ${ }^{2}$ Joint International Research Laboratory of Atmospheric and Earth System Sciences (JirLATEST), School of Atmospheric \\ Sciences, Nanjing University, Nanjing, China \\ ${ }^{3}$ State Key Joint Laboratory of Environmental Simulation and Pollution Control, College of Environmental Sciences and \\ Engineering, Peking University, Beijing, China \\ ${ }^{4}$ Beijing National Laboratory for Molecular Sciences, State Key Laboratory for Structural Chemistry of Unstable and Stable \\ Species, Institute of Chemistry, Chinese Academy of Sciences, Beijing, China \\ ${ }^{5}$ Department of Civil and Environmental Engineering, Faculty of Science and Technology, University of Macau, Avenida da \\ Universidade, Taipa, Macau, China \\ ${ }^{6}$ Institute of Mass Spectrometer and Atmospheric Environment, Jinan University, Guangzhou, China \\ ${ }^{7}$ Center for Excellence in Regional Atmospheric Environment, Institute of Urban Environment, Chinese Academy of \\ Sciences, Xiamen 361021, China
}

Correspondence to: Mingjin Tang (mingjintang@gig.ac.cn) and Tong Zhu (tzhu@ @ku.edu.cn)

Received: 15 May 2017 - Discussion started: 31 May 2017

Revised: 18 August 2017 - Accepted: 4 September 2017 - Published: 5 October 2017

\begin{abstract}
Heterogeneous reactions of mineral dust aerosol with trace gases in the atmosphere could directly and indirectly affect tropospheric oxidation capacity, in addition to aerosol composition and physicochemical properties. In this article we provide a comprehensive and critical review of laboratory studies of heterogeneous uptake of $\mathrm{OH}, \mathrm{NO}_{3}, \mathrm{O}_{3}$, and their directly related species as well (including $\mathrm{HO}_{2}, \mathrm{H}_{2} \mathrm{O}_{2}$, $\mathrm{HCHO}, \mathrm{HONO}$, and $\mathrm{N}_{2} \mathrm{O}_{5}$ ) by mineral dust particles. The atmospheric importance of heterogeneous uptake as sinks for these species is assessed (i) by comparing their lifetimes with respect to heterogeneous reactions with mineral dust to lifetimes with respect to other major loss processes and (ii) by discussing relevant field and modeling studies. We have also outlined major open questions and challenges in laboratory studies of heterogeneous uptake by mineral dust and discussed research strategies to address them in order to better understand the effects of heterogeneous reactions with mineral dust on tropospheric oxidation capacity.
\end{abstract}

\section{Introduction}

\subsection{Mineral dust in the atmosphere}

Mineral dust, emitted from arid and semiarid regions with an annual flux of $\sim 2000 \mathrm{Tg}$ per year, is one of the most abundant types of aerosol particles in the troposphere (Zhang et al., 2003b; Textor et al., 2006; Huneeus et al., 2011; Ginoux et al., 2012; Huang et al., 2016). After being emitted into the atmosphere, mineral dust aerosol has an average lifetime of a few days in the troposphere and can be transported over several thousand kilometers, thus having important impacts globally (Prospero, 1999; Uno et al., 2009; Huneeus et al., 2011). Mineral dust aerosol has a myriad of significant impacts on atmospheric chemistry and climate. For example, dust aerosol particles can influence the radiative balance of the Earth system directly by scattering and absorbing solar and terrestrial radiation (Balkanski et al., 2007; Jung et al., 2010; Lemaitre et al., 2010; Huang et al., 2014, 2015b; Zhang et al., 2015; Bi et al., 2016, 2017; Kok et al., 2017; Moteki et al., 2017) and indirectly by serving 
as cloud condensation nuclei (CCN) to form cloud droplets (Koehler et al., 2009; Kumar et al., 2009; Twohy et al., 2009; Garimella et al., 2014; Tang et al., 2016a) and ice nucleation particles (INPs) to form ice particles (DeMott et al., 2003; Hoose and Moehler, 2012; Murray et al., 2012; Ladino et al., 2013; DeMott et al., 2015). Mineral dust particles are believed to be the dominant ice nucleation particles in the troposphere (Hoose et al., 2010; Creamean et al., 2013; Cziczo et al., 2013), therefore having a large impact on the radiative balance, precipitation, and the hydrological cycle (Rosenfeld et al., 2001; Lohmann and Feichter, 2005; Rosenfeld et al., 2008). In addition, deposition of mineral dust is a major source for several important nutrient elements (e.g., Fe and $\mathrm{P})$ in remote regions such as open-ocean waters and the Amazon (Jickells et al., 2005; Mahowald et al., 2005, 2008; Boyd and Ellwood, 2010; Nenes et al., 2011; Schulz et al., 2012; Shi et al., 2012), strongly affecting several biogeochemical cycles and the climate system of the Earth (Jickells et al., 2005; Mahowald, 2011; Mahowald et al., 2011; Schulz et al., 2012). The impacts of mineral dust aerosol on air quality, atmospheric visibility, and public health have also been widely documented (Prospero, 1999; Mahowald et al., 2007; Meng and Lu, 2007; De Longueville et al., 2010, 2013; Giannadaki et al., 2014; Yang et al., 2017).

It is worth emphasizing that impacts of mineral dust aerosol on various aspects of atmospheric chemistry and climate depend on its mineralogy (Journet et al., 2008; Crowley et al., 2010a; Formenti et al., 2011; Highwood and Ryder, 2014; Jickells et al., 2014; Morman and Plumlee, 2014; Fitzgerald et al., 2015; Tang et al., 2016a), which shows large geographical and spatial variability (Claquin et al., 1999; Ta et al., 2003; Zhang et al., 2003a; Jeong, 2008; Nickovic et al., 2012; Scheuvens et al., 2013; Formenti et al., 2014; Journet et al., 2014; Scanza et al., 2015). According to a recent global modeling study (Scanza et al., 2015), major minerals contained by tropospheric mineral dust particles include quartz, illite, montmorillonite, feldspar, kaolinite, calcite, hematite, and gypsum. Formenti et al. (2011) summarized published measurements of tropospheric mineral dust particles, and the size of mineral dust particles depends on dust sources and transport, with typical volume median diameters being a few micrometers or larger.

Mineral dust particles can undergo heterogeneous and/or multiphase reactions during their transport (Dentener et al., 1996; Usher et al., 2003a; Crowley et al., 2010a). These reactions will modify the composition of dust particles (Matsuki et al., 2005; Ro et al., 2005; Sullivan et al., 2007; Shi et al., 2008; Li and Shao, 2009; He et al., 2014) and subsequently change their physicochemical properties, including hygroscopicity, CCN, and ice nucleation activities (Krueger et al., 2003b; Sullivan et al., 2009b; Chernoff and Bertram, 2010; Ma et al., 2012; Tobo et al., 2012; Sihvonen et al., 2014; Wex et al., 2014; Kulkarni et al., 2015), as well as the solubility of Fe and P, etc. (Meskhidze et al., 2005; Vlasenko et al., 2006; Duvall et al., 2008; Nenes et al., 2011; Shi et al.,
2012; Ito and $\mathrm{Xu}, 2014)$. The effects of heterogeneous and multiphase reactions on the hygroscopicity and $\mathrm{CCN}$ and ice nucleation activities of dust particles have been comprehensively summarized by a very recent review paper (Tang et al., 2016a), and the impacts of atmospheric aging processes on the Fe solubility of mineral dust has also been reviewed (Shi et al., 2012).

Heterogeneous reactions of mineral dust in the troposphere can also remove or produce a variety of reactive trace gases, directly and/or indirectly modifying the gasphase compositions of the troposphere and thus changing its oxidation capacity. The global impact of mineral dust aerosol on tropospheric chemistry through heterogeneous reactions were proposed in the mid-1990s by a modeling study (Dentener et al., 1996). According to this study, heterogeneous reactions with mineral dust could largely impact tropospheric photochemical oxidation cycles, resulting in up to $10 \%$ decreases in $\mathrm{O}_{3}$ concentrations in dust source regions and nearby. The pioneering work by Dentener et al. (1996) has motivated many following laboratory, field, and modeling works (de Reus et al., 2000; Tie et al., 2001; Bian and Zender, 2003; Usher et al., 2003a; Bauer et al., 2004; Crowley et al., 2010a; Zhu et al., 2010; Wang et al., 2012; Nie et al., 2014). It should be noted that the regional impact of heterogeneous reactions of mineral dust aerosol was even recognized earlier (Zhang et al., 1994). It has also been suggested that dust aerosol could indirectly impact tropospheric chemistry by affecting radiative fluxes and thus photolysis rates (Liao et al., 1999; Bian and Zender, 2003; Jeong and Sokolik, 2007; Real and Sartelet, 2011).

A few minerals (e.g., $\mathrm{TiO}_{2}$ ) with higher refractive indices, compared to stratospheric sulfuric acid particles, have been proposed as potentially suitable materials (Pope et al., 2012; Tang et al., 2014d; Weisenstein et al., 2015) instead of sulfuric acid and its precursors to be delivered into the stratosphere in order to scatter more solar radiation back into space, as one of the solar radiation management methods for climate engineering (Crutzen, 2006). Heterogeneous uptake of reactive trace gases by minerals is also of interest in this aspect for assessment of impacts of particle injection on stratospheric chemistry and especially stratospheric ozone (Pope et al., 2012; Tang et al., 2014d, 2016b). In addition, some minerals, such as $\mathrm{CaCO}_{3}$ and $\mathrm{TiO}_{2}$, are widely used as raw materials in construction, and their heterogeneous interactions with reactive trace gases can be important for local outdoor and indoor air quality (Langridge et al., 2009; Raff et al., 2009; Ammar et al., 2010; Baergen and Donaldson, 2016; George et al., 2016) and deterioration of construction surfaces (Lipfert, 1989; Webb et al., 1992; Striegel et al., 2003; Walker et al., 2012).

\subsection{An introduction to heterogeneous kinetics}

The rates of atmospheric heterogeneous reactions are usually described or approximated as pseudo-first-order reac- 
tions. The pseudo-first-order removal rate of a trace gas (X), $k_{\mathrm{I}}(\mathrm{X})$, due to the heterogeneous reaction with mineral dust, depends on its average molecular speed, $c(\mathrm{X})$, the surface area concentration of mineral dust aerosol, $S_{\mathrm{a}}$, and the uptake coefficient, $\gamma$, given by Eq. (1) (Crowley et al., 2010a; Kolb et al., 2010; Ammann et al., 2013; Tang et al., 2014b):

$k_{\mathrm{I}}(X)=0.25 \cdot c(\mathrm{X}) \cdot S_{\mathrm{A}} \cdot \gamma$.

The uptake coefficient is the net probability that a molecule $\mathrm{X}$ is actually removed from the gas phase upon collision with the surface, equal to the ratio of the number of molecules removed from the gas phase to the total number of gas-surface collisions (Crowley et al., 2010a).

Heterogeneous reaction of a trace gas (X) will lead to depletion of $\mathrm{X}$ close to the surface, and thus the effective uptake coefficient, $\gamma_{\text {eff }}$, will be smaller than the true uptake coefficient, $\gamma$, as described by Eq. (2) (Crowley et al., 2010a; Davidovits et al., 2011; Tang et al., 2014b):

$\frac{1}{\gamma_{\mathrm{eff}}}=\frac{1}{\gamma}+\frac{1}{\Gamma_{\mathrm{diff}}}$

where $\Gamma_{\text {diff }}$ represents the gas-phase diffusion limitation. For the uptake onto spherical particles, Eq. (3) (the FuchsSutugin equation) can be used to calculate $\Gamma_{\text {diff }}$ (Tang et al., 2014b, 2015):

$$
\frac{1}{\Gamma_{\text {diff }}}=\frac{0.75+0.286 K n}{K n \cdot(K n+1)},
$$

where $K n$ is the Knudsen number, given by Eq. (4),

$K n=\frac{2 \lambda(\mathrm{X})}{d_{\mathrm{p}}}=\frac{6 D(\mathrm{X})}{c(\mathrm{X}) \cdot d_{\mathrm{p}}}$

where $\lambda(\mathrm{X}), D(\mathrm{X})$, and $d_{\mathrm{p}}$ are the mean free path of $\mathrm{X}$, the gas-phase diffusion coefficient of $X$, and the particle diameter, respectively. Experimentally measured gas-phase diffusion coefficients of trace gases with atmospheric relevance have been recently compiled and evaluated (Tang et al., 2014b, 2015); if not available, they can be estimated using Fuller's semiempirical method (Fuller et al., 1966; Tang et al., 2015). A new method has also been proposed to calculate $K n$ without the knowledge of $D(\mathrm{X})$, given by Eq. (5):

$K n=\frac{2}{d_{\mathrm{p}}} \cdot \frac{\lambda_{P}}{P}$,

where $P$ is the pressure in the atmosphere and $\lambda_{P}$ is the pressure-normalized mean free path which is equal to $100 \mathrm{~nm}$ atm (Tang et al., 2015).

\subsection{Scope of this review}

Usher et al. (2003a) provided the first comprehensive review in this field, and heterogeneous reactions of mineral dust with a myriad of trace gases, including nitrogen oxides, $\mathrm{SO}_{2}, \mathrm{O}_{3}$, and some organic compounds, are included. After that, the IUPAC Task Group on Atmospheric Chemical Kinetic Data Evaluation published the first critical evaluation of kinetic data for heterogeneous reactions of solid substrates including mineral dust particles (Crowley et al., 2010a), and kinetic data for heterogeneous uptake of several trace gases (including $\mathrm{O}_{3}, \mathrm{H}_{2} \mathrm{O}_{2}, \mathrm{NO}_{2}, \mathrm{NO}_{3}, \mathrm{HNO}_{3}, \mathrm{~N}_{2} \mathrm{O}_{5}$, and $\mathrm{SO}_{2}$ ) onto mineral dust have been recommended. It should be pointed out that in addition to this and other review articles published by Atmospheric Chemistry and Physics, the IUPAC task group keeps updating recommended kinetic data online (http: //iupac.pole-ether.fr/). We note that a few other review papers and monographs have also mentioned atmospheric heterogeneous reactions of mineral dust particles (Cwiertny et al., 2008; Zhu et al., 2011; Chen et al., 2012; Rubasinghege and Grassian, 2013; Shen et al., 2013; Burkholder et al., 2015; Ge et al., 2015; George et al., 2015; Akimoto, 2016), in a less comprehensive manner compared to Usher et al. (2003a) and Crowley et al. (2010a). For example, Cwiertny et al. (2008) reviewed heterogeneous reactions and heterogeneous photochemical reactions of $\mathrm{O}_{3}$ and $\mathrm{NO}_{2}$ with mineral dust. Atmospheric heterogeneous photochemistry was summarized by Chen et al. (2012) for $\mathrm{TiO}_{2}$ and by George et al. (2015) for other minerals. Heterogeneous reactions of mineral dust with a few volatile organic compounds (VOCs), such as formaldehyde, acetone, methacrolein, methyl vinyl ketone, and organic acids, have been covered by a review article on heterogeneous reactions of VOCs (Shen et al., 2013). The NASAJPL data evaluation panel has compiled and evaluated kinetic data for heterogeneous reactions with alumina (Burkholder et al., 2015). In a very recent paper, Ge et al. (2015) summarized previous studies on heterogeneous reactions of mineral dust with $\mathrm{NO}_{2}, \mathrm{SO}_{2}$, and monocarboxylic acids, with work conducted by scientists in China emphasized. In his monograph entitled Atmospheric Reaction Chemistry, Akimoto (2016) briefly discussed some heterogeneous reactions of mineral dust particles in the troposphere. The roles that heterogeneous chemistry of aerosol particles (including mineral dust) play in haze formation in China were outlined (Zhu et al., 2011), and effects of surface-adsorbed water and thus relative humidity $(\mathrm{RH})$ on heterogeneous reactions of mineral dust have also been discussed by a recent feature article (Rubasinghege and Grassian, 2013).

After the publication of the two benchmark review articles (Usher et al., 2003a; Crowley et al., 2010a), much advancement has been made in this field. For example, heterogeneous uptake of $\mathrm{HO}_{2}$ radicals by mineral dust particles had not been explored at the time when Crowley et al. (2010a) published the IUPAC evaluation, and in the last few years this reaction has been investigated by two groups (Bedjanian et al., 2013a; Matthews et al., 2014). A large number of new studies on the heterogeneous reactions of mineral dust with $\mathrm{H}_{2} \mathrm{O}_{2}$ (Wang et al., 2011; Zhao et al., 2011b, 2013; Romanias et al., 2012a, 2013; Yi et al., 2012; Zhou et al., 2012, 2016; El Zein et al., 2014) and $\mathrm{N}_{2} \mathrm{O}_{5}$ (Tang et al., 2012, 2014a, c, d) have 
emerged. Therefore, a review on atmospheric heterogeneous reaction of mineral dust is both timely and necessary.

Furthermore, the novelty of our current review, which distinguishes it from previous reviews in the same or similar fields (Usher et al., 2003a; Cwiertny et al., 2008; Crowley et al., 2010a; Zhu et al., 2011; Chen et al., 2012; Shen et al., 2013; Ge et al., 2015; George et al., 2015), is the fact that the atmospheric relevance and significance of laboratory studies are illustrated, discussed, and emphasized. We hope that this paper will be useful not only for those whose expertise is laboratory work but also for experts in field measurements and atmospheric modeling. The following approaches are used to achieve this goal: (1) lifetimes of reactive trace gases with respect to heterogeneous uptake by mineral dust, calculated using preferred uptake coefficients and typical mineral dust mass concentrations, are compared to their lifetimes in the troposphere (discussed in Sect. 2.1) in order to discuss the significance of heterogeneous reactions as atmospheric sinks for these trace gases; (2) the atmospheric importance of these heterogeneous reactions is further discussed by referring to representative box, regional, and global modeling studies reported previously; (3) we also describe two of the largest challenges in the laboratory studies of heterogeneous reactions of mineral dust particles (Sect. 2.2) and explain why reported uptake coefficients show large variability and how we should interpret and use these kinetic data. In fact, the major expertise of a few coauthors of this review paper is field measurements and/or modeling studies, and their contribution should largely increase the readability of this paper for the entire atmospheric chemistry community regardless of the academic background of individual readers.

$\mathrm{OH}, \mathrm{NO}_{3}$, and $\mathrm{O}_{3}$ are the most important gas-phase oxidants in the troposphere, and their contribution to tropospheric oxidation capacity has been well recognized (Brown and Stutz, 2012; Stone et al., 2012). $\mathrm{HO}_{2}$ radicals are closely linked with $\mathrm{OH}$ radicals (Stone et al., 2012). $\mathrm{H}_{2} \mathrm{O}_{2}, \mathrm{HCHO}$, and $\mathrm{HONO}$ are important precursors for $\mathrm{OH}$ radicals in the troposphere (Stone et al., 2012), and they may also be important oxidants in the aqueous phase (Seinfeld and Pandis, 2006). Tropospheric $\mathrm{N}_{2} \mathrm{O}_{5}$ is found to be in dynamic equilibrium with $\mathrm{NO}_{3}$ radicals (Brown and Stutz, 2012). Therefore, in order to provide a comprehensive view of the implications of heterogeneous reactions of mineral dust particles for tropospheric oxidation capacity, not only heterogeneous uptake of $\mathrm{OH}, \mathrm{NO}_{3}$, and $\mathrm{O}_{3}$ but also heterogeneous reactions of $\mathrm{HO}_{2}, \mathrm{H}_{2} \mathrm{O}_{2}, \mathrm{HCHO}, \mathrm{HONO}$, and $\mathrm{N}_{2} \mathrm{O}_{5}$ are included. $\mathrm{Cl}$ atoms (Spicer et al., 1998; Osthoff et al., 2008; Thornton et al., 2010; Phillips et al., 2012; Liao et al., 2014; Wang et al., 2016) and stable Criegee radicals (Mauldin III et al., 2012; Welz et al., 2012; Percival et al., 2013; Taatjes et al., 2013) are proposed to be potentially important oxidants in the troposphere, though their atmospheric significance is to be systematically assessed (Percival et al., 2013; Taatjes et al., 2014; Simpson et al., 2015). In addition, their heterogeneous reactions with mineral dust have seldom been explored. Therefore, heterogeneous uptake of $\mathrm{Cl}$ atoms (and their precursors such as $\mathrm{ClNO}_{2}$ ) and stable Criegee radicals by mineral dust is not included here.

In Sect. 2, a brief introduction to tropospheric chemistry of $\mathrm{OH}, \mathrm{HO}_{2}, \mathrm{H}_{2} \mathrm{O}_{2}, \mathrm{O}_{3}, \mathrm{HCHO}, \mathrm{HONO}, \mathrm{NO}_{3}$, and $\mathrm{N}_{2} \mathrm{O}_{5}$ (eight species in total) is provided first. After that, we describe two major challenges in laboratory studies of heterogeneous reactions of mineral dust particles, and then discuss their implications in reporting and interpreting kinetic data. Following this in Sect. 3, we review previous laboratory studies of heterogeneous reactions of mineral dust particles with these eight reactive trace gases, and we have tried our best to cover all the journal articles (limited to those in English) published in this field. Uncertainties for each individual reaction are discussed, and future work required to reduce these uncertainties is suggested. In addition, atmospheric importance of these reactions is discussed by (1) comparing their lifetimes with respect to heterogeneous uptake to typical lifetimes in the troposphere and (2) discussing representative modeling studies on various spatial and temporal scales. Finally in Sect. 4 we outline key challenges which preclude better understanding of impacts of heterogeneous reactions of mineral dust on tropospheric oxidation capacity and discuss how they can be addressed by future work.

\section{Background}

In first part of this section we provide a brief introduction of production and removal pathways, chemistry, and lifetimes of $\mathrm{OH}, \mathrm{HO}_{2}, \mathrm{H}_{2} \mathrm{O}_{2}, \mathrm{O}_{3}, \mathrm{HCHO}, \mathrm{HONO}, \mathrm{NO}_{3}$, and $\mathrm{N}_{2} \mathrm{O}_{5}$ in the troposphere. In the second part we describe two of the largest challenges in laboratory investigation of heterogeneous reactions of mineral dust particles and discuss their implications for reporting, interpreting, and using uptake coefficients.

\subsection{Sources and sinks of tropospheric oxidants}

Figure 1 shows a simplified schematic diagram of atmospheric chemistry of major free radicals in the troposphere. Sources, sinks, and atmospheric lifetimes of these radicals and their important precursors are discussed below.

\subsubsection{OH, $\mathrm{HO}_{2}$, and $\mathrm{H}_{2} \mathrm{O}_{2}$}

Large amounts of $\mathrm{OH}\left(10^{6}-10^{7}\right.$ molecule $\left.\mathrm{cm}^{-3}\right)$ and $\mathrm{HO}_{2}$ radicals $\left(10^{8}-10^{9} \mathrm{~cm}^{-3}\right)$ have been observed and predicted for the lower troposphere (Stone et al., 2012). The first major primary source of $\mathrm{OH}$ radicals in the troposphere is the reaction of water vapor with $\mathrm{O}\left({ }^{1} \mathrm{D}\right)$ (Reaction $\left.\mathrm{R} 1\right)$, which is produced from photolysis of $\mathrm{O}_{3}$ by UV radiation with wavelengths smaller than $325 \mathrm{~nm}$ (Reaction R2) (Atkinson et al., 


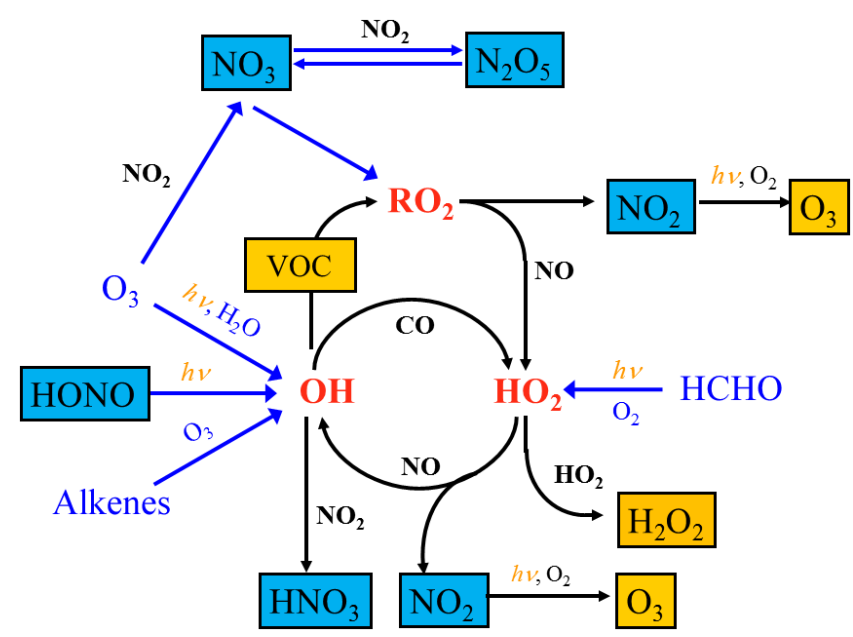

Figure 1. Simplified schematic diagram of the chemistry of major free radicals in the troposphere.

2004; Burkholder et al., 2015).

$\mathrm{O}\left({ }^{1} \mathrm{D}\right)+\mathrm{H}_{2} \mathrm{O} \rightarrow \mathrm{OH}+\mathrm{OH}$

$\mathrm{O}_{3}+h v(\lambda<325 \mathrm{~nm}) \rightarrow \mathrm{O}_{2}+\mathrm{O}\left({ }^{1} \mathrm{D}\right)$

In polluted urban areas, another two primary sources of $\mathrm{OH}$ and $\mathrm{HO}_{2}$ radicals, i.e., photolysis of $\mathrm{HONO}$ and $\mathrm{HCHO}$, become significant (Seinfeld and Pandis, 2006) and sometimes even dominate the primary production of $\mathrm{OH}$ (Su et al., 2008).

$$
\begin{aligned}
& \mathrm{HONO}+h v(\lambda<400 \mathrm{~nm}) \rightarrow \mathrm{NO}+\mathrm{OH} \\
& \mathrm{HCHO}+h v(\lambda<340 \mathrm{~nm}) \rightarrow \mathrm{H}+\mathrm{HCO} \\
& \mathrm{H}+\mathrm{O}_{2}+\mathrm{M} \rightarrow \mathrm{HO}_{2}+\mathrm{M} \\
& \mathrm{HCO}+\mathrm{O}_{2} \rightarrow \mathrm{HO}_{2}+\mathrm{CO}
\end{aligned}
$$

Photolysis of higher oxygenated volatile organic compounds (OVOCs) such as dicarbonyl compounds has also been suggested as an important primary source for $\mathrm{HO}_{x}$ radicals in megacities in China (Lu et al., 2012, 2013) and Mexico (Dusanter et al., 2009). Under twilight conditions as well as during wintertime, ozonolysis of alkenes and photolysis of OVOCs have been found to be dominant primary sources of $\mathrm{OH}$ and $\mathrm{HO}_{2}$ (Geyer et al., 2003; Heard et al., 2004; Kanaya et al., 2007b; Edwards et al., 2014; Lu et al., 2014).

After initiation by primary production channels described above, $\mathrm{OH}$ radicals further react with VOCs to generate organic peroxy radicals $\left(\mathrm{RO}_{2}\right) \cdot \mathrm{RO}_{2}$ radicals are then converted to $\mathrm{HO}_{2}$ radicals by reacting with $\mathrm{NO}$ (Reaction R5), and the produced $\mathrm{HO}_{2}$ radicals are finally recycled back to $\mathrm{OH}$ via reaction with NO (Reaction R6).

$\mathrm{RO}_{2}+\mathrm{NO} \rightarrow \mathrm{HO}_{2}+\mathrm{NO}_{2}$

$\mathrm{HO}_{2}+\mathrm{NO} \rightarrow \mathrm{OH}+\mathrm{NO}_{2}$

Due to these chain reactions, ambient $\mathrm{OH}$ levels are sustained and emitted reductive trace-gas compounds (e.g., VOCs and
NO) are catalytically oxidized (Seinfeld and Pandis, 2006). These chain reactions are terminated by reaction of $\mathrm{OH}$ with $\mathrm{NO}_{2}$ (Reaction R7, in which $\mathrm{M}$ is the third-body molecule) at high $\mathrm{NO}_{x}$ conditions and by cross-reaction of $\mathrm{HO}_{2}$ with $\mathrm{RO}_{2}$ and self-reaction of $\mathrm{HO}_{2}$ radicals (Reaction $\mathrm{R} 8$ ) at low $\mathrm{NO}_{x}$ conditions.

$\mathrm{OH}+\mathrm{NO}_{2}+\mathrm{M} \rightarrow \mathrm{HNO}_{3}+\mathrm{M}$

$\mathrm{HO}_{2}+\mathrm{HO}_{2} \rightarrow \mathrm{H}_{2} \mathrm{O}_{2}+\mathrm{O}_{2}$

In recent years, a new $\mathrm{OH}$ regeneration mechanism, which has not been completely elucidated so far, has been identified for low $\mathrm{NO}_{x}$ environments including both forested (Lelieveld et al., 2008) and rural areas (Hofzumahaus et al., 2009; Lu et al., 2012). This new mechanism is found to stabilize the observed $\mathrm{OH}-j\left(\mathrm{O}^{1} \mathrm{D}\right)$ relationships and enables a type of maximum efficiency of $\mathrm{OH}$ sustainment under low $\mathrm{NO}_{x}$ conditions (Rohrer et al., 2014). Nevertheless, in a recent study (Mao et al., 2012), the proposed new $\mathrm{OH}$ regeneration mechanism is thought to be at least partly caused by unrecognized instrumental interference in $\mathrm{OH}$ measurements (Mao et al., 2012). A community effort is now started to assure the data quality of the $\mathrm{OH}$ measurement under different conditions, especially for the chemically complex areas (http://www.fz-juelich.de/iek/iek8/EN/AboutUs/Projects/ HOxROxWorkingGroup/HOxWorkshop2015_node.html).

Table 1 summarizes representative lifetimes of $\mathrm{OH}$ and $\mathrm{HO}_{2}$ radicals in the troposphere as determined by previous field campaigns. The $\mathrm{OH}$ lifetime is an important parameter to characterize $\mathrm{HO}_{x}$ chemistry as well as VOC reactivity in the troposphere. As a result, it has been widely measured at different locations using a variety of experimental methods (Sinha et al., 2008; Ingham et al., 2009), as discussed by a very recent paper (Yang et al., 2016b). OH lifetimes in clean environments, like open ocean and remote continental areas, are dominated by reactions with $\mathrm{CO}, \mathrm{CH}_{4}$, and HCHO, summed up to values of about 0.5-1 s (Ehhalt, 1999; Brauers et al., 2001). OH lifetimes in forested areas, mainly contributed by oxidation of biogenic VOCs, are typically in the range of 0.01-0.05 s (Ingham et al., 2009; Nölscher et al., 2012). In urban areas, OH lifetimes are determined by anthropogenically emitted hydrocarbons, $\mathrm{NO}_{x}, \mathrm{CO}$, and biogenic VOCs as well, and they are typically smaller than $0.1 \mathrm{~s}$ (Ren et al., 2003; Mao et al., 2010b; Lu et al., 2013).

Compared to $\mathrm{OH}$ radicals, lifetimes of $\mathrm{HO}_{2}$ radicals have been investigated much less and are mainly determined by ambient NO concentrations when NO is larger than $10 \mathrm{pptv}$ (parts per trillion by volume). Therefore, the lower limit of $\mathrm{HO}_{2}$ lifetimes, on the order of $0.1 \mathrm{~s}$, often appear in polluted urban areas (Ren et al., 2003; Kanaya et al., 2007a; Lu et al., 2012). The upper limit of $\mathrm{HO}_{2}$ lifetimes, up to 1000-2000 s, is often observed in clean regions and sometimes also in urban areas during nighttime (Holland et al., 2003; Lelieveld et al., 2008; Whalley et al., 2011). In addition, heterogeneous uptake of $\mathrm{HO}_{2}$ radicals has been frequently considered in the 
Table 1. Summary of typical lifetimes of $\mathrm{OH}, \mathrm{HO}_{2}, \mathrm{NO}_{3}$, and $\mathrm{N}_{2} \mathrm{O}_{5}$ in the troposphere reported by field measurements.

\begin{tabular}{|c|c|c|c|}
\hline Time & Location & Lifetimes & Reference \\
\hline \multicolumn{4}{|c|}{$\mathrm{OH}$ radicals } \\
\hline Oct-Nov 1996 & Tropical Atlantic Ocean & $1 \mathrm{~s}$ & Brauers et al. (2001) \\
\hline Aug 1994 & Mecklenburg-Vorpommern, Germany & $0.5 \mathrm{~s}$ & Ehhalt (1999) \\
\hline Jul-Aug 1998 & Pabstthum (rural Berlin), Germany & $0.15-0.5 \mathrm{~s}$ & Mihelcic et al. (2003) \\
\hline Aug-Sep 2000 & Houston, US & $0.08-0.15 \mathrm{~s}$ & Mao et al. (2010b) \\
\hline Jun-Aug 2001 & New York, US & $0.04-0.06 \mathrm{~s}$ & Ren et al. (2003) \\
\hline Aug 2007 & Tokyo, Japan & $0.01-0.1 \mathrm{~s}$ & Chatani et al. (2009) \\
\hline Jul 2006 & Back garden (rural Guangzhou), China & $0.008-0.1 \mathrm{~s}$ & Lou et al. (2010) \\
\hline Aug 2006 & Yufa (rural Beijing), China & $0.01-0.1 \mathrm{~s}$ & Lu et al. (2013) \\
\hline Apr-May 2008 & Borneo, Malaysia & $0.015-0.1 \mathrm{~s}$ & Ingham et al. (2009) \\
\hline Jul-Aug 2010 & Hyytiälä, Finland & $0.01-0.5 \mathrm{~s}$ & Nölscher et al. (2012) \\
\hline \multicolumn{4}{|c|}{$\mathrm{HO}_{2}$ radicals } \\
\hline Jul-Aug 1998 & Pabstthum (rural Berlin), Germany & $3-500 \mathrm{~s}$ & Holland et al. (2003) \\
\hline Jun-Aug 2001 & New York, US & $0.1-1.5 \mathrm{~s}$ & Ren et al. (2003) \\
\hline Jul-Aug 2004 & Tokyo, Japan & $0.05-1000 \mathrm{~s}$ & Kanaya et al. (2007a) \\
\hline Jul 2006 & Back garden (rural Guangzhou), China & $0.1-500 \mathrm{~s}$ & Lu et al. (2012) \\
\hline Aug 2006 & Yufa (rural Beijing), China & $0.06-500 \mathrm{~s}$ & Lu et al. (2013) \\
\hline Oct 2005 & Suriname & $500-1000 \mathrm{~s}$ & Lelieveld et al. (2008) \\
\hline Apr-May 2008 & Borneo, Malaysia & $20-2000 \mathrm{~s}$ & Whalley et al. (2011) \\
\hline \multicolumn{4}{|c|}{$\mathrm{NO}_{3}$ radicals } \\
\hline Oct 1996 & Heligoland, Germany & $10-1000 \mathrm{~s}$ & Martinez et al. (2000) \\
\hline Jul-Aug 1998 & Berlin, Germany & $10-500 \mathrm{~s}$ & Geyer et al. (2001) \\
\hline Jul-Aug 2002 & US east coast & typically a few $\min$, up to $20 \mathrm{~min}$ & Aldener et al. (2006) \\
\hline May 2008 & Klein Feldberg, Germany & up to $\sim 1500 \mathrm{~s}$ & Crowley et al. (2010b) \\
\hline Aug-Sep 2011 & Klein Feldberg, Germany & up to $1 \mathrm{~h}$, with an average value of $\sim 200 \mathrm{~s}$ & Sobanski et al. (2016) \\
\hline \multicolumn{4}{|c|}{$\mathrm{N}_{2} \mathrm{O}_{5}$} \\
\hline Oct 1996 & Helgoland, Germany & hundred to thousand seconds & Martinez et al. (2000) \\
\hline Jan 2004 & Contra Costa, California, US & $600-1800 \mathrm{~s}$ & Wood et al. (2005) \\
\hline Jul-Aug 2002 & US east coast & up to $60 \mathrm{~min}$ & Aldener et al. (2006) \\
\hline Nov 2009 & Fairbank, Alaska, US & $\sim 6 \min$ on average & Huff et al. (2011) \\
\hline Nov-Dec 2013 & Hong Kong, China & from $<0.1$ to $13 \mathrm{~h}$ & Brown et al. (2016) \\
\hline
\end{tabular}

budget analysis of $\mathrm{HO}_{x}$ radicals for marine and polluted urban regions (Abbatt et al., 2012).

Formation and removal of gas-phase $\mathrm{H}_{2} \mathrm{O}_{2}$ in the troposphere is closely linked with the $\mathrm{HO}_{x}$ radical chemistry. Tropospheric $\mathrm{H}_{2} \mathrm{O}_{2}$ is mainly produced from self-reaction of $\mathrm{HO}_{2}$ radicals (Reaction $\mathrm{R} 8$ ) and this process is further enhanced by the presence of water vapor (Stockwell, 1995). In addition to dry and wet deposition, another two pathways, i.e., photolysis (Reaction R9) and the reaction with $\mathrm{OH}(\mathrm{Re}-$ action R10), dominate the removal of $\mathrm{H}_{2} \mathrm{O}_{2}$ in the troposphere.

$\mathrm{H}_{2} \mathrm{O}_{2}+h v(\lambda<360 \mathrm{~nm}) \rightarrow \mathrm{OH}+\mathrm{OH}$

$\mathrm{H}_{2} \mathrm{O}_{2}+\mathrm{OH} \rightarrow \mathrm{H}_{2} \mathrm{O}+\mathrm{HO}_{2}$

Typical $J\left(\mathrm{H}_{2} \mathrm{O}_{2}\right)$ daily maximum values are $\sim 7.7 \times$ $10^{-6} \mathrm{~s}^{-1}$ for a solar zenith angle of $0^{\circ}$ and $\sim 6.0 \times 10^{-6} \mathrm{~s}^{-1}$ in the northern midlatitude (Stockwell et al., 1997), cor- responding to $\tau_{\text {phot }}\left(\mathrm{H}_{2} \mathrm{O}_{2}\right)\left(\mathrm{H}_{2} \mathrm{O}_{2}\right.$ lifetimes with respect to photolysis) of 33-56 h (or 1.5-2 days). The rate constant for the bimolecular reaction of $\mathrm{H}_{2} \mathrm{O}_{2}$ with $\mathrm{OH}$ radicals is $1.7 \times 10^{-12} \mathrm{~cm}^{3}$ molecule $\mathrm{s}^{-1}$ at room temperature, and its temperature dependence is quite small (Atkinson et al., 2004). Concentrations of $\mathrm{OH}$ radicals in the troposphere are usually in the range of $(1-10) \times 10^{6}$ molecule $\mathrm{cm}^{-3}$, and thus $\tau_{\mathrm{OH}}\left(\mathrm{H}_{2} \mathrm{O}_{2}\right)\left(\mathrm{H}_{2} \mathrm{O}_{2}\right.$ lifetimes with respect to reaction with $\mathrm{OH}$ radicals) are estimated to be around $16-160 \mathrm{~h}$. Dry deposition rates of $\mathrm{H}_{2} \mathrm{O}_{2}$ were determined to be $\sim 5 \mathrm{~cm} \mathrm{~s}^{-1}$ (Hall and Claiborn, 1997), and an assumed boundary height of $1 \mathrm{~km}$ gives $\tau_{\text {dry }}\left(\mathrm{H}_{2} \mathrm{O}_{2}\right)\left(\mathrm{H}_{2} \mathrm{O}_{2}\right.$ lifetimes with respect to dry deposition) of 5-6 h. Therefore, dry deposition is a major sink for near-surface $\mathrm{H}_{2} \mathrm{O}_{2}$. We do not estimate $\mathrm{H}_{2} \mathrm{O}_{2}$ lifetimes with respect to wet deposition because wet deposition rates depend on the amount of precipitation which shows large spatial and temporal variation. Heterogeneous uptake of $\mathrm{H}_{2} \mathrm{O}_{2}$ 
by ambient aerosols as well as fog and rain droplets is also considered to be a significant sink for $\mathrm{H}_{2} \mathrm{O}_{2}$, especially when the ambient $\mathrm{SO}_{2}$ concentrations are high (de Reus et al., 2005; Hua et al., 2008).

As mentioned previously, $\mathrm{HONO}$ and $\mathrm{HCHO}$ are two important precursors for $\mathrm{OH}$ radicals, and therefore their removal (as well as production) significantly affects tropospheric oxidation capacity. The typical $J(\mathrm{HONO})$ daily maximum value for the northern midlatitude is $\sim 1.63 \times 10^{-3} \mathrm{~s}^{-1}$ (Stockwell et al., 1997), corresponding to $\tau_{\text {phot }}(\mathrm{HONO})$ of about $10 \mathrm{~min}$. This is supported by field measurements which suggest that lifetimes of HONO due to photolysis during the daytime are typically in the range of 10-20 min (Alicke et al., 2003; Li et al., 2012). The second-order rate constant for the reaction of $\mathrm{HONO}$ with $\mathrm{OH}$ radicals is $6.0 \times 10^{-12} \mathrm{~cm}^{3}$ molecule ${ }^{-1} \mathrm{~s}^{-1}$ at $298 \mathrm{~K}$ (Atkinson et al., $2004)$, giving $\tau_{\mathrm{OH}}(\mathrm{HONO})$ of $\sim 280 \mathrm{~min}(\sim 4.6 \mathrm{~h})$ if $\mathrm{OH}$ concentration is assumed to be $1 \times 10^{7}$ molecule $\mathrm{cm}^{-3}$. Dry deposition velocities of HONO reported by previous work show large variability, ranging from 0.077 to $3 \mathrm{~cm} \mathrm{~s}^{-1}$ (Harrison and Kitto, 1994; Harrison et al., 1996; Stutz et al., 2002), and thus $\tau_{\text {dry }}$ (HONO) are estimated to be in the range of $\sim 9 \mathrm{~h}$ to several days if a boundary height of $1 \mathrm{~km}$ is assumed. Therefore, photolysis is the main sink for HONO in the troposphere and the contribution from dry deposition and reaction with $\mathrm{OH}$ is quite minor.

The second-order rate constant for the reaction of $\mathrm{HCHO}$ with $\mathrm{OH}$ radicals is $8.5 \times 10^{12} \mathrm{~cm}^{3}$ molecule $\mathrm{s}^{-1} \mathrm{~s}^{-1}$ at $298 \mathrm{~K}$ (Atkinson et al., 2006), and $\tau_{\mathrm{OH}}(\mathrm{HCHO})$ is calculated to be $\sim 200 \mathrm{~min}(\sim 3.3 \mathrm{~h})$ if $\mathrm{OH}$ concentration is assumed to be $1 \times 10^{7}$ molecule $\mathrm{cm}^{-3}$. The typical $J(\mathrm{HCHO})$ daily maximum value for the northern midlatitude is $\sim 5.67 \times 10^{-5} \mathrm{~s}^{-1}$ (Stockwell et al., 1997), giving $\tau_{\text {phot }}(\mathrm{HCHO})$ of about $300 \mathrm{~min}(\sim 5 \mathrm{~h})$. The dry deposition velocity for HCHO was measured to be $1.4 \mathrm{~cm} \mathrm{~s}^{-1}$ (Seyfioglu et al., 2006), corresponding to $\tau_{\text {dry }}(\mathrm{HCHO})$ of $\sim 20 \mathrm{~h}$ if the boundary layer height is assumed to be $1 \mathrm{~km}$. To summarize, lifetimes of $\mathrm{HCHO}$ in the troposphere are estimated to be a few hours, with photolysis and reaction with $\mathrm{OH}$ radicals being major sinks.

\subsection{2 $\mathrm{O}_{3}$}

After being emitted, $\mathrm{NO}$ is converted to $\mathrm{NO}_{2}$ in the troposphere through its reactions with $\mathrm{O}_{3}$ (Reaction $\mathrm{R} 11$ ) and peroxy radicals (Reactions $\mathrm{R} 5, \mathrm{R} 6$ ). $\mathrm{NO}_{2}$ is further photolyzed to generate $\mathrm{O}_{3}$ (Reaction $\mathrm{R} 12$ ), and $\mathrm{NO}$ oxidation processes through Reactions (R5) and (R6) are the reason for $\mathrm{O}_{3}$ increase in the troposphere (Wang and Jacob, 1998).

$\mathrm{O}_{3}+\mathrm{NO} \rightarrow \mathrm{NO}_{2}+\mathrm{O}_{2}$

$\mathrm{NO}_{2}+\mathrm{O}_{2}+h v(\lambda<420 \mathrm{~nm}) \rightarrow \mathrm{O}_{3}+\mathrm{NO}$

Tropospheric $\mathrm{O}_{3}$ is mainly destroyed via its photolysis ( $\mathrm{Re}$ action R1) and the subsequent reaction of $\mathrm{O}^{1} \mathrm{D}$ with $\mathrm{H}_{2} \mathrm{O}$ (Reaction R2). Other important removal pathways include dry deposition, reaction with $\mathrm{NO}_{2}$ (to produce $\mathrm{NO}_{3}$ radicals) (Reaction R13), and ozonolysis of alkenes, etc.

$\mathrm{NO}_{2}+\mathrm{O}_{3} \rightarrow \mathrm{NO}_{3}+\mathrm{O}_{2}$

In addition, the loss of $\mathrm{NO}_{2}$ through reaction with $\mathrm{OH}(\mathrm{Re}-$ action R7) and the loss of peroxy radicals through their selfreactions (Reaction $\mathrm{R} 8$ ) would be a significant term of $\mathrm{O}_{3}$ losses on large scales. Therefore, it is anticipated that both the formation and destruction of $\mathrm{O}_{3}$ is closely related with gas-phase $\mathrm{HO}_{x}$ and $\mathrm{NO}_{x}$ radical chemistry.

Several processes remove $\mathrm{O}_{3}$ from the troposphere. The first one is the photolysis of $\mathrm{O}_{3}$ to produce $\mathrm{O}^{1} \mathrm{D}$ (Reaction $\mathrm{R} 1)$ and the subsequent reaction of $\mathrm{O}^{1} \mathrm{D}$ with $\mathrm{H}_{2} \mathrm{O}(\mathrm{Re}-$ action $\mathrm{R} 2$ ); therefore, the removal rate of $\mathrm{O}_{3}$ through this pathway depends on solar radiation and $\mathrm{RH}$. In the troposphere, $\tau_{\text {pho }}\left(\mathrm{O}_{3}\right)$ is typically in the range of 1.8-10 days (Stockwell et al., 1997). Ozonolysis of alkenes is another significant sink for $\mathrm{O}_{3}$ under high VOCs conditions, and $\tau_{\text {alkene }}\left(\mathrm{O}_{3}\right)$ with respect to reaction with alkenes is estimated to be 3-8 h for urban and forested areas (Shirley et al., 2006; Kanaya et al., 2007b; Whalley et al., 2011; Lu et al., 2013, 2014). $\mathrm{O}_{3}$ lifetimes in the remote troposphere are primarily determined by $\mathrm{O}_{3}$ photolysis (and the subsequent reaction of $\mathrm{O}^{1} \mathrm{D}$ with $\mathrm{H}_{2} \mathrm{O}$ ) and reactions of $\mathrm{O}_{3}$ with $\mathrm{HO}_{2}$ and $\mathrm{OH}$. For typical conditions $\left(j\left(\mathrm{O}^{1} \mathrm{D}\right), \mathrm{H}_{2} \mathrm{O}, \mathrm{HO}_{2}, \mathrm{OH}\right.$, temperature, and pressure) over northern midlatitude oceans, $\mathrm{O}_{3}$ lifetimes are calculated to be a few days in summer, 1-2 weeks in spring-autumn, and about a month in winter, using the GEOS-Chem model (to be published). $\mathrm{O}_{3}$ dry deposition has been extensively studied and as a rule of thumb, $1 \mathrm{~cm} \mathrm{~s}^{-1}$ is taken as its dry deposition rate (Wesely and Hicks, 2000). Consequently, $\tau_{\text {dry }}\left(\mathrm{O}_{3}\right)$ is calculated to be $\sim 28 \mathrm{~h}$, assuming a boundary height of $1 \mathrm{~km}$. Reactions with $\mathrm{NO}$ and $\mathrm{NO}_{2}$ will further contribute to the removal of $\mathrm{O}_{3}$ in the troposphere at night. The second-order rate constants are $1.9 \times 10^{-14} \mathrm{~cm}^{3}$ molecule $\mathrm{s}^{-1}$ for the reaction of $\mathrm{O}_{3}$ with $\mathrm{NO}$ and $3.5 \times 10^{-17} \mathrm{~cm}^{3}$ molecule $\mathrm{s}^{-1}$ for its reaction with $\mathrm{NO}_{2}$ at $298 \mathrm{~K}$ (Atkinson et al., 2004), and $\mathrm{O}_{3}$ lifetimes are calculated to be $\sim 29$ and $\sim 32 \mathrm{~h}$ in the presence of $20 \mathrm{pptv}$ $\mathrm{NO}$ and $10 \mathrm{ppbv}$ (parts per billion by volume) $\mathrm{NO}_{2}$, respectively.

Moreover, heterogeneous processes may also strongly influence the budget of $\mathrm{O}_{3}$ through impacts on sources and sinks of $\mathrm{HO}_{x}$ and $\mathrm{NO}_{x}$ (Dentener et al., 1996; Jacob, 2000; Zhu et al., 2010), the production of halogen radicals (Thornton et al., 2010; Phillips et al., 2012; Wang et al., 2016), and possibly also direct removal of $\mathrm{O}_{3}$ due to heterogeneous uptake (de Reus et al., 2000).

\subsection{3 $\mathrm{NO}_{3}$ radicals (and $\left.\mathrm{N}_{2} \mathrm{O}_{5}\right)$}

Oxidation of $\mathrm{NO}_{2}$ by $\mathrm{O}_{3}$ (Reaction $\mathrm{R} 13$ ) is the dominant source for $\mathrm{NO}_{3}$ radicals in the troposphere. $\mathrm{NO}_{3}$ radicals further react with $\mathrm{NO}_{2}$ to form $\mathrm{N}_{2} \mathrm{O}_{5}$ (Reaction $\mathrm{R} 14$ ), which can thermally dissociate back to $\mathrm{NO}_{3}$ and $\mathrm{NO}_{2}$ (Reaction R15) 
(Wayne et al., 1991; Brown and Stutz, 2012).

$\mathrm{NO}_{2}+\mathrm{O}_{3} \rightarrow \mathrm{NO}_{3}+\mathrm{O}_{2}$

$\mathrm{NO}_{2}+\mathrm{NO}_{3}+\mathrm{M} \rightarrow \mathrm{N}_{2} \mathrm{O}_{5}+\mathrm{M}$

$\mathrm{N}_{2} \mathrm{O}_{5}+\mathrm{M} \rightarrow \mathrm{NO}_{2}+\mathrm{NO}_{3}+\mathrm{M}$

The equilibrium between $\mathrm{NO}_{3}$ and $\mathrm{N}_{2} \mathrm{O}_{5}$ is usually reached within several seconds under typical tropospheric conditions. Therefore, $\mathrm{NO}_{3}$ radicals are considered to be in dynamic equilibrium with $\mathrm{N}_{2} \mathrm{O}_{5}$, as confirmed by a number of field measurements (Brown and Stutz, 2012, and references therein). As a result, $\mathrm{NO}_{3}$ and $\mathrm{N}_{2} \mathrm{O}_{5}$ are discussed together here. Recently reactions of Criegee radicals with $\mathrm{NO}_{2}$ are proposed as another source for $\mathrm{NO}_{3}$ radicals (Ouyang et al., 2013), though atmospheric significance of this source has not been systematically assessed yet (Sobanski et al., 2016).

Photolysis of $\mathrm{NO}_{3}$ (Reaction R17) and its reaction with NO (Reaction R16) are both very fast (Wayne et al., 1991), and atmospheric chemistry of $\mathrm{NO}_{3}$ (and thus $\mathrm{N}_{2} \mathrm{O}_{5}$ ) is only important during nighttime, though the daytime presence of $\mathrm{NO}_{3}$ and $\mathrm{N}_{2} \mathrm{O}_{5}$ in the troposphere has also been reported (Brown and Stutz, 2012). Therefore, for a sink to be important for $\mathrm{NO}_{3}$ or $\mathrm{N}_{2} \mathrm{O}_{5}$, the lifetime with respect to this sink should be comparable to or shorter than a half-day.

$\mathrm{NO}_{3}+\mathrm{NO} \rightarrow \mathrm{NO}_{2}+\mathrm{NO}_{2}$

$\mathrm{NO}_{3}+(\lambda<11080 \mathrm{~nm}) \rightarrow \mathrm{NO}+\mathrm{O}_{2}$

$\mathrm{NO}_{3}+(\lambda<587 \mathrm{~nm}) \rightarrow \mathrm{NO}_{2}+\mathrm{O}$

The predominant sinks for tropospheric $\mathrm{NO}_{3}$ and $\mathrm{N}_{2} \mathrm{O}_{5}$ include reactions with unsaturated VOCs, reaction with dimethyl sulfite in the marine and coastal troposphere, and heterogeneous uptake by aerosol particles and cloud droplets (Brown and Stutz, 2012). The gas-phase reaction of $\mathrm{N}_{2} \mathrm{O}_{5}$ with water vapor was investigated by a laboratory study (Wahner et al., 1998), and several field measurements have suggested that this reaction is unlikely to be significant in the troposphere (Brown et al., 2009; Crowley et al., 2010b; Brown and Stutz, 2012). Lifetimes of $\mathrm{NO}_{3}$ and $\mathrm{N}_{2} \mathrm{O}_{5}$ during nighttime depend on a variety of atmospheric conditions (including concentrations of VOCs and aerosols, aerosol composition and mixing state, RH, etc.) (Brown and Stutz, 2012), exhibiting large spatial and temporal variations. As shown in Table $1, \mathrm{NO}_{3}$ lifetimes typically range from tens of seconds to $1 \mathrm{~h}$, while $\mathrm{N}_{2} \mathrm{O}_{5}$ lifetimes are usually longer, spanning from $<10$ min to several hours.

\subsection{Laboratory studies of atmospheric heterogeneous reactions of mineral dust particles}

Kinetics of heterogeneous reactions can be determined by measuring the decay and/or production rates of trace gases in the gas phase (Hanisch and Crowley, 2001; Usher et al., 2003b; Liu et al., 2008a; Vlasenko et al., 2009; Pradhan et al., 2010a; Tang et al., 2012; Zhou et al., 2014). Alternatively, reaction rates can also be measured by detecting changes in particle composition (Goodman et al., 2000; Sullivan et al., 2009a; Li et al., 2010; Tong et al., 2010; Ma et al., 2012; Kong et al., 2014). A number of experimental techniques have been developed and utilized to investigate heterogeneous reactions of mineral dust particles, as summarized in Table 2. It should be emphasized that this list is far from being complete and only techniques mentioned in this review paper are included. These techniques can be classified into three groups according to the way particles under investigation exist: (1) particle ensembles deposited on a substrate, (2) an ensemble of particles as an aerosol, and (3) single particles, either levitated or deposited on a substrate. Detailed description of these techniques can be found in several previous review articles and monographies (Usher et al., 2003a; Cwiertny et al., 2008; Crowley et al., 2010a; Kolb et al., 2010; Akimoto, 2016) and thus is not repeated here. Instead, in this paper we intend to discuss two critical issues in determining and reporting uptake coefficients for heterogeneous reactions of mineral dust particles, i.e., (1) surface area available for heterogeneous uptake and (2) time dependence of heterogeneous kinetics. In addition to these two important issues, it should also be mentioned that single minerals (e.g., illite, calcite, and quartz) and authentic dust samples (e.g., Saharan dust and Arizona test dust) may not necessarily reflect mineral dust particles found in the troposphere. After being emitted into the troposphere, mineral dust particles will undergo heterogeneous reactions and cloud processing (Usher et al., 2003a; Tang et al., 2016a), forming soluble inorganic and organic materials coated on dust particles (Sullivan et al., 2007; Sullivan and Prather, 2007; Formenti et al., 2011; Fitzgerald et al., 2015). Therefore, heterogeneous reactivity of ambient mineral dust particles can be largely different from those used in laboratory studies.

For experiments in which single particles are used, surface techniques, including Raman spectroscopy (Liu et al., 2008b; Zhao et al., 2011a), scanning electron microscopy (SEM) (Krueger et al., 2003a; Laskin et al., 2005b), and secondary ion mass spectroscopy (SIMS) (Harris et al., 2012), can usually be utilized to characterize their compositional and morphological changes simultaneously. Nevertheless, it is still nontrivial to derive quantitative information for most of the surface techniques. In addition to being deposited on a substrate, single particles can also be levitated by an electrodynamic balance (Lee and Chan, 2007; Pope et al., 2010) or optical levitation (Tong et al., 2011; Krieger et al., 2012; Rkiouak et al., 2014), and Raman spectroscopy can be used to measure the compositional changes of levitated particles (Lee et al., 2008; Tang et al., 2014a).

\subsubsection{Surface area available for heterogeneous uptake}

As described by Eq. (1), surface area concentration is required to derive uptake coefficients from measured pseudofirst-order reaction rates. However, it can be a difficult task to obtain surface area concentrations of particles. In fact, vari- 
Table 2. Abbreviations of experimental techniques used by previous laboratory studies to investigate heterogeneous reactions of mineral dust. Only techniques mentioned in this review paper are included.

\begin{tabular}{ll}
\hline Abbreviation & Full name \\
\hline AFT & Aerosol flow tube \\
CIMS & Chemical ionization mass spectrometry \\
CLD & Chemiluminescence detector \\
CRDS & Cavity ring-down spectroscopy \\
CRFT & Coated rod flow tube \\
CWFT & Coated wall flow tube \\
DRIFTS & Diffuse reflectance infrared Fourier transform \\
& spectroscopy \\
EC & Environmental chamber \\
KC & Knudsen cell reactor \\
IC & Ion chromatography \\
LIF & Laser-induced fluorescence \\
MS & Mass spectrometry \\
T-FTIR & Transmission FTIR \\
\hline
\end{tabular}

ation in estimated surface area available for heterogeneous uptake is one of the main reasons why large differences in uptake coefficients have been reported by different groups for the same reaction system of interest.

For experiments in which aerosol particles are used, surface area concentrations are typically derived from size distribution measured using an aerodynamic particle sizer (APS) or scanning mobility particle sizer (SMPS). Because of the nonsphericity of mineral dust particles, it is not straightforward to convert aerodynamic and mobility diameters to surface area. It has been reported that the median aspect ratios are in the range of 1.6-1.7 for Saharan dust particles (Chou et al., 2008; Kandler et al., 2009) and 1.41.5 for Asian dust particles (Okada et al., 2001). In some aerosol chamber studies, surface areas available for heterogeneous uptake are assumed to be equal to the BET (BrunauerEmmett-Teller) surface areas of dust particles introduced into the chamber (Mogili et al., 2006b; Chen et al., 2011b). Some dust particles are porous, making their BET surface areas much larger than the corresponding geometrical surface areas. The values of $\gamma\left(\mathrm{N}_{2} \mathrm{O}_{5}\right)$ for airborne $\mathrm{SiO}_{2}$ particles reported by two previous studies (Mogili et al., 2006b; Wagner et al., 2009) differed by almost 2 orders of magnitude. Tang et al. (2014a) suggested that such a large difference is mainly due to the fact that different methods were used to calculate surface area available for heterogeneous uptake. Specifically, Mogili et al. (2006b) used the BET surface area, while Wagner et al. (2009) used Stoke diameters derived from APS measurements to calculate the surface area. Tang et al. (2014a) further found that if the same method is used to calculate surface area concentrations, the values of $\gamma\left(\mathrm{N}_{2} \mathrm{O}_{5}\right)$ reported by the two studies (Mogili et al., 2006b; Wagner et al., 2009) agree fairly well.
This issue becomes even more severe for experiments using mineral dust particles deposited on a substrate. In these experiments the surface area available for heterogeneous uptake is assumed to be either the projected area of dust particles (usually also referred to as the geometrical area of dust particles, equal to the geometrical surface area of the sample holder) or the BET surface area of the dust sample. Descriptions of methods used in measuring BET surface area of solid particles can be found elsewhere (Sing, 2014; Naderi, 2015). Multiple layers of powdered dust samples are typically deposited on a substrate. Consequently, it is not uncommon that the BET surface area is several orders of magnitude larger than the projected area (Nicolas et al., 2009; Liu et al., 2010; Tong et al., 2010). The surface area actually available for heterogeneous uptake falls between the two extreme cases and varies for different studies. When gas molecules are transported towards the top layer of the powdered sample, they may collide with the surface of particles on the top layer, be adsorbed, and undergo heterogeneous reaction; they may also be transported within the interior space and then collide and react with particles in the underlying layers. The depth that gas molecules can reach depends on the microstructure of the powdered sample (e.g., how compactly particles are stacked) as well as their reactivity towards the surface. For a very fast heterogeneous reaction it is likely that only the topmost few layers of a powdered sample are accessible for the reactive trace gases, whereas more underlying layers become available for slower uptake processes. Therefore, uptake coefficients reported by experiments using aerosol samples, if available, are preferred and used in this study to estimate the atmospheric importance of heterogeneous reactions. We note that a similar strategy has also been adopted by the IUPAC task group (Crowley et al., 2010a).

In theory, transport of gaseous molecules within the interior space of the powdered sample coupled to the reaction with the particle surface can be described by mathematical models. The KML (Keyser-Moore-Leu) model, initially developed to describe diffusion and reaction of gaseous molecules in porous ice (Keyser et al., 1991, 1993), has been used to derive uptake coefficients for heterogeneous reactions of mineral dust particles. An "effectiveness factor" was determined and used in the KML model to account for the contribution of underlying layers to the observed heterogeneous uptake. One major drawback of the KML model (and other models with similar principles but different complexities) is that it can be difficult to measure or accurately calculate diffusion constants of reactive trace gases through powdered samples (Underwood et al., 2000).

Grassian and coworkers developed a simple method to calculate surface area available for heterogeneous uptake (Underwood et al., 2000; Li et al., 2002). If the thickness of a powdered sample is smaller than the interrogation depth of the reactive trace gas (i.e., depth of the sample which can actually be reached by the reactive trace gas), all the particles should be accessible for heterogeneous uptake. In 


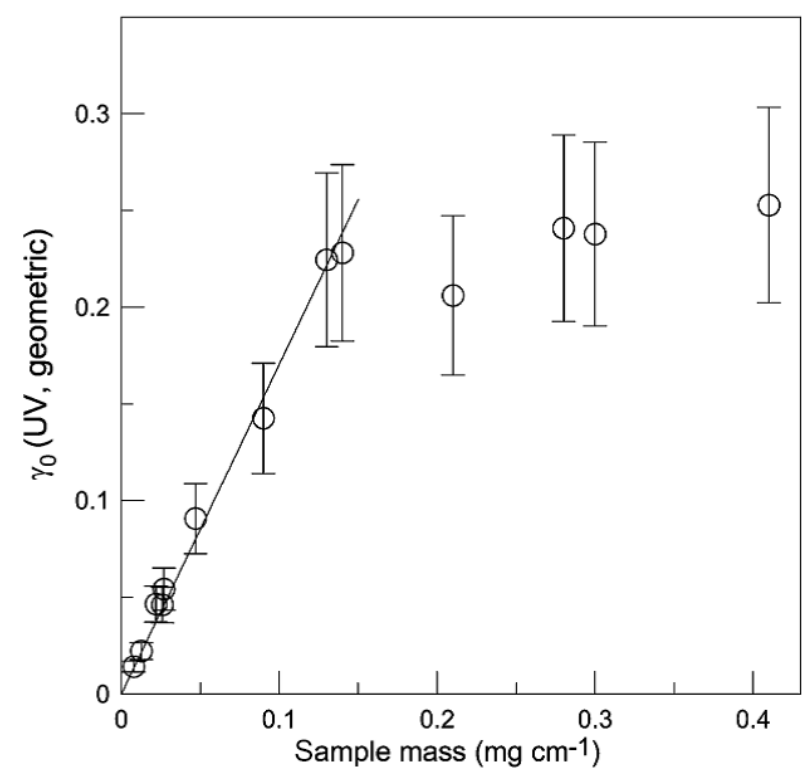

Figure 2. Projected-area-based uptake coefficients of $\mathrm{H}_{2} \mathrm{O}_{2}$ on irradiated $\mathrm{TiO}_{2}$ particles as a function of $\mathrm{TiO}_{2}$ sample mass (per centimeter length of the support tube onto which $\mathrm{TiO}_{2}$ particles were deposited). Reprinted with permission from (Romanias et al., 2012a). () 2012 American Chemical Society.

this case, uptake coefficients calculated using the projected area should exhibit a linear mass dependence. The linear mass-dependent (LMD) regime can be experimentally determined, with an example shown in Fig. 2. Figure 2 suggests that when the $\mathrm{TiO}_{2}$ sample mass is $<0.15 \mathrm{mg} \mathrm{cm}^{-1}$, the projected-area-based uptake coefficients depend linearly on the sample mass. If measurements are carried out within the LMD regime, surfaces of all the particles are available for heterogeneous uptake and the BET surface area should be used to calculate uptake coefficients (Underwood et al., 2000; Romanias et al., 2012a; Bedjanian et al., 2013a).

Another way to circumvent the problem due to diffusion within the interior space of powdered samples is to use particles fewer than one layer (Hoffman et al., 2003a, b). This experimental strategy was used to investigate heterogeneous reactions of $\mathrm{NaCl}$ with $\mathrm{HNO}_{3}, \mathrm{~N}_{2} \mathrm{O}_{5}$, and $\mathrm{ClONO}_{2}$, and a mathematical model was developed to calculate the effective surface area exposed to reactive trace gases (Hoffman et al., 2003a, b). Nevertheless, to our knowledge this method has not yet been used by laboratory studies of heterogeneous reactions of mineral dust particles.

\subsubsection{Time dependence of heterogeneous kinetics}

When exposed to reactive trace gases, mineral dust surface may become deactivated and thus gradually lose its heterogeneous reactivity. Figure 3 shows three representative examples of changes in the measured concentration of a reactive trace gas, X, after exposure to mineral dust particles. For the

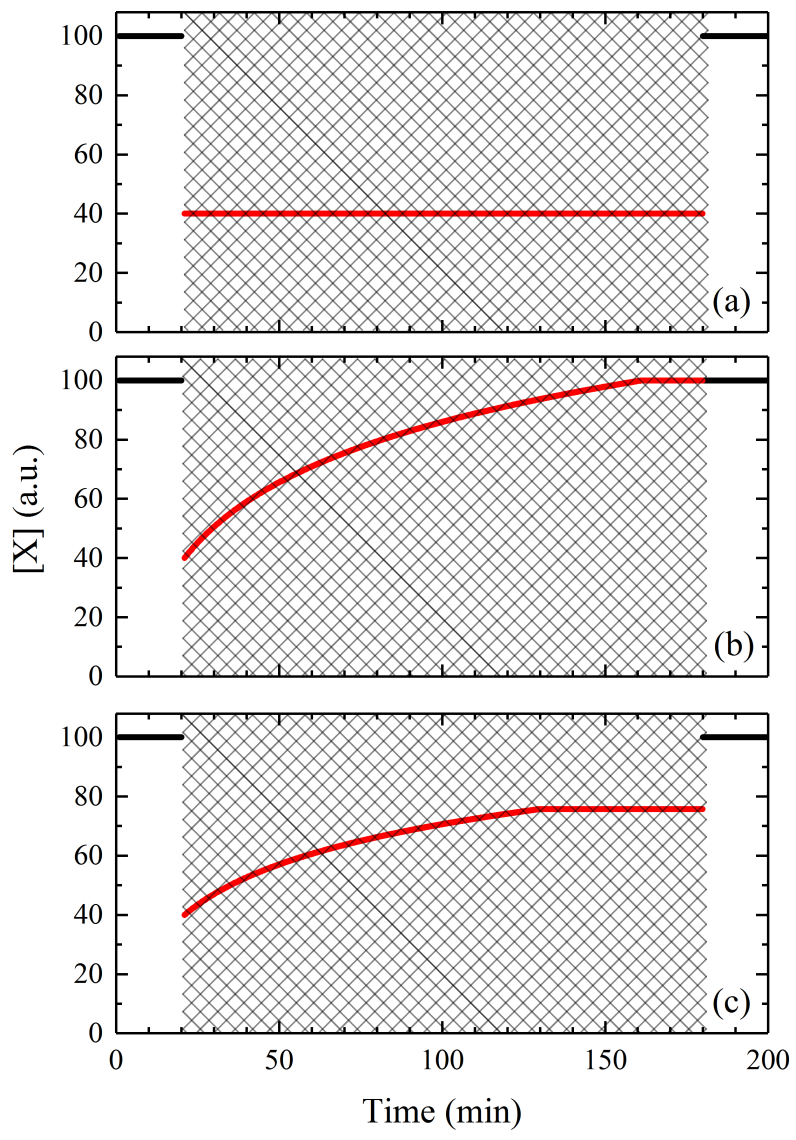

Figure 3. Synthetic data of changes in the measured concentration of a trace gas, $\mathrm{X}$, due to heterogeneous reaction when it is exposed to mineral dust particles. The heterogeneous reaction starts at $20 \mathrm{~min}$ and ceases at $180 \mathrm{~min}$ (the shadowed area). Black curves represent the measured concentration of $\mathrm{X}$ without exposure to mineral dust particles (i.e., initial $[\mathrm{X}]$ ), and red curves represent the evolution of measured $[\mathrm{X}]$ during exposure of $\mathrm{X}$ to mineral dust particles. (a) No surface deactivation, (b) complete surface deactivation, (c) partial surface deactivation. Surface deactivation would result in reduced loss of $\mathrm{X}$ due to heterogeneous uptake and thus increase in measured $[\mathrm{X}]$.

case shown in Fig. 3a, no surface active sites are consumed and the uptake rate is independent of reaction time. Figure $3 b$ displays another case in which surface reactive sites may be consumed and heterogeneous uptake will cease after some exposure. In addition, as shown in Fig. 3c, an initial large uptake rate gradually decreases with time to a nonzero constant value for longer exposure (i.e., the heterogeneous reaction reaches a "steady state").

In atmospheric chemistry community, heterogeneous reactions are usually treated as pseudo-first-order processes (with respect to reactive trace gases), as implied by Eq. (1). However, deactivation of mineral dust surfaces has been reported for a variety of trace gases by experiments using particle ensembles deposited on a substrate (Underwood et al., 2001; 
Hanisch and Crowley, 2003a; Ndour et al., 2009; Tang et al., 2010; Zhou et al., 2012; Romanias et al., 2013; Liu et al., 2015). Therefore, uptake coefficients are normally set to be time dependent (instead of assuming to be a constant), such that Eq. (1) is still valid for time-dependent heterogeneous kinetics. Many studies (Michel et al., 2003; Seisel et al., 2005; Karagulian et al., 2006; Wang et al., 2011; El Zein et al., 2014) have reported initial and/or steady-state uptake coefficients ( $\gamma_{0}$ and $\gamma_{\mathrm{ss}}$, respectively). What makes interpreting reported uptake coefficients more difficult is that even for the same heterogeneous reaction, $\gamma_{0}$ and $\gamma_{\mathrm{ss}}$ may exhibit dependence on experimental conditions (e.g., dust sample mass, trace-gas concentration, temperature, etc.). For example, it takes less time for a reaction to reach steady state when higher concentrations are used for the same reactive trace gas. In many cases, surface may be completely deactivated given sufficient reaction time. Furthermore, $\gamma_{0}$ is usually reported as the first measurable uptake coefficient, which largely depends on the response time (and time resolution) of the instrument used to detect the trace gas.

In aerosol flow tube experiments, on the other hand, exposure time of mineral dust aerosol particles to trace gases are very short (typically $<1 \mathrm{~min}$ ). Therefore, significant surface deactivation is not observed and decays of trace gases can usually be well described by pseudo-first-order kinetics with time-independent uptake coefficients (Vlasenko et al., 2006; Pradhan et al., 2010a; Tang et al., 2012; Matthews et al., 2014).

Ideally laboratory studies of heterogeneous reactions should be carried out at or at least close to atmospherically relevant conditions, such that experimental results can be directly used. However, due to experimental challenges, laboratory studies are usually performed on much shorter timescales (from $<1$ min to a few hours, compared to the average residence time of several days for mineral dust aerosol) and with much higher trace-gas concentrations. Alternatively, measurements can be conducted over a wide range of experimental conditions in order for fundamental physical and chemical processes to be deconvoluted and corresponding rate constants to be determined (Kolb et al., 2010; Davidovits et al., 2011; Pöschl, 2011). With more accurate kinetic data, kinetic models which integrate these fundamental processes can be constructed and applied to predict uptake coefficients for atmospherically relevant conditions (Ammann and Poschl, 2007; Pöschl et al., 2007; Shiraiwa et al., 2012; Berkemeier et al., 2013). Unfortunately, measurements of this type are resource-demanding. In practice laboratory studies of heterogeneous kinetics are usually carried out under very limited experimental conditions. Therefore, there is a great need to invest more resources in fundamental laboratory research.
Table 3. Uptake coefficients used in this work to calculate lifetimes of $\mathrm{OH}, \mathrm{HO}_{2}, \mathrm{H}_{2} \mathrm{O}_{2}, \mathrm{O}_{3}, \mathrm{HCHO}, \mathrm{HONO}, \mathrm{NO}_{3}$, and $\mathrm{N}_{2} \mathrm{O}_{5}$ with respect to heterogeneous reactions with mineral dust aerosol.

\begin{tabular}{lrlr}
\hline Species & $\begin{array}{r}\text { Uptake } \\
\text { coefficient }\end{array}$ & Species & $\begin{array}{r}\text { Uptake } \\
\text { coefficient }\end{array}$ \\
\hline $\mathrm{OH}$ & 0.2 & $\mathrm{HCHO}$ & $1 \times 10^{-5}$ \\
$\mathrm{HO}_{2}$ & 0.031 & $\mathrm{HONO}$ & $1 \times 10^{-6}$ \\
$\mathrm{H}_{2} \mathrm{O}_{2}$ & $1 \times 10^{-3}$ & $\mathrm{NO}_{3}$ & 0.018 \\
$\mathrm{O}_{3}$ & $4.5 \times 10^{-6}$ & $\mathrm{~N}_{2} \mathrm{O}_{5}$ & 0.020 \\
\hline
\end{tabular}

\section{Heterogeneous reactions of mineral dust particles with tropospheric oxidants and their direct precursors}

The importance of a heterogeneous reaction for removal of a trace gas, $X$, is determined by the uptake coefficient and the aerosol surface area concentration, as suggested by Eq. (1). It also depends on the rates of other removal processes in competition, although it is not uncommon that this aspect has not been fully taken into account. In this section, previous laboratory studies of heterogeneous reactions of mineral dust particles with $\mathrm{OH}, \mathrm{HO}_{2}, \mathrm{H}_{2} \mathrm{O}_{2}, \mathrm{O}_{3}, \mathrm{HCHO}, \mathrm{HONO}, \mathrm{NO}_{3}$, and $\mathrm{N}_{2} \mathrm{O}_{5}$ are summarized, analyzed, and discussed. After that, the lifetimes of each trace gas with respect to their heterogeneous reactions with mineral dust are calculated, using uptake coefficients listed in Table 3 , followed by discussion of the relative importance of heterogeneous reactions for their removal in the troposphere. In addition, we also discuss representative modeling studies to further demonstrate and illustrate the importance of these heterogeneous reactions.

Uptake coefficients which are used in this paper to calculate lifetimes with respect to heterogeneous reactions with mineral dust particles are shown in Table 3. The IUPAC Task Group on Atmospheric Chemical Kinetic Data Evaluation has been compiling and evaluating kinetic data for atmospheric heterogeneous reactions (Crowley et al., 2010a), and preferred uptake coefficients are also recommended. It should be noted that uptake coefficients listed in Table 3 do not intend to compete with those recommended by the IUPAC task group. Instead, some of our values are largely based on their recommended values, if available and proper. We also acknowledge that a single uptake coefficient may not always be enough to describe the kinetics of a heterogeneous reaction of mineral dust, because (1) uptake kinetics may change with reaction time, as discussed in Sect. 2.2; (2) uptake kinetics are also affected by particle mineralogy and composition, $\mathrm{RH}$, temperature, the copresence of other reactive trace gases, etc.; and (3) for some reactive trace gases, such as $\mathrm{O}_{3}$, the uptake coefficients may strongly depend on their concentrations.

The pseudo-first-order loss rate depends on the aerosol surface area concentration, which depends on aerosol num- 
ber concentration and its size distribution. Although particle sizing instruments such as aerodynamic particle sizer and scanning particle mobility sizer are commercially available, particle mass concentrations are still more widely measured and reported. Therefore, it is convenient to calculate lifetimes based on mass concentration instead of surface area concentration. This calculation requires information of particle size and density. For simplicity dust aerosol particles are assumed to have an average particle diameter of $1 \mu \mathrm{m}$ and a density of $2.7 \mathrm{~g} \mathrm{~cm}^{-3}$. Consequently, the lifetime of $\mathrm{X}$ with respect to its heterogeneous reaction with mineral dust, $\tau_{\text {het }}(\mathrm{X})$, can be described by Eq. (6) (Wagner et al., 2008; Tang et al., 2010, 2012):

$\tau_{\text {het }}(X)=\frac{1.8 \times 10^{8}}{\gamma_{\mathrm{eff}}(\mathrm{X}) \cdot c(\mathrm{X}) \cdot L}$,

where $\gamma_{\text {eff }}(X)$ is the effective uptake coefficient of $X, c(X)$ is the average molecular speed of $\mathrm{X}\left(\mathrm{cm} \mathrm{s}^{-1}\right)$, and $L$ is the mineral dust loading (i.e., mass concentration) in micrograms per cubic meter $\left(\mu \mathrm{g} \mathrm{m}^{-3}\right)$. Mass concentrations of mineral dust aerosol particles in the troposphere show high variability, ranging from a few micrograms per cubic meter in background regions such as the North Atlantic to $>1000 \mu \mathrm{g} \mathrm{m}^{-3}$ during extreme dust storms (Prospero, 1979; Zhang et al., 1994; de Reus et al., 2000; Gobbi et al., 2000; Alfaro et al., 2003). To take into account this spatial and temporal variation, mass concentrations of 10,100 , and $1000 \mu \mathrm{g} \mathrm{m}^{-3}$ are used in this paper to assess the atmospheric significance of heterogeneous reactions with mineral dust for the removal of trace gases.

\section{1 $\mathrm{OH}$ and $\mathrm{HO}_{2}$ radicals}

\subsubsection{OH radicals}

Heterogeneous uptake of $\mathrm{OH}$ radicals by mineral dust particles was first investigated using a coated wall flow tube with detection of $\mathrm{OH}$ radicals by electron paramagnetic resonance (EPR) (Gershenzon et al., 1986). The uptake coefficient was reported to be $0.04 \pm 0.02$ for $\mathrm{Al}_{2} \mathrm{O}_{3}$ and $0.0056 \pm 0.0020$ for $\mathrm{SiO}_{2}$, independent of temperature in the range of 253$348 \mathrm{~K}$ (Gershenzon et al., 1986). Using laser-induced fluorescence (LIF), Suh et al. (2000) measured concentration changes of $\mathrm{OH}$ radicals after the gas flow was passed through a wire screen loaded with $\mathrm{TiO}_{2}$ (anatase or rutile), $\alpha-\mathrm{Al}_{2} \mathrm{O}_{3}$, or $\mathrm{SiO}_{2}$ under dry conditions. It is shown that the uptake coefficients, $\gamma(\mathrm{OH})$, increased with temperature from $\sim 310$ to $\sim 350 \mathrm{~K}$ for all the three oxides, being $(2-4) \times 10^{-4}$ for $\mathrm{TiO}_{2}$, $(2-4) \times 10^{-3}$ for $\mathrm{SiO}_{2}$, and (5-6) $\times 10^{-3}$ for $\alpha-\mathrm{Al}_{2} \mathrm{O}_{3}(\mathrm{Suh}$ et al., 2000). Unfortunately, most of the results reported by Suh et al. (2000) are only presented graphically. In an earlier study (Bogart et al., 1997), $\gamma(\mathrm{OH})$ was reported to be $0.41 \pm 0.04$ at $300 \mathrm{~K}$ on deposited $\mathrm{SiO}_{2}$ films, decreasing with temperature. $\mathrm{OH}\left(\mathrm{X}^{2} \Pi\right)$ radicals used by Bogart et al. were generated in a 20:80 tetraethoxysilane $/ \mathrm{O}_{2}$ plasmas and

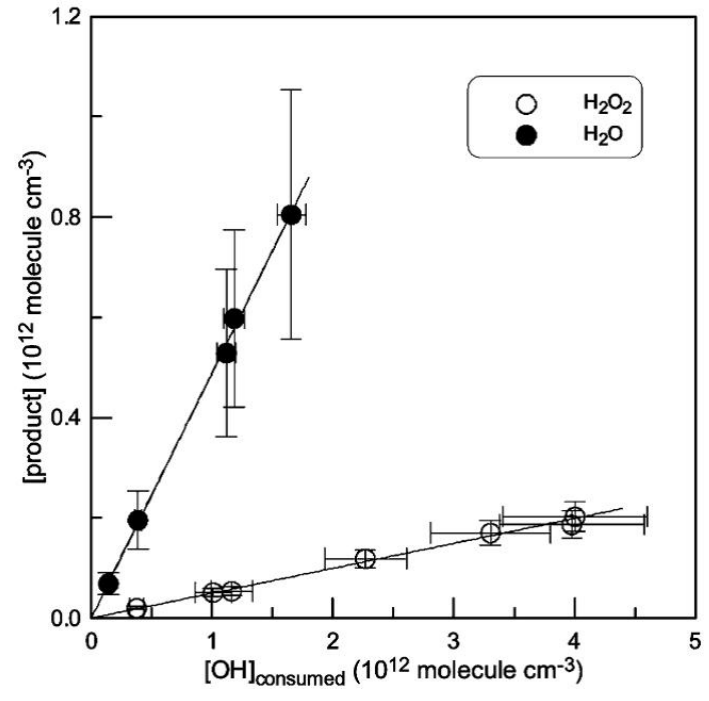

Figure 4. Concentrations of $\mathrm{H}_{2} \mathrm{O}$ (solid circles) and $\mathrm{H}_{2} \mathrm{O}_{2}$ (open circles) produced in the gas phase due to heterogeneous reaction of $\mathrm{OH}$ radicals with ATD particles. Reprinted with permission from Bedjanian et al. (2013b). (C) 2013 American Chemical Society.

their atmospheric relevance is not very clear; therefore, this study is not included in Table 1 or further discussed.

The average $\gamma(\mathrm{OH})$ was determined to be 0.20 for $\mathrm{Al}_{2} \mathrm{O}_{3}$ at room temperature under dry conditions (Bertram et al., 2001), using a coated wall flow tube coupled to chemical ionization mass spectrometry (CIMS). In a following study, the $\mathrm{RH}$ dependence of $\gamma(\mathrm{OH})$ on $\mathrm{SiO}_{2}$ and $\mathrm{Al}_{2} \mathrm{O}_{3}$ at room temperature was investigated (Park et al., 2008). It is found that $\gamma(\mathrm{OH})$ increased from $0.032 \pm 0.007$ at $0 \% \mathrm{RH}$ to $0.098 \pm 0.022$ at $33 \% \mathrm{RH}$ for $\mathrm{SiO}_{2}$ and from $0.045 \pm 0.005$ at $0 \% \mathrm{RH}$ to $0.084 \pm 0.012$ at $38 \% \mathrm{RH}$ for $\mathrm{Al}_{2} \mathrm{O}_{3}$ (Park et al., 2008).

Recently a coated rod flow tube was used to investigate uptake of $\mathrm{OH}$ radicals by Arizona test dust (ATD) particles (Bedjanian et al., 2013b) as a function of temperature (275$320 \mathrm{~K})$ and RH (0.03-25.9\%). Gradual surface deactivation was observed, and the initial uptake coefficient was found to be independent of temperature and decrease with increasing $\mathrm{RH}$, given by Eq. (7):

$\gamma_{0}=0.2 /\left(1+\mathrm{RH}^{0.36}\right)$

with an estimated uncertainty of $\pm 30 \%$. Please note that uptake coefficients reported by Bedjanian et al. (2013b) are based on the geometrical area of the rod coated with ATD particles and thus should be considered as the upper limit. No effect of UV radiation, with $J\left(\mathrm{NO}_{2}\right)$ up to $0.012 \mathrm{~s}^{-1}$, was observed (Bedjanian et al., 2013b). In addition, $\mathrm{H}_{2} \mathrm{O}$ and $\mathrm{H}_{2} \mathrm{O}_{2}$ were found to be the major and minor products in the gas phase, respectively (Bedjanian et al., 2013b), as shown in Fig. 4. 
Table 4. Summary of previous laboratory studies on heterogeneous reactions of mineral dust with $\mathrm{OH}$ and $\mathrm{HO}_{2}$ radicals. RT: room temperature

\begin{tabular}{|c|c|c|c|c|c|c|}
\hline $\begin{array}{l}\text { Trace } \\
\text { gases }\end{array}$ & Dust & Reference & $T(\mathrm{~K})$ & $\begin{array}{r}\text { Concentration } \\
\left(\text { molecule } \mathrm{cm}^{-3}\right)\end{array}$ & Uptake coefficients & Techniques \\
\hline \multirow[t]{9}{*}{$\mathrm{OH}$} & $\mathrm{TiO}_{2}$ & Suh et al. (2000) & 308 to 350 & $\sim 4 \times 10^{12}$ & $(2-4) \times 10^{-4}$, increasing with temperature & LIF \\
\hline & $\mathrm{SiO}_{2}$ & Gershenzon et al. (1986) & 253-343 & $<2 \times 10^{12}$ & $0.0056 \pm 0.002$, independent of temperature & CWFT-EPR \\
\hline & & Suh et al. (2000) & 308 to 350 & $\sim 4 \times 10^{12}$ & $(2-4) \times 10^{-3}$, increasing with temperature & LIF \\
\hline & & Park et al. (2008) & RT & $\sim 4 \times 10^{11}$ & $\begin{array}{l}0.032 \pm 0.007 \text { at } 0 \% \mathrm{RH} \text { and } 0.098 \pm 0.022 \text { at } \\
33 \% \mathrm{RH}\end{array}$ & CWFT-CIMS \\
\hline & $\mathrm{Al}_{2} \mathrm{O}_{3}$ & Gershenzon et al. (1986) & $253-343$ & $<2 \times 10^{12}$ & $0.04 \pm 0.02$, independent of temperature & CWFT-EPR \\
\hline & & Suh et al. (2000) & 308 to 350 & $\sim 4 \times 10^{12}$ & $(5-6) \times 10^{-3}$, increasing with temperature & LIF \\
\hline & & Bertram et al. (2001) & RT & $(1-100) \times 10^{9}$ & 0.20 & CWFT-CIMS \\
\hline & & Park et al. (2008) & RT & $\sim 4 \times 10^{11}$ & $\begin{array}{l}0.045 \pm 0.005 \text { at } 0 \% \mathrm{RH} \text { and } 0.084 \pm 0.012 \text { at } \\
38 \% \mathrm{RH}\end{array}$ & CWFT-CIMS \\
\hline & ATD & Bedjanian et al. (2013b) & $275-320$ & $(0.4-5.2) \times 10^{12}$ & $\begin{array}{l}0.20 \text { at } 0 \% \mathrm{RH} \text {, showing a negative } \mathrm{RH} \text { depen- } \\
\text { dence but no dependence on temperatures }\end{array}$ & CRFT-MS \\
\hline \multirow[t]{6}{*}{$\mathrm{HO}_{2}$} & ATD & Bedjanian et al. (2013a) & $275-320$ & $(0.35-3.3) \times 10^{12}$ & $\begin{array}{l}0.067 \pm 0.004 \text { at } 0 \% \mathrm{RH} \text {, showing a negative } \\
\mathrm{RH} \text { dependence }(0.02-94 \%) \text { but no dependence } \\
\text { on temperature }\end{array}$ & CRFT-MS \\
\hline & & Matthews et al. (2014) & $291 \pm 2$ & $(3-10) \times 10^{8}$ & $\begin{array}{l}0.018 \pm 0.006 \text { when } \mathrm{HO}_{2} \text { concentration was } \\
3 \times 10^{8} \text { molecule } \mathrm{cm}^{-3} \text { and } 0.031 \pm 0.008 \text { when } \\
\mathrm{HO}_{2} \text { concentration was } 3 \times 10^{8} \text { molecule } \mathrm{cm}^{-3} \text {. } \\
\text { No } \mathrm{RH}(5-76 \%) \text { dependence was observed }\end{array}$ & AFT-FAGE \\
\hline & Forsterite & James et al. (2017) & 293 & $1.6 \times 10^{9}$ & $(4.3 \pm 0.4) \times 10^{-3}$ at $12 \% \mathrm{RH}$ & AFT-FAGE \\
\hline & Olivine & James et al. (2017) & 293 & $1.6 \times 10^{9}$ & $(6.9 \pm 1.2) \times 10^{-2}$ at $10 \% \mathrm{RH}$ & AFT-FAGE \\
\hline & Fayalite & James et al. (2017) & 293 & $1.6 \times 10^{9}$ & $(7.3 \pm 0.4) \times 10^{-2}$ at $10 \% \mathrm{RH}$ & AFT-FAGE \\
\hline & $\mathrm{TiO}_{2}$ & Moon et al. (2017) & 293 & $1.6 \times 10^{9}$ & $\begin{array}{l}0.021 \pm 0.001 \text { at } \sim 11 \% \mathrm{RH}, 0.029 \pm 0.005 \text { at } \\
\sim 45 \%, \text { and } 0.037 \pm 0.007 \text { at } \sim 66 \%, \text { showing } \\
\text { a positive dependence on } \mathrm{RH}\end{array}$ & AFT-FAGE \\
\hline
\end{tabular}

As shown in Fig. 5, $\gamma(\mathrm{OH})$ reported by previous flow tube studies, except that on $\mathrm{SiO}_{2}$ particles reported by Gershenzon et al. (1986), shows reasonably good agreement, considering that different minerals were used. Reported $\gamma(\mathrm{OH})$ is larger than 0.02 in general, suggesting that mineral dust exhibits relatively large reactivity towards $\mathrm{OH}$ radicals. Discrepancies are also identified from data presented in Fig. 5, with the most evident one being the effect of RH. Park et al. (2008) found that $\gamma(\mathrm{OH})$ increased significantly with $\mathrm{RH}$ for both $\mathrm{SiO}_{2}$ and $\mathrm{Al}_{2} \mathrm{O}_{3}$, while Bedjanian et al. (2013b) suggested that $\gamma(\mathrm{OH})$ showed a negative dependence on RH. It is not clear yet whether different minerals used by these two studies can fully account for the different RH dependence observed. Furthermore, a positive dependence of $\gamma(\mathrm{OH})$ on temperature was found by Suh et al. (2000) for $\mathrm{TiO}_{2}, \alpha-\mathrm{Al}_{2} \mathrm{O}_{2}$, and $\mathrm{SiO}_{2}$, while Bogart et al. (1997) reported a negative temperature effect for deposited $\mathrm{SiO}_{2}$ film and no significant dependence on temperature was found for ATD (Bedjanian et al., 2013b).

A $\gamma(\mathrm{OH})$ value of 0.2 , reported by Bedjanian et al. (2013b) for ATD, is used in our present work to evaluate the importance of heterogeneous uptake of $\mathrm{OH}$ radicals by mineral dust aerosol. According to Eq. (6), dust mass loadings of 10,100 , and $1000 \mathrm{\mu g} \mathrm{m}^{-3}$ correspond to $\tau_{\text {het }}(\mathrm{OH})$ of $\sim 25 \mathrm{~min}, 150$, and $15 \mathrm{~s}$ with respect to heterogeneous uptake by mineral dust. As discussed in Sect. 2.1.1, lifetimes of tropospheric $\mathrm{OH}$ are in the range of

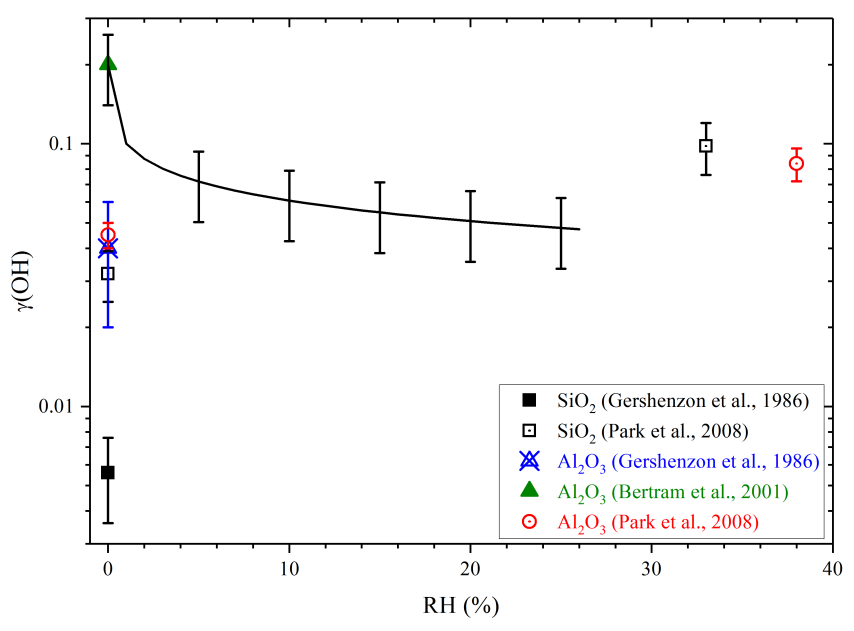

Figure 5. Uptake coefficients of $\mathrm{OH}$ radicals for different minerals at room temperature, as reported by different studies. The plotted $\mathrm{RH}$ dependence of $\gamma(\mathrm{OH})$ for ATD (solid curve) is based on the parameterization reported by Bedjanian et al. (2013b), i.e., Eq. (7).

$1 \mathrm{~s}$ or less in very clean regions and $<0.1 \mathrm{~s}$ in polluted and forested areas, much shorter than $\tau_{\text {het }}(\mathrm{OH})$. Even if $\gamma(\mathrm{OH})$ is assumed to be 1 , for uptake by $1 \mu \mathrm{m}$ particles $\gamma_{\mathrm{eff}}(\mathrm{OH})$ is calculated to be 0.23 , which is only $15 \%$ larger than what we use to calculate $\tau_{\text {het }}(\mathrm{OH})$. Therefore, it can be concluded 
that heterogeneous reaction with mineral dust aerosol is not a significant sink for $\mathrm{OH}$ radicals in the troposphere.

\subsection{2 $\quad \mathrm{HO}_{2}$ radicals}

A few laboratory studies have investigated heterogeneous uptake of $\mathrm{HO}_{2}$ radicals by mineral dust particles. Bedjanian et al. (2013a) used a coated rod flow tube to study the interaction of $\mathrm{HO}_{2}$ radicals with ATD film as a function of temperature and RH. Surface deactivation was observed, and $\gamma_{0}$, based on the geometrical area of dust films, was determined to be $0.067 \pm 0.004$ under dry conditions (Bedjanian et al., 2013a). The initial uptake coefficient, independent of temperature, was found to decrease with RH, given by Eq. (8):

$\gamma_{0}=1.2 /\left(18.7+\mathrm{RH}^{1.1}\right)$,

with an estimated uncertainty of $\pm 30 \%$. UV radiation, with $J\left(\mathrm{NO}_{2}\right)$ ranging from 0 to $0.012 \mathrm{~s}^{-1}$, did not affect uptake kinetics significantly. In addition, the yield of $\mathrm{H}_{2} \mathrm{O}_{2}(\mathrm{~g})$, defined as the ratio of formed $\mathrm{H}_{2} \mathrm{O}_{2}(\mathrm{~g})$ molecules to consumed $\mathrm{HO}_{2}$ radicals, was determined to be $<5 \%$ (Bedjanian et al., 2013a). In the second study (Matthews et al., 2014), an aerosol flow tube was deployed to measure $\gamma\left(\mathrm{HO}_{2}\right)$ onto ATD aerosol particles at $291 \pm 2 \mathrm{~K}$, with $\mathrm{HO}_{2}$ detection via the fluorescence assay by the gas expansion technique. No significant effect of RH in the range of 5-76\% was observed, and $\gamma\left(\mathrm{HO}_{2}\right)$ was reported to be $0.031 \pm 0.008$ for $\left[\mathrm{HO}_{2}\right]$ of $3 \times 10^{8}$ molecule $\mathrm{cm}^{-3}$ and $0.018 \pm 0.006$ for $\left[\mathrm{HO}_{2}\right]$ of $1 \times 10^{9}$ molecule $\mathrm{cm}^{-3}$ (Matthews et al., 2014). In addition, $\gamma\left(\mathrm{HO}_{2}\right)$ was found to decrease with increasing reaction time. The negative dependence of $\gamma\left(\mathrm{HO}_{2}\right)$ on $\left[\mathrm{HO}_{2}\right]$ and reaction time implies that ATD surface is gradually deactivated upon exposure to $\mathrm{HO}_{2}$ radicals, as directly observed by Bedjanian et al. (2013a).

Figure 6 shows the effect of $\mathrm{RH}$ on $\gamma\left(\mathrm{HO}_{2}\right)$ for ATD particles. A quick look at Fig. 6 could lead to the impression that the values of $\gamma\left(\mathrm{HO}_{2}\right)$ reported by two previous studies (Bedjanian et al., 2013a; Matthews et al., 2014) agree relatively well, especially considering that two very different experimental techniques were used. Nevertheless, Matthews et al. (2014), who conducted their measurements with initial $\left[\mathrm{HO}_{2}\right]$ which are 3-4 orders of magnitude lower than those used by Bedjanian et al. (2013a), found a significant negative dependence of $\gamma\left(\mathrm{HO}_{2}\right)$ on initial $\left[\mathrm{HO}_{2}\right]$. If this trend can be further extrapolated to higher initial $\left[\mathrm{HO}_{2}\right]$, one may expect that if carried out with initial $\left[\mathrm{HO}_{2}\right]$ similar to those used by Bedjanian et al. (2013a), Matthews et al. (2014) may find much smaller $\gamma\left(\mathrm{HO}_{2}\right)$. In addition, these two studies also suggest very different RH effects, as is evident from Fig. 6.

In a very recent study (Moon et al., 2017), heterogeneous reaction of $\mathrm{HO}_{2}$ with $\mathrm{TiO}_{2}$ aerosol particles was examined as a function of $\mathrm{RH}$ at room temperature. As shown in Fig. 6, $\gamma\left(\mathrm{HO}_{2}\right)$ was observed to depend on $\mathrm{RH}$, increasing from $0.021 \pm 0.001$ at $\sim 11 \% \mathrm{RH}$ to $0.029 \pm 0.005$ at

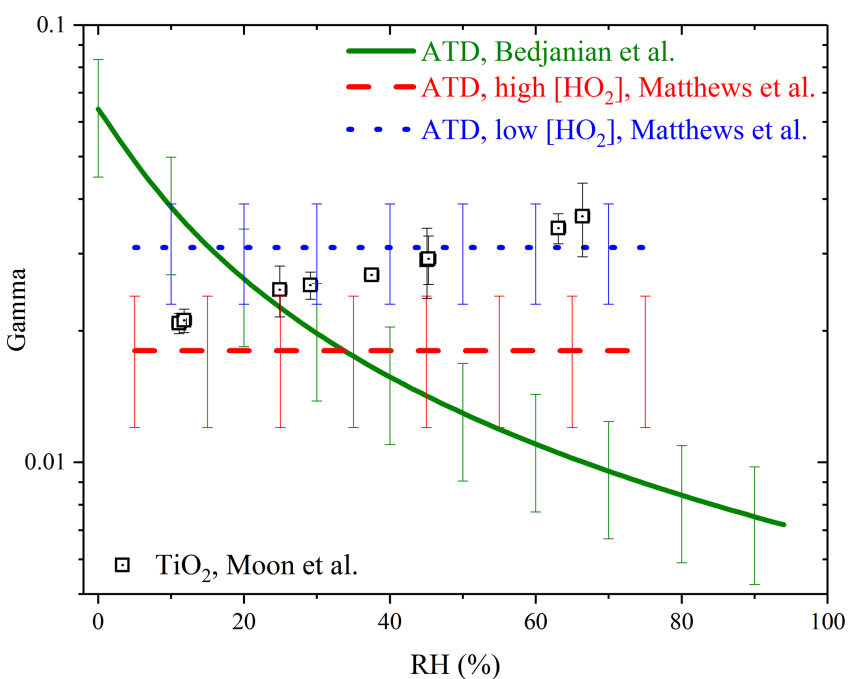

Figure 6. $\mathrm{RH}$ dependence of $\gamma\left(\mathrm{HO}_{2}\right)$ for ATD and $\mathrm{TiO}_{2}$ reported by previous studies. Solid curve, reported by Bedjanian et al. (2013a) with initial $\left[\mathrm{HO}_{2}\right]$ in the range of $(0.35-3) \times 10^{12}$ molecule $\mathrm{cm}^{-3}$; dashed and dotted curve, reported by Matthews et al. (2014) with initial $\left[\mathrm{HO}_{2}\right]$ of $1 \times 10^{9}$ and $3 \times 10^{8}$ molecule $\mathrm{cm}^{-3}$, respectively. Numerical data for $\gamma\left(\mathrm{HO}_{2}\right)$ at different $\mathrm{RH}$ were not provided by Matthews et al. (2014), and thus in this figure we plot their reported average $\gamma\left(\mathrm{HO}_{2}\right)$ together with their estimated uncertainties. The plotted $\mathrm{RH}$ dependence of $\gamma\left(\mathrm{HO}_{2}\right)$ reported by Bedjanian et al. (2013b) is based on their proposed parameterization, i.e., Eq. (8).

$\sim 45 \%$ and $0.037 \pm 0.007$ at $\sim 66 \%$. More specifically, it has been shown that for the RH range covered (11-66\%), $\gamma\left(\mathrm{HO}_{2}\right)$ depends linearly on the amount of water adsorbed on $\mathrm{TiO}_{2}$ particles, revealing the critical role adsorbed water plays in heterogeneous uptake of $\mathrm{HO}_{2}$ radicals by $\mathrm{TiO}_{2}$. Apart from these displayed in Fig. 6, the uptake of $\mathrm{HO}_{2}$ by analogues of meteoric smoke particles was also examined at room temperature (James et al., 2017), using an aerosol flow tube. At $(10 \pm 1) \% \mathrm{RH}$, the uptake coefficient was determined to be $0.069 \pm 0.012$ for olivine $\left(\mathrm{MgFeSiO}_{4}\right)$, $0.073 \pm 0.004$ for fayalite $\left(\mathrm{Fe}_{2} \mathrm{SiO}_{4}\right)$, and $0.0043 \pm 0.0004$ for forsterite $\left(\mathrm{Mg}_{2} \mathrm{SiO}_{4}\right)$. It appears that compared to meteoric smoke particles which do not contain $\mathrm{Fe}, \mathrm{Fe}$-containing meteoric smoke particles show much larger heterogeneous reactivity towards $\mathrm{HO}_{2}$ radicals. The experimental result indicates a catalytic role of $\mathrm{Fe}$ in $\mathrm{HO}_{2}$ uptake, as supported by electronic structure calculations (James et al., 2017). Though its tropospheric relevance is limited, this study provides valuable mechanistic insights into the heterogeneous reaction of mineral dust with $\mathrm{HO}_{2}$ radicals.

For reasons discussed in Sect. 2.2.1, $\gamma\left(\mathrm{HO}_{2}\right)$ reported by Matthews et al. (2014) using ATD aerosol samples is used to calculate $\tau_{\text {het }}\left(\mathrm{HO}_{2}\right)$ with respect to uptake onto mineral dust. Another reason that the data reported by Matthews et al. (2014) are preferred is that $\left[\mathrm{HO}_{2}\right]$ used in this study was low enough to be of direct atmospheric relevance. 
As a result, $\gamma\left(\mathrm{HO}_{2}\right)$ measured at lower initial $\left[\mathrm{HO}_{2}\right](3 \times$ $10^{8}$ molecule $\mathrm{cm}^{-3}$ ), equal to $0.031 \pm 0.008$, is adopted in our current work to assess the significance of $\mathrm{HO}_{2}$ uptake by mineral dust. Using Eq. (6), $\tau_{\text {het }}\left(\mathrm{HO}_{2}\right)$ is estimated to be 2.2, 22, and $222 \mathrm{~min}$ for dust mass concentrations of 1000, 100, and $10 \mu \mathrm{g} \mathrm{m}^{-3}$, respectively. Typical $\mathrm{HO}_{2}$ lifetimes in the troposphere, as summarized in Table 1, show large variability, ranging from $<1 \mathrm{~s}$ (Ren et al., 2003) to $>30 \mathrm{~min}$ (Whalley et al., 2011). Therefore, dust aerosol with moderate mass concentrations could be a significant tropospheric $\mathrm{HO}_{2}$ sink, except in regions with very high NO levels.

The importance of heterogeneous uptake as a $\mathrm{HO}_{2}$ sink in the troposphere has also been demonstrated by several more sophisticated modeling studies. For example, it is found that while standard gas-phase chemical mechanism used by the GEOS-Chem model would overestimate $\mathrm{HO}_{2}$ and $\mathrm{H}_{2} \mathrm{O}_{2}$ concentrations observed in the Arctic troposphere in the spring, including heterogeneous reaction of $\mathrm{HO}_{2}$ with an average $\gamma\left(\mathrm{HO}_{2}\right)$ of $>0.1$ in the model could better reproduce the measured concentrations and vertical profiles of $\mathrm{HO}_{2}$ and $\mathrm{H}_{2} \mathrm{O}_{2}$ (Mao et al., 2010a). Though not directly relevant for mineral dust aerosol, this study provided strong evidence that heterogeneous uptake can be an important but yet not fully recognized sink for tropospheric $\mathrm{HO}_{2}$ radicals (Mao et al., 2010a). Using a global tropospheric model, Macintyre and Evans (2011) analyzed the sensitivity of model output to $\gamma\left(\mathrm{HO}_{2}\right)$ values used in the model. A global average $\gamma\left(\mathrm{HO}_{2}\right)$ of 0.028 was derived from available laboratory studies (Macintyre and Evans, 2011), and large regional differences in modeled $\mathrm{O}_{3}$ were observed between simulations using $\gamma\left(\mathrm{HO}_{2}\right)$ parameterization developed by Macintyre and Evans (2011) and those using a constant $\gamma\left(\mathrm{HO}_{2}\right)$ of 0.2 . This result highlights the importance of accurate determination of $\gamma\left(\mathrm{HO}_{2}\right)$ under different tropospheric conditions (e.g., aerosol composition, $\mathrm{RH}$, and temperature).

The impact of $\mathrm{HO}_{2}$ uptake by mineral dust has also been investigated by several modeling studies. For example, an observation-constrained box model study (Matthews et al., 2014) suggested that heterogeneous reaction with mineral dust could result in $>10 \%$ reduction in $\mathrm{HO}_{2}$ concentrations in Cape Verde, using a $\gamma\left(\mathrm{HO}_{2}\right)$ of 0.038. A WRF-Chem simulation, using $\gamma\left(\mathrm{HO}_{2}\right)$ reported by Bedjanian et al. (2013a), showed that heterogeneous uptake by mineral dust could reduce $\mathrm{HO}_{2}$ concentrations by up to $40 \%$ over northern India during a premonsoon dust storm (Kumar et al., 2014).

One may assume that heterogeneous reaction of $\mathrm{HO}_{2}$ with aerosol particles leads to the formation of $\mathrm{H}_{2} \mathrm{O}_{2}$ (Graedel et al., 1986; Thornton and Abbatt, 2005). A second channel without $\mathrm{H}_{2} \mathrm{O}_{2}$ formation, i.e., simple decomposition of $\mathrm{HO}_{2}$ radicals to $\mathrm{H}_{2} \mathrm{O}$ and $\mathrm{O}_{2}$, may also be important (Bedjanian et al., 2013a; Mao et al., 2013a). Atmospheric impacts can be very different for these two mechanisms. While the second pathway represents a net sink for $\mathrm{HO}_{2}$ in the troposphere, the first channel only converts $\mathrm{HO}_{2}$ to $\mathrm{H}_{2} \mathrm{O}_{2}$ via heterogeneous reaction and is thus of limited efficacy as a net sink for
$\mathrm{HO}_{x}$ because $\mathrm{H}_{2} \mathrm{O}_{2}$ can undergo photolysis to generate $\mathrm{OH}$ radicals.

The relative importance of these two mechanisms has been explored by modeling studies. In the modeling work carried out by de Reus et al. (2005), $\gamma\left(\mathrm{HO}_{2}\right)$ was assumed to be 0.2 for heterogeneous uptake onto Saharan dust particles. If no $\mathrm{H}_{2} \mathrm{O}_{2}$ is formed in heterogeneous reaction of $\mathrm{HO}_{2}$ with Saharan dust, modeled $\mathrm{H}_{2} \mathrm{O}_{2}$ concentrations would agree well with measurements; in contrast, if heterogeneous uptake of $\mathrm{HO}_{2}$ radicals were assumed to produce $\mathrm{H}_{2} \mathrm{O}_{2}$, modeled $\mathrm{H}_{2} \mathrm{O}_{2}$ concentrations would be much larger than measured values. In a more recent study, Mao et al. (2010a) found that only including the first reaction channel (with $\mathrm{H}_{2} \mathrm{O}_{2}$ production) will overestimate $\mathrm{H}_{2} \mathrm{O}_{2}$ in the Arctic, while only considering the second channel (without $\mathrm{H}_{2} \mathrm{O}_{2}$ production) would cause underestimation of $\mathrm{H}_{2} \mathrm{O}_{2}$. Consequently, it seems that both channels have nonnegligible contributions in the troposphere (Mao et al., 2010a). Significant differences in modeled $\mathrm{OH}, \mathrm{HO}_{2}, \mathrm{O}_{3}$, and sulfate concentrations have been found by a global model study when including two mechanisms separately (Macintyre and Evans, 2011). One experimental study (Bedjanian et al., 2013a) measured gasphase products for heterogeneous reaction of $\mathrm{HO}_{2}$ radicals with ATD particles and found that gaseous $\mathrm{H}_{2} \mathrm{O}_{2}$ formed in this reaction is minor but probably nonnegligible. Considering the importance of mechanisms of heterogeneous reactions of $\mathrm{HO}_{2}$ with mineral dust, further experimental work is required. Furthermore, mineralogy and RH may also impact the yield of $\mathrm{H}_{2} \mathrm{O}_{2}(\mathrm{~g})$, but these effects are not clear yet.

\section{$3.2 \quad \mathrm{H}_{2} \mathrm{O}_{2}$}

Pradhan et al. (2010a, b) utilized an aerosol flow tube to investigate heterogeneous interaction of $\mathrm{H}_{2} \mathrm{O}_{2}$ with airborne $\mathrm{TiO}_{2}$, Gobi dust, and Saharan dust particles at $295 \pm 2 \mathrm{~K}$, and $\mathrm{H}_{2} \mathrm{O}_{2}$ was detected by CIMS. A negative dependence of $\gamma\left(\mathrm{H}_{2} \mathrm{O}_{2}\right)$ on $\mathrm{RH}$ was observed for $\mathrm{TiO}_{2}$, with $\gamma\left(\mathrm{H}_{2} \mathrm{O}_{2}\right)$ decreasing from $(1.53 \pm 0.11) \times 10^{-3}$ at $15 \% \mathrm{RH}$ to $(6.47 \pm$ $0.74) \times 10^{-4}$ at $40 \% \mathrm{RH}$ and $(5.04 \pm 0.58) \times 10^{-4}$ at $70 \%$ $\mathrm{RH}$ (Pradhan et al., 2010a). In contrast, $\mathrm{H}_{2} \mathrm{O}_{2}$ uptake kinetics displayed positive dependence on RH for Gobi and Saharan dust, with $\gamma\left(\mathrm{H}_{2} \mathrm{O}_{2}\right)$ increasing from $(3.33 \pm 0.26) \times 10^{-4}$ at $15 \% \mathrm{RH}$ to $(6.03 \pm 0.42) \times 10^{-4}$ at $70 \% \mathrm{RH}$ for Gobi dust and from $(6.20 \pm 0.22) \times 10^{-4}$ at $15 \% \mathrm{RH}$ to $(9.42 \pm 0.41) \times$ $10^{-4}$ at $70 \%$ RH for Saharan dust (Pradhan et al., 2010b). It appears that heterogeneous reactivity of Saharan dust towards $\mathrm{H}_{2} \mathrm{O}_{2}$ is significantly higher than Gobi dust.

Heterogeneous interaction of gaseous $\mathrm{H}_{2} \mathrm{O}_{2}$ with $\mathrm{SiO}_{2}$ and $\alpha-\mathrm{Al}_{2} \mathrm{O}_{3}$ particles was investigated at $298 \pm 1 \mathrm{~K}$, using transmission FTIR to probe particle surfaces and a HPLCbased offline technique to measure gaseous $\mathrm{H}_{2} \mathrm{O}_{2}$ (Zhao et al., 2011b). It is found that most of $\mathrm{H}_{2} \mathrm{O}_{2}$ molecules were physisorbed on the $\mathrm{SiO}_{2}$ surface and a small amount of molecularly adsorbed $\mathrm{H}_{2} \mathrm{O}_{2}$ underwent thermal decomposition. In contrast, catalytic decomposition occurred to a large 
fraction of $\mathrm{H}_{2} \mathrm{O}_{2}$ uptaken by $\alpha-\mathrm{Al}_{2} \mathrm{O}_{3}$, though some $\mathrm{H}_{2} \mathrm{O}_{2}$ molecules were also physisorbed on the surface (Zhao et al., 2011b). The uptake coefficient, based on the BET surface area, was found to be independent of initial $\mathrm{H}_{2} \mathrm{O}_{2}$ concentrations (1.27-13.8 ppmv) while largely affected by RH (Zhao et al., 2011b). Values of $\gamma\left(\mathrm{H}_{2} \mathrm{O}_{2}\right)$ decreased from (1.55 \pm $0.14) \times 10^{-8}$ at $2 \% \mathrm{RH}$ to $(0.81 \pm 0.11) \times 10^{-8}$ at $21 \% \mathrm{RH}$ for $\mathrm{SiO}_{2}$ particles, and further increases in $\mathrm{RH}$ (up to $76 \%$ ) did not affect the uptake kinetics (Zhao et al., 2011b). A similar dependence of $\gamma\left(\mathrm{H}_{2} \mathrm{O}_{2}\right)$ on RH was also observed for $\alpha-\mathrm{Al}_{2} \mathrm{O}_{3}: \gamma\left(\mathrm{H}_{2} \mathrm{O}_{2}\right)$ decreased from $(1.21 \pm 0.04) \times 10^{-7}$ at $2 \% \mathrm{RH}$ to $(0.84 \pm 0.07) \times 10^{-7}$ at $21 \% \mathrm{RH}$, and the effect of RH was not significant for RH in the range of 21-76\% (Zhao et al., 2011b). Compared to $\mathrm{SiO}_{2}, \alpha-\mathrm{Al}_{2} \mathrm{O}_{3}$ appears to be much more reactive towards $\mathrm{H}_{2} \mathrm{O}_{2}$.

In a following study, using the same experimental setup, Zhao et al. (2013) explored the heterogeneous interaction of $\mathrm{H}_{2} \mathrm{O}_{2}$ with fresh, $\mathrm{HNO}_{3}$-processed, and $\mathrm{SO}_{2}$-processed $\mathrm{CaCO}_{3}$ particles. The uptake of $\mathrm{H}_{2} \mathrm{O}_{2}$ on fresh $\mathrm{CaCO}_{3}$ particles was drastically reduced with increasing $\mathrm{RH}$, indicating that $\mathrm{H}_{2} \mathrm{O}_{2}$ and $\mathrm{H}_{2} \mathrm{O}$ compete for surface reactive sites. In addition, about 85-90\% of $\mathrm{H}_{2} \mathrm{O}_{2}$ molecules uptaken by fresh $\mathrm{CaCO}_{3}$ particles undergo decomposition (Zhao et al., 2013). Unfortunately no uptake coefficients were reported (Zhao et al., 2013). Pretreatment of $\mathrm{CaCO}_{3}$ particles with $\mathrm{HNO}_{3}$ or $\mathrm{SO}_{2}$ can significantly affect their heterogeneous reactivity towards $\mathrm{H}_{2} \mathrm{O}_{2}$. The effect of $\mathrm{HNO}_{3}$ pretreatment increases with surface coverage of nitrate (formed on $\mathrm{CaCO}_{3}$ particles), showing an interesting dependence on RH. Pretreatment of $\mathrm{CaCO}_{3}$ with $\mathrm{HNO}_{3}$ reduced its heterogeneous reactivity by $30-85 \%$ at $3 \% \mathrm{RH}$, while it led to enhancement of reactivity towards $\mathrm{H}_{2} \mathrm{O}_{2}$ by $20-60 \%$ at $25 \% \mathrm{RH}$, a factor of $1-3$ at $45 \% \mathrm{RH}$, and a factor of 3-8 at $75 \% \mathrm{RH}$ (Zhao et al., 2013). At low $\mathrm{RH}$, formation of $\mathrm{Ca}\left(\mathrm{NO}_{3}\right)_{2}$ on the surface could deactivate $\mathrm{CaCO}_{3}$; however, $\mathrm{Ca}\left(\mathrm{NO}_{3}\right)_{2}$ may exit as an aqueous film at higher RH (Krueger et al., 2003b; Liu et al., 2008b), consequently leading to large enhancement of $\mathrm{H}_{2} \mathrm{O}_{2}$ uptake. Compared to fresh $\mathrm{CaCO}_{3}, \mathrm{SO}_{2}$-processed particles always exhibit much higher reactivity towards $\mathrm{H}_{2} \mathrm{O}_{2}$, and enhancement factors, increasing with $\mathrm{RH}$, were observed to fall into the range of 3-10 (Zhao et al., 2013).

Heterogeneous uptake of $\mathrm{H}_{2} \mathrm{O}_{2}$ by several oxides was investigated at $298 \mathrm{~K}$ using a Knudsen cell reactor with $\mathrm{H}_{2} \mathrm{O}_{2}$ measured by a quadrupole mass spectrometer (Wang et al., 2011). The value of $\gamma_{0}\left(\mathrm{H}_{2} \mathrm{O}_{2}\right)$, based on the BET surface area of sample powders, was determined to be $(1.00 \pm 0.11) \times$ $10^{-4}$ for $\alpha-\mathrm{Al}_{2} \mathrm{O}_{3},(1.66 \pm 0.23) \times 10^{-4}$ for $\mathrm{MgO},(9.70 \pm$ $1.95) \times 10^{-5}$ for $\mathrm{Fe}_{2} \mathrm{O}_{3}$, and $(5.22 \pm 0.90) \times 10^{-5}$ for $\mathrm{SiO}_{2}$ (Wang et al., 2011). Surface deactivation occurred for all the surfaces, though complete surface saturation was only observed for $\mathrm{SiO}_{2}$ after extended $\mathrm{H}_{2} \mathrm{O}_{2}$ exposure. This may indicate that the uptake of $\mathrm{H}_{2} \mathrm{O}_{2}$ by $\alpha-\mathrm{Al}_{2} \mathrm{O}_{3}, \mathrm{MgO}$, and $\mathrm{Fe}_{2} \mathrm{O}_{3}$ are of catalytic nature to some extent (Wang et al., 2011).

Continuous-wave CRDS was employed to detect the depletion of $\mathrm{H}_{2} \mathrm{O}_{2}$ and formation of $\mathrm{HO}_{2}$ radicals in the gas phase above $\mathrm{TiO}_{2}$ films which were exposed to gaseous $\mathrm{H}_{2} \mathrm{O}_{2}$ and illuminated by a light-emitting diode at $375 \mathrm{~nm}$ (Yi et al., 2012). Three different $\mathrm{TiO}_{2}$ samples were investigated, including Degussa $\mathrm{P} 25 \mathrm{TiO}_{2}$, Aldrich anatase, and Aldrich rutile. $\mathrm{H}_{2} \mathrm{O}_{2}$ decays did not occur in the absence of $\mathrm{TiO}_{2}$. In addition, production of $\mathrm{HO}_{2}$ radicals was only observed in the presence of $\mathrm{H}_{2} \mathrm{O}_{2}$, and the presence of $\mathrm{O}_{2}$ did not have a significant effect. Therefore, Yi et al. (2012) suggested that the production of $\mathrm{HO}_{2}$ radicals is due to the photodecomposition of $\mathrm{H}_{2} \mathrm{O}_{2}$ on $\mathrm{TiO}_{2}$ surfaces. Decays of $\mathrm{H}_{2} \mathrm{O}_{2}$ and formation of $\mathrm{HO}_{2}$ are found to vary with $\mathrm{TiO}_{2}$ samples (Yi et al., 2012). Photodegradation of $\mathrm{H}_{2} \mathrm{O}_{2}$ is fast for $\mathrm{P} 25$ $\mathrm{TiO}_{2}$ samples and much slower for anatase and rutile; furthermore, significant production of $\mathrm{HO}_{2}$ radicals in the gas phase was observed for anatase and rutile but not for P25 $\mathrm{TiO}_{2}$. However, no uptake coefficients were reported by $\mathrm{Yi}$ et al. (2012).

Zhou et al. (2012) first explored the temperature dependence of heterogeneous reactivity of mineral dust towards $\mathrm{H}_{2} \mathrm{O}_{2}$, using a Knudsen cell reactor coupled to a quadrupole mass spectrometer. The uptake kinetics show negative temperature dependence, with $\gamma_{0}\left(\mathrm{H}_{2} \mathrm{O}_{2}\right)$ (BET surface area based) decreasing from $(12.6 \pm 2.52) \times 10^{-5}$ at $253 \mathrm{~K}$ to $(6.08 \pm 1.22) \times 10^{-5}$ at $313 \mathrm{~K}$ for $\mathrm{SiO}_{2}$ and from $(7.11 \pm$ $1.42) \times 10^{-5}$ at $253 \mathrm{~K}$ to $(3.00 \pm 0.60) \times 10^{-5}$ at $313 \mathrm{~K}$ for $\mathrm{CaCO}_{3}$ (Zhou et al., 2012). Complete surface deactivation was observed for both dust samples after long exposure to $\mathrm{H}_{2} \mathrm{O}_{2}$ (Zhou et al., 2012). In a following study, the effects of temperature on the uptake of $\mathrm{H}_{2} \mathrm{O}_{2}$ by ATD and two Chinese dust samples were also investigated (Zhou et al., 2016). Values of $\gamma_{0}\left(\mathrm{H}_{2} \mathrm{O}_{2}\right)$, based on the BET surface area, were observed to decrease with temperature, from $(2.71 \pm 0.54) \times$ $10^{-4}$ at $253 \mathrm{~K}$ to $(1.47 \pm 0.29) \times 10^{-4}$ at $313 \mathrm{~K}$ for ATD, from $(3.56 \pm 0.71) \times 10^{-4}$ at $253 \mathrm{~K}$ to $(2.19 \pm 0.44) \times 10^{-4}$ at $313 \mathrm{~K}$ for Inner Mongolia desert dust, and from $(7.34 \pm 1.47) \times 10^{-5}$ at $268 \mathrm{~K}$ to $(4.46 \pm 0.889) \times 10^{-4}$ at $313 \mathrm{~K}$ for Xinjiang sierozem (Zhou et al., 2016). In addition, loss of heterogeneous reactivity towards $\mathrm{H}_{2} \mathrm{O}_{2}$ was observed for all the three dust samples (Zhou et al., 2016).

A coated rod flow tube was coupled to a quadrupole mass spectrometer to investigate heterogeneous reactions of $\mathrm{H}_{2} \mathrm{O}_{2}$ with a variety of mineral dust particles as a function of initial $\mathrm{H}_{2} \mathrm{O}_{2}$ concentrations, irradiance intensity, $\mathrm{RH}$, and temperature (Romanias et al., 2012a, 2013; El Zein et al., 2014). Under dark conditions, quick surface deactivation was observed for $\mathrm{TiO}_{2}$. When $\left[\mathrm{H}_{2} \mathrm{O}_{2}\right]_{0}$ was $<1 \times 10^{12}$ molecule $\mathrm{cm}^{-3}, \gamma_{0}$ was found to be independent of $\left[\mathrm{H}_{2} \mathrm{O}_{2}\right]_{0}$; however, when $\left[\mathrm{H}_{2} \mathrm{O}_{2}\right]_{0}$ was above this threshold, a negative dependence of $\gamma_{0}$ on $\left[\mathrm{H}_{2} \mathrm{O}_{2}\right]_{0}$ occurred. At $275 \mathrm{~K}, \gamma_{0}$ (based on BET surface area) depended on RH (up to $82 \%$ ), given by the following equation (Romanias et al., 2012a):

$\gamma_{0}($ dark $)=4.1 \times 10^{-3} /\left(1+\mathrm{RH}^{0.65}\right)$.

The uncertainty was estimated to be $\pm 30 \%$. 
Table 5. Summary of previous laboratory studies on heterogeneous reactions of mineral dust with $\mathrm{H}_{2} \mathrm{O}_{2}$.

\begin{tabular}{|c|c|c|c|c|c|}
\hline Dust & Reference & $T(\mathrm{~K})$ & $\begin{array}{r}\text { Concentration } \\
\left(\text { molecule } \mathrm{cm}^{-3}\right)\end{array}$ & Uptake coefficient & Techniques \\
\hline \multirow[t]{3}{*}{$\mathrm{TiO}_{2}$} & Pradhan et al. (2010a) & $295 \pm 2$ & $\sim 4.1 \times 10^{12}$ & $\begin{array}{l}(1.53 \pm 0.11) \times 10^{-3} \text { at } 15 \% \mathrm{RH},(6.47 \pm 0.74) \times 10^{-4} \text { at } \\
40 \% \mathrm{RH} \text {, and }(5.04 \pm 0.58) \times 10^{-4} \text { at } 70 \% \mathrm{RH} .\end{array}$ & AFT-CIMS \\
\hline & Romanias et al. (2012a) & $275-320$ & $(0.17-120) \times 10^{12}$ & $\begin{array}{l}\text { Under dark conditions at } 275 \mathrm{~K}, \gamma_{0} \text { was determined to be } \\
(4.1 \pm 1.2) \times 10^{-3} \text { at } 0 \% \mathrm{RH},(5.1 \pm 1.5) \times 10^{-4} \text { at } 20 \% \\
\mathrm{RH},(3.4 \pm 1.0) \times 10^{-4} \text { at } 40 \% \mathrm{RH},(2.7 \pm 0.8) \times 10^{4} \text { at } 60 \% \\
\mathrm{RH} \text {, and }(2.3 \pm 0.7) \times 10^{-4} \text { at } 80 \% \mathrm{RH} \text {. Surface deactivation } \\
\text { was observed under dark conditions, and } \mathrm{UV} \text { illumination } \\
\text { could enhance the steady-state uptake of } \mathrm{H}_{2} \mathrm{O}_{2} \text {. }\end{array}$ & CRFT-MS \\
\hline & Yi et al. (2012) & Not stated & $(3 \pm 1) \times 10^{13}$ & No uptake coefficients were not reported. & CRDS \\
\hline \multirow[t]{3}{*}{$\mathrm{SiO}_{2}$} & Zhao et al. (2011) & $298 \pm 1$ & $(3.2-34.5) \times 10^{13}$ & $\begin{array}{l}\gamma\left(\mathrm{H}_{2} \mathrm{O}_{2}\right) \text { decreased from }(1.55 \pm 0.14) \times 10^{-8} \text { at } 2 \% \mathrm{RH} \\
\text { to }(0.81 \pm 0.11) \times 10^{-8} \text { at } 21 \% \mathrm{RH} \text {, and further increases } \\
\text { in } \mathrm{RH} \text { (up to } 76 \%) \text { did not affect uptake kinetics. }\end{array}$ & T-FTIR, HPLC \\
\hline & Wang et al. (2011) & 298 & $(1-25) \times 10^{11}$ & $\gamma_{0}:(5.22 \pm 0.90) \times 10^{-5}$ & KC-MS \\
\hline & Zhou et al. (2012) & $253-313$ & $(0.37-3.7) \times 10^{12}$ & $\begin{array}{l}\text { Under dry conditions, } \gamma_{0} \text { decreased from }(12.6 \pm 2.52) \times \\
10^{-5} \text { at } 253 \mathrm{~K} \text { to }(6.08 \pm 1.22) \times 10^{-5} \text { at } 313 \mathrm{~K} \text {. }\end{array}$ & KC-MS \\
\hline \multirow[t]{3}{*}{$\mathrm{Al}_{2} \mathrm{O}_{3}$} & Zhao et al. (2011) & $298 \pm 1$ & $(3.2-34.5) \times 10^{13}$ & $\begin{array}{l}\gamma\left(\mathrm{H}_{2} \mathrm{O}_{2}\right) \text { decreased from }(1.21 \pm 0.04) \times 10^{-7} \text { at } 2 \% \mathrm{RH} \\
\text { to }(0.84 \pm 0.07) \times 10^{-7} \text { at } 21 \% \mathrm{RH} \text {, and the effect of RH } \\
\text { was not significant for } \mathrm{RH} \text { in the range of } 21-76 \% \text {. }\end{array}$ & T-FTIR, HPLC \\
\hline & Wang et al. (2011) & & $(1-25) \times 10^{11}$ & $\gamma_{0}:(1.00 \pm 0.11) \times 10^{-4} ; \gamma_{\mathrm{ss}}: 1.1 \times 10^{-5}$ & KC-MS \\
\hline & Romanias et al. (2013) & $268-320$ & $(0.16-12.6) \times 10^{12}$ & $\begin{array}{l}\text { At } 280 \mathrm{~K}, \gamma_{0} \text { was determined to be }(1.1 \pm 0.3) \times 10^{-3} \text { at } \\
0 \% \mathrm{RH},(1.2 \pm 0.3) \times 10^{-4} \text { at } 10 \% \mathrm{RH},(3.5 \pm 1.0) \times 10^{-5} \\
\text { at } 40 \% \mathrm{RH} \text {, and }(2.1 \pm 0.6) \times 10^{-5} \text { at } 70 \% \mathrm{RH} \text {, showing } \\
\text { a negative dependence on RH. No significant effect was ob- } \\
\text { served for UV illumination. }\end{array}$ & CRFT-MS \\
\hline \multirow[t]{2}{*}{$\mathrm{Fe}_{2} \mathrm{O}_{3}$} & Wang et al. (2011) & 298 & $(1-25) \times 10^{11}$ & $\gamma_{0}:(9.70 \pm 1.95) \times 10^{-4} ; \gamma_{\mathrm{ss}}: 5.5 \times 10^{-5}$ & KC-MS \\
\hline & Romanias et al. (2013) & $268-320$ & $(0.16-12.6) \times 10^{12}$ & $\begin{array}{l}\text { At } 280 \mathrm{~K}, \gamma_{0} \text { was determined to be }(1.1 \pm 0.3) \times 10^{-3} \text { at } \\
0 \% \mathrm{RH},(1.7 \pm 0.5) \times 10^{-4} \text { at } 10 \% \mathrm{RH},(6.7 \pm 2.0) \times 10^{-5} \\
\text { at } 40 \% \mathrm{RH} \text {, and }(4.5 \pm 1.4) \times 10^{-5} \text { at } 70 \% \mathrm{RH} \text {, showing } \\
\text { a negative dependence on RH. No significant effect was ob- } \\
\text { served for UV illumination. }\end{array}$ & CRFT-MS \\
\hline \multirow[t]{2}{*}{$\mathrm{CaCO}_{3}$} & Zhou et al. (2012) & $253-313$ & $(0.37-3.7) \times 10^{12}$ & $\begin{array}{l}\text { Under dry conditions, } \gamma_{0} \text { decreased from }(7.11 \pm 1.42) \times \\
10^{-5} \text { at } 253 \mathrm{~K} \text { to }(3.00 \pm 0.60) \times 10^{-5} \text { at } 313 \mathrm{~K} \text {. }\end{array}$ & KC-MS \\
\hline & Zhao et al. (2013) & $298 \pm 1$ & $1.3 \times 10^{14}$ & $\begin{array}{l}\text { The uptake of } \mathrm{H}_{2} \mathrm{O}_{2} \text { on fresh } \mathrm{CaCO}_{3} \text { particles decreased } \\
\text { drastically with RH. Pretreatment with } \mathrm{SO}_{2} \text { always en- } \\
\text { hances its reactivity towards } \mathrm{H}_{2} \mathrm{O}_{2} \text {, whereas exposure to } \\
\mathrm{HNO}_{3} \text { could either enhance or suppress } \mathrm{H}_{2} \mathrm{O}_{2} \text { uptake, de- } \\
\text { pending on } \mathrm{RH} \text {. Numerical values for uptake coefficients } \\
\text { were reported. }\end{array}$ & T-FTIR, HPLC \\
\hline \multirow[t]{2}{*}{ ATD } & El Zein et al. (2014) & $268-320$ & $(0.18-5.1) \times 10^{12}$ & $\begin{array}{l}\text { Under dark conditions at } 275 \mathrm{~K}, \gamma_{0} \text { was determined to be } \\
(4.8 \pm 1.4) \times 10^{-4} \text { at } 0 \% \mathrm{RH},(5.8 \pm 1.8) \times 10^{-5} \text { at } 20 \% \\
\mathrm{RH},(3.9 \pm 1.2) \times 10^{-5} \text { at } 40 \% \mathrm{RH} \text {, and }(3.0 \pm 0.9) \times 10^{-5} \\
\text { at } 60 \% \mathrm{RH} \text {. Surface deactivation was observed under dark } \\
\text { conditions, and UV illumination could enhance the steady- } \\
\text { state uptake of } \mathrm{H}_{2} \mathrm{O}_{2} \text {. }\end{array}$ & CRFT-MS \\
\hline & Zhou et al. (2016) & $253-313$ & $(0.26-1.2) \times 10^{12}$ & $\begin{array}{l}\text { Under dry conditions, } \gamma_{0} \text { decreased with temperature, from } \\
(2.71 \pm 0.54) \times 10^{-4} \text { at } 253 \mathrm{~K} \text { to }(1.47 \pm 0.29) \times 10^{-4} \text { at } \\
313 \mathrm{~K} \text {. }\end{array}$ & KC-MS \\
\hline Saharan dust & Pradhan et al. (2012b) & $295 \pm 2$ & $\sim 4.2 \times 10^{12}$ & $\begin{array}{l}\gamma\left(\mathrm{H}_{2} \mathrm{O}_{2}\right) \text { increased from }(6.20 \pm 0.22) \times 10^{-4} \text { at } 15 \% \mathrm{RH} \\
\text { to }(9.42 \pm 0.41) \times 10^{-4} \text { at } 70 \% \mathrm{RH} \text {. }\end{array}$ & AFT-CIMS \\
\hline Gobi dust & Pradhan et al. (2012b) & $295 \pm 2$ & $\sim 4.2 \times 10^{12}$ & $\begin{array}{l}\gamma\left(\mathrm{H}_{2} \mathrm{O}_{2}\right) \text { increased from }(3.33 \pm 0.26) \times 10^{-4} \text { at } 15 \% \mathrm{RH} \\
\text { to }(6.03 \pm 0.42) \times 10^{-4} \text { at } 70 \% \mathrm{RH} \text {. }\end{array}$ & AFT-CIMS \\
\hline Chinese dust & Zhou et al. (2016) & $253-313$ & $(0.26-1.2) \times 10^{12}$ & $\begin{array}{l}\text { Under dry conditions, } \gamma_{0} \text { decreased with temperature, from } \\
(3.56 \pm 0.71) \times 10^{-4} \text { at } 253 \mathrm{~K} \text { to }(2.19 \pm 0.44) \times 10^{-4} \text { at } \\
313 \mathrm{~K} \text { for Inner Mongolia desert dust and from }(7.34 \pm \\
1.47) \times 10^{-4} \text { at } 268 \mathrm{~K} \text { to }(4.46 \pm 0.89) \times 10^{-4} \text { at } 313 \mathrm{~K} \text { for } \\
\text { Xinjiang sierozem. }\end{array}$ & KC-MS \\
\hline $\mathrm{MgO}$ & Wang et al. (2011) & 298 & $(1-25) \times 10^{11}$ & $\gamma_{0}:(1.66 \pm 0.23) \times 10^{-4} ; \gamma_{\mathrm{ss}}: 1.6 \times 10^{-5}$ & KC-MS \\
\hline
\end{tabular}




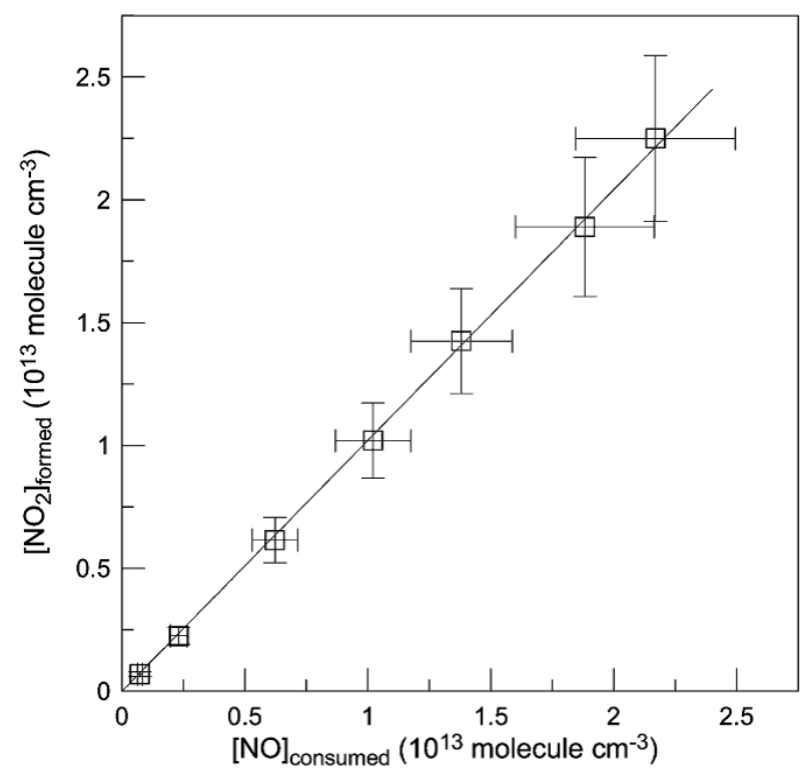

Figure 7. Consumed $\mathrm{NO}$ vs. formed $\mathrm{NO}_{2}$ in the heterogeneous reaction of $\mathrm{H}_{2} \mathrm{O}_{2}$ with $\mathrm{TiO}_{2}$ particles under illumination. Reprinted with permission from Romanias et al. (2012a). (C) 2012 American Chemical Society.

UV illumination (315-400 nm) could lead to photocatalytic decomposition of $\mathrm{H}_{2} \mathrm{O}_{2}$ on $\mathrm{TiO}_{2}$ surfaces. The steadystate uptake coefficient, $\gamma_{\mathrm{ss}}(\mathrm{UV})$, increasing linearly with illumination intensity, was found to be independent of $\mathrm{RH}$ and depended inversely on $\left[\mathrm{H}_{2} \mathrm{O}_{2}\right]_{0}$ (Romanias et al., 2012a). When $\left[\mathrm{H}_{2} \mathrm{O}_{2}\right]_{0}$ is $\sim 5 \times 10^{11}$ molecule $\mathrm{cm}^{-3}$ and $J\left(\mathrm{NO}_{2}\right)$ for UV illumination is $0.012 \mathrm{~s}^{-1}$, the dependence of $\gamma_{\mathrm{ss}}(\mathrm{UV})$ on temperature $(275-320 \mathrm{~K})$ at $0.3 \% \mathrm{RH}$ can be described by the following equation (Romanias et al., 2012a):

$\gamma_{\mathrm{ss}}(\mathrm{UV})=(7.2 \pm 1.9) \times 10^{-4} \times \exp [(460 \pm 80) / T]$

It has also been found that $\mathrm{NO}$ added into the gas flow was converted to $\mathrm{NO}_{2}$ during heterogeneous reaction of $\mathrm{H}_{2} \mathrm{O}_{2}$ with $\mathrm{TiO}_{2}$. As shown in Fig. 7, the ratio of consumed $\mathrm{NO}$ to formed $\mathrm{NO}_{2}$ is close to 1 . This indirect evidence suggests that $\mathrm{HO}_{2}$ radicals (which could convert $\mathrm{NO}$ to $\mathrm{NO}_{2}$ ) were found in the gas phase due to photocatalytic reaction of $\mathrm{H}_{2} \mathrm{O}_{2}$ with $\mathrm{TiO}_{2}$ particles (Romanias et al., 2012a).

Gradual surface deactivation was also observed for uptake of $\mathrm{H}_{2} \mathrm{O}_{2}$ by ATD particles. The value of $\gamma_{0}$, independent of $\left[\mathrm{H}_{2} \mathrm{O}_{2}\right]_{0}$ in the range of $(0.18-5.1) \times 10^{12}$ molecule $^{-3}$ and irradiation for $J\left(\mathrm{NO}_{2}\right)$ up to $0.012 \mathrm{~s}^{-1}$, was observed to decrease with RH and temperature (El Zein et al., 2014). At $275 \mathrm{~K}$, the dependence of $\gamma_{0}$ on RH (up to $69 \%$ ) can be described by the following equation (El Zein et al., 2014):

$\gamma_{0}=4.8 \times 10^{-4} /\left(1+\mathrm{RH}^{0.66}\right)$.
At $0.35 \% \mathrm{RH}$, the effect of temperature on $\gamma_{0}$ is given by the following equation (El Zein et al., 2014):

$\gamma_{0}=3.2 \times 10^{-4} /\left[1+2.5 \times 10^{10} \times \exp \left(-\frac{7360}{T}\right)\right]$.

It has also been found that $\gamma_{\mathrm{ss}}$, independent of $\mathrm{RH}$ and $T$, decreased with $\left[\mathrm{H}_{2} \mathrm{O}_{2}\right]_{0}$ under dark and irradiated conditions, given by the following equation (El Zein et al., 2014):

$\gamma_{\mathrm{ss}}($ dark $)=3.8 \times 10^{-5} \times\left(\left[\mathrm{H}_{2} \mathrm{O}_{2}\right]_{0}\right)^{-0.6}$.

UV irradiation could enhance heterogeneous reactivity of ATD towards $\mathrm{H}_{2} \mathrm{O}_{2}$. For example, when $J\left(\mathrm{NO}_{2}\right)$ was equal to $0.012 \mathrm{~s}^{-1}, \gamma_{\mathrm{ss}}($ dark $)$ and $\gamma_{\mathrm{ss}}(\mathrm{UV})$ were determined to be $(0.95 \pm 0.30) \times 10^{-5}$ and $(1.85 \pm 0.55) \times 10^{-5}$, respectively (El Zein et al., 2014).

Romanias et al. (2013) examined heterogeneous interactions of $\mathrm{H}_{2} \mathrm{O}_{2}$ with $\gamma-\mathrm{Al}_{2} \mathrm{O}_{3}$ and $\mathrm{Fe}_{2} \mathrm{O}_{3}$, and found that both surfaces were gradually deactivated after exposure to $\mathrm{H}_{2} \mathrm{O}_{2} ; \gamma_{0}$, independent of $\left[\mathrm{H}_{2} \mathrm{O}_{2}\right]_{0}$ in the range of $(0.15-$ 16.6) $\times 10^{12}$ molecule $\mathrm{cm}^{-3}$, was found to vary with $\mathrm{RH}$ and temperature (Romanias et al., 2013). At $280 \mathrm{~K}$, the dependence of $\gamma_{0}$ on RH (up to $73 \%$ ) can be given by

$\gamma_{0}\left(\mathrm{Al}_{2} \mathrm{O}_{3}\right)=1.10 \times 10^{-3} /\left(1+\mathrm{RH}^{0.93}\right)$,
$\gamma_{0}\left(\mathrm{Fe}_{2} \mathrm{O}_{3}\right)=1.05 \times 10^{-3} /\left(1+\mathrm{RH}^{0.73}\right)$.

At $0.3 \% \mathrm{RH}$, the dependence of $\gamma_{0}$ on temperature $(T)$ in the range of $268-320 \mathrm{~K}$ can be described by the following equation:

$$
\begin{aligned}
\gamma_{0}\left(\mathrm{Al}_{2} \mathrm{O}_{3}\right)= & 8.7 \times 10^{-4} / \\
& {\left[1+5.0 \times 10^{13} \times \exp (-9700 / T)\right], } \\
\gamma_{0}\left(\mathrm{Fe}_{2} \mathrm{O}_{3}\right)= & 9.3 \times 10^{-4} / \\
& {\left[1+3.6 \times 10^{14} \times \exp (-10300 / T)\right] . }
\end{aligned}
$$

In contrast to $\mathrm{TiO}_{2}$ and ATD, no significant effects of UV irradiation with $J\left(\mathrm{NO}_{2}\right)$ up to $0.012 \mathrm{~s}^{-1}$ were observed for $\gamma-\mathrm{Al}_{2} \mathrm{O}_{3}$ and $\mathrm{Fe}_{2} \mathrm{O}_{3}$ (Romanias et al., 2013).

\subsubsection{Discussion of previous laboratory studies}

The dependence of $\gamma\left(\mathrm{H}_{2} \mathrm{O}_{2}\right)$ on $\mathrm{RH}$, measured at room temperature, is plotted in Fig. 8 for different dust particles. Uptake coefficients reported by Zhao et al. (2011b) are several orders of magnitude smaller than those reported by other studies, and therefore they are not included in Fig. 8. For studies using dust particles supported on substrates, $\gamma_{0}\left(\mathrm{H}_{2} \mathrm{O}_{2}\right)$ are plotted.

Figure 8 suggests that different minerals show various heterogeneous reactivity towards $\mathrm{H}_{2} \mathrm{O}_{2}$, and the effects of $\mathrm{RH}$ also appear to be different. Two previous studies have investigated heterogeneous uptake of $\mathrm{H}_{2} \mathrm{O}_{2}$ by $\mathrm{TiO}_{2}$ at different 

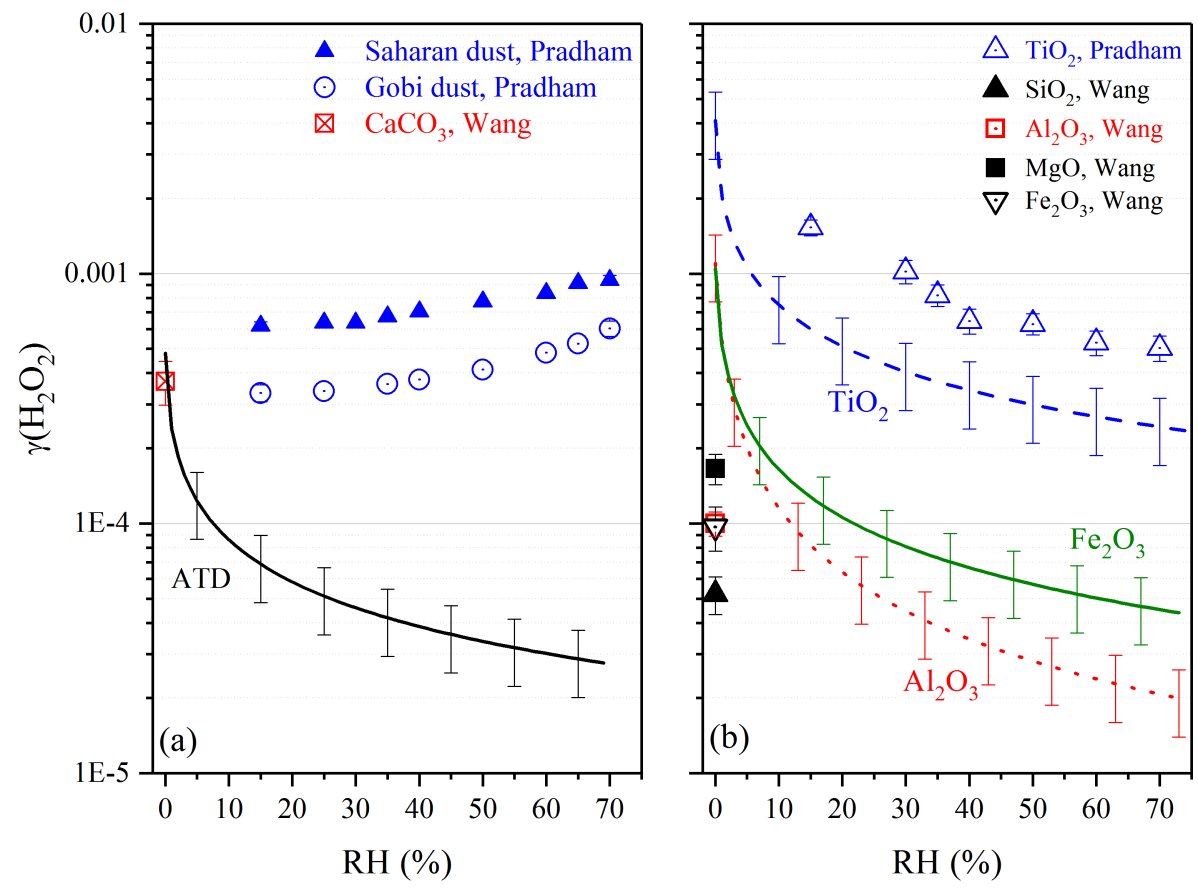

Figure 8. RH dependence of $\gamma\left(\mathrm{H}_{2} \mathrm{O}_{2}\right)$ for mineral dust particles as reported by previous studies (Pradhan et al., 2010a, b; Wang et al., 2011; Romanias et al., 2012a, 2013; El Zein et al., 2014). Solid black curve: ATD (El Zein et al., 2014); dashed blue curve: TiO 2 (Romanias et al., 2012); solid olive curve: $\mathrm{Fe}_{2} \mathrm{O}_{3}$ (Romanias et al., 2013); dashed red curve: $\mathrm{Al}_{2} \mathrm{O}_{3}$ (Romanias et al., 2013).

RH under dark conditions, one using an aerosol flow tube (Pradhan et al., 2010a) and the other using a coated rod flow tube (Romanias et al., 2012a). For $\mathrm{TiO}_{2}, \gamma\left(\mathrm{H}_{2} \mathrm{O}_{2}\right)$ reported by Romanias et al. (2012a) is around $40-50 \%$ of those determined by Pradhan et al. (2010a) over $10-75 \%$ RH. The agreement is quite good considering the fact that two very different techniques were used. Wang et al. (2011) and Romanias (2013) examined heterogeneous reactions of $\mathrm{H}_{2} \mathrm{O}_{2}$ with $\mathrm{Fe}_{2} \mathrm{O}_{3}$ and $\mathrm{Al}_{2} \mathrm{O}_{3}$. Their reported $\gamma_{0}\left(\mathrm{H}_{2} \mathrm{O}_{2}\right)$ values differ significantly, though BET surface area was used by both studies to calculate uptake coefficients. This may be largely explained by the variation of the interrogation depth of $\mathrm{H}_{2} \mathrm{O}_{2}$ molecules under investigation in different studies, as discussed in Sect. 2.2.1. Experiments in which aerosol samples are used can largely overcome the difficulty in estimating surface area available for heterogeneous uptake. Up to now only two studies (Pradhan et al., 2010a, b) used aerosol flow tubes, and more aerosol flow tube studies will help better constrain $\gamma\left(\mathrm{H}_{2} \mathrm{O}_{2}\right)$ onto mineral dust particles.

The effects of temperature on heterogeneous reactions of $\mathrm{H}_{2} \mathrm{O}_{2}$ with mineral dust have also been explored. As shown in Fig. 9, $\gamma_{0}\left(\mathrm{H}_{2} \mathrm{O}_{2}\right)$ decreases with increasing temperature. Zhou et al. $(2012,2016)$ suggest that $\gamma_{0}\left(\mathrm{H}_{2} \mathrm{O}_{2}\right)$ is reduced by a factor of $\sim 2$ for all the five minerals they investigated when temperature increase from 253 to $313 \mathrm{~K}$. Romanias et al. (2013) and El Zein et al. (2014) reported larger temperature impacts, with $\gamma_{0}\left(\mathrm{H}_{2} \mathrm{O}_{2}\right)$ reduced by a factor of $\sim 4$ when temperature increases from 268 to $320 \mathrm{~K}$. These studies

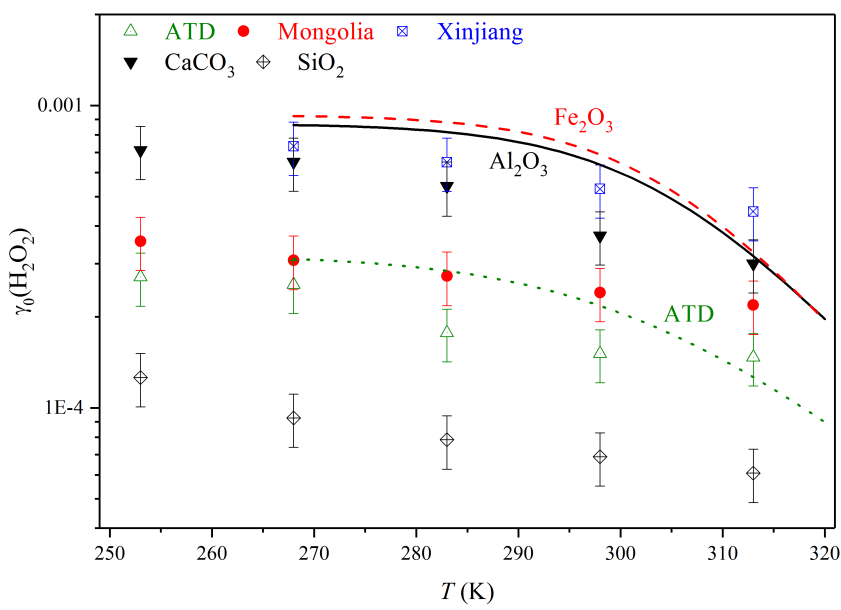

Figure 9. Temperature dependence of $\gamma_{0}\left(\mathrm{H}_{2} \mathrm{O}_{2}\right)$ for mineral dust particles under dark conditions as reported by previous studies. Upward triangles: ATD (Zhou et al., 2016); circles: Inner Mongolia desert dust (Zhou et al., 2016); squares: Xinjiang sierozem (Zhou et al., 2016); downward triangles: $\mathrm{CaCO}_{3}$ (Zhou et al., 2012); diamonds: $\mathrm{SiO}_{2}$ (Zhou et al., 2012); dashed olive curve: ATD (El Zein et al., 2014); solid black curve: $\mathrm{Al}_{2} \mathrm{O}_{3}$ (Romanias et al., 2013); dashed red curve: $\mathrm{Fe}_{2} \mathrm{O}_{3}$ (Romanias et al., 2013).

show that the temperature effect is significant and should be taken into account when assessing the importance of heterogeneous uptake of $\mathrm{H}_{2} \mathrm{O}_{2}$ by mineral dust in the troposphere. 
It should also be pointed out that the effect of temperature on heterogeneous reactions of $\mathrm{H}_{2} \mathrm{O}_{2}$ with airborne mineral dust particles has never been investigated.

In addition, it has been suggested that uptake of $\mathrm{H}_{2} \mathrm{O}_{2}$ by mineral dust can affect heterogeneous oxidation of other trace gases (Zhao et al., 2011b, 2013; Huang et al., 2015a). For example, heterogeneous uptake of $\mathrm{H}_{2} \mathrm{O}_{2}$ could convert sulfite formed by the adsorption of $\mathrm{SO}_{2}$ on $\mathrm{CaCO}_{3}$ particles to sulfate, and this conversion is enhanced by adsorbed water (Zhao et al., 2013). Similarly, Huang et al. (2015a) found that the presence of $\mathrm{H}_{2} \mathrm{O}_{2}$ could enhance the uptake of $\mathrm{SO}_{2}$ on Asian mineral dust, Tengger desert dust, and ATD, and the enhancement factors, varying with dust mineralogy and $\mathrm{RH}$, can be as large as $\sim 6$. Heterogeneous oxidation of methacrolein on kaolinite, $\alpha-\mathrm{Al}_{2} \mathrm{O}_{3}, \alpha-\mathrm{Fe}_{2} \mathrm{O}_{3}$, and $\mathrm{TiO}_{2}$ (but not on $\mathrm{CaCO}_{3}$ ) is largely accelerated by the presence of $\mathrm{H}_{2} \mathrm{O}_{2}$, which also changes the oxidation products (Zhao et al., 2014).

\subsubsection{Atmospheric implication}

For reasons we have discussed in Sect. 2.2.1, $\gamma\left(\mathrm{H}_{2} \mathrm{O}_{2}\right)$ reported by studies using aerosol samples (Pradhan et al., 2010a, b) are preferred. Since Saharan dust is the most abundant mineral dust in the troposphere, in our work we use $\gamma\left(\mathrm{H}_{2} \mathrm{O}_{2}\right)$ reported by Pradhan et al. (2010b) for Saharan dust to assess the atmospheric importance of heterogeneous uptake of $\mathrm{H}_{2} \mathrm{O}_{2}$. The value of $\gamma\left(\mathrm{H}_{2} \mathrm{O}_{2}\right)$ onto Saharan dust depends on $\mathrm{RH}$, increasing from $6.2 \times 10^{-4}$ at $15 \%$ to $9.4 \times 10^{-4}$ at $70 \%$ RH. For simplicity, a $\gamma\left(\mathrm{H}_{2} \mathrm{O}_{2}\right)$ value of $1 \times 10^{-3}$, very close to that at $70 \%$, is used here to calculate $\tau_{\text {het }}\left(\mathrm{H}_{2} \mathrm{O}_{2}\right)$. When dust mass concentrations are 10,100 , and $1000 \mu \mathrm{g} \mathrm{m}^{-3}, \tau_{\text {het }}\left(\mathrm{H}_{2} \mathrm{O}_{2}\right)$ are calculated to be 120,12 , and $1.2 \mathrm{~h}$, using Eq. (6). Typical $\tau\left(\mathrm{H}_{2} \mathrm{O}_{2}\right)$ is estimated to be 33$56 \mathrm{~h}$ with respect to photolysis and $16-160 \mathrm{~h}$ with respect to reaction with $\mathrm{OH}$ radicals. Therefore, heterogeneous uptake by mineral dust particles can be a significant sink for $\mathrm{H}_{2} \mathrm{O}_{2}$ even when dust mass concentration is as low as $10 \mu \mathrm{g} \mathrm{m}^{-3}$.

Several modeling studies have also discussed and evaluated the contribution of heterogeneous uptake by mineral dust to the removal of $\mathrm{H}_{2} \mathrm{O}_{2}$ in the troposphere. Pradhan et al. (2010b) determined $\gamma\left(\mathrm{H}_{2} \mathrm{O}_{2}\right)$ for Saharan dust as a function of RH experimentally and then included this reaction in a box model based on the Master Chemical Mechanism (MCM). It has been found that heterogeneous uptake by mineral dust could reduce simulated $\mathrm{H}_{2} \mathrm{O}_{2}$ concentrations by up to $\sim 40 \%$, and its impacts on total peroxy organic radicals, $\mathrm{OH}, \mathrm{O}_{3}$, and $\mathrm{NO}_{x}$ are small but nonnegligible (Pradhan et al., 2010b). In another box model study, $\gamma\left(\mathrm{H}_{2} \mathrm{O}_{2}\right)$ onto Saharan dust was varied in order to reproduce $\mathrm{H}_{2} \mathrm{O}_{2}$ concentrations measured in July-August 2002 at Tenerife (de Reus et al., 2005). It is found that using $\gamma\left(\mathrm{H}_{2} \mathrm{O}_{2}\right)$ of $5 \times 10^{-4}$, which agrees very well with that measured by Pradhan et al. (2010b), could reach the best agreement between measured and simulated $\mathrm{H}_{2} \mathrm{O}_{2}$ concentrations (de Reus et al., 2005).

In addition to the uncertainties in $\gamma\left(\mathrm{H}_{2} \mathrm{O}_{2}\right)$ related to the effects of mineralogy, $\mathrm{RH}$, and temperature, products formed in heterogeneous reactions of $\mathrm{H}_{2} \mathrm{O}_{2}$ with mineral dust are not entirely clear. Three pathways have been proposed, including (i) simple partitioning of $\mathrm{H}_{2} \mathrm{O}_{2}$ onto dust particles (Zhao et al., 2011b, 2013), (ii) surface decomposition of $\mathrm{H}_{2} \mathrm{O}_{2}$ to $\mathrm{H}_{2} \mathrm{O}$ and $\mathrm{O}_{2}$, and (iii) heterogeneous conversion of $\mathrm{H}_{2} \mathrm{O}_{2}$ to $\mathrm{HO}_{2}$ radicals (Romanias et al., 2012a; Yi et al., 2012). Branching ratios seem to depend on mineralogy, $\mathrm{RH}$, and probably also UV illumination (Zhao et al., 2011b, 2013; Yi et al., 2012); however, our knowledge in this aspect is very limited. Since these three different pathways may have very different impacts on tropospheric oxidation capacity, product distribution in heterogeneous reactions of $\mathrm{H}_{2} \mathrm{O}_{2}$ with mineral dust deserves further investigation.

\section{$\begin{array}{ll}3.3 & \mathrm{O}_{3}\end{array}$}

Heterogeneous reactions of $\mathrm{O}_{3}$ with $\mathrm{Al}_{2} \mathrm{O}_{3}, \mathrm{CaCO}_{3}$, Saharan dust were explored using a fluidized bed reactor more than 2 decades ago, and substantial $\mathrm{O}_{3}$ decays were observed after interactions with dust power in the reactor (AlebićJuretić et al., 1992). This study did not report uptake coefficients and thus is not included in Table 6. Uptake coefficients in the range of $(1-100) \times 10^{-11}$ were reported for $\mathrm{Al}_{2} \mathrm{O}_{3}$ (Hanning-Lee et al., 1996). Since their experiments were carried out with $\mathrm{O}_{3}$ concentrations in the range of (5200) $\times 10^{15}$ molecule $\mathrm{cm}^{-3}$, which are several orders of magnitude higher than typical $\mathrm{O}_{3}$ levels in the troposphere, this work is also not included in Table 6.

A Knudsen cell reactor was used by Grassian and coworkers (Michel et al., 2002, 2003; Usher et al., 2003b) to study heterogeneous reactions of $\mathrm{O}_{3}$ with fresh and aged mineral dust particles. Measurements were carried out in the linear mass-dependent regime (see Sect. 2.2.1 for more explanations of the linear mass-dependent regime), and thus the BET surface areas of dust samples were used to calculate uptake coefficients. In the first study (Michel et al., 2002), $\gamma_{0}\left(\mathrm{O}_{3}\right)$ was determined to be $(1.8 \pm 0.7) \times 10^{-4}$ for $\alpha-\mathrm{Fe}_{2} \mathrm{O}_{3},(8 \pm 5) \times 10^{-5}$ for $\alpha-\mathrm{Al}_{2} \mathrm{O}_{3},(5 \pm 3) \times 10^{-5}$ for $\mathrm{SiO}_{2},(2.7 \pm 0.9) \times 10^{-5}$ for China loess, $(6 \pm 3) \times 10^{-5}$ for ground Saharan dust, and $(4 \pm 2) \times 10^{-6}$ for sieved Saharan dust at $296 \mathrm{~K}$ when $\left[\mathrm{O}_{3}\right]_{0}$ was $1.9 \times 10^{11}$ molecule $\mathrm{cm}^{-3}$. In a following study, Michal et al. (2003) systematically investigated heterogeneous reactions of $\mathrm{O}_{3}$ with several mineral dust particles, and progressive surface deactivation was observed for all the dust samples. At $295 \pm 1 \mathrm{~K}$ and $\left[\mathrm{O}_{3}\right]_{0}$ of $(1.9 \pm 0.6) \times 10^{11}$ molecule $\mathrm{cm}^{-3}, \gamma_{0}\left(\mathrm{O}_{3}\right)$ were reported to be $(2.0 \pm 0.3) \times 10^{-4}$ for $\alpha-\mathrm{Fe}_{2} \mathrm{O}_{3},(1.2 \pm 0.4) \times 10^{-4}$ for $25 \mu \mathrm{m}$ $\alpha-\mathrm{Al}_{2} \mathrm{O}_{3},(6.3 \pm 0.9) \times 10^{-5}$ for $\mathrm{SiO}_{2},(3 \pm 1) \times 10^{-5}$ for kaolinite, $(2.7 \pm 0.8) \times 10^{-5}$ for China loess, $(6 \pm 2) \times 10^{-5}$ for ground Saharan dust, and $(2.7 \pm 0.9) \times 10^{-6}$ for ground $\mathrm{Sa}-$ haran dust, respectively; $\gamma_{0}\left(\mathrm{O}_{3}\right)$ was also measured for $1 \mu \mathrm{m}$ 
$\alpha-\mathrm{Al}_{2} \mathrm{O}_{3}$, and with the experimental uncertainties it shows no difference with that for $25 \mu \mathrm{m} \alpha-\mathrm{Al}_{2} \mathrm{O}_{3}$. The steady-state uptake coefficients, $\gamma_{\mathrm{ss}}$, were determined to be $2.2 \times 10^{-5}$ for $\alpha$ $\mathrm{Fe}_{2} \mathrm{O}_{3}, 7.6 \times 10^{-6}$ for $\alpha-\mathrm{Al}_{2} \mathrm{O}_{3}$, and $6 \times 10^{-6}$ for ground $\mathrm{Sa}-$ haran dust. The effect of initial $\mathrm{O}_{3}$ concentration in the range of $(1-10) \times 10^{11}$ molecule $\mathrm{cm}^{-3}$ on $\gamma_{0}\left(\mathrm{O}_{3}\right)$ is insignificant for either $\alpha-\mathrm{Al}_{2} \mathrm{O}_{3}$ or $\alpha-\mathrm{Fe}_{2} \mathrm{O}_{3}$. In addition, $\gamma_{0}\left(\mathrm{O}_{3}\right)$ was found to have a very weak dependence on temperature $(250-330 \mathrm{~K})$ for $\alpha-\mathrm{Al}_{2} \mathrm{O}_{3}$, with an activation energy of $7 \pm 4 \mathrm{~kJ} \mathrm{~mol}^{-1}$ (Michel et al., 2003).

Heterogeneous processing of mineral dust particles by other trace gases could affect $\mathrm{O}_{3}$ uptake. It has been observed that $\gamma_{0}\left(\mathrm{O}_{3}\right)$ was reduced by $\sim 70 \%$ after pretreatment of $\alpha$ $\mathrm{Al}_{2} \mathrm{O}_{3}$ with $\mathrm{HNO}_{3}$ and increased by $33 \%$ after pretreatment with $\mathrm{SO}_{2}$ (Usher et al., 2003b). Similarly, functionalization of $\mathrm{SiO}_{2}$ with a $\mathrm{C} 8$ alkene would increase its heterogeneous reactivity towards $\mathrm{O}_{3}$ by $40 \%$, whereas its heterogeneous reactivity was reduced by about $40 \%$ if functionalized by a $\mathrm{C} 8$ alkane (Usher et al., 2003b). The presence of $\mathrm{O}_{3}$ can also promote heterogeneous oxidation of other trace gases on mineral dust surface (Ullerstam et al., 2002; Hanisch and Crowley, 2003b; Li et al., 2006; Chen et al., 2008; Wu et al., 2011), including $\mathrm{NO}, \mathrm{SO}_{2}$, methacrolein, methyl vinyl ketone, etc.

Another two groups also utilized Knudsen cell reactors to investigate $\mathrm{O}_{3}$ uptake by mineral dust (Hanisch and Crowley, 2003a; Karagulian and Rossi, 2006). The uptake of $\mathrm{O}_{3}$ by Saharan dust was investigated over a broad range of $\left[\mathrm{O}_{3}\right]_{0}$ by Hanisch and Crowley (2003a), and $\gamma_{0}\left(\mathrm{O}_{3}\right)$ and $\gamma_{\mathrm{ss}}\left(\mathrm{O}_{3}\right)$ were determined to be $3.5 \times 10^{-4}$ and $4.8 \times 10^{-5}$ when $\left[\mathrm{O}_{3}\right]_{0}$ was $(5.4 \pm 0.8) \times 10^{10}$ molecule $\mathrm{cm}^{-3}, 5.8 \times 10^{-5}$ and $1.3 \times 10^{-5}$ when $\left[\mathrm{O}_{3}\right]_{0}$ was $2.8 \times 10^{11}$ molecule $\mathrm{cm}^{-3}$, and $5.5 \times 10^{-6}$ and $2.2 \times 10^{-4}$ when $\left[\mathrm{O}_{3}\right]_{0}$ was $(8.4 \pm$ 3.4) $\times 10^{12}$ molecule $\mathrm{cm}^{-3}$, showing a negative dependence on $\left[\mathrm{O}_{3}\right]_{0}$. It should be noted that the KML model (Keyser et al., 1991, 1993) was applied by Hanisch and Crowley (2003a) to derive the uptake coefficients. Furthermore, they found that $\mathrm{O}_{3}$ was converted to $\mathrm{O}_{2}$ after reaction with Saharan dust and physisorption was negligible (Hanisch and Crowley, 2003a).

Karagulian and Rossi et al. (2006) investigated heterogeneous interactions of $\mathrm{O}_{3}$ with kaolinite, $\mathrm{CaCO}_{3}$, natural limestone, Saharan dust, and ATD. Based on the projected surface areas of dust samples, their reported $\gamma_{0}$ is in the range of $(2.3 \pm 0.4) \times 10^{-2}$ to $(9.3 \pm 2.6) \times 10^{-2}$, and $\gamma_{\mathrm{ss}}$ is in the range of $(3.5 \pm 1.6) \times 10^{-5}$ to $(1.0 \pm 0.2) \times 10^{-2}$. These values, summarized in Table 6 together with corresponding $\left[\mathrm{O}_{3}\right]_{0}$, are not repeated here. Pore-diffusion-corrected $\gamma_{\text {ss }}$ was reported to be $(2.7 \pm 0.3) \times 10^{-6}$ for kaolinite when $\left[\mathrm{O}_{3}\right]_{0}$ was $2.4 \times 10^{12}$ molecule $\mathrm{cm}^{-3}$ and $(7.8 \pm 0.7) \times 10^{-7}$ for $\mathrm{CaCO}_{3}$ when $\left[\mathrm{O}_{3}\right]_{0}$ was $5.3 \times 10^{12}$ molecule $\mathrm{cm}^{-3}$, more than 3 orders of magnitude smaller than those based on the projected surface area (Karagulian and Rossi, 2006).

The uptake of $\mathrm{O}_{3}$ on $\alpha-\mathrm{Al}_{2} \mathrm{O}_{3}$ (Sullivan et al., 2004) and Saharan dust (Chang et al., 2005) was investigated using a static reactor, in which a dust-coated Pyrex tube was ex- posed to $\mathrm{O}_{3}$ at room temperature. In the first few tens of seconds after exposure to dust particles, $\mathrm{O}_{3}$ decays followed an exponential manner, and the average decay rates were used to derive uptake coefficients. The value of $\gamma\left(\mathrm{O}_{3}\right)$, based on the BET surface area, was found to decrease with increasing initial $\left[\mathrm{O}_{3}\right]$. For $\alpha-\mathrm{Al}_{2} \mathrm{O}_{3}, \gamma\left(\mathrm{O}_{3}\right)$ decreased from $\sim 1 \times 10^{-5}$ to $\sim 1 \times 10^{-6}$ when $\left[\mathrm{O}_{3}\right]$ increased from $1 \times 10^{13}$ to $1 \times 10^{14}$ molecule $\mathrm{cm}^{-3}$ (Sullivan et al., 2004). For Saharan dust, $\gamma\left(\mathrm{O}_{3}\right)$ decreased from $2 \times 10^{-7}$ to $2 \times 10^{-6}$ when $\left[\mathrm{O}_{3}\right]$ increased from $2 \times 10^{12}$ to $1 \times 10^{14}$ molecule $\mathrm{cm}^{-3}$, and the dependence of $\gamma\left(\mathrm{O}_{3}\right)$ on $\left[\mathrm{O}_{3}\right]$ can be described by Eq. (18) (Chang et al., 2005):

$\gamma\left(\mathrm{O}_{3}\right)=7.5 \times 10^{5} \times\left[\mathrm{O}_{3}\right]^{-0.90}$,

where $\left[\mathrm{O}_{3}\right]$ is the $\mathrm{O}_{3}$ concentration in molecules per cubic centimeter (molecule $\left.\mathrm{cm}^{-3}\right)$. No significant effect of $\mathrm{RH}(0-$ $75 \%)$ on uptake kinetics was observed for $\alpha-\mathrm{Al}_{2} \mathrm{O}_{3}$ and Saharan dust (Sullivan et al., 2004; Chang et al., 2005).

An environmental chamber in which $\mathrm{O}_{3}$ was exposed to suspended particles was deployed to investigate heterogeneous reactions of airborne mineral dust with $\mathrm{O}_{3}$ under dark and illuminated conditions (Mogili et al., 2006a; Chen et al., 2011a, b). $\mathrm{O}_{3}$ concentrations in the chamber, detected using FTIR or UV-visible absorption spectroscopy, were found to decay exponentially with reaction time. As shown in Fig. 10, uptake of $\mathrm{O}_{3}$ by $\alpha-\mathrm{Fe}_{2} \mathrm{O}_{3}$ was significantly suppressed at increasing $\mathrm{RH}$, and a negative effect of $\mathrm{RH}$ was also observed for uptake of $\mathrm{O}_{3}$ by $\alpha-\mathrm{Al}_{2} \mathrm{O}_{3}$ (Mogili et al., 2006a). In addition, increasing $\left[\mathrm{O}_{3}\right]_{0}$ resulted in a reduction in $\gamma\left(\mathrm{O}_{3}\right)$ for both minerals. Heterogeneous reactivity towards $\mathrm{O}_{3}$ under similar conditions is higher for $\alpha-\mathrm{Fe}_{2} \mathrm{O}_{3}$ when compared to $\alpha-\mathrm{Al}_{2} \mathrm{O}_{3}$ (Mogili et al., 2006a). For $\alpha-\mathrm{Fe}_{2} \mathrm{O}_{3}$, when $\left[\mathrm{O}_{3}\right]_{0}$ was $7.9 \times 10^{14}$ molecule $\mathrm{cm}^{-3}, \gamma\left(\mathrm{O}_{3}\right)$ decreased from $(1.0 \pm 0.3) \times 10^{-7}$ at $<1 \% \mathrm{RH}$ to $(1.2 \pm 0.3) \times 10^{-8}$ at $23 \%$ $\mathrm{RH}$ and to $(2.5 \pm 0.6) \times 10^{-9}$ at $58 \% \mathrm{RH}$; when $\left[\mathrm{O}_{3}\right]_{0}$ was $2.1 \times 10^{14}$ molecule $\mathrm{cm}^{-3}, \gamma\left(\mathrm{O}_{3}\right)$ was reduced from $(5.0 \pm$ $1.2) \times 10^{-8}$ at $<1 \% \mathrm{RH}$ to $(2.0 \pm 0.5) \times 10^{-8}$ at $21 \% \mathrm{RH}$ and to $(9.0 \pm 2.3) \times 10^{-9}$ at $43 \% \mathrm{RH}$. Meanwhile, $\gamma\left(\mathrm{O}_{3}\right)$ was observed to decrease from $(3.5 \pm 0.9) \times 10^{-8}$ at $<1 \% \mathrm{RH}$ to $(4.5 \pm 1.1) \times 10^{-9}$ at $19 \%$ RH for $\alpha-\mathrm{Al}_{2} \mathrm{O}_{3}$ when $\left[\mathrm{O}_{3}\right]_{0}$ was $1 \times 10^{15}$ molecule $\mathrm{cm}^{-3}$.

A solar simulator was coupled to the environmental chamber by Chen et al. (2011a), and irradiation from the solar simulator was found to enhance heterogeneous uptake of $\mathrm{O}_{3}$ by $\alpha-\mathrm{Fe}_{2} \mathrm{O}_{3}$ and $\alpha-\mathrm{Al}_{2} \mathrm{O}_{3}$; however, no uptake coefficient was reported. In a following study, Chen et al. (2011b) found that heterogeneous uptake of $\mathrm{O}_{3}$ by $\alpha-\mathrm{Al}_{2} \mathrm{O}_{3}$ was insignificant under both dark and irradiated conditions. In contrast, while the uptake of $\mathrm{O}_{3}$ by $\mathrm{TiO}_{2}$ was negligible under dark conditions, when irradiated $\gamma\left(\mathrm{O}_{3}\right)$ was determined to be $(2.0 \pm 0.1) \times 10^{-7}$ at $<2 \% \mathrm{RH},(2.2 \pm 0.1) \times 10^{-7}$ at $12 \%$ $\mathrm{RH},(2.4 \pm 0.1) \times 10^{-7}$ at $22 \% \mathrm{RH}$, and $(1.9 \pm 0.1) \times 10^{-7}$ at $39 \% \mathrm{RH}$ (Chen et al., 2011b). Photoenhanced $\mathrm{O}_{3}$ uptake was also observed for $\alpha-\mathrm{Fe}_{2} \mathrm{O}_{3}$ (Chen et al., 2011b). Under dark conditions $\gamma\left(\mathrm{O}_{3}\right)$ decreased from $(4.1 \pm 0.2) \times 10^{-7}$ 
Table 6. Summary of previous laboratory studies on heterogeneous reactions of mineral dust with $\mathrm{O}_{3}$. RT: room temperature.

\begin{tabular}{|c|c|c|c|c|c|}
\hline Dust & Reference & $T(\mathrm{~K})$ & $\begin{array}{r}\text { Concentration } \\
\left(\text { molecule } \mathrm{cm}^{-3}\right)\end{array}$ & Uptake coefficient & Techniques \\
\hline \multirow[t]{7}{*}{$\mathrm{Al}_{2} \mathrm{O}_{3}$} & Michel et al. (2002) & 296 & $1.9 \times 10^{11}$ & $\gamma_{0}:(8 \pm 5) \times 10^{-5}$ & KC-MS \\
\hline & Michel et al. (2003) & $250-330$ & $(1-10) \times 10^{11}$ & $\begin{array}{l}\text { At } 296 \mathrm{~K}, \gamma_{0} \text { was determined to be }(1.2 \pm 0.4) \times 10^{-4} \text { and } \gamma_{\mathrm{ss}} \text { was determined to be } \\
7.6 \times 10^{-6} \text {. A very weak temperature dependence was observed. }\end{array}$ & KC-MS \\
\hline & Usher et al. (2003b) & $295 \pm 1$ & $1.9 \times 10^{11}$ & $\begin{array}{l}\text { Compared to fresh particles, } \gamma_{0} \text { was reduced by } 72 \% \text { to }(3.4 \pm 0.6) \times 10^{-5} \text { when } \\
\text { the surface coverage of } \mathrm{HNO}_{3} \text { was }(6 \pm 3) \times 10^{14} \text { molecule } \mathrm{cm}^{-2} \text { and increased by } \\
33 \% \text { to }(1.6 \pm 0.2) \times 10^{-4} \text { when the surface coverage of } \mathrm{SO}_{2} \text { was }(1.5 \pm 0.3) \times \\
10^{14} \text { molecule } \mathrm{cm}^{-2} \text {. }\end{array}$ & KC-MS \\
\hline & Sullivan et al. (2004) & RT & $(1-10) \times 10^{13}$ & $\begin{array}{l}\gamma\left(\mathrm{O}_{3}\right) \text { decreased from } \sim 1 \times 10^{-5} \text { to } \sim 1 \times 10^{-6} \text { when initial } \mathrm{O}_{3} \text { concentration in- } \\
\text { creased from } 1 \times 10^{13} \text { to } 1 \times 10^{14} \text { molecule } \mathrm{cm}^{-3} \text {. }\end{array}$ & static reactor \\
\hline & Mogili et al. (2006a) & RT & $1 \times 10^{15}$ & $\begin{array}{l}\gamma\left(\mathrm{O}_{3}\right) \text { decreased from }(3.5 \pm 0.9) \times 10^{-8} \text { at }<1 \% \mathrm{RH} \text { to }(4.5 \pm 1.1) \times 10^{-9} \text { at } 19 \% \\
\mathrm{RH} .\end{array}$ & $\mathrm{EC}$ \\
\hline & Chen et al. (2011a) & RT & $\sim 1.9 \times 10^{15}$ & $\begin{array}{l}\text { Irradiation from a solar simulation could enhance } \mathrm{O}_{3} \text { uptake by } \alpha-\mathrm{Al}_{2} \mathrm{O}_{3} \text {, but no uptake } \\
\text { coefficient was reported. }\end{array}$ & EC \\
\hline & Chen et al. (2011b) & RT & $(2-3) \times 10^{15}$ & Uptake of $\mathrm{O}_{3}$ by $\alpha-\mathrm{Al}_{2} \mathrm{O}_{3}$ was insignificant under both dark and irradiated conditions. & EC \\
\hline \multirow[t]{5}{*}{ Saharan dust } & Michel et al. (2002) & 296 & $1.9 \times 10^{11}$ & $\begin{array}{l}\gamma_{0} \text { was determined to be }(6 \pm 3) \times 10^{-5} \text { for ground Saharan dust and }(4 \pm 2) \times 10^{-6} \text { for } \\
\text { sieved Saharan dust. }\end{array}$ & KC-MS \\
\hline & Hanisch and Crowley (2003a) & 296 & $(0.54-84) \times 10^{11}$ & $\begin{array}{l}\gamma_{0}=3.5 \times 10^{-4} \text { and } \gamma_{\mathrm{ss}}=4.8 \times 10^{-5} \text { when }\left[\mathrm{O}_{3}\right]_{0}=5.4 \times 10^{10} \text { molecule } \mathrm{cm}^{3} ; \gamma_{0}= \\
5.8 \times 10^{-5} \text { and } \gamma_{\mathrm{ss}}=1.3 \times 10^{-5} \text { when }\left[\mathrm{O}_{3}\right]_{0}=2.8 \times 10^{11} \text { molecule } \mathrm{cm}^{-3} ; \gamma_{0}=5.5 \times \\
10^{6} \text { and } \gamma_{\mathrm{ss}}=2.2 \times 10^{-6} \text { when }\left[\mathrm{O}_{3}\right]_{0}=8.4 \times 10^{12} \text { molecule } \mathrm{cm}^{-3} \text {. }\end{array}$ & KC-MS \\
\hline & Michel et al. (2003) & $295 \pm 1$ & $(1.9 \pm 0.6) \times 10^{11}$ & $\begin{array}{l}\text { For ground Saharan dust, } \gamma_{0}:(6 \pm 2) \times 10^{-5} \text { and } \gamma_{\mathrm{ss}}: 6 \times 10^{-6} \text {. For sieved Saharan dust, } \\
\gamma_{0}:(2.7 \pm 0.9) \times 10^{-6} \text {. }\end{array}$ & KC-MS \\
\hline & Chang et al. (2005) & RT & $(0.2-10) \times 10^{13}$ & $\begin{array}{l}\gamma\left(\mathrm{O}_{3}\right) \text { decreased from } 6 \times 10^{-6} \text { to } \sim 2 \times 10^{-7} \text { when }\left[\mathrm{O}_{3}\right] \text { increased from } 2 \times 10^{12} \text { to } \\
1 \times 10^{14} \text { molecule } \mathrm{cm}^{-3} \text {. }\end{array}$ & static reactor \\
\hline & Karagulian and Rossi (2006) & $298 \pm 2$ & $(3.5-10) \times 10^{12}$ & $\begin{array}{l}\gamma_{0}=(9.3 \pm 2.6) \times 10^{2} \quad \text { and } \gamma_{\mathrm{ss}}=(6.7 \pm 1.3) \times 10^{3} \text { when }\left[\mathrm{O}_{3}\right]_{0}=3.5 \times \\
10^{12} \text { molecule } \mathrm{cm}^{-3} ; \gamma_{0}=(3.7 \pm 1.8) \times 10^{3} \text { and } \gamma_{\mathrm{ss}}=(3.3 \pm 2.5) \times 10^{3} \text { when } \\
{\left[\mathrm{O}_{3}\right]_{0}=1.0 \times 10^{13} \text { molecule } \mathrm{cm}^{-3} \text {. Reported uptake coefficients were based on the }} \\
\text { projected surface area. }\end{array}$ & $\mathrm{KC}-\mathrm{MS}$ \\
\hline \multirow[t]{5}{*}{$\mathrm{Fe}_{2} \mathrm{O}_{3}$} & Michel et al. (2002) & 296 & $1.9 \times 10^{11}$ & $\gamma_{0}:(1.8 \pm 0.7) \times 10^{-4}$ & KC-MS \\
\hline & Michel et al. (2003) & $295 \pm 1$ & $(1-10) \times 10^{11}$ & $\gamma_{0}:(2.0 \pm 0.3) \times 10^{-4} ; \gamma_{\mathrm{ss}}: 2.2 \times 10^{-5}$ & KC-MS \\
\hline & Mogili et al. (2006a) & RT & $(1.8-8.5) \times 10^{14}$ & $\begin{array}{l}\text { When }\left[\mathrm{O}_{3}\right]_{0} \text { was } 7.9 \times 10^{14} \text { molecule } \mathrm{cm}^{-3}, \gamma\left(\mathrm{O}_{3}\right) \text { decreased from }(1.0 \pm 0.3) \times 10^{-7} \\
\text { at }<1 \% \mathrm{RH} \text { to }(1.2 \pm 0.3) \times 10^{-8} \text { at } 23 \% \mathrm{RH} \text { and to }(2.5 \pm 0.6) \times 10^{-9} \text { at } 58 \% \mathrm{RH} \text {. } \\
\text { When }\left[\mathrm{O}_{3}\right]_{0} \text { was } 2.1 \times 10^{14} \text { molecule } \mathrm{cm}^{3}, \gamma\left(\mathrm{O}_{3}\right) \text { decreased from }(5.0 \pm 1.2) \times 10^{-8} \\
\text { at }<1 \% \mathrm{RH} \text { to }(2.0 \pm 0.5) \times 10^{-8} \text { at } 21 \% \mathrm{RH} \text { and to }(9.0 \pm 2.3) \times 10^{-9} \text { at } 43 \% \mathrm{RH} \text {. }\end{array}$ & $\mathrm{EC}$ \\
\hline & Chen et al. (2011a) & RT & $\sim 1.9 \times 10^{15}$ & $\begin{array}{l}\text { Irradiation from a solar simulation could enhance the } \mathrm{O}_{3} \text { uptake by } \alpha-\mathrm{Fe}_{2} \mathrm{O}_{3} \text {, but no } \\
\text { uptake coefficient was reported. }\end{array}$ & $\mathrm{EC}$ \\
\hline & Chen et al. (2011b) & RT & $(2-3) \times 10^{15}$ & $\begin{array}{l}\text { Under dark conditions, } \gamma\left(\mathrm{O}_{3}\right) \text { decreased from }(4.1 \pm 0.2) \times 10^{-7} \text { at }<2 \% \mathrm{RH} \text { to }(2.7 \pm \\
0.1) \times 10^{-7} \text { at } 21 \% \mathrm{RH} \text {. When irradiated, } \gamma\left(\mathrm{O}_{3}\right) \text { decreased from }(6.6 \pm 0.3) \times 10^{-7} \\
\text { at }<2 \% \mathrm{RH} \text { to }(5.5 \pm 0.3) \times 10^{-7} \text { at } 12 \% \mathrm{RH} \text { and to }(1.1 \pm 0.1) \times 10^{-7} \text { at } 25 \% \mathrm{RH} \text {. }\end{array}$ & $\mathrm{EC}$ \\
\hline \multirow[t]{4}{*}{$\mathrm{SiO}_{2}$} & Michel et al. (2002) & 296 & $1.9 \times 10^{11}$ & $\gamma_{0}:(5 \pm 3) \times 10^{-5}$ & KC-MS \\
\hline & Michel et al. (2003) & $295 \pm 1$ & $(1.9 \pm 0.6) \times 10^{11}$ & $\gamma_{0}:(6.3 \pm 0.9) \times 10^{-5}$ & KC-MS \\
\hline & Usher et al. (2003b) & $295 \pm 1$ & $1.9 \times 10^{11}$ & $\begin{array}{l}\text { Compared to fresh particles, } \gamma_{0} \text { was increased by } 40 \% \text { to }(7 \pm 2) \times 10^{-5} \text { when the } \\
\text { surface coverage of a C } 8 \text { alkene was }(2 \pm 1) \times 10^{14} \text { molecule } \mathrm{cm}^{-2} \text { and reduced by } \\
40 \% \text { to }(3 \pm 1) \times 10^{-5} \text { when the surface coverage of a C } 8 \text { alkane was }(2 \pm 1) \times \\
10^{14} \text { molecule } \mathrm{cm}^{-2} \text {. }\end{array}$ & KC-MS \\
\hline & Nicolas et al. (2009) & 298 & $(1.3-7.3) \times 10^{12}$ & $\begin{array}{l}\gamma\left(\mathrm{O}_{3}\right) \text { was found to be }<1 \times 10^{-8} \text {, showing negative dependence on }\left[\mathrm{O}_{3}\right]_{0} \text { and } \mathrm{RH} \text {. } \\
\text { No difference in } \gamma\left(\mathrm{O}_{3}\right) \text { under dark and illuminated conditions was reported. }\end{array}$ & CWFT \\
\hline \multirow[t]{2}{*}{ China loess } & Michel et al. (2002) & 296 & $1.9 \times 10^{11}$ & $\gamma_{0}:(2.7 \pm 0.9) \times 10^{-5}$ & KC-MS \\
\hline & Michel et al. (2003) & $295 \pm 1$ & $(1.9 \pm 0.6) \times 10^{11}$ & $\gamma_{0}:(2.7 \pm 0.8) \times 10^{-5}$ & KC-MS \\
\hline \multirow[t]{2}{*}{ Kaolinite } & Michel et al. (2003) & $295 \pm 1$ & $(1.9 \pm 0.6) \times 10^{11}$ & $\gamma_{0}:(3 \pm 1) \times 10^{-5}$ & KC-MS \\
\hline & Karagulian and Rossi (2006) & $298 \pm 2$ & $(2.4 \pm 0.7) \times 10^{12}$ & $\begin{array}{l}\text { Projected surface area based: } \gamma_{0}=(6.3 \pm 0.2) \times 10^{2} \text { and } \gamma_{\mathrm{ss}}=(1.0 \pm 0.2) \times 10^{2} \text {; Pore- } \\
\text { diffusion-corrected } \gamma_{\mathrm{ss}}:(2.7 \pm 0.3) \times 10^{-6} \text {. }\end{array}$ & KC-MS \\
\hline $\mathrm{CaCO}_{3}$ & Karagulian and Rossi (2006) & $298 \pm 2$ & $(5.3 \pm 0.7) \times 10^{12}$ & $\begin{array}{l}\text { Projected surface area based: } \gamma_{0}=(1.2 \pm 0.3) \times 10^{2} \text { and } \gamma_{\mathrm{ss}}=(3.6 \pm 0.2) \times 10^{3} ; \text { Pore- } \\
\text { diffusion-corrected } \gamma_{\mathrm{ss}}:(7.8 \pm 0.7) \times 10^{-7} \text {. }\end{array}$ & KC-MS \\
\hline \multirow[t]{2}{*}{$\mathrm{TiO}_{2}$} & Nicolas et al. (2009) & 298 & $(1.3-7.3) \times 10^{12}$ & $\begin{array}{l}\gamma\left(\mathrm{O}_{3}\right) \text { on } \mathrm{TiO}_{2} / \mathrm{SiO}_{2} \text { decreased with }\left[\mathrm{O}_{3}\right]_{0} \text { and } \mathrm{RH} \text { under both dark and illumi- } \\
\text { nated conditions. Under illuminated conditions it increased with } \mathrm{TiO}_{2} \text { mass fraction } \\
\text { in } \mathrm{TiO}_{2} / \mathrm{SiO}_{2} \text { and depended almost linearly on irradiance intensity. At } 24 \% \mathrm{RH} \text { and } \\
{\left[\mathrm{O}_{3}\right]_{0} \text { of } 51 \mathrm{ppbv}, \gamma\left(\mathrm{O}_{3}\right) \text { on } 1 \mathrm{wt} \% \mathrm{TiO}_{2} / \mathrm{SiO}_{2} \text { was reported to be }(2.8 \pm 0.4) \times 10^{-9}} \\
\text { under dark conditions and }(4.7 \pm 0.7) \times 10^{-8} \text { under a near-UV irradiance of } 3.2 \times \\
10^{-8} \mathrm{~mW} \mathrm{~cm}^{-2} \text {. }\end{array}$ & CWFT \\
\hline & Chen et al. (2011b) & RT & $(2-3) \times 10^{15}$ & $\begin{array}{l}\text { Uptake of } \mathrm{O}_{3} \text { was negligible under dark conditions. Under the irradiation of a solar } \\
\text { simulator, } \gamma\left(\mathrm{O}_{3}\right) \text { was determined to be }(2.0 \pm 0.1) \times 10^{7} \text { at }<2 \% \mathrm{RH},(2.2 \pm 0.1) \times \\
10^{-7} \text { at } 12 \% \mathrm{RH},(2.4 \pm 0.1) \times 10^{-7} \text { at } 22 \% \mathrm{RH} \text {, and }(1.9 \pm 0.1) \times 10^{-7} \text { at } 39 \% \mathrm{RH} \text {, } \\
\text { respectively. }\end{array}$ & $\mathrm{EC}$ \\
\hline ATD & Karagulian and Rossi (2006) & $298 \pm 2$ & $(3.3-8.0) \times 10^{12}$ & $\begin{array}{l}\gamma_{0}=(1.3 \pm 0.6) \times 10^{2} \text { and } \gamma_{\mathrm{ss}}=(2.2 \pm 1.2) \times 10^{3} \text { when }\left[\mathrm{O}_{3}\right]_{0}=3.3 \times \\
10^{12} \text { molecule } \mathrm{cm}^{-3} ; \quad \gamma_{0}=(1.3 \pm 0.7) \times 10^{2} \text { and } \gamma_{\mathrm{ss}}=(2.5 \pm 1.2) \times 10^{3} \text { when } \\
{\left[\mathrm{O}_{3}\right]_{0}=8 \times 10^{12} \text { molecule } \mathrm{cm}^{-3} \text {. Reported uptake coefficients were based on the }} \\
\text { projected surface area. }\end{array}$ & KC-MS \\
\hline Limestone & Karagulian and Rossi (2006) & $298 \pm 2$ & $(3-20) \times 10^{12}$ & $\begin{array}{l}\gamma_{0}=(1.3 \pm 0.2) \times 10^{2} \quad \text { and } \gamma_{\mathrm{ss}}=(1.6 \pm 0.5) \times 10^{3} \quad \text { when }\left[\mathrm{O}_{3}\right]_{0}=3 \times \\
10^{12} \text { molecule } \mathrm{cm}^{-3} ; \quad \gamma_{0}=(2.1 \pm 0.3) \times 10^{3} \text { and } \gamma_{\mathrm{ss}}=(2.4 \pm 0.7) \times 10^{4} \text { when } \\
{\left[\mathrm{O}_{3}\right]_{0}=2 \times 10^{13} \text { molecule } \mathrm{cm}^{-3} \text {. Reported uptake coefficients were based on the }} \\
\text { projected surface area. }\end{array}$ & KC-MS \\
\hline
\end{tabular}




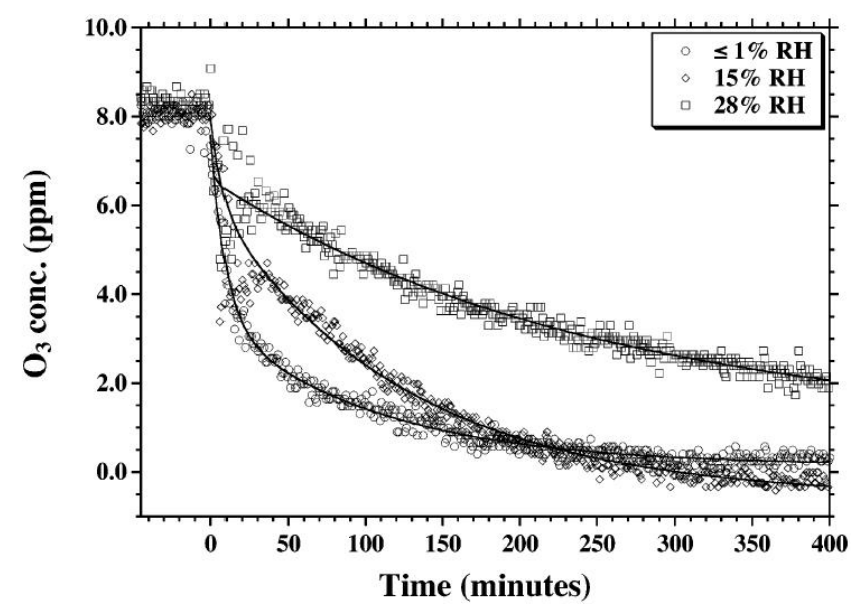

Figure 10. Measured $\mathrm{O}_{3}$ decays in an aerosol chamber due to interaction with airborne $\alpha-\mathrm{Fe}_{2} \mathrm{O}_{3}$ particles (starting at $0 \mathrm{~min}$ ). The solid curves represent exponential fits to the measured $\mathrm{O}_{3}$ concentrations as a function of reaction time. Reprinted with permission from Mogili et al. (2006b). (C) 2006 American Chemical Society.

at $<2 \% \mathrm{RH}$ to $(2.7 \pm 0.1) \times 10^{-7}$ at $21 \% \mathrm{RH}$, while irradiated $\gamma\left(\mathrm{O}_{3}\right)$ was reported to be $(6.6 \pm 0.3) \times 10^{-7}$ at $<2 \%$ $\mathrm{RH},(5.5 \pm 0.3) \times 10^{-7}$ at $12 \% \mathrm{RH}$, and $(1.1 \pm 0.1) \times 10^{-7}$ at $25 \% \mathrm{RH}$.

Photoenhanced catalytic decomposition of $\mathrm{O}_{3}$ on mineral dust was in fact first reported by a coated wall flow tube study at $298 \mathrm{~K}$ (Nicolas et al., 2009). Under their experimental conditions ( $\left[\mathrm{O}_{3}\right]_{0}: 50-290 \mathrm{ppbv}$; $\mathrm{RH}$ : 3-60\%), the BET-surface-area-based $\gamma_{\mathrm{ss}}\left(\mathrm{O}_{3}\right)$, was found to be $<1 \times 10^{-8}$ for $\mathrm{SiO}_{2}$ and $\mathrm{TiO}_{2} / \mathrm{SiO}_{2}$ mixture with $\mathrm{TiO}_{2}$ mass fraction up to $5 \%$ under dark conditions. Near-UV irradiation could largely increase the uptake of $\mathrm{O}_{3}$ by $\mathrm{TiO}_{2} / \mathrm{SiO}_{2}$ mixture, and the effect increased with the $\mathrm{TiO}_{2}$ mass fraction (the effect is insignificant for pure $\mathrm{SiO}_{2}$ ) and almost depended linearly on the intensity of UV irradiance (Nicolas et al., 2009). When $\mathrm{RH}$ was $24 \%$ and $\left[\mathrm{O}_{3}\right]_{0}$ was $51 \mathrm{ppbv}, \gamma\left(\mathrm{O}_{3}\right)$ for $\mathrm{TiO}_{2} / \mathrm{SiO}_{2}$ mixture with a $\mathrm{TiO}_{2}$ mass fraction of $1 \%$ was measured to be $(2.8 \pm 0.4) \times 10^{-9}$ under dark conditions and $(4.7 \pm 0.7) \times 10^{-8}$ under near-UV irradiation of $3.0 \times 10^{-8} \mathrm{~mW} \mathrm{~cm}^{-2}$. RH was found to play a profound role in heterogeneous photochemical reaction of $\mathrm{O}_{3}$ with $\mathrm{TiO}_{2} / \mathrm{SiO}_{2}$. Figure 11 shows that the irradiance-normalized uptake coefficient, defined as the uptake coefficient divided by the irradiance intensity, increased with $\mathrm{RH}$ for $\mathrm{RH}<20 \%$ and then decreased significantly with RH when RH was further increased. This phenomenon was also observed by Chen et al. (2011b), who found that under illuminated conditions $\gamma\left(\mathrm{O}_{3}\right)$ first increased and then decreased with $\mathrm{RH}$ for $\mathrm{TiO}_{2}$ aerosol particles.

Heterogeneous uptake of $\mathrm{O}_{3}$ may lead to oxidation of organic materials coated on mineral dust particles. Gligorovski and coworkers extensively investigated heterogeneous ozonation of aromatic compounds adsorbed on silica

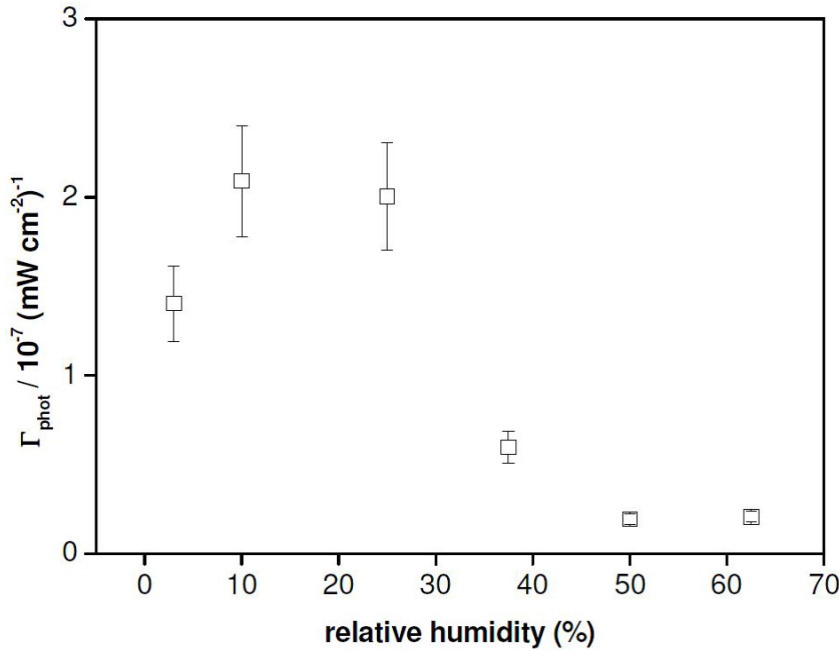

Figure 11. Effects of $\mathrm{RH}$ on the irradiance-normalized $\mathrm{O}_{3}$ uptake coefficients. The $\mathrm{TiO}_{2} / \mathrm{SiO}_{2}$ films which contained 1 wt $\% \mathrm{TiO}_{2}$ were exposed to $37 \mathrm{ppbv} \mathrm{O}_{3}$ at $298 \mathrm{~K}$ under irradiance of $2.7 \times$ $10^{14}$ photons $\mathrm{cm}^{-2} \mathrm{~s}^{-1}$. Reprinted with permission from Nicolas et al. (2009). (C) 2009 American Chemical Society.

particles used as a proxy of mineral dust particles in the atmosphere (Net et al., 2009, 2010a-d, 2011). For example, compared to dark conditions, loss of veratraldehyde coated on silica particles due to heterogeneous ozonolysis was increased under exposure to light (Net et al., 2010b). Heterogeneous reactivity of 4-phenoxyphenol towards ozone was significantly enhanced in the presence of aromatic ketones (4-carboxybenzophenone) under light irradiation compared to the dark ozone reaction (Net et al., 2010d). This photosensitized reaction proceeds through the electron transfer reaction to ozone with formation of an ozonide anion $\left(\mathrm{O}_{3}^{-}\right)$which can further react to produce $\mathrm{OH}$ radicals (De Laurentiis et al., 2013), and the formation of $\mathrm{OH}$ radicals was confirmed during such photochemical processing on the silica particles. The same group (Net et al., 2009) proposed a comprehensive reaction mechanism based on identified products arising from the $\mathrm{OH}$-addition to 4-phenoxyphenol. The phenoxyl radicals were proposed as a key intermediate which may react with $\mathrm{OH}$ radicals, producing hydroquinone, catechol, or other polyhydroxylated benzenes. The phenoxyl radicals are also responsible for the formation of oligomers by adding to another 4-phenoxyphenol molecule. Heterogeneous ozonolysis of phenols and methoxyphenols adsorbed on the mineral oxide surface is substantially impacted by sunlight irradiation. These photosensitized processes may play important roles in many issues, such as adverse health effects of inhaled particles and formation of secondary organic aerosols.

\subsubsection{Discussion}

All the initial $\gamma\left(\mathrm{O}_{3}\right)$ values reported by previous studies for different minerals are summarized in Fig. 12 as a function of 


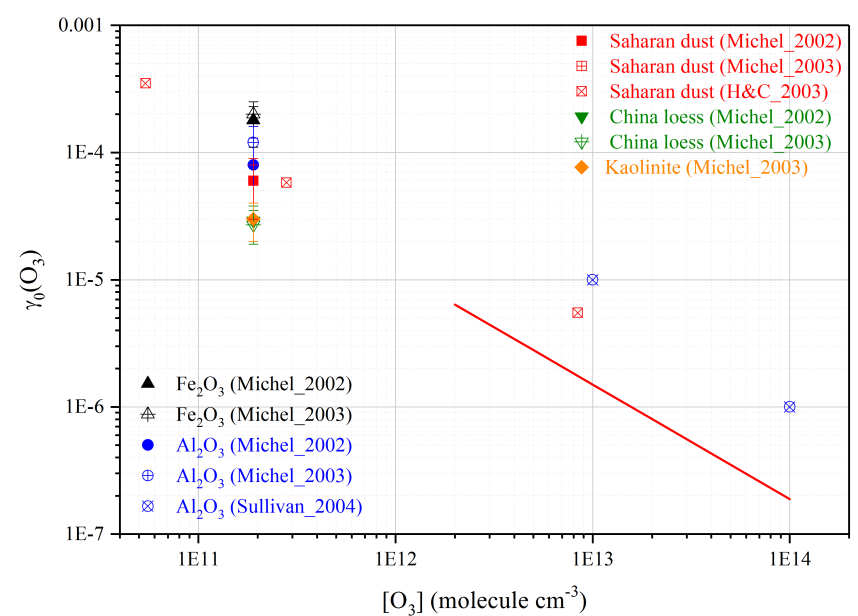

Figure 12. Dependence of $\gamma_{0}\left(\mathrm{O}_{3}\right)$ on initial $\mathrm{O}_{3}$ concentrations under dry conditions for different mineral dust particles as reported by previous studies: Michel_2002 (Michel et al., 2002), Michel_2003 (Michel et al., 2003), H\&C_2003 (Hanisch and Crowley, 2003a), Sullivan_2004 (Sullivan et al., 2004). The red curve represents the dependence of $\gamma\left(\mathrm{O}_{3}\right)$ on $\left[\mathrm{O}_{3}\right]$ for Saharan dust reported by Chang et al. (2005). Both $\mathrm{O}_{3}$ concentrations and $\gamma\left(\mathrm{O}_{3}\right)$ are plotted on the logarithm scale because their values span a few orders of magnitude.

$\left[\mathrm{O}_{3}\right]$. Karagulian and Rossi (2006) reported projected-areabased $\gamma_{0}\left(\mathrm{O}_{3}\right)$, which are several orders of magnitude larger than values reported by other work. This is because $\mathrm{O}_{3}$ uptake by mineral dust is relatively slow and some underlying dust layers, if not all, must be accessible by $\mathrm{O}_{3}$ molecules. Therefore, results reported by Karagulian and Rossi (2006) are not included in Fig. 12. Sullivan et al. (2004) and Chang et al. (2005) measured $\mathrm{O}_{3}$ decay rates in the first tens of seconds due to interaction with dust particles deposited onto the inner wall of a Pyrex tube to derive $\gamma\left(\mathrm{O}_{3}\right)$. Their reported $\gamma\left(\mathrm{O}_{3}\right)$ are in fact the average uptake coefficients in the first tens of seconds, and can be classified as either $\gamma_{0}\left(\mathrm{O}_{3}\right)$ and $\gamma_{\mathrm{ss}}\left(\mathrm{O}_{3}\right)$. Therefore, $\gamma\left(\mathrm{O}_{3}\right)$ values reported by Sullivan et al. (2004) and Chang et al. (2005) are included in Fig. 12, which summarizes $\gamma_{0}\left(\mathrm{O}_{3}\right)$, and also in Fig. 13, which summarizes $\gamma_{\mathrm{ss}}\left(\mathrm{O}_{3}\right)$.

It should be noted that all the studies included in Fig. 12 used dust powder samples supported on substrates. Significant variation in reported $\gamma_{0}\left(\mathrm{O}_{3}\right)$ is evident from Fig. 12. For example, $\gamma_{0}\left(\mathrm{O}_{3}\right)$ values determined at $\left[\mathrm{O}_{3}\right]$ of $\sim 2 \times$ $10^{11}$ molecule $\mathrm{cm}^{-3}$ differed by a factor of $\sim 10$. The observed difference in $\gamma_{0}\left(\mathrm{O}_{3}\right)$ may be caused by (1) variability in heterogeneous reactivity of different minerals and (2) different experimental methods leading to different results. For example, it has been suggested that pretreatment of mineral dust particles (e.g., heating, grounding, and evacuation) could modify their initial heterogeneous reactivity towards $\mathrm{O}_{3}$ (Hanisch and Crowley, 2003a; Michel et al., 2003). Furthermore, as discussed in Sect. 2.2, time resolution in dif-

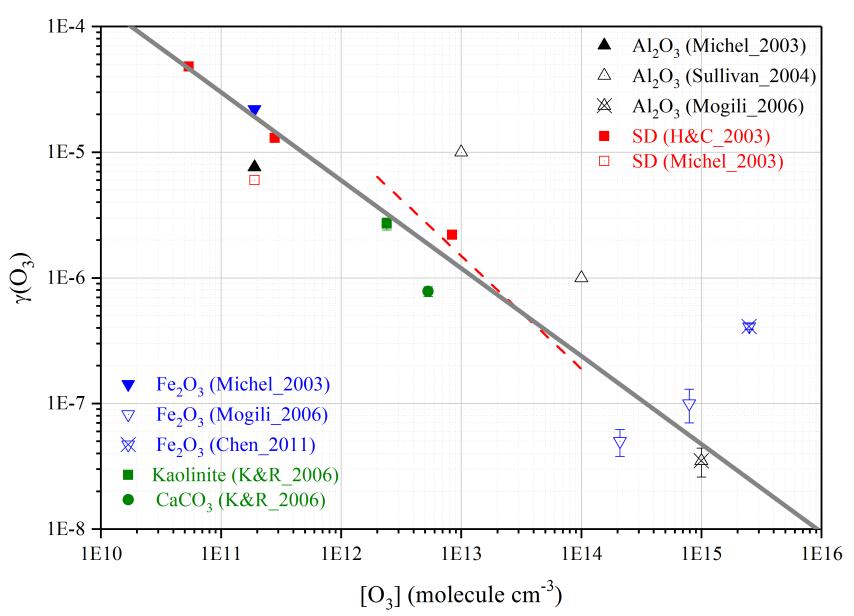

Figure 13. Dependence of $\gamma_{\mathrm{ss}}\left(\mathrm{O}_{3}\right)$ on initial $\mathrm{O}_{3}$ concentrations under dry conditions for different mineral dust particles: Michel_2003 (Michel et al., 2003), H\&C_2003 (Hanisch and Crowley, 2003a), Sullivan_2004 (Sullivan et al., 2004), Mogili_2006 (Mogili et al., 2006a), K\&R_2006 (Karagulian and Rossi, 2006), and Chen_2011 (Chen et al., 2011b). The red dashed curve represents the dependence of $\gamma\left(\mathrm{O}_{3}\right)$ on $\left[\mathrm{O}_{3}\right]$ for Saharan dust reported by Chang et al. (2005), and the grey solid curve represents the dependence of $\gamma\left(\mathrm{O}_{3}\right)$ on $\left[\mathrm{O}_{3}\right]$ for mineral dust particles recommended by the IUPAC Task Group on Atmospheric Chemical Kinetic Data Evaluation. Reprinted (with modification) with permission from the IUPAC Task Group on Atmospheric Chemical Kinetic Data Evaluation (http://iupac.pole-ether.fr).

ferent studies is also different, making interpretation of $\gamma_{0}$ difficult.

In contrast, $\gamma_{\mathrm{ss}}\left(\mathrm{O}_{3}\right)$ values reported by previous studies under dry conditions show fairly good agreement (as displayed in Fig. 13), considering the fact that very different experimental techniques have been used (for example, aerosol samples were used by Mogili et al. (2006b) and Chen et al. (2011b) while all the other studies used dust powder samples supported on substrates). In addition, a rather strong dependence of $\gamma_{\mathrm{ss}}\left(\mathrm{O}_{3}\right)$ on initial $\mathrm{O}_{3}$ concentration can be observed. Eq. (19) has been recommended by the IUPAC task group on Atmospheric Chemical Kinetic Data Evaluation to parameterize the dependence of $\gamma_{\mathrm{ss}}\left(\mathrm{O}_{3}\right)$ on $\left[\mathrm{O}_{3}\right]$ (Crowley et al., 2010a):

$\gamma\left(\mathrm{O}_{3}\right)=1500 \times\left[\mathrm{O}_{3}\right]^{-0.7}$,

where $\left[\mathrm{O}_{3}\right]$ is $\mathrm{O}_{3}$ concentration in molecules per cubic centimeter $\left(\right.$ molecule $\left.\mathrm{cm}^{-3}\right)$. It is quite surprising that $\gamma_{\mathrm{ss}}\left(\mathrm{O}_{3}\right)$ under dry conditions is very similar for all the minerals investigated. It can also been observed from Fig. 13 that $\gamma_{\mathrm{ss}}\left(\mathrm{O}_{3}\right)$ for $\alpha-\mathrm{Al}_{2} \mathrm{O}_{3}$ reported by Sullivan et al. (2004) and for $\alpha$ $\mathrm{Fe}_{2} \mathrm{O}_{3}$ reported by Chen et al. (2011b) may be significantly larger than those recommended by Crowley et al. (2010a), and the reason is not very clear yet. It should be pointed out that the work by Sullivan et al. (2004), though already published at that time, was not included in the original figure 
prepared by the IUPAC Task Group. In addition, the work by Chen et al. (2011b) was published after the IUACP report was released online.

Only three previous studies have explored effects of RH on heterogeneous reactions of $\mathrm{O}_{3}$ with mineral dust, and different results have been reported. While a strong negative effect of $\mathrm{RH}$ on $\mathrm{O}_{3}$ uptake kinetics was observed for $\alpha-\mathrm{Al}_{2} \mathrm{O}_{3}$ and $\alpha-\mathrm{Fe}_{2} \mathrm{O}_{3}$ by Mogili et al. (2006b), the other two studies (Sullivan et al., 2004; Chang et al., 2005) suggested that the influence of $\mathrm{RH}$ on heterogeneous uptake of $\mathrm{O}_{3}$ by $\alpha-\mathrm{Al}_{2} \mathrm{O}_{3}$ and Saharan dust was insignificant. Further experimental and theoretical work is required to better understand the effect of $\mathrm{RH}$ on $\mathrm{O}_{3}$ uptake by mineral dust. As discussed below, surface-adsorbed water may play different roles in heterogeneous reaction of minerals with $\mathrm{O}_{3}$.

A few other studies (Li et al., 1998; Li and Oyama, 1998; Roscoe and Abbatt, 2005; Lampimaki et al., 2013) used different surface techniques to monitor mineral dust surfaces during exposure to $\mathrm{O}_{3}$. These studies did not report uptake coefficients and hence are not included in Table 6. Nevertheless, they have provided valuable insights into reaction mechanisms at the molecular level and are worthy of further discussion. A new Raman peak at $884 \mathrm{~cm}^{-1}$ was observed after exposure of $\mathrm{MnO}_{2}$ to $\mathrm{O}_{3}$, and it is attributed to peroxide species (i.e., $\mathrm{SS}^{-\mathrm{O}_{2}}$ ) by combining Raman spectroscopy, ${ }^{18} \mathrm{O}$ isotope substitution measurements, and ab initio calculation (Li et al., 1998). Consequently, the following reaction mechanism has been proposed for heterogeneous reaction of $\mathrm{O}_{3}$ with metal oxides (Li et al., 1998):

$\mathrm{O}_{3}(\mathrm{~g})+\mathrm{SS} \rightarrow \mathrm{SS}-\mathrm{O}+\mathrm{O}_{2}(\mathrm{~g})$,

$\mathrm{SS}-\mathrm{O}+\mathrm{O}_{3}(\mathrm{~g}) \rightarrow \mathrm{SS}^{-} \mathrm{O}_{2}+\mathrm{O}_{2}(\mathrm{~g})$,

where SS represents reactive surface sites towards $\mathrm{O}_{3}$. The intensity of the $\mathrm{SS}-\mathrm{O}_{2}$ peak was found to decrease gradually with time after $\mathrm{O}_{3}$ exposure was terminated, suggesting that SS-O ${ }_{2}$ would slowly decompose to $\mathrm{O}_{2}$ (Li et al., 1998):

$\mathrm{SS}-\mathrm{O}_{2} \rightarrow \mathrm{SS}+\mathrm{O}_{2}(\mathrm{~g})$.

A following study by the same group (Li and Oyama, 1998) suggested that the steady state and transient kinetics of heterogeneous decomposition of $\mathrm{O}_{3}$ on $\mathrm{MnO}_{2}$ could be well described by the aforementioned reaction mechanism (Reactions R18a-R18c). Reaction (R18a) is expected to be of the Eley-Rideal type, because desorption of $\mathrm{O}_{3}$ from mineral surfaces has never been observed (Hanisch and Crowley, 2003a; Michel et al., 2003; Karagulian and Rossi, 2006), and thus the Langmuir-Hinshelwood mechanism is unlikely. It is also suggested that Reaction (R18a) is much faster than the other two steps and the reactivation step (Reaction R18c) is slowest (Li et al., 1998; Li and Oyama, 1998).

The reaction mechanism proposed by $\mathrm{Li}$ et al. was supported by several following studies. For example, gradual surface passivation was observed for a variety of minerals
(Hanisch and Crowley, 2003a; Michel et al., 2003), suggesting that the number of reactive surface sites towards $\mathrm{O}_{3}$ is limited, as implied by Reaction (R18a) and (R18b). On the other hand, two previous studies (Hanisch and Crowley, 2003a; Sullivan et al., 2004) observed that surface reactivation would slowly occur after $\mathrm{O}_{3}$ exposure was stopped, and Michel et al. (2003) found that heterogeneous uptake of $\mathrm{O}_{3}$ by minerals is of catalytic nature to some extent. These studies (Hanisch and Crowley, 2003a; Michel et al., 2003; Sullivan et al., 2004) clearly demonstrate that a slow surface reactivation step exists, consistent with the reaction mechanism (more precisely, Reaction R18c) proposed by Li and coworkers (Li et al., 1998; Li and Oyama, 1998).

Using DRIFTS, Roscoe and Abbatt (2005) monitored the change of alumina during its heterogeneous interaction with $\mathrm{O}_{3}$ and water vapor. A new IR peak at $1380 \mathrm{~cm}^{-1}$, attributed to SS-O, appeared after alumina was exposed to $\mathrm{O}_{3}$. Because alumina is opaque below $1100 \mathrm{~cm}^{-1}$, the $\mathrm{SS}-\mathrm{O}_{2}$ peak, expected to appear at around $884 \mathrm{~cm}^{-1}$ (Li et al., 1998), could not be detected by IR. When alumina was simultaneously exposed $\mathrm{O}_{3}$ and water vapor, the intensity of the SS-O peak was substantially decreased, compared to the case of exposure to $\mathrm{O}_{3}$ alone. This suggests that water molecules can be adsorbed strongly to sites which would otherwise react with $\mathrm{O}_{3}$, thus suppressing the formation of SS-O on the surface (Roscoe and Abbatt, 2005). In this aspect, increasing RH will reduce heterogeneous reactivity of alumina towards $\mathrm{O}_{3}$. It was further found that if $\mathrm{O}_{3}$-reacted alumina was exposed to water vapor, the intensity of the SS-O IR peak would gradually decrease while the amount of surface-adsorbed water would increase. This indicates that SS-O would react with adsorbed water to regenerate reactive surface sites (i.e., SS as shown in Reaction R18a), implying that the presence of water vapor may also promote $\mathrm{O}_{3}$ uptake by alumina. As we discussed before, previous studies which examined the effects of RH on heterogeneous reactions of $\mathrm{O}_{3}$ with minerals (Sullivan et al., 2004; Chang et al., 2005; Mogili et al., 2006a) do not agree with each other. This inconsistence may be (at least partly) caused by complex roles which adsorbed water plays in heterogeneous uptake of $\mathrm{O}_{3}$ by mineral dust. Further work is required to elucidate the effect of $\mathrm{RH}$, especially considering that the heterogeneous reaction of $\mathrm{O}_{3}$ with minerals is of interest not only for atmospheric chemistry but also for indoor air quality and industrial application (Dhandapani and Oyama, 1997).

\subsubsection{Atmospheric implications}

Using the dependence of $\gamma\left(\mathrm{O}_{3}\right)$ on $\left[\mathrm{O}_{3}\right]$ recommended by Crowley et al. (2010a) and assuming a typical $\mathrm{O}_{3}$ concentration of $1.5 \times 10^{12}$ molecule $\mathrm{cm}^{-3}(\sim 60 \mathrm{ppbv})$ in the troposphere, $\gamma\left(\mathrm{O}_{3}\right)$ is calculated to be $4.5 \times 10^{-6}$. Consequently, lifetimes of $\mathrm{O}_{3}$ with respect to heterogeneous reaction with mineral dust, $\tau_{\text {het }}\left(\mathrm{O}_{3}\right)$, are estimated to be about 1280,128 , and 13 days for dust mass concentrations of 10,100 , and 
$1000 \mu \mathrm{g} \mathrm{m}^{-3}$, respectively. As discussed in Sect. 2.1.2, in polluted and forested areas where alkenes are abundant, $\mathrm{O}_{3}$ lifetimes are around several hours; in these regions, $\mathrm{O}_{3}$ removal due to direct heterogeneous uptake by mineral dust is unlikely to be significant. On the other hand, $\mathrm{O}_{3}$ lifetimes in remote free troposphere are in the range of several days to a few weeks; therefore, direct removal of $\mathrm{O}_{3}$ by heterogeneous reaction with mineral dust could play a minor but nonnegligible role for some regions in the remote free troposphere heavily impacted by mineral dust.

\subsection{HCHO}

The photocatalytic oxidation of $\mathrm{HCHO}$ on the $\mathrm{P} 25 \mathrm{TiO}_{2}$ surface was investigated as a function of $\mathrm{HCHO}$ concentration and RH (Obee and Brown, 1995). It has been shown that at a given $\mathrm{HCHO}$ concentration, oxidation rates of $\mathrm{HCHO}$ first increased and then decreased with RH. Noguchi et al. (1998) found that under dark conditions, $\mathrm{P} 25 \mathrm{TiO}_{2}$ particles showed higher $\mathrm{HCHO}$ adsorption capacity (after normalized to surface area) than activated carbon. Under UV illumination, $\mathrm{TiO}_{2}$ thin films could convert $\mathrm{HCHO}$ completely to $\mathrm{CO}_{2}$ and $\mathrm{H}_{2} \mathrm{O}$, with formic acid $(\mathrm{HCOOH})$ being an intermediate product; furthermore, the dependence of photodegradation rates on $[\mathrm{HCHO}]_{0}$ could be described by the LangmuirHinshelwood model (Noguchi et al., 1998). In another study (Liu et al., 2005), it has also been suggested that kinetics of photocatalytic oxidation of $\mathrm{HCHO}$ on the $\mathrm{TiO}_{2}$ surface could be described by the Langmuir-Hinshelwood model, and CO was identified as one of the products.

Ao et al. (2004) explored the effects of $\mathrm{NO}, \mathrm{SO}_{2}$, and VOCs (including benzene, toluene, ethylbenzene, and oxylene) on the photodegradation of $\mathrm{HCHO}$ on $\mathrm{P}_{25} \mathrm{TiO}_{2}$ particles. Formic acid was identified as a major reaction intermediate, and $\mathrm{HCHO}$ degradation rates and $\mathrm{HCOOH}$ yields both decreased with increasing RH (Ao et al., 2004). In addition, NO could accelerate $\mathrm{HCHO}$ oxidation rates and increase $\mathrm{HCOOH}$ yields, whereas the copresence of $\mathrm{SO}_{2}$ and VOCs used in this study was found to inhibit photooxidation of HCHO (Ao et al., 2004). DRIFTS was used by Sun et al. (2010) to investigate adsorption and photooxidation of $\mathrm{HCHO}$ on $\mathrm{TiO}_{2}$. It has been shown that adsorbed HCHO molecules can be rapidly converted to formate on the surface under UV irradiation, and the presence of water vapor could significantly accelerate oxidation of $\mathrm{HCHO}$ on $\mathrm{TiO}_{2}$ (Sun et al., 2010).

All the aforementioned studies (Obee and Brown, 1995; Noguchi et al., 1998; Ao et al., 2004; Liu et al., 2005; Sun et al., 2010) clearly showed that UV illumination could largely enhance heterogeneous uptake of $\mathrm{HCHO}$ by $\mathrm{TiO}_{2}$ particles, and $\mathrm{HCOOH} / \mathrm{HCOO}^{-}, \mathrm{CO}_{2}, \mathrm{CO}$, and $\mathrm{H}_{2} \mathrm{O}$ were identified as reaction intermediates and/or products. Though these studies provide useful insights into mechanisms of heterogeneous reactions of $\mathrm{HCHO}$ with $\mathrm{TiO}_{2}$ surface, they are not listed in Table 7 because no uptake coefficients have been reported. The heterogeneous reaction of HCHO (10$40 \mathrm{ppbv}$ ) with soil samples was investigated using a coated wall flow tube (Li et al., 2016). At $0 \% \mathrm{RH}$, the initial uptake coefficient was determined to be $(1.1 \pm 0.05) \times 10^{-4}$, gradually decreasing to $(5.5 \pm 0.4) \times 10^{-5}$ within $8 \mathrm{~h}$. Increasing $\mathrm{RH}$ would suppress the uptake of $\mathrm{HCHO}$, and around two-thirds of HCHO molecules uptaken by the soil were reversible ( $\mathrm{Li}$ et al., 2016). The soil samples used by $\mathrm{Li}$ et al. were collected from a cultivated field site (Mainz, Germany) and may not resemble the composition and mineralogy of mineral dust aerosol; therefore, this study is not included in Table 7.

Carlos-Cuellar et al. (2003) first determined uptake coefficients of $\mathrm{HCHO}$ on several mineral dust particles at room temperature, using a Knudsen cell reactor. Gradual surface deactivation was observed for all three types of particles, and initial uptake coefficients $\left(\gamma_{0}\right)$, based on the BET surface area, were reported to be $(1.1 \pm 0.5) \times 10^{-4}$ for $\alpha-\mathrm{Fe}_{2} \mathrm{O}_{3}$, $(7.7 \pm 0.3) \times 10^{-5}$ for $\alpha-\mathrm{Al}_{2} \mathrm{O}_{3}$, and $(2.6 \pm 0.9) \times 10^{-7}$ for $\mathrm{SiO}_{2}$ (Carlos-Cuellar et al., 2003).

Using DRIFTs and ion chromatography, Xu and coworkers systematically investigated heterogeneous reactions of HCHO with $\alpha-\mathrm{Al}_{2} \mathrm{O}_{3}$ (Xu et al., 2006), $\gamma-\mathrm{Al}_{2} \mathrm{O}_{3}$ (Xu et al., 2011), and $\mathrm{TiO}_{2}$ particles (Xu et al., 2010) as a function of temperature, UV irradiation, and $\mathrm{HCHO}$ concentration. It has been found that $\mathrm{HCHO}$ was first converted to dioxymethylene which was then oxidized to formate on the surface, and UV irradiation and increasing temperature both could enhance heterogeneous reactivity of all three types of particles towards $\mathrm{HCHO}$ (Xu et al., 2006, 2010, 2011). The value of $\gamma_{0}(\mathrm{HCHO})$ on $\alpha-\mathrm{Al}_{2} \mathrm{O}_{3}$ at $293 \mathrm{~K}$ was determined to be $(9.4 \pm 1.7) \times 10^{-9}$ based on the BET surface area of the sample and $(2.3 \pm 0.5) \times 10^{-5}$ based on the geometrical area of the sample holder (Xu et al., 2006). At room temperature $(295 \pm 2 \mathrm{~K})$ and under dark conditions, $\gamma_{0}(\mathrm{HCHO})$, based on the BET surface area, was determined to be in the range of $0.5 \times 10^{-8}$ to $5 \times 10^{-8}$ for $\mathrm{TiO}_{2}$ (Xu et al., 2010), increasing linearly with $\mathrm{HCHO}$ concentration $\left(1 \times 10^{13}\right.$ to $2 \times$ $10^{14}$ molecule $\mathrm{cm}^{-3}$ ). Under the same condition, $\gamma_{0}$ (HCHO) was determined to be $(3.6 \pm 0.8) \times 10^{-4}$ based on the geometrical area and $(1.4 \pm 0.31) \times 10^{-8}$ based on the BET surface area for $\gamma-\mathrm{Al}_{2} \mathrm{O}_{3}$ (Xu et al., 2011). The effect of RH was further studied for $\gamma-\mathrm{Al}_{2} \mathrm{O}_{3}$ at $295 \pm 2 \mathrm{~K}$, and the dependence of BET-surface-area-based $\gamma_{0}$ (HCHO) on RH is given by the following equation (Xu et al., 2011):

$\ln \left[\gamma_{0}(\mathrm{BET})\right]=-17.5-0.0127 \times \mathrm{RH}$,

where $\mathrm{RH}$ is in the unit of percentage (\%).

A coated wall flow tube was deployed to investigate heterogeneous reactions of $\mathrm{HCHO}$ with $\mathrm{TiO}_{2}$ and $\mathrm{SiO}_{2}$ particles, and the effects of UV irradiation, temperature (278-303 K), RH (6-70\%), and HCHO concentration (3.5$32.5 \mathrm{ppbv}$ ) were systematically examined (Sassine et al., 2010). Under dark conditions, the uptake of HCHO onto $\mathrm{SiO}_{2}$ and $\mathrm{TiO}_{2}$ was very slow, with BET-surface-area-based 
Table 7. Summary of previous laboratory studies on heterogeneous reactions of mineral dust with HCHO.

\begin{tabular}{|c|c|c|c|c|c|}
\hline Dust & Reference & $T(\mathrm{~K})$ & $\begin{array}{r}\text { Concentration } \\
\left(\text { molecule } \mathrm{cm}^{-3}\right)\end{array}$ & Uptake coefficient & Techniques \\
\hline \multirow[t]{2}{*}{$\mathrm{TiO}_{2}$} & Xu et al. (2010) & $163-673$ & $(1-20) \times 10^{13}$ & $\begin{array}{l}\text { At } 295 \pm 2 \mathrm{~K}, \gamma_{0} \text { (based on the BET sur- } \\
\text { face area) was determined to be in the range } \\
\text { of } 0.5 \times 10^{-8} \text { to } 5 \times 10^{8} \text {, increasing lin- } \\
\text { early with } \mathrm{HCHO} \text { concentration }\left(1 \times 10^{13}\right. \\
\left.\text { to } 2 \times 10^{14} \text { molecule } \mathrm{cm}^{-3}\right) \text {. UV irradiation } \\
\text { and increasing temperature could both ac- } \\
\text { celerate this reaction. }\end{array}$ & DRIFTS, IC \\
\hline & Sassine et al. (2010) & $278-303$ & $(9-82) \times 10^{10}$ & $\begin{array}{l}\gamma_{\text {ss }} \text { was determined to range from }(3.00 \pm \\
0.45) \times 10^{-9} \text { to }(2.26 \pm 0.34) \times 10^{-6} \text {, de- } \\
\text { pending on UV irradiation, HCHO concen- } \\
\text { tration, RH, and temperature. }\end{array}$ & CWFT \\
\hline \multirow[t]{3}{*}{$\mathrm{Al}_{2} \mathrm{O}_{3}$} & Carlos-Cuellar et al. (2003) & 295 & $1.9 \times 10^{11}$ & $\gamma_{0}:(7.7 \pm 0.3) \times 10^{-5}$ & KC-MS \\
\hline & Xu et al. (2006) & $273-333$ & $(1-10) \times 10^{13}$ & $\begin{array}{l}\text { At } 296 \mathrm{~K}, \gamma_{0} \text { was determined to be }(9.4 \pm \\
1.7) \times 10^{-9} \text { based on the BET surface area } \\
\text { and }(2.3 \pm 0.5) \times 10^{-5} \text { based on the geomet- } \\
\text { rical area for } \alpha-\mathrm{Al}_{2} \mathrm{O}_{3} \text {. UV irradiation and } \\
\text { increasing temperature could both acceler- } \\
\text { ate this reaction. }\end{array}$ & DRIFTS, IC \\
\hline & Xu et al. (2011) & $84-573$ & $(1.3-3.6) \times 10^{13}$ & $\begin{array}{l}\text { At } 295 \pm 2 \mathrm{~K}, \gamma_{0} \text { was determined to be } \\
(3.6 \pm 0.8) \times 10^{-4} \text { based on the geometri- } \\
\text { cal area and }(1.4 \pm 0.31) \times 10^{-8} \text { based on } \\
\text { the BET surface area for } \gamma-\mathrm{Al}_{2} \mathrm{O}_{3} . \mathrm{UV} \text { ir- } \\
\text { radiation and increasing temperature could } \\
\text { both accelerate this reaction. }\end{array}$ & DRIFTS, IC \\
\hline \multirow[t]{2}{*}{$\mathrm{SiO}_{2}$} & Carlos-Cuellar et al. (2003) & 295 & $1.9 \times 10^{11}$ & $\gamma_{0}:(2.6 \pm 0.9) \times 10^{-7}$ & KC-MS \\
\hline & Sassine et al. (2010) & $278-303$ & $(9-82) \times 10^{10}$ & $\gamma_{\text {ss }}$ under dark conditions: $\sim 3 \times 10^{-9}$ & CWFT \\
\hline $\mathrm{Fe}_{2} \mathrm{O}_{3}$ & Carlos-Cuellar et al. (2003) & 295 & $1.9 \times 10^{11}$ & $\gamma_{0}:(1.1 \pm 0.5) \times 10^{-5}$ & KC-MS \\
\hline
\end{tabular}

$\gamma_{\mathrm{ss}}$ being $(3.00 \pm 0.45) \times 10^{-9}$. Nevertheless, its uptake on $\mathrm{TiO}_{2}$ and $\mathrm{TiO}_{2} / \mathrm{SiO}_{2}$ mixture was largely enhanced by nearUV irradiation (340-420 nm) (Sassine et al., 2010). For pure $\mathrm{TiO}_{2}$ under the condition of $293 \mathrm{~K}, 30 \% \mathrm{RH}$, and 2 ppbv $\mathrm{HCHO}, \gamma_{\mathrm{ss}}$ depended linearly on irradiation intensity $\left(1.9 \times 10^{15}\right.$ to $2.7 \times 10^{15}$ photons $\left.\mathrm{cm}^{-2} \mathrm{~s}^{-1}\right)$. The uptake kinetics can be described by the Langmuir-Hinshelwood model: under the condition of $293 \mathrm{~K}, 6 \% \mathrm{RH}$, and $2.7 \times$ $10^{15}$ photons $\mathrm{cm}^{-2} \mathrm{~s}^{-1}, \gamma_{\mathrm{ss}}$ decreased from $(6.0 \pm 0.9) \times 10^{-7}$ to $(2.0 \pm 0.3) \times 10^{-7}$ for $\mathrm{TiO}_{2}$ when $[\mathrm{HCHO}$ increased from 3.5 to 32.5 ppbv (Sassine et al., 2010).

In addition, the effects of $\mathrm{RH}$ and temperature were also explored. As shown in Fig. 14, $\gamma_{\mathrm{ss}}$ was found to first increase with $\mathrm{RH}$ for $\mathrm{TiO}_{2}$ (and $\mathrm{TiO}_{2} / \mathrm{SiO}_{2}$ mixture as well), reaching a maximum at $\sim 30 \%$, and then decrease with $\mathrm{RH}$. Under conditions of $30 \% \mathrm{RH}, 11 \mathrm{ppbv} \mathrm{HCHO}$, and $2.7 \times$ $10^{15}$ photons $\mathrm{cm}^{-2} \mathrm{~s}^{-1}, \gamma_{\mathrm{ss}}$ increased from $(1.8 \pm 0.3) \times 10^{-7}$ at $298 \mathrm{~K}$ to $(3.2 \pm 0.5) \times 10^{-7}$ at $303 \mathrm{~K}$ (Sassine et al., 2010).

\subsubsection{Discussion and atmospheric implication}

Two previous studies determined BET-surface-area-based $\gamma_{0}(\mathrm{HCHO})$ for $\alpha-\mathrm{Al}_{2} \mathrm{O}_{3}$ particles under dry conditions at room temperature, and $\gamma_{0}(\mathrm{HCHO})$ reported by CarlosCuellar et al. (2003) is $>3$ orders of magnitude larger than that reported by $\mathrm{Xu}$ et al. (2006). It is not very clear yet why such a large difference was found between these two studies. Two studies (Sassine et al., 2010; Xu et al., 2010) measured $\gamma(\mathrm{HCHO})$ for $\mathrm{TiO}_{2}$ particles; however, it is difficult to make comparisons because one study reported $\gamma_{0}$ (Xu et al., 2010) and the other one reported $\gamma_{\mathrm{ss}}$ (Sassine et al., 2010).

What we can conclude from previous studies as summarized in Table 7 is that our understanding of atmospheric heterogeneous reaction of $\mathrm{HCHO}$ with mineral dust is very limited. For example, all the previous studies only examined its reactions with oxides, while clay minerals and authentic dust samples have never been investigated. Second, as discussed above, large discrepancies are found for uptake coefficients reported by previous studies. Furthermore, roles of $\mathrm{RH}$ in heterogeneous uptake of $\mathrm{HCHO}$ by mineral dust are not fully 


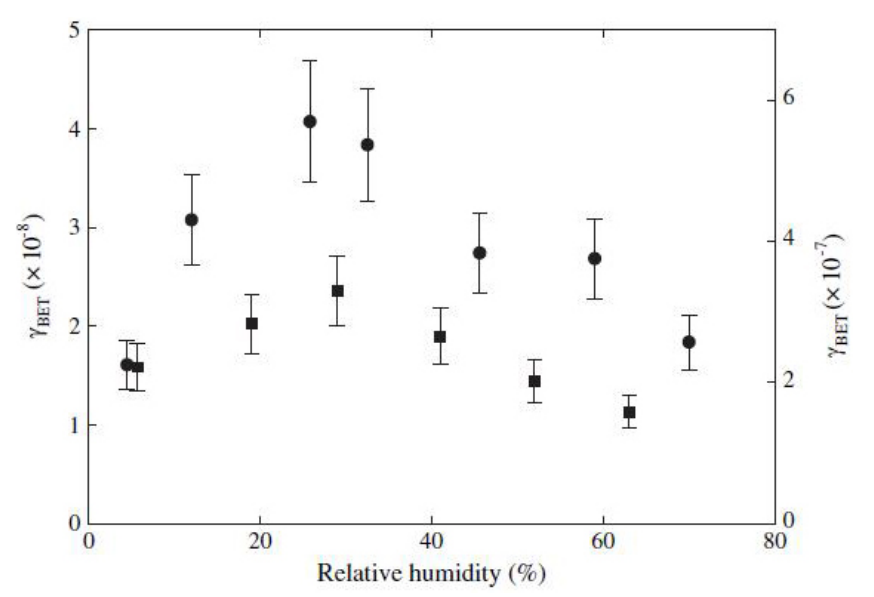

Figure 14. Effects of RH on heterogeneous uptake of HCHO by pure $\mathrm{TiO}_{2}$ (circles, right $y$ axis) and $\mathrm{TiO}_{2} / \mathrm{SiO}_{2}$ mixture (squares, left $y$ axis) which contains $5 \mathrm{wt} \% \mathrm{TiO}_{2}$. Experimental conditions: $293 \mathrm{~K}, 11$ ppbv HCHO, $2.7 \times 10^{15}$ photons $\mathrm{cm}^{-2} \mathrm{~s}^{-1}$ illumination. Reprinted with permission from Sassine et al. (2010). (C) Elsevier 2010.

understood. Last but not least, though several studies have observed that UV illumination could largely enhance heterogeneous reaction of $\mathrm{HCHO}$ with mineral particles, it is nontrivial to know that compared to dark conditions, to which extent this reaction is accelerated under irradiation conditions relevant to the troposphere. Therefore, it is difficult to assess the significance of heterogeneous uptake by mineral dust aerosol particles as a sink for HCHO in a reliable manner.

An uptake coefficient of $(9.7 \pm 1.4) \times 10^{-6}$ was used by Sassine et al. (2010) to evaluate the significance of heterogeneous reactions of $\mathrm{HCHO}$ with pure $\mathrm{TiO}_{2}$ particles as a sink for HCHO. This value was linearly extrapolated from their experimental measurements ( 2 ppbv HCHO, $293 \mathrm{~K}$, and $30 \% \mathrm{RH})$ to realistic solar conditions in the troposphere $\left(1.21 \times 10^{16}\right.$ photons $\left.\mathrm{cm}^{-2} \mathrm{~s}^{-1}\right)$. The value used by Sassine et al. (2010) is also adopted here to preliminarily assess the impact of heterogeneous reactions of $\mathrm{HCHO}$ with mineral dust. For simplicity, in our work $\gamma(\mathrm{HCHO})$ is set to $1 \times 10^{-5}$ which is only $3 \%$ larger than that used by Sassine et al. (2010). Consequently, $\tau_{\text {het }}(\mathrm{HCHO})$ is calculated to be about 456,46 , and 4.6 days for mineral dust mass concentrations of 10,100 , and $1000 \mu \mathrm{g} \mathrm{m}^{-3}$, respectively. For comparison, as we have discussed in Sect. 2.1, typical lifetimes of $\mathrm{HCHO}$ are a few hours in the troposphere, with photolysis and reaction with $\mathrm{OH}$ radicals being the two major removal processes. It is quite clear that $\tau_{\text {het }}(\mathrm{HCHO})$ is much larger than typical lifetimes of $\mathrm{HCHO}$, and thus heterogeneous reaction with mineral dust is unlikely to be significant for the removal of $\mathrm{HCHO}$ in the troposphere.

\subsection{HONO}

Bedjanian and coworkers utilized a coated rod flow tube coupled to a mass spectrometer to investigate heterogeneous reaction of $\mathrm{HONO}$ with $\mathrm{TiO}_{2}, \gamma-\mathrm{Al}_{2} \mathrm{O}_{3}, \mathrm{Fe}_{2} \mathrm{O}_{3}$, and ATD particles under dark and illuminated conditions (El Zein and Bedjanian, 2012; Romanias et al., 2012b; El Zein et al., 2013, b). All these measurements were carried out with dust mass in the linear mass-dependent regime, and thus BET surface area was used to calculate uptake coefficients. We note that several previous studies have explored heterogeneous interactions between HONO and Pyrex (Kaiser and Wu, 1977; Ten Brink and Spoelstra, 1998), borosilicate glass (Syomin and Finlayson-Pitts, 2003), and $\mathrm{TiO}_{2}$-doped commercial paints (Laufs et al., 2010). However, these studies are not further discussed here because they are not of direct atmospheric relevance. Uptake of HONO by soil samples was investigated using a coated-wall flow tube (Donaldson et al., 2014), and uptake coefficients were found to decrease with $\mathrm{RH}$, from $(2.5 \pm 0.4) \times 10^{-4}$ at $0 \% \mathrm{RH}$ to $(1.1 \pm 0.4) \times 10^{-5}$ at $80 \% \mathrm{RH}$. Soil used by Donaldson et al. were collected from an agricultural field in Indiana and its mineralogical composition may be quite different from mineral dust aerosol; as a result, this study is not included in Table 8 .

El Zein and Bedjanian (2012) measured heterogeneous uptake of $\mathrm{HONO}$ by $\mathrm{TiO}_{2}$ particles under dark conditions. Upon exposure to $\mathrm{HONO}$, heterogeneous reactivity of $\mathrm{TiO}_{2}$ was progressively reduced, and the steady-state uptake coefficients were at least 1 order of magnitude smaller than the corresponding initial uptake coefficients, $\gamma_{0}$ (El Zein and Bedjanian, 2012). Independent of initial HONO concentrations in the range of $(0.3-3.3) \times 10^{12}$ molecule $\mathrm{cm}^{-3}, \gamma_{0}$ showed strong dependence on RH and a slightly negative dependence on temperature. The effects of temperature $(275-320 \mathrm{~K})$ at $0.001 \% \mathrm{RH}$ and of RH at $300 \mathrm{~K}$ on $\gamma_{0}$ are given by the following equation (El Zein and Bedjanian, 2012):

$$
\begin{aligned}
& \gamma_{0}=(1.4 \pm 0.5) \times 10^{-5} \times \exp [(1405 \pm 110) / T], \\
& \gamma_{0}=1.8 \times 10^{-5} \times \mathrm{RH}^{-0.63} .
\end{aligned}
$$

HONO uptaken by $\mathrm{TiO}_{2}$ undergoes chemical conversion on the surface, and molecularly adsorbed HONO is insignificant (El Zein and Bedjanian, 2012). This was confirmed by gasphase production analysis, showing that the total yield of NO and $\mathrm{NO}_{2}$ is equal to 1 within the experimental uncertainties. The yields of $\mathrm{NO}$ and $\mathrm{NO}_{2}$ were determined to be $0.42 \pm 0.07$ and $0.60 \pm 0.09$, respectively, independent of $\mathrm{RH}$, temperature, and the initial HONO concentration (El Zein and Bedjanian, 2012).

In a following study, El Zein et al. (2013a) examined the effect of illumination on the uptake of $\mathrm{HONO}$ by $\mathrm{TiO}_{2}$ and found that under illuminated conditions HONO uptake rates also decreased with reaction time. Compared to dark conditions, HONO uptake was enhanced, though no difference in the $\gamma_{0}$ was observed by varying UV illumination from 
Table 8. Summary of previous laboratory studies on heterogeneous reactions of mineral dust with HONO.

\begin{tabular}{|c|c|c|c|c|c|}
\hline Dust & Reference & $T(\mathrm{~K})$ & $\begin{array}{r}\text { Concentration } \\
\left(\text { molecule } \mathrm{cm}^{-3}\right)\end{array}$ & Uptake coefficient & Techniques \\
\hline \multirow[t]{2}{*}{$\mathrm{TiO}_{2}$} & El Zein and Bedjanian (2012) & $275-320$ & $(0.3-3.3) \times 10^{12}$ & $\begin{array}{l}\gamma_{0} \text { was determined to be } \sim 4.2 \times 10^{-6} \text { at } \\
10 \% \mathrm{RH} \text { and } 300 \mathrm{~K} \text {, showing negative de- } \\
\text { pendence on } \mathrm{RH} \text { (up to } 12.6 \% \text { ) and } T(275- \\
320 \mathrm{~K} \text { ). }\end{array}$ & CRFT-MS \\
\hline & El Zein et al. (2013a) & $275-320$ & $(0.5-5) \times 10^{12}$ & $\begin{array}{l}\text { Under illuminated conditions, } \gamma_{0} \text { increased } \\
\text { to } \sim 3.5 \times 10^{-4} \text { at } 10 \% \mathrm{RH} \text { and } 280 \mathrm{~K} \text {, } \\
\text { showing negative dependence on } \mathrm{RH} \text { (up to } \\
60 \%) \text { and } T(275-320 \mathrm{~K}) \text {. Though illumi- } \\
\text { nation enhanced } \mathrm{HONO} \text { uptake compared } \\
\text { to dark conditions, further increases in illu- } \\
\text { mination intensity for } J\left(\mathrm{NO}_{2}\right) \text { in the range } \\
\text { of } 0.002-0.012 \mathrm{~s}^{-1} \text { did not affect } \gamma_{0} \text {. }\end{array}$ & CRFT-MS \\
\hline $\mathrm{Al}_{2} \mathrm{O}_{2}$ & Romanias et al. (2012b) & $275-320$ & $(0.6-3.5) \times 10^{12}$ & $\begin{array}{l}\text { At } 10 \% \mathrm{RH}, \gamma_{0} \text { was determined to be } \\
\sim 1.2 \times 10^{-6} \text { and } \sim 6.2 \times 10^{-6} \text { under dark } \\
\text { and illuminated conditions, respectively. } \gamma_{0} \\
\text { was found to increase linearly with } J\left(\mathrm{NO}_{2}\right) \\
\text { in the range of } 0.002-0.012 \mathrm{~s}^{-1} \text {. In addi- } \\
\text { tion, } \gamma_{0} \text { decreased with } \mathrm{RH} \text {, and no depen- } \\
\text { dence on temperature was observed. }\end{array}$ & CRFT-MS \\
\hline $\mathrm{Fe}_{2} \mathrm{O}_{3}$ & El Zein et al. (2013b) & $275-320$ & $(0.6-15.0) \times 10^{12}$ & $\begin{array}{l}\text { No significant effect of UV illumination, } \\
\text { with } J\left(\mathrm{NO}_{2}\right) \text { up to } 0.012 \mathrm{~s}^{-1} \text {, was ob- } \\
\text { served. } \gamma_{0} \text { was determined to be } \sim 4.1 \times \\
10^{-7} \text { at } 10 \% \mathrm{RH} \text { and } 300 \mathrm{~K} \text {, showing neg- } \\
\text { ative dependence on } \mathrm{RH}(\text { up to } 14.4 \%) \text { and } \\
\text { no dependence on } T(275-320 \mathrm{~K}) \text {. }\end{array}$ & CRFT-MS \\
\hline ATD & El Zein et al. (2013b) & $275-320$ & $(0.6-15.0) \times 10^{12}$ & $\begin{array}{l}\text { No significant effect of UV illumination, } \\
\text { with } J\left(\mathrm{NO}_{2}\right) \text { up to } 0.012 \mathrm{~s}^{-1} \text {, was ob- } \\
\text { served. } \gamma_{0} \text { was determined to be } \sim 9.3 \times \\
10^{-7} \text { at } 10 \% \mathrm{RH} \text { and } 275 \mathrm{~K} \text {, showing neg- } \\
\text { ative dependence on } \mathrm{RH}(\text { up to } 84.1 \%) \text { and } \\
\text { no dependence on } T(275-320 \mathrm{~K}) \text {. }\end{array}$ & CRFT-MS \\
\hline
\end{tabular}

0.002 to $0.012 \mathrm{~s}^{-1}$ (El Zein et al., 2013a). Under illuminated conditions, $\gamma_{0}$ is independent of initial HONO concentration but depends inversely on temperature and RH. The effects of temperature $(275-320 \mathrm{~K})$ at $0.002 \% \mathrm{RH}$ and of RH $(0.001-$ $60 \%)$ at $280 \mathrm{~K}$ can be described by the following equation (El Zein et al., 2013a):

$\gamma_{0}=(3.0 \pm 1.5) \times 10^{-5} \times \exp [(1390 \pm 150) / T]$,

$\gamma_{0}=6.9 \times 10^{-4} \times \mathrm{RH}^{-0.3}$.

Similar to dark conditions, all the HONO molecules removed from the gas phase have been converted $\mathrm{NO}$ and $\mathrm{NO}_{2}$. Yields of $\mathrm{NO}$ and $\mathrm{NO}_{2}$ were determined to be $0.48 \pm 0.07$ and $0.52 \pm$ 0.08, respectively (El Zein et al., 2013a), independent of RH, temperature, and initial $\mathrm{HONO}$ concentration.

The uptake of $\mathrm{HONO}$ by $\gamma-\mathrm{Al}_{2} \mathrm{O}_{3}, \mathrm{Fe}_{2} \mathrm{O}_{3}$, and ATD particles was also investigated under dark and illuminated conditions as a function of temperature and RH. Progres- sive surface deactivation was observed in all the experiments. For uptake onto $\gamma-\mathrm{Al}_{2} \mathrm{O}_{3}$, under both dark and irradiated conditions, $\gamma_{0}(\mathrm{HONO})$ was found to be independent of initial HONO concentration $\left(0.3 \times 10^{12}\right.$ to $3.3 \times$ $10^{12}$ molecule $\left.\mathrm{cm}^{-3}\right)$ and temperature $(275-320 \mathrm{~K})$, though $\mathrm{RH}$ has a profound influence. Under dark conditions, $\gamma_{0}$ is given by the following equation (Romanias et al., 2012b),

$\gamma_{0}=4.8 \times 10^{-6} \times \mathrm{RH}^{-0.61}$,

for $\mathrm{RH}$ in the range of 0.00014 to $10.5 \%$. UV illumination linearly enhances initial HONO uptake, with $\gamma_{0}$ under illumination with $J\left(\mathrm{NO}_{2}\right)$ equal to $0.012 \mathrm{~s}^{-1}$ given by the following equation (Romanias et al., 2012b),

$\gamma_{0}=1.7 \times 10^{-5} \times \mathrm{RH}^{-0.44}$,

for $\mathrm{RH}$ in the range of 0.0003 to $35.4 \%$. $\mathrm{NO}$ and $\mathrm{NO}_{2}$ yields were determined to be $0.40 \pm 0.06$ and $0.60 \pm 0.09$ for all the experimental conditions. 


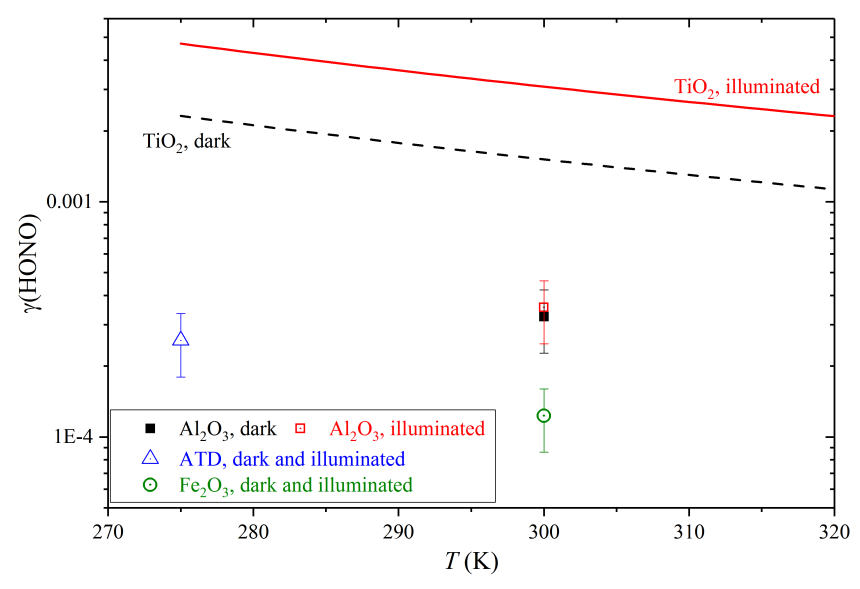

Figure 15. Temperature dependence of $\gamma_{0}(\mathrm{HONO})$ for $\mathrm{TiO}_{2}(\mathrm{El}$ Zein and Bedjanian, 2012; El Zein et al., 2013a), $\mathrm{Al}_{2} \mathrm{O}_{3}$ (Romanias et al., 2012b), ATD (El Zein et al., 2013b), and $\mathrm{Fe}_{2} \mathrm{O}_{3}$ (El Zein et al., 2013b) under dark and illuminated conditions. Data at $0.001 \% \mathrm{RH}$ were presented except for illuminated $\mathrm{TiO}_{2}$ at $0.002 \% \mathrm{RH}$. Please note that no significant temperature $(275-320 \mathrm{~K})$ effect was found for $\mathrm{Al}_{2} \mathrm{O}_{3}$, ATD, and $\mathrm{Fe}_{2} \mathrm{O}_{3}$. In addition, no difference in uptake kinetics was observed between dark and illuminated conditions for ATD and $\mathrm{Fe}_{2} \mathrm{O}_{3}$.

No significant effects of UV irradiation with $J\left(\mathrm{NO}_{2}\right)$ up to $0.012 \mathrm{~s}^{-1}$ were observed for heterogeneous reaction of $\mathrm{HONO}$ with $\mathrm{Fe}_{2} \mathrm{O}_{3}$ and ATD particles (El Zein et al., $2013 \mathrm{~b})$. Values of $\gamma_{0}(\mathrm{HONO})$ were found to be independent of the initial HONO concentration $\left(0.6 \times 10^{12}\right.$ to $15.0 \times$ $10^{12}$ molecule $\mathrm{cm}^{-3}$ ) and temperature $(275-320 \mathrm{~K})$, while RH has a significant impact, given by the following equation (El Zein et al., 2013b),

$\gamma_{0}=1.7 \times 10^{-6} \times \mathrm{RH}^{-0.62}$,

for $\mathrm{Fe}_{2} \mathrm{O}_{3}$ and $\mathrm{RH}$ in the range of 0.0003 to $14.4 \%$, and

$\gamma_{0}=3.8 \times 10^{-6} \times \mathrm{RH}^{-0.61}$

for ATD and RH in the range of 0.00039 to $84.1 \%$. NO and $\mathrm{NO}_{2}$ yields, independent of experimental conditions, were reported to be $0.40 \pm 0.06$ and $0.60 \pm 0.09$, respectively (El Zein et al., 2013b).

The dependence of $\gamma_{0}(\mathrm{HONO})$ on temperature is displayed in Fig. 15 for different mineral dust under dark and illuminated conditions. No significant effect of temperature was observed for uptake onto $\mathrm{Al}_{2} \mathrm{O}_{3}, \mathrm{Fe}_{2} \mathrm{O}_{3}$, and ATD. When temperature increases from 275 to $320 \mathrm{~K}, \gamma_{0}(\mathrm{HONO})$ is reduced by a factor of about 2 under both dark and illuminated conditions for $\mathrm{TiO}_{2}$. It is interesting to note that UV illumination has different impacts on HONO uptake for different minerals. $\mathrm{HONO}$ uptake onto $\mathrm{Al}_{2} \mathrm{O}_{3}$ is enhanced by UV radiation, and the extent of enhancement shows linear dependence on illumination intensity for $J\left(\mathrm{NO}_{2}\right)$ in the range of $0.002-0.012 \mathrm{~s}^{-1}$ (Romanias et al., 2012b). In contrast, photoenhancement was found to be insignificant for ATD and

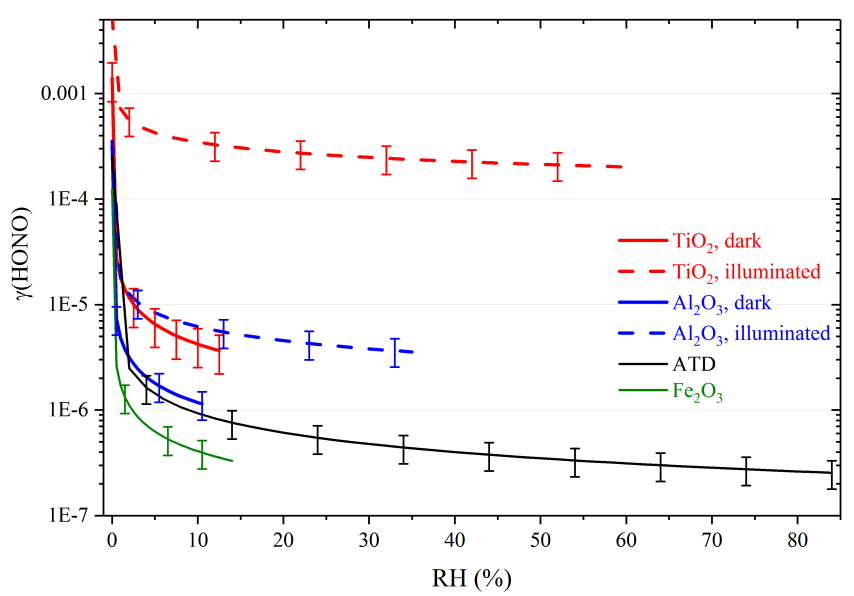

Figure 16. $\mathrm{RH}$ dependence of $\gamma_{0}$ (HONO) for $\mathrm{TiO}_{2}$ (El Zein and Bedjanian, 2012; El Zein et al., 2013a), $\mathrm{Al}_{2} \mathrm{O}_{3}$ (Romanias et al., 2012b), ATD (El Zein et al., 2013b), and $\mathrm{Fe}_{2} \mathrm{O}_{3}$ (El Zein et al., 2013b) under dark and illuminated conditions at around room temperature.

$\mathrm{Fe}_{2} \mathrm{O}_{3}$ with $J\left(\mathrm{NO}_{2}\right)$ up to $0.012 \mathrm{~s}^{-1}$ (El Zein et al., 2013b). Significant enhancement in $\gamma_{0}$ (HONO) was observed for illuminated $\mathrm{TiO}_{2}$ with $J\left(\mathrm{NO}_{2}\right)$ of $0.002 \mathrm{~s}^{-1}$ when compared to dark conditions, especially at evaluated $\mathrm{RH}$ as shown in Fig. 16; however, further increases in illumination intensity with $J\left(\mathrm{NO}_{2}\right)$ up to $0.012 \mathrm{~s}^{-1}$ did not lead to further increases in $\gamma_{0}$ (HONO) (El Zein et al., 2013a). In addition, we note that $\mathrm{NO}$ and $\mathrm{NO}_{2}$ yields were found to be $\sim 0.40$ and 0.60 for all the four types of minerals investigated, independent of experimental conditions.

Figure 16 shows the effects of $\mathrm{RH}$ on $\gamma_{0}(\mathrm{HONO})$ at around room temperature for $\mathrm{TiO}_{2}, \mathrm{Al}_{2} \mathrm{O}_{3}$, ATD, and $\mathrm{Fe}_{2} \mathrm{O}_{3}$. Most of the measurements were only carried out at low $\mathrm{RH}(<$ $15 \%$ ), and thus their atmospheric relevance is rather limited. Experiments using ATD and illuminated $\mathrm{TiO}_{2}$ particles were conducted at $\mathrm{RH}$ over a wide range, and a negative dependence of $\gamma_{0}(\mathrm{HONO})$ on RH was observed. When RH increases from 10 to $60 \%, \gamma_{0}(\mathrm{HONO})$ is reduced by $\sim 66$ and $\sim 42 \%$ for ATD and illuminated $\mathrm{TiO}_{2}$, respectively.

\subsubsection{Discussion and atmospheric implication}

All the four studies shown in Figs. 15 and 16 were carried out by the same group. Furthermore, heterogeneous interactions of HONO with authentic dust and clay minerals, which are the major components for tropospheric dust, have not been explored yet. Future studies can provide more scientific insights to reaction mechanisms and better quantify uptake kinetics.

In this work we use $\gamma_{0}(\mathrm{HONO})$ for ATD, the only authentic dust sample investigated, to preliminarily assess the significance of heterogeneous uptake by mineral dust as a HONO sink. As shown in Fig. 16, $\gamma_{0}(\mathrm{HONO})$ decreases 
from $9.3 \times 10^{-7}$ at $10 \%$ to $2.6 \times 10^{-7}$ at $80 \%$. A $\gamma($ HONO) value of $1 \times 10^{-6}$ is adopted here to calculate $\tau_{\text {het }}(\mathrm{HONO})$ with respect to heterogeneous reaction with mineral dust. This may represent an upper limit for its atmospheric significance, because (i) at typical RH found in the troposphere, $\gamma_{0}$ (HONO) should be $<1 \times 10^{-6}$ according to the work by El Zein et al. (2013b), and (ii) surface deactivation was observed, and thus the average $\gamma(\mathrm{HONO})$ should be smaller than $\gamma_{0}$ (HONO) (El Zein et al., 2013b). Using Eq. (6), $\tau_{\text {het }}(\mathrm{HONO})$ is calculated to be $\sim 57$ days for dust mass concentration of $1000 \mu \mathrm{g} \mathrm{m}^{-3}$ which can only occur during dust storms. For comparison, typical HONO lifetimes in the troposphere are estimated to be 10-20 min, with the major sink being photolysis (in Sect. 2.1). Therefore, heterogeneous uptake by mineral dust is a negligible sink for HONO in the troposphere.

\section{6 $\mathrm{N}_{2} \mathrm{O}_{5}$ and $\mathrm{NO}_{3}$ radicals}

$\mathrm{N}_{2} \mathrm{O}_{5}$ and $\mathrm{NO}_{3}$ in the troposphere are in dynamic equilibrium, as introduced in Sect. 2.1.3. Therefore, their heterogeneous reactions with mineral dust are discussed together in this section.

\subsection{1 $\quad \mathrm{N}_{2} \mathrm{O}_{5}$}

Heterogeneous reactions of $\mathrm{N}_{2} \mathrm{O}_{5}$ with mineral dust particles were investigated for the first time by Seisel et al. (2005), using DRIFTS and a Knudsen cell reactor coupled to quadruple mass spectrometry. The initial uptake coefficient of $\mathrm{N}_{2} \mathrm{O}_{5}$ on Saharan dust was determined to be $0.080 \pm 0.003$ at $298 \mathrm{~K}$ and slowly decreased to a steady-state value of $0.013 \pm 0.003$ (Seisel et al., 2005). Formation of nitrate on dust particles was observed, and $\mathrm{N}_{2} \mathrm{O}_{5}$ uptake was suggested to proceed with two mechanisms, i.e., heterogeneous hydrolysis and its reaction with surface $\mathrm{OH}$ groups (Seisel et al., 2005). A Knudsen cell reactor was also used by Karagulian et al. (2006) to investigate heterogeneous uptake of $\mathrm{N}_{2} \mathrm{O}_{5}$ by several different types of mineral dust. Both the initial and steady-state uptake coefficient were found to decrease with increasing initial $\mathrm{N}_{2} \mathrm{O}_{5}$ concentrations. When $\mathrm{N}_{2} \mathrm{O}_{5}$ concentration was $(4.0 \pm 1.0) \times 10^{11}$ molecule $\mathrm{cm}^{-3}, \gamma_{0}$ and $\gamma_{\mathrm{ss}}$ were determined to be $0.30 \pm 0.08$ and $0.20 \pm 0.05$ for Saharan dust, $0.12 \pm 0.04$ and $0.021 \pm 0.006$ for $\mathrm{CaCO}_{3}, 0.20 \pm 0.06$ and $0.11 \pm 0.03$ for ATD, $0.16 \pm 0.04$ and $0.021 \pm 0.006$ for kaolinite, and $0.43 \pm 0.13$ and $0.043 \pm 0.013$ for natural limestone, respectively. When $\mathrm{N}_{2} \mathrm{O}_{5}$ concentration increased to $(3.8 \pm 0.5) \times 10^{12}$ molecule $\mathrm{cm}^{-3}, \gamma_{0}$ and $\gamma_{\mathrm{ss}}$ were determined to be $0.090 \pm 0.026$ and $0.059 \pm 0.016$ for Saharan dust, $0.033 \pm 0.010$ and $0.0062 \pm 0.0018$ for $\mathrm{CaCO}_{3}, 0.064 \pm 0.019$ and $0.016 \pm 0.004$ for ATD, $0.14 \pm 0.04$ and $0.022 \pm 0.006$ for kaolinite, and $0.011 \pm 0.003$ and $0.0022 \pm 0.0006$ for natural limestone, respectively (Karagulian et al., 2006). Formation of $\mathrm{HNO}_{3}$ in the gas phase was detected, with production yield varying with dust mineralogy. The postulated reason is that partitioning of formed $\mathrm{HNO}_{3}$ between gas and particle phases may vary for different dust samples (Karagulian et al., 2006).

Wagner et al. (2008) utilized a Knudsen cell reactor to study heterogeneous uptake of $\mathrm{N}_{2} \mathrm{O}_{5}$ by Saharan dust, ATD, and $\mathrm{CaCO}_{3}$ particles at $296 \pm 2 \mathrm{~K}$. Interestingly, surface deactivation was only observed for $\mathrm{CaCO}_{3}$ under their experimental conditions. Therefore, $\gamma_{0}$ and $\gamma_{\mathrm{ss}}$ are equal for the other two types of dust, being $0.037 \pm 0.012$ for Saharan dust and $0.022 \pm 0.008$ for ATD, respectively (Wagner et al., 2008). The initial uptake coefficient was reported to be $0.05 \pm 0.02$ for $\mathrm{CaCO}_{3}$; preheating could reduce its heterogeneous reactivity towards $\mathrm{N}_{2} \mathrm{O}_{5}$ (Wagner et al., 2008), very likely due to the loss of surface-adsorbed water and surface $\mathrm{OH}$ groups. It should be noted that all the uptake coefficients measured by using Knudsen cell reactors are based on the projected area of dust samples (Seisel et al., 2005; Karagulian et al., 2006; Wagner et al., 2008).

Heterogeneous reactions of $\mathrm{N}_{2} \mathrm{O}_{5}$ with airborne mineral dust particles were also investigated by several previous studies, with the first one being carried out by Mogili et al. (2006b). In this study, in situ FTIR measurements were carried out to determine $\mathrm{N}_{2} \mathrm{O}_{5}$ loss due to reactions with dust particles in an environmental chamber at $290 \mathrm{~K}$. The uptake coefficients of $\mathrm{N}_{2} \mathrm{O}_{5}$, based on the BET area of dust particles, increase with $\mathrm{RH}$ for $\mathrm{SiO}_{2}$, from $(4.4 \pm 0.4) \times 10^{-5}$ at $<1 \%$ $\mathrm{RH}$ to $(9.3 \pm 0.1) \times 10^{-5}$ at $11 \% \mathrm{RH},(1.2 \pm 0.2) \times 10^{-4}$ at $19 \% \mathrm{RH}$, and $(1.8 \pm 0.4) \times 10^{-4}$ at $43 \% \mathrm{RH}$ (Mogili et al., 2006b). In addition, $\gamma\left(\mathrm{N}_{2} \mathrm{O}_{5}\right)$ at $<1 \% \mathrm{RH}$ was determined to be for $(1.9 \pm 0.2) \times 10^{-4}$ for $\mathrm{CaCO}_{3},(9.8 \pm 0.1) \times 10^{-4}$ for kaolinite, $(4.0 \pm 0.4) \times 10^{-4}$ for $\alpha-\mathrm{Fe}_{2} \mathrm{O}_{3}$, and $(1.9 \pm 0.2) \times$ $10^{-4}$ for montmorillonite (Mogili et al., 2006b).

An atmospheric pressure aerosol flow tube was deployed by Wagner et al. $(2008,2009)$ to investigate heterogeneous reactions of $\mathrm{N}_{2} \mathrm{O}_{5}$ with Saharan dust, ATD, calcite, and $\mathrm{SiO}_{2}$ aerosol particles at $296 \pm 2 \mathrm{~K}$, and $\mathrm{N}_{2} \mathrm{O}_{5}$ decays in the flow tube were detected by using a modified chemiluminescence method. Slightly negative dependence of $\gamma\left(\mathrm{N}_{2} \mathrm{O}_{5}\right)$ on RH was observed for Saharan dust, ATD, and $\mathrm{SiO}_{2}$ aerosol particles. The value of $\gamma\left(\mathrm{N}_{2} \mathrm{O}_{5}\right)$ was determined to be $0.026 \pm 0.004$ at $0 \% \mathrm{RH}, 0.016 \pm 0.004$ at $29 \% \mathrm{RH}$, and $0.010 \pm 0.004$ at $58 \%$ RH for Saharan dust (Wagner et al., 2008); $0.0086 \pm 0.0006$ at $0 \% \mathrm{RH}$ and $0.0045 \pm 0.0005$ at $29 \%$ for $\mathrm{SiO}_{2}$ (Wagner et al., 2009); and $0.0098 \pm 0.0010$ at $0 \% \mathrm{RH}$ and $0.0073 \pm 0.0007$ at $29 \% \mathrm{RH}$ for ATD (Wagner et al., 2009), respectively. In contrast, $\gamma\left(\mathrm{N}_{2} \mathrm{O}_{5}\right)$ increases with $\mathrm{RH}$ for $\mathrm{CaCO}_{3}$, from $0.0048 \pm 0.0007$ at $0 \% \mathrm{RH}$ to $0.0194 \pm 0.0022$ at $71 \% \mathrm{RH}$ (Wagner et al., 2009). It should be pointed out that in the original paper (Wagner et al., 2008) the uptake coefficients for Saharan dust were based on the aerosol surface area concentrations after the shape factor correction was applied. In order to keep consistency with other studies, $\gamma\left(\mathrm{N}_{2} \mathrm{O}_{5}\right)$ reported by Wagner et al. (2008) has been recalculated in this review without taking into account the shape factor of Saharan dust. 
Table 9. Summary of previous laboratory studies on heterogeneous reactions of mineral dust with $\mathrm{N}_{2} \mathrm{O}_{5}$.

\begin{tabular}{|c|c|c|c|c|c|}
\hline Dust & Reference & $T(\mathrm{~K})$ & $\begin{array}{l}\text { Concentration } \\
\left(\text { molecule } \mathrm{cm}^{-3}\right)\end{array}$ & Uptake coefficient & Techniques \\
\hline \multirow[t]{4}{*}{ Saharan dust } & Seisel et al. (2005) & 298 & $(0.03-5) \times 10^{12}$ & $\gamma_{0}: 0.080 \pm 0.003$ and $\gamma_{\mathrm{ss}}: 0.013 \pm 0.003$ & KC, DRIFTS \\
\hline & Karagulian et al. (2006) & $298 \pm 2$ & $(0.4-3.8) \times 10^{12}$ & $\begin{array}{l}\text { When }\left[\mathrm{N}_{2} \mathrm{O}_{5}\right] \text { was }(4.0 \pm 1.0) \times 10^{11} \text { molecule } \mathrm{cm}^{-3}, \gamma_{0}= \\
0.30 \pm 0.08 \text { and } \gamma_{\mathrm{ss}}=0.20 \pm 0.05 ; \text { when }\left[\mathrm{N}_{2} \mathrm{O}_{5}\right] \text { was }(3.8 \pm \\
0.5) \times 10^{12} \text { molecule } \mathrm{cm}^{-3}, \gamma_{0}=0.090 \pm 0.026 \text { and } \gamma_{\mathrm{ss}}= \\
0.059 \pm 0.016\end{array}$ & $\mathrm{KC}$ \\
\hline & Wagner et al. (2008) & $296 \pm 2$ & $\begin{array}{l}\text { KC: }(3.0-11.0) \times 10^{9} \\
\text { AFT: }(5-20) \times 10^{12}\end{array}$ & $\begin{array}{l}\text { KC measurements: } \gamma_{0}=\gamma_{\mathrm{ss}}=0.037 \pm 0.012 \text {; AFT mea- } \\
\text { surements: } 0.026 \pm 0.004 \text { at } 0 \% \mathrm{RH}, 0.016 \pm 0.004 \text { at } 29 \% \\
\mathrm{RH} \text {, and } 0.010 \pm 0.004 \text { at } 58 \% \mathrm{RH} \text {. }\end{array}$ & KC-MS, AFT-CLD \\
\hline & Tang et al. (2012) & $297 \pm 1$ & $(0.5-30) \times 10^{12}$ & $0.02 \pm 0.01$, independent of RH $(0-67 \%)$ & AFT-CRDS \\
\hline \multirow[t]{4}{*}{ ATD } & Karagulian et al. (2006) & $298 \pm 2$ & $(0.4-3.8) \times 10^{12}$ & $\begin{array}{l}\text { When }\left[\mathrm{N}_{2} \mathrm{O}_{5}\right] \text { was }(4.0 \pm 1.0) \times 10^{11} \text { molecule } \mathrm{cm}^{-3}, \gamma_{0}= \\
0.20 \pm 0.06 \text { and } \gamma_{\mathrm{ss}}=0.11 \pm 0.03 \text {; when }\left[\mathrm{N}_{2} \mathrm{O}_{5}\right] \text { was }(3.8 \pm \\
0.5) \times 10^{12} \text { molecule } \mathrm{cm}^{-3}, \gamma_{0}=0.064 \pm 0.019 \text { and } \gamma_{\mathrm{ss}}= \\
0.016 \pm 0.004\end{array}$ & $\mathrm{KC}$ \\
\hline & Wagner et al. (2008) & $296 \pm 2$ & $(3.3-10.4) \times 10^{9}$ & $\gamma_{0}=\gamma_{\mathrm{ss}}=0.022 \pm 0.008$ & KC-MS \\
\hline & Wagner et al. (2009) & $296 \pm 2$ & $(10-44) \times 10^{12}$ & $\begin{array}{l}0.0098 \pm 0.0010 \text { at } 0 \% \mathrm{RH} \text { and } 0.0073 \pm 0.0007 \text { at } 29 \% \\
\text { RH. }\end{array}$ & AFT-CLD \\
\hline & Tang et al. (2014c) & $297 \pm 1$ & $(11-22) \times 10^{12}$ & $\begin{array}{l}(7.7 \pm 1.0) \times 10^{-3} \text { at } 0 \% \mathrm{RH},(6.0 \pm 2.0) \times 10^{-3} \text { at } 17 \% \\
\mathrm{RH},(7.4 \pm 0.7) \times 10^{-3} \text { at } 33 \% \mathrm{RH},(4.9 \pm 1.3) \times 10^{-3} \text { at } \\
50 \% \mathrm{RH} \text {, and }(5.0 \pm 0.3) \times 10^{3} \text { at } 67 \% \mathrm{RH} .\end{array}$ & AFT-CRDS \\
\hline \multirow[t]{4}{*}{$\mathrm{CaCO}_{3}$} & Karagulian et al. (2006) & $298 \pm 2$ & $(0.4-3.8) \times 10^{12}$ & $\begin{array}{l}\text { When }\left[\mathrm{N}_{2} \mathrm{O}_{5}\right] \text { was }(4.0 \pm 1.0) \times 10^{11} \text { molecule } \mathrm{cm}^{-3}, \gamma_{0}= \\
0.12 \pm 0.04 \text { and } \gamma_{\mathrm{ss}}=0.021 \pm 0.006 ; \text { when }\left[\mathrm{N}_{2} \mathrm{O}_{5}\right] \text { was } \\
(3.8 \pm 0.5) \times 10^{12} \text { molecule } \mathrm{cm}^{-3}, \gamma_{0}=0.033 \pm 0.010 \text { and } \\
\gamma_{\mathrm{ss}}=0.0062 \pm 0.0018\end{array}$ & $\mathrm{KC}$ \\
\hline & Mogili et al. (2006b) & 290 & $(2-3) \times 10^{15}$ & $(1.9 \pm 0.2) \times 10^{-4}$ at $<1 \% \mathrm{RH}$ & $\mathrm{EC}$ \\
\hline & Wagner et al. (2008) & $296 \pm 2$ & $(1.7-4.5) \times 10^{9}$ & $\gamma_{0}=0.05 \pm 0.02$ & KC-MS \\
\hline & Wagner et al. (2009) & $296 \pm 2$ & $(1-40) \times 10^{12}$ & $\begin{array}{l}0.0048 \pm 0.0007 \text { at } 0 \% \mathrm{RH}, 0.0053 \pm 0.0010 \text { at } 29 \% \mathrm{RH} \text {, } \\
0.0113 \pm 0.0016 \text { at } 58 \% \mathrm{RH} \text {, and } 0.0194 \pm 0.0022 \text { at } 71 \% \\
\mathrm{RH} .\end{array}$ & AFT-CLD \\
\hline \multirow[t]{3}{*}{$\mathrm{SiO}_{2}$} & Mogili et al. (2006b) & 290 & $(2-3) \times 10^{15}$ & $\begin{array}{l}(4.4 \pm 0.4) \times 10^{-5} \text { at }<1 \% \mathrm{RH},(9.3 \pm 0.1) \times 10^{-5} \text { at } 11 \% \\
\mathrm{RH},(1.2 \pm 0.2) \times 10^{-4} \text { at } 19 \% \mathrm{RH}, \text { and }(1.8 \pm 0.4) \times 10^{-4} \\
\text { at } 43 \% \mathrm{RH} .\end{array}$ & $\mathrm{EC}$ \\
\hline & Wagner et al. (2009) & $296 \pm 2$ & $(0.5-30) \times 10^{12}$ & $0.0086 \pm 0.0006$ at $0 \% \mathrm{RH}$ and $0.0045 \pm 0.0005$ at $29 \%$ & AFT-CLD \\
\hline & Tang et al. (2014a) & $296 \pm 2$ & $(10-50) \times 10^{12}$ & $\begin{array}{l}(7.2 \pm 0.6) \times 10^{-3} \text { at }(7 \pm 2) \% \mathrm{RH},(5.6 \pm 0.6) \times 10^{-3} \text { at } \\
(26 \pm 2) \% \mathrm{RH} \text {, and }(5.3 \pm 0.8) \times 10^{-3} \text { at }(40 \pm 3) \% \mathrm{RH}\end{array}$ & AFT-CLD \\
\hline \multirow[t]{2}{*}{ Kaolinite } & Karagulian et al. (2006) & $298 \pm 2$ & $(0.4-3.8) \times 10^{12}$ & $\begin{array}{l}\text { When }\left[\mathrm{N}_{2} \mathrm{O}_{5}\right] \text { was }(4.0 \pm 1.0) \times 10^{11} \text { molecule } \mathrm{cm}^{-3}, \gamma_{0}= \\
0.16 \pm 0.04 \text { and } \gamma_{\mathrm{ss}}=0.021 \pm 0.006 \text {; when }\left[\mathrm{N}_{2} \mathrm{O}_{5}\right] \text { was } \\
(3.8 \pm 0.5) \times 10^{12} \text { molecule } \mathrm{cm}^{-3}, \quad \gamma_{0}=0.14 \pm 0.04 \text { and } \\
\gamma_{\mathrm{ss}}=0.022 \pm 0.006 \text {. }\end{array}$ & $\mathrm{KC}$ \\
\hline & Mogili et al. (2006b) & 290 & $(2-3) \times 10^{15}$ & $(9.8 \pm 0.1) \times 10^{-4}$ at $<1 \% \mathrm{RH}$ & $\mathrm{EC}$ \\
\hline Natural limestone & Karagulian et al. (2006) & $298 \pm 2$ & $(0.4-3.8) \times 10^{12}$ & $\begin{array}{l}\text { When }\left[\mathrm{N}_{2} \mathrm{O}_{5}\right] \text { was }(4.0 \pm 1.0) \times 10^{11} \text { molecule } \mathrm{cm}^{-3}, \gamma_{0}= \\
0.43 \pm 0.13 \text { and } \gamma_{\mathrm{ss}}=0.043 \pm 0.013 \text {; when }\left[\mathrm{N}_{2} \mathrm{O}_{5}\right] \text { was } \\
(3.8 \pm 0.5) \times 10^{12} \text { molecule } \mathrm{cm}^{-3}, \gamma_{0}=0.011 \pm 0.003 \text { and } \\
\gamma_{\mathrm{ss}}=0.0022 \pm 0.0006\end{array}$ & $\mathrm{KC}$ \\
\hline Montmorillonite & Mogili et al. (2006b) & 290 & $(2-3) \times 10^{15}$ & $(1.8 \pm 0.2) \times 10^{-4}$ at $<1 \% \mathrm{RH}$ & EC \\
\hline Illite & Tang et al. (2014c) & $297 \pm 1$ & $(8-24) \times 10^{12}$ & $\begin{array}{l}0.091 \pm 0.039 \text { at } 0 \% \mathrm{RH} \text { and } 0.093 \pm 0.008 \text { at } 17 \% \mathrm{RH} \\
0.072 \pm 0.021 \text { at } 33 \% \mathrm{RH}, 0.049 \pm 0.006 \text { at } 50 \% \mathrm{RH} \text {, and } \\
0.039 \pm 0.012 \text { at } 67 \% \mathrm{RH} \text {. }\end{array}$ & AFT-CRDS \\
\hline $\mathrm{TiO}_{2}$ & Tang et al. (2014d) & $296 \pm 2$ & $(10-50) \times 10^{12}$ & $\begin{array}{l}(1.83 \pm 0.32) \times 10^{-3} \text { at }(5 \pm 1) \% \mathrm{RH},(2.01 \pm 0.27) \times 10^{-3} \\
\text { at }(12 \pm 2) \% \mathrm{RH},(1.02 \pm 0.20) \times 10^{-3} \text { at }(23 \pm 2) \% \mathrm{RH} \text {, } \\
(1.29 \pm 0.26) \times 10^{-3} \text { at }(33 \pm 2) \% \mathrm{RH},(2.28 \pm 0.51) \times 10^{-3} \\
\text { at }(45 \pm 3) \% \mathrm{RH} \text {, and }(4.47 \pm 2.04) \times 10^{-3} \text { at }(30 \pm 3) \% \\
\mathrm{RH} \text {. }\end{array}$ & AFT-CLD \\
\hline $\mathrm{Fe}_{2} \mathrm{O}_{3}$ & Mogili et al. (2006b) & 290 & $(2-3) \times 10^{15}$ & $(4.0 \pm 0.4) \times 10^{-4}$ at $<1 \% \mathrm{RH}$ & EC \\
\hline
\end{tabular}

Tang and coworkers systematically investigated the dependence of $\gamma\left(\mathrm{N}_{2} \mathrm{O}_{5}\right)$ on $\mathrm{RH}$ and dust mineralogy, using aerosol flow tubes with $\mathrm{N}_{2} \mathrm{O}_{5}$ measured by a modified chemiluminescence method (Tang et al., 2012, 2014c) or cavity ring-down spectroscopy (Tang et al., 2014a, d). Within experimental uncertainties, $\gamma\left(\mathrm{N}_{2} \mathrm{O}_{5}\right)$ was determined to be $0.02 \pm 0.01$ for Saharan dust (Tang et al., 2012), independent of $\mathrm{RH}(0-67 \%)$ and initial $\mathrm{N}_{2} \mathrm{O}_{5}$ concentration $(5 \times$ $10^{11}$ to $3 \times 10^{13}$ molecule $\mathrm{cm}^{-3}$ ). Product analysis suggests that $\mathrm{N}_{2} \mathrm{O}_{5}$ is converted to particulate nitrate after heteroge- 


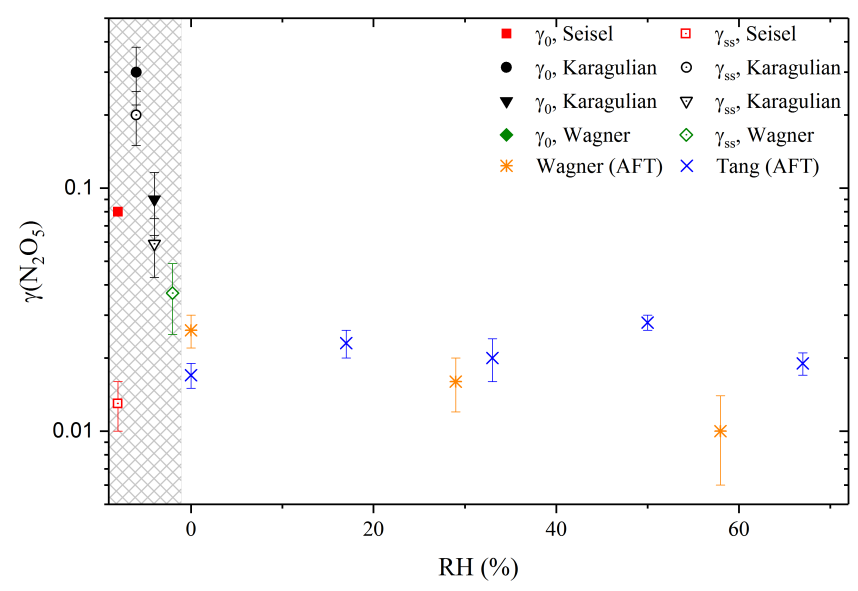

Figure 17. Uptake coefficients of $\mathrm{N}_{2} \mathrm{O}_{5}$ for Saharan dust, as reported by previous studies. Knudsen cell studies were all carried out under vacuum conditions (i.e., $0 \% \mathrm{RH}$ ), and for better readability these results are plotted in the region of $\mathrm{RH}<0 \%$ (shadowed region). Karagulian et al. (2006) reported $\gamma_{0}$ and $\gamma_{\mathrm{ss}}$ at two different $\mathrm{N}_{2} \mathrm{O}_{5}$ concentrations (circles: $\sim 4 \times 10^{11}$ molecule $\mathrm{cm}^{-3}$; triangles: $\sim 4 \times 10^{12}$ molecule $\left.\mathrm{cm}^{-3}\right) ; \gamma_{0}$ and $\gamma_{\mathrm{ss}}$ reported by Wagner et al. (2008) using a Knudsen cell reactor are equal and thus overlapped with each other in Fig. 17.

neous reaction with Saharan dust, and that the formation of $\mathrm{NO}_{2}$ in the gas phase is negligible (Tang et al., 2012). It has also been shown that if pretreated with high levels of gaseous $\mathrm{HNO}_{3}$, heterogeneous reactivity of Saharan dust towards $\mathrm{N}_{2} \mathrm{O}_{5}$ would be substantially reduced (Tang et al., 2012). A strong negative effect of $\mathrm{RH}$ on $\gamma\left(\mathrm{N}_{2} \mathrm{O}_{5}\right)$ was found for uptake onto illite, with $\gamma\left(\mathrm{N}_{2} \mathrm{O}_{5}\right)$ decreasing from $0.091 \pm 0.039$ at $0 \% \mathrm{RH}$ to $0.039 \pm 0.012$ at $67 \% \mathrm{RH}$. The negative effect of RH is much smaller for ATD, with $\gamma\left(\mathrm{N}_{2} \mathrm{O}_{5}\right)$ determined to be $0.0077 \pm 0.0010$ at $0 \% \mathrm{RH}$ and $0.0050 \pm 0.0003$ at $67 \% \mathrm{RH}$ (Tang et al., 2014c). The value of $\gamma\left(\mathrm{N}_{2} \mathrm{O}_{5}\right)$ on $\mathrm{SiO}_{2}$ particles decreases from $0.0072 \pm 0.0006$ at $(7 \pm 2) \% \mathrm{RH}$ to $0.0053 \pm 0.0008$ at $(40 \pm 2) \% \mathrm{RH}$ (Tang et al., 2014a), also showing a weak negative RH dependence. $\mathrm{RH}$ exhibits complex effects on heterogeneous reaction of $\mathrm{N}_{2} \mathrm{O}_{5}$ with $\mathrm{TiO}_{2}$ particles, and the reported $\gamma\left(\mathrm{N}_{2} \mathrm{O}_{5}\right)$ first decreases with RH from $(1.83 \pm 0.32) \times 10^{-3}$ at $(5 \pm 1) \%$ $\mathrm{RH}$ to $(1.02 \pm 0.20) \times 10^{-3}$ at $(23 \pm 2) \% \mathrm{RH}$, and then increases with RH to $(4.47 \pm 2.04) \times 10^{-3}$ at $(60 \pm 3) \% \mathrm{RH}$ (Tang et al., 2014e). Analysis of optically levitated singlemicrometer-sized $\mathrm{SiO}_{2}$ particles using Raman spectroscopy during their reaction with $\mathrm{N}_{2} \mathrm{O}_{5}$ (Tang et al., 2014a) suggests that $\mathrm{HNO}_{3}$ formed in this reaction can partition between gas and particle phases, with partitioning largely governed by $\mathrm{RH}$.

Figure 17 summarizes $\gamma\left(\mathrm{N}_{2} \mathrm{O}_{5}\right)$ onto Saharan dust reported by previous work. Values of $\gamma\left(\mathrm{N}_{2} \mathrm{O}_{5}\right)$ reported by the three studies using Knudsen cell reactors (Seisel et al., 2005; Karagulian et al., 2006; Wagner et al., 2008) show large variation, with $\gamma_{\mathrm{ss}}\left(\mathrm{N}_{2} \mathrm{O}_{5}\right)$ ranging from $0.013 \pm 0.003$ to $0.20 \pm 0.05$. This comparison demonstrates that sample preparation methods could heavily influence reported uptake coefficients using particles supported on a substrate, even though they all used Knudsen cell reactors (as discussed in Sect. 2.2.1). In addition, significant surface saturation was observed by Seisel et al. (2005) and Karagulian et al. (2006), but not by Wagner et al. (2008). For the same reason, $\gamma\left(\mathrm{N}_{2} \mathrm{O}_{5}\right)$ reported by two Knudsen studies (Karagulian et al., 2006; Wagner et al., 2008) exhibit significant discrepancies for Arizona test dust (and reasonably good agreement is found for $\mathrm{CaCO}_{3}$ ). Instead, the two aerosol flow tube studies (Wagner et al., 2008; Tang et al., 2012) show good agreement in $\gamma\left(\mathrm{N}_{2} \mathrm{O}_{5}\right)$ onto Saharan dust considering experimental uncertainties, though RH was found to have a slightly negative effect by Wagner et al. (2008) while no significant effect of RH was observed by Tang et al. (2012). Since cavity ring-down spectroscopy used by Tang et al. (2012) to detect $\mathrm{N}_{2} \mathrm{O}_{5}$ is more sensitive and selective than the chemiluminescence method used by Wagner et al. (2008), in this work we choose to use the uptake coefficient $(0.02 \pm 0.01)$ reported by Tang et al. (2012), as recommended by the IUPAC task group, to assess $\tau_{\text {het }}\left(\mathrm{N}_{2} \mathrm{O}_{5}\right)$ in the troposphere.

It is somehow unexpected that $\gamma\left(\mathrm{N}_{2} \mathrm{O}_{5}\right)$ onto $\mathrm{SiO}_{2}$ reported by the first two studies (Mogili et al., 2006b; Wagner et al., 2009), both using aerosol samples, differ by about 2 orders of magnitude. A third study (Tang et al., 2014a), using an aerosol flow tube, concluded that this discrepancy is largely due to the fact that $\mathrm{SiO}_{2}$ particles are likely to be porous. Mogili et al. (2006b) and Wagner et al. (2009) used BET surface area and the Stokes diameter to calculate the aerosol surface area, respectively. If BET surface area is used, values of $\gamma\left(\mathrm{N}_{2} \mathrm{O}_{5}\right)$ reported by Tang et al. (2014a) show good agreement with those determined by Mogili et al. (2006b); if mobility diameters are used to derive aerosol surface area, they agree well with those reported by Wagner et al. (2009). Nevertheless, some discrepancies still remain: Wagner et al. (2009) and Tang et al. (2014a) suggested a small negative dependence of $\gamma\left(\mathrm{N}_{2} \mathrm{O}_{5}\right)$ on $\mathrm{RH}$, and Mogili et al. (2006b) found that $\gamma\left(\mathrm{N}_{2} \mathrm{O}_{5}\right)$ significantly increases with RH. In addition, $\gamma\left(\mathrm{N}_{2} \mathrm{O}_{5}\right)$ onto $\mathrm{CaCO}_{3}$ aerosol particles at $<1 \% \mathrm{RH}$, as reported by Mogili et al. (2006b) and Wagner et al. (2009), differs by a factor of $>20$. It is not yet clear if the difference in calculating surface area (BET surface area vs. Stokes-diameter-based surface area) could explain such a large difference, and further work is required to resolve this issue.

Aerosol flow tubes have been deployed to investigate heterogeneous interactions between $\mathrm{N}_{2} \mathrm{O}_{5}$ and different types of mineral dust, with reported $\gamma\left(\mathrm{N}_{2} \mathrm{O}_{5}\right)$ summarized in Fig. 18. Two distinctive features can be identified. First, different minerals exhibit very different heterogeneous reactivity towards $\mathrm{N}_{2} \mathrm{O}_{5}$. Values of $\gamma\left(\mathrm{N}_{2} \mathrm{O}_{5}\right)$ at $<10 \% \mathrm{RH}$ increase from $(1.83 \pm 0.32) \times 10^{-3}$ for $\mathrm{TiO}_{2}$ to $0.091 \pm 0.039$ for illite, spanning over almost 2 orders of magnitude. Second, RH (and thus surface-adsorbed water) plays important and 


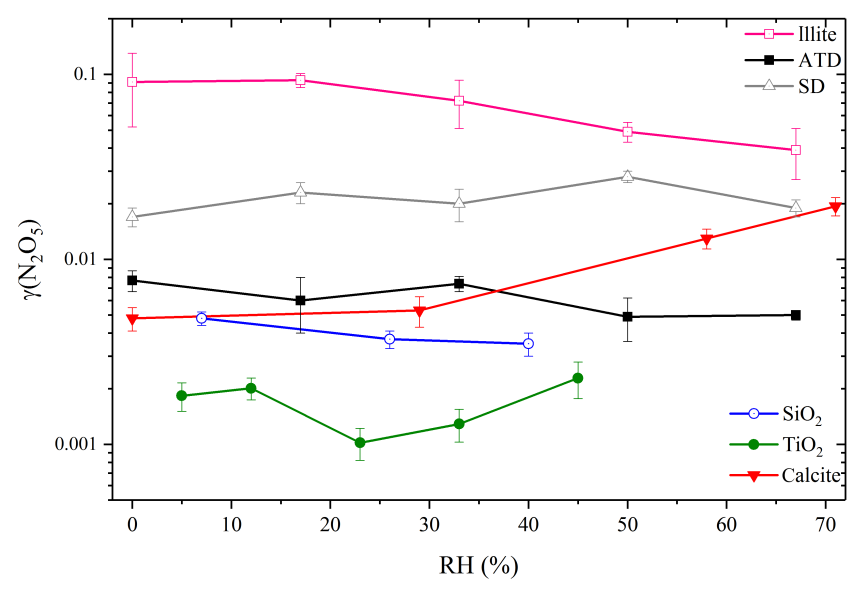

Figure 18. Uptake coefficients of $\mathrm{N}_{2} \mathrm{O}_{5}$ for Saharan dust (Tang et al., 2012), ATD (Tang et al., 2014c), illite (Tang et al., 2014c), $\mathrm{CaCO}_{3}$ (Wagner et al., 2009), $\mathrm{SiO}_{2}$ (Tang et al., 2014a), and $\mathrm{TiO}_{2}$ (Tang et al., 2014d), as reported by aerosol flow tube studies.

various roles in uptake kinetics. For example, increasing RH significantly suppresses $\mathrm{N}_{2} \mathrm{O}_{5}$ uptake onto illite but largely enhances its uptake onto $\mathrm{CaCO}_{3}$, while it does not show a significant effect for Saharan dust. In this paper $\gamma\left(\mathrm{N}_{2} \mathrm{O}_{5}\right)$ onto Saharan dust is used to assess the significance of heterogeneous reactions of $\mathrm{N}_{2} \mathrm{O}_{5}$ with mineral dust. Mineralogy of Asian dust is different from Saharan dust, and thus their heterogeneous reactivity (and probably the effect of $\mathrm{RH}$ ) towards $\mathrm{N}_{2} \mathrm{O}_{5}$ can be different. Considering that Asian dust is transported over eastern Asia with high levels of $\mathrm{NO}_{x}$ and $\mathrm{O}_{3}$ (Zhang et al., 2007; Geng et al., 2008; Shao et al., 2009; Ding et al., 2013; Itahashi et al., 2014) and thus also $\mathrm{N}_{2} \mathrm{O}_{5}$ (Brown et al., 2016; Tham et al., 2016; Wang et al., 2016), heterogeneous reactions of $\mathrm{N}_{2} \mathrm{O}_{5}$ with Asian dust deserve further investigation.

Using $\gamma\left(\mathrm{N}_{2} \mathrm{O}_{5}\right)$ of $0.02, \tau_{\text {het }}\left(\mathrm{N}_{2} \mathrm{O}_{5}\right)$ are estimated to be $\sim 10, \sim 1 \mathrm{~h}$, and $\sim 6 \mathrm{~min}$ for dust loading of 10, 100, and $1000 \mu \mathrm{mm}^{-3}$, respectively. $\mathrm{N}_{2} \mathrm{O}_{5}$ lifetimes in the troposphere is typically in the range of several minutes to several hours, as shown in Table 1. Therefore, heterogeneous uptake by mineral dust could contribute significantly to and in some regions even dominate tropospheric $\mathrm{N}_{2} \mathrm{O}_{5}$ removal. Since uptake of $\mathrm{N}_{2} \mathrm{O}_{5}$ leads to the formation of nitrate, it can also substantially modify chemical composition and physicochemical properties of mineral dust.

A global modeling study (Dentener and Crutzen, 1993) suggested that including heterogeneous reactions of $\mathrm{N}_{2} \mathrm{O}_{5}$ with tropospheric aerosol particles with $\gamma\left(\mathrm{N}_{2} \mathrm{O}_{5}\right)$ equal to 0.1 could reduce modeled yearly average global $\mathrm{NO}_{x}$ burden by $50 \%$. It is found by other global and regional modeling studies (Evans and Jacob, 2005; Chang et al., 2016) that modeled $\mathrm{NO}_{x}$ and $\mathrm{O}_{3}$ concentrations agree better with observations if $\gamma\left(\mathrm{N}_{2} \mathrm{O}_{5}\right)$ parameterization based on new laboratory results is adopted. In the study by Evans and Jacob
(2005), $\gamma\left(\mathrm{N}_{2} \mathrm{O}_{5}\right)$ was set to be 0.01 for mineral dust, independent of RH. A recent modeling study (Macintyre and Evans, 2010) suggests that simulated $\mathrm{NO}_{x}, \mathrm{O}_{3}$, and $\mathrm{OH}$ concentrations are very sensitive to the choice of $\gamma\left(\mathrm{N}_{2} \mathrm{O}_{5}\right)$ in the range of 0.001-0.02, which significantly overlaps with the range of laboratory measured $\gamma\left(\mathrm{N}_{2} \mathrm{O}_{5}\right)$ for mineral dust particles. Therefore, in order to better assess the impacts of heterogeneous reactions of $\mathrm{N}_{2} \mathrm{O}_{5}$ with mineral dust on tropospheric oxidation capacity, $\gamma\left(\mathrm{N}_{2} \mathrm{O}_{5}\right)$ and its dependence on mineralogy and RH should be better understood.

Mineralogy and composition of mineral dust aerosol particles in the ambient air are always more complex than those for dust samples used in laboratory studies. Measurements of $\mathrm{NO}_{3}, \mathrm{~N}_{2} \mathrm{O}_{5}$, and other trace gases and aerosols in the troposphere enable steady-state $\mathrm{NO}_{3}$ and $\mathrm{N}_{2} \mathrm{O}_{5}$ lifetimes to be determined and $\gamma\left(\mathrm{N}_{2} \mathrm{O}_{5}\right)$ onto ambient aerosol particles to be derived (Brown et al., 2006, 2009; Morgan et al., 2015; Phillips et al., 2016). It will be very beneficial to investigate $\mathrm{N}_{2} \mathrm{O}_{5}$ uptake (and other reactive trace gases as well) by ambient mineral dust aerosol. Recently such experimental apparatus, based on the aerosol flow tube technique, has been developed and deployed to directly measure $\gamma\left(\mathrm{N}_{2} \mathrm{O}_{5}\right)$ onto ambient aerosol particles (Bertram et al., 2009a, b). To our knowledge these measurements have never been carried out in dust-impacted regions yet, though they will undoubtedly improve our understanding of heterogeneous reactions of $\mathrm{N}_{2} \mathrm{O}_{5}$ with mineral dust in the troposphere.

\subsection{2 $\mathrm{NO}_{3}$ radicals}

To our knowledge only two previous studies have explored the heterogeneous uptake of $\mathrm{NO}_{3}$ radicals by mineral dust particles. Heterogeneous reactions of $\mathrm{NO}_{3}$ radicals with mineral dust were investigated for the first time at $298 \pm 2 \mathrm{~K}$, using a Knudsen cell reactor (Karagulian and Rossi, 2005). Products observed in the gas phase include $\mathrm{N}_{2} \mathrm{O}_{5}$ (formed in the Eley-Rideal reaction of $\mathrm{NO}_{3}$ with $\mathrm{NO}_{2}$ on the dust surface) and $\mathrm{HNO}_{3}$ (formed in the heterogeneous reaction of $\mathrm{N}_{2} \mathrm{O}_{5}$ and subsequently released into the gas phase) (Karagulian and Rossi, 2005). Surface deactivation occurred for all types of dust particles investigated. Dependence of uptake kinetics on the initial $\mathrm{NO}_{3}$ concentration was observed (Karagulian and Rossi, 2005). When $\left[\mathrm{NO}_{3}\right]_{0}$ was $(7.0 \pm$ $1.0) \times 10^{11} \mathrm{~cm}^{-3}$, the initial and steady-state uptake coefficients $\left(\gamma_{0}\right.$ and $\left.\gamma_{\mathrm{ss}}\right)$ were determined to be $0.13 \pm 0.10$ and $0.067 \pm 0.040$ for $\mathrm{CaCO}_{3}, 0.12 \pm 0.08$ and $0.034 \pm 0.016$ for natural limestone, $0.11 \pm 0.08$ and $0.14 \pm 0.02$ for kaolinite, $0.23 \pm 0.20$ and $0.12 \pm 0.08$ for Saharan dust, and $0.2 \pm 0.1$ and $0.10 \pm 0.06$ for ATD, respectively. When $\left[\mathrm{NO}_{3}\right]_{0}$ was $(4.0 \pm 1.0) \times 10^{12} \mathrm{~cm}^{-3}, \gamma_{0}$ and $\gamma_{\mathrm{ss}}$ were determined to be $0.14 \pm 0.05$ and $0.014 \pm 0.004$ for $\mathrm{CaCO}_{3}, 0.20 \pm 0.07$ and $0.022 \pm 0.005$ for natural limestone, $0.12 \pm 0.04$ and $0.050 \pm$ 0.014 for kaolinite, $0.16 \pm 0.05$ and $0.065 \pm 0.012$ for Saharan dust, and $0.14 \pm 0.04$ and $0.025 \pm 0.007$ for ATD, respectively. 
Table 10. Summary of previous laboratory studies on heterogeneous reactions of mineral dust with $\mathrm{NO}_{3}$ radicals.

\begin{tabular}{|c|c|c|c|c|c|}
\hline Dust & Reference & $T(\mathrm{~K})$ & $\begin{array}{r}\text { Concentration } \\
\left(\text { molecule } \mathrm{cm}^{-3}\right)\end{array}$ & Uptake coefficient & Techniques \\
\hline \multirow[t]{2}{*}{ Saharan dust } & Karagulian and Rossi (2005) & $298 \pm 2$ & $(0.7-4.0) \times 10^{10}$ & $\begin{array}{l}\gamma_{0}=0.23 \pm 0.20 \text { and } \gamma_{\mathrm{ss}}=0.12 \pm 0.08 \\
\text { when }\left[\mathrm{NO}_{3}\right]_{0}=(7.0 \pm 1.0) \times 10^{11} \mathrm{~cm}^{-3} \\
\gamma_{0}=0.16 \pm 0.05 \text { and } \gamma_{\mathrm{ss}}=0.065 \pm 0.012 \\
\text { when }\left[\mathrm{NO}_{3}\right]_{0}=(4.0 \pm 1.0) \times 10^{12} \mathrm{~cm}^{-3}\end{array}$ & $\mathrm{KC}$ \\
\hline & Tang et al. (2010) & $296 \pm 2$ & $(0.4-1.6) \times 10^{10}$ & $\begin{array}{l}\gamma\left(\mathrm{NO}_{3}\right) / \gamma\left(\mathrm{N}_{2} \mathrm{O}_{5}\right) \text { was reported to be } 0.9 \pm \\
0.4, \text { independent of } \mathrm{RH} \text { (up to } 70 \%) .\end{array}$ & CRDS \\
\hline $\mathrm{CaCO}_{3}$ & Karagulian and Rossi (2005) & $298 \pm 2$ & $(0.4-3.8) \times 10^{12}$ & $\begin{array}{l}\gamma_{0}=0.13 \pm 0.10 \text { and } \gamma_{\mathrm{ss}}=0.067 \pm 0.040 \\
\text { when }\left[\mathrm{NO}_{3}\right]_{0}=(7.0 \pm 1.0) \times 10^{11} \mathrm{~cm}^{-3} \\
\gamma_{0}=0.14 \pm 0.05 \text { and } \gamma_{\mathrm{ss}}=0.014 \pm 0.004 \\
\text { when }\left[\mathrm{NO}_{3}\right]_{0}=(4.0 \pm 1.0) \times 10^{12} \mathrm{~cm}^{-3}\end{array}$ & $\mathrm{KC}$ \\
\hline Kaolinite & Karagulian and Rossi (2005) & $298 \pm 2$ & $(0.4-3.8) \times 10^{12}$ & $\begin{array}{l}\gamma_{0}=0.11 \pm 0.08 \text { and } \gamma_{\mathrm{ss}}=0.14 \pm 0.02 \\
\text { when }\left[\mathrm{NO}_{3}\right]_{0}=(7.0 \pm 1.0) \times 10^{11} \mathrm{~cm}^{-3} \\
\gamma_{0}=0.12 \pm 0.04 \text { and } \gamma_{\mathrm{ss}}=0.065 \pm 0.012 \\
\text { when }\left[\mathrm{NO}_{3}\right]_{0}=(4.0 \pm 1.0) \times 10^{12} \mathrm{~cm}^{-3}\end{array}$ & $\mathrm{KC}$ \\
\hline Limestone & Karagulian and Rossi (2005) & $298 \pm 2$ & $(0.4-3.8) \times 10^{12}$ & $\begin{array}{l}\gamma_{0}=0.12 \pm 0.08 \text { and } \gamma_{\mathrm{ss}}=0.034 \pm 0.016 \\
\text { when }\left[\mathrm{NO}_{3}\right]_{0}=(7.0 \pm 1.0) \times 10^{11} \mathrm{~cm}^{-3} \\
\gamma_{0}=0.20 \pm 0.07 \text { and } \gamma_{\mathrm{ss}}=0.022 \pm 0.005 \\
\text { when }\left[\mathrm{NO}_{3}\right]_{0}=(4.0 \pm 1.0) \times 10^{12} \mathrm{~cm}^{-3}\end{array}$ & $\mathrm{KC}$ \\
\hline ATD & Karagulian and Rossi (2005) & $298 \pm 2$ & $(0.4-3.8) \times 10^{12}$ & $\begin{array}{l}\gamma_{0}=0.2 \pm 0.1 \text { and } \gamma_{\mathrm{ss}}=0.10 \pm 0.016 \text { when } \\
{\left[\mathrm{NO}_{3}\right]_{0}=(7.0 \pm 1.0) \times 10^{11} \mathrm{~cm}^{-3} ; \quad \gamma_{0}=} \\
0.14 \pm 0.04 \text { and } \gamma_{\mathrm{ss}}=0.025 \pm 0.007 \text { when } \\
{\left[\mathrm{NO}_{3}\right]_{0}=(4.0 \pm 1.0) \times 10^{12} \mathrm{~cm}^{-3} .}\end{array}$ & $\mathrm{KC}$ \\
\hline
\end{tabular}

In the second study (Tang et al., 2010), a novel relativerate method was developed to investigate heterogeneous uptake of $\mathrm{NO}_{3}$ and $\mathrm{N}_{2} \mathrm{O}_{5}$ by mineral dust. Changes in $\mathrm{NO}_{3}$ and $\mathrm{N}_{2} \mathrm{O}_{5}$ concentrations due to reactions with dust particles (loaded on filters) were simultaneously detected by cavity ring-down spectroscopy. Experiments were carried out at room temperature $(296 \pm 2 \mathrm{~K})$ and at different RH up to $70 \%$. The value of $\gamma\left(\mathrm{NO}_{3}\right) / \gamma\left(\mathrm{N}_{2} \mathrm{O}_{5}\right)$ was reported to be $0.9 \pm 0.4$ for Saharan dust particles, independent of RH within the experimental uncertainties (Tang et al., 2010). In addition, even though very low levels of $\mathrm{NO}_{3}$ and $\mathrm{N}_{2} \mathrm{O}_{5}$ (a few hundred pptv) were used, surface deactivation was still observed for both species (Tang et al., 2010).

With the reported $\gamma\left(\mathrm{NO}_{3}\right) / \gamma\left(\mathrm{N}_{2} \mathrm{O}_{5}\right)$ ratio of 0.9 (Tang et al., 2010), $\gamma\left(\mathrm{NO}_{3}\right)$ of 0.018 is thus adopted to evaluate $\tau_{\text {het }}\left(\mathrm{NO}_{3}\right)$ due to its heterogeneous uptake by mineral dust, based on the $\gamma\left(\mathrm{N}_{2} \mathrm{O}_{5}\right)$ value of 0.02 (Sect. 3.6.1). Using Eq. (6), mineral dust mass concentrations of 10, 100, and $1000 \mu \mathrm{m} \mathrm{m}^{-3}$ result in $\tau_{\text {het }}\left(\mathrm{NO}_{3}\right)$ of $\sim 9 \mathrm{~h}, \sim 52 \mathrm{~min}$, and $\sim 5$ min, respectively. Field measurements, as summarized in Table 1 , suggest that tropospheric $\mathrm{NO}_{3}$ lifetimes are typically several minutes. Therefore, uptake by mineral dust is unlikely to be a significant sink for $\mathrm{NO}_{3}$ in the troposphere, except for regions which are close to dust sources and thus heavily impacted by dust storms. Similar conclusions were drawn by Tang et al. (2010), who used an uptake coefficient of 0.009 , which is a factor of 2 smaller than the value used here. 3-D GEOS-Chem model simulations suggest that modeled $\mathrm{O}_{3}$ appears to be insensitive to the choice of $\gamma\left(\mathrm{NO}_{3}\right)$ in the range of 0.0001 to 0.1 (Mao et al., 2013b). To conclude, heterogeneous reaction with mineral dust is not an important sink for tropospheric $\mathrm{NO}_{3}$ radicals except in regions with heavy dust loadings.

\section{Summary and outlook}

It has been widely recognized that heterogeneous reactions with mineral dust particles can significantly affect tropospheric oxidation capacity directly and indirectly. These reactions can also change the composition of dust particles, thereby modifying their physicochemical properties important for direct and indirect radiative forcing. In the past two decades there have been a large number of laboratory (as well as field and modeling) studies which have examined these reactions. In this paper we provide a comprehensive and timely review of laboratory studies of heterogeneous reactions of mineral dust aerosol with $\mathrm{OH}, \mathrm{NO}_{3}$, and $\mathrm{O}_{3}$ as well as several other reactive species (including $\mathrm{HO}_{2}, \mathrm{H}_{2} \mathrm{O}_{2}, \mathrm{HCHO}$, $\mathrm{HONO}$, and $\mathrm{N}_{2} \mathrm{O}_{5}$ ) which are directly related to $\mathrm{OH}, \mathrm{NO}_{3}$, and $\mathrm{O}_{3}$. Lifetimes of these species with respect to heterogeneous uptake by mineral dust are compared to their lifetimes due to other major loss processes in the troposphere in order to provide a quick assessment of the atmospheric significance 
of heterogeneous reactions as sinks for these species. In addition, representative field and modeling work is also discussed to further illustrate the roles these heterogeneous reactions play in tropospheric oxidation capacity. As shown in Sect. 3, these studies have significantly improved our understanding of the effects of these reactions on tropospheric oxidation capacity. Nevertheless, there are still a number of open questions which cannot be answered by laboratory work alone but only by close collaboration among laboratory, field, and modeling studies. Several major challenges, and the strategies we propose to address these challenges, are outlined below.

(1) Mineral dust in the troposphere is in fact mineralogically complex and its mineralogy vary with dust sources and also residence time in the troposphere (Claquin et al., 1999; Ta et al., 2003; Zhang et al., 2003a; Nickovic et al., 2012; Journet et al., 2014; Scanza et al., 2015). Different minerals can exhibit large variabilities in heterogeneous reactivity towards trace gases, as shown by Tables 4-10. However, Tables 4-10 also reveal that simple oxides (e.g., $\mathrm{SiO}_{2}$ and $\mathrm{Al}_{2} \mathrm{O}_{3}$ ) and $\mathrm{CaCO}_{3}$ have been much more widely investigated compared to authentic dust samples (except, probably, ATD) and clay minerals which are the major components of mineral dust aerosol particles (Claquin et al., 1999). The relative importance of clay minerals will be increased after long-range transport due to their smaller sizes compared to $\mathrm{SiO}_{2}$ and $\mathrm{CaCO}_{3}$. Therefore, more attention should be paid in future work to heterogeneous reactions of clay minerals and authentic dust samples.

(2) In the last several years, the important roles that $\mathrm{RH}$ (and thus surface-adsorbed water) plays in heterogeneous reactions of mineral dust have been widely recognized by many studies and discussed in a recent review paper (Rubasinghege and Grassian, 2013). Tables 4-10 show that most of previous studies have been conducted at $\mathrm{RH}<80 \%$, and heterogeneous reactivity at higher $\mathrm{RH}$ largely remains unknown. In addition, effects of $\mathrm{RH}$ on heterogeneous reactions of mineral dust with a few important reactive trace gases, such as $\mathrm{HO}_{2}$ radicals (Bedjanian et al., 2013a; Matthews et al., 2014) and $\mathrm{O}_{3}$ (Sullivan et al., 2004; Chang et al., 2005; Mogili et al., 2006a), are still under debate. It has been known that heterogeneous processing can modify chemical composition and hygroscopicity of mineral dust particles (Tang et al., 2016a), and at evaluated RH aged dust particles may consist of a solid core and an aqueous shell (Krueger et al., 2003b; Laskin et al., 2005a; Liu et al., 2008b; Shi et al., 2008; Li and Shao, 2009; Ma et al., 2012). Under such circumstances, reactions are no longer limited to the particle surface but instead involve gas, liquid, and solid phases and their interfaces, and hence mutual influence among chemical reactivity, composition, and physicochemical properties has to be taken into account (Tang et al., 2016a).

(3) Temperature in the troposphere varies from $<200$ to $>300 \mathrm{~K}$. However, most laboratory studies of heterogeneous reactions of mineral dust were carried out at room temperature (around $296 \mathrm{~K}$ ). Once lifted into the atmosphere, mineral dust aerosol is mainly transported in the free troposphere, in which temperature is much lower than that at the ground level. Some work has started to examine the influence of temperature on heterogeneous uptake by mineral dust (Michel et al., 2003; Xu et al., 2006, 2010, 2011; Wu et al., 2011, 2013b; Romanias et al., 2012a, b, 2013; Zhou et al., 2012, 2016; Bedjanian et al., 2013a; El Zein et al., 2013a, b, 2014; Hou et al., 2016). It has been found that temperature may have significant effects on some reactions. However, to the best of our knowledge, no study has explored the influence of temperature on heterogeneous reactions of airborne mineral dust particles.

(4) Laboratory studies may not entirely mimic actual heterogeneous reactions in the troposphere for several reasons. First of all, laboratory studies are typically carried out with timescales of $<1$ min to several hours, compared to lifetimes of a few days for mineral dust in the troposphere. Secondly, it is not uncommon that concentrations of reactive trace gases used in laboratory work are several orders of magnitude larger than those in the troposphere. These two aspects can make it nontrivial to extrapolate laboratory results to the real atmosphere. In addition, dust samples used in laboratory studies, even when authentic dust samples are used, do not exactly mimic the complexity of ambient dust particles in composition and mineralogy. Very recently a new type of experiment, sometimes called "laboratory work in the field", can at least partly provide solutions to this challenge. For example, an aerosol flow tube has been deployed to explore heterogeneous uptake of $\mathrm{N}_{2} \mathrm{O}_{5}$ by ambient aerosol particles at a few locations (Bertram et al., 2009a, b; Ryder et al., 2014), revealing the roles of RH and particle composition in heterogeneous reactivity of ambient aerosol particles. To our knowledge, this technique has not been used to investigate heterogeneous uptake of $\mathrm{N}_{2} \mathrm{O}_{5}$ by ambient mineral dust aerosol. This technique can also be extended to examine heterogeneous reactions of ambient aerosol particles with other reactive trace gases, especially those whose heterogeneous reactions are anticipated to be efficient (e.g., $\mathrm{HO}_{2}$ and $\mathrm{H}_{2} \mathrm{O}_{2}$ ).

(5) Decreases in heterogeneous reactivity due to surface passivation have been observed by many studies using dust powders supported by substrates. On the other hand, increases in heterogeneous reactivity, due to conversion of solid particles to aqueous droplets with solid 
cores (caused by formation of hygroscopic materials), have also been reported. In addition, it has been widely recognized that the copresence of two or more reactive trace gases may change the rates of heterogeneous reactions of each individual gases (Li et al., 2006; Raff et al., 2009; Liu et al., 2012; Rubasinghege and Grassian, 2012; Wu et al., 2013a; Zhao et al., 2015; Yang et al., 2016a), typically termed as synergistic effects. Parameterization of these complex processes is very difficult, and the lack of sophisticated parameterizations impedes us from a quantitative assessment of their atmospheric significance via modeling studies. Kinetic models have been developed to integrate physical and chemical processes in and between different phases (Pöschl et al., 2007; Shiraiwa et al., 2012; Berkemeier et al., 2013), and these models have been successfully used to investigate multiphase chemistry of aqueous aerosol particles and cloud droplets (Shiraiwa et al., 2011; Arangio et al., 2015; Pöschl and Shiraiwa, 2015). Future efforts devoted to development and application of comprehensive kinetic models to study heterogeneous and multiphase reactions of mineral dust particles would largely improve our understanding in the field.

(6) It has been found that UV and visible radiation can substantially enhance the heterogeneous reactivity of mineral dust towards several trace gases, including but not limited to $\mathrm{H}_{2} \mathrm{O}_{2}, \mathrm{O}_{3}$, and $\mathrm{HCHO}$, and in some cases even reactivate mineral surfaces which have been passivated (Cwiertny et al., 2008; Chen et al., 2012; George et al., 2015). In addition, photolysis of materials (such as nitrate) formed on mineral surface can also be sources for some trace gases (Nanayakkara et al., 2013, 2014; Gankanda and Grassian, 2014). Although the effects of photoradiation in heterogeneous reactions with mineral dust have been recognized for more than 1 decade, it largely remains unclear to which extent these reactions are photoenhanced under ambient solar radiation, and thus quantitative evaluation of impacts of heterogeneous photochemistry on tropospheric oxidation capacity is lacking.

(7) There is still a considerably large gap between laboratory work and modeling studies used to explain field measurements and predict future changes. One reason is that the communication and collaboration between laboratory and modeling communities, though enhanced in the past few decades, are still not enough and should be further encouraged and stimulated in future. Furthermore, many laboratory studies have been designed from the perspective of classical chemical kinetics such that, although experimental results are beautiful, they are difficult to be parameterized and then included in models. As mentioned, heterogeneous reactivity is highly dependent on temperature, $\mathrm{RH}$, copresence of other trace gases, and mutual influences among these factors. Given that most models are capable of resolving and assimilating meteorological variables and trace-gas concentrations at high temporal resolution, multivariate analysis and integrated numerical expressions are encouraged to be conducted in laboratory studies so as to better characterize heterogeneous chemistry and its climate and environmental effects in numerical models. Therefore, it is suggested that when a laboratory study is designed, it should be kept in mind how experimental results can be used by modeling studies. On the other hand, modeling work is encouraged to include new laboratory results in numerical simulations and to identify missing reactions and key parameters which deserve further laboratory investigation. Field campaigns which are specifically designed to assess the impacts of mineral dust aerosol on tropospheric oxidation capacity have proved to be very beneficial (de Reus et al., 2000, 2005; GalyLacaux et al., 2001; Seinfeld et al., 2004; Tang et al., 2004; Umann et al., 2005; Arimoto et al., 2006; Song et al., 2007), and more campaigns of this types should be organized. Overall, as urged by a few recent articles (Kolb et al., 2010; Abbatt et al., 2014; Burkholder et al., 2017), the three-legged stool approach (laboratory studies, field observations, and modeling studies) adopted by atmospheric chemistry research for a long time should be emphasized, and mutual communication and active collaboration among these three "legs" should be further enhanced.

Data availability. The data used in this work are available from Mingjin Tang (mingjintang@gig.ac.cn) upon request.

Competing interests. The authors declare that they have no conflict of interest.

Special issue statement. This article is part of the special issue "Regional transport and transformation of air pollution in eastern China". It does not belong to a conference.

Acknowledgements. The preparation of this paper was inspired by the first International Workshop on Heterogeneous Kinetics Related to Atmospheric Aerosols (August 2015, Beijing, China), endorsed by the International Global Atmospheric Chemistry (IGAC) Project, and Mingjin Tang and Tong Zhu would like to thank all the participants for their valuable presentations and discussion. Financial support provided by Chinese National Science Foundation (91644106 and 21522701), Chinese Academy of Sciences international collaborative project (132744KYSB20160036), and State Key Laboratory of Organic Geochemistry (SKLOGA201603A) is acknowledged. Mingjin Tang is also sponsored by Chinese Academy of Sciences Pioneer Hundred Talents Program. This is contribution no. IS-2436 from GIGCAS. 
Edited by: Jianmin Chen

Reviewed by: four anonymous referees

\section{References}

Abbatt, J. P. D., Lee, A. K. Y., and Thornton, J. A.: Quantifying trace gas uptake to tropospheric aerosol: recent advances and remaining challenges, Chem. Soc. Rev., 41, 6555-6581, 2012.

Abbatt, J., George, C., Melamed, M., Monks, P., Pandis, S., and Rudich, Y.: New directions: Fundamentals of atmospheric chemistry: Keeping a three-legged stool balanced, Atmos. Environ., 84, 390-391, 2014.

Akimoto, H.: Heterogeneous reactions in the atmosphere and uptake coefficients, in: Atmospheric Reaction Chemistry, Springer Japan, Tokyo, 239-284, 2016.

Aldener, M., Brown, S. S., Stark, H., Williams, E. J., Lerner, B. M., Kuster, W. C., Goldan, P. D., Quinn, P. K., Bates, T. S., Fehsenfeld, F. C., and Ravishankara, A. R.: Reactivity and loss mechanisms of $\mathrm{NO}_{3}$ and $\mathrm{N}_{2} \mathrm{O}_{5}$ in a polluted marine environment: results from in situ measurements during New England Air Quality Study 2002, J. Geophys. Res.-Atmos., 111, D23S73, https://doi.org/10.1029/2006JD007252, 2006.

Alebić-Juretić, A., Cvitaš, T., and Klasinc, L.: Ozone destruction on powders, Ber. Bunsen. Phys. Chem., 96, 493-495, 1992.

Alfaro, S. C., Gomes, L., Rajot, J. L., Lafon, S., Gaudichet, A., Chatenet, B., Maille, M., Cautenet, G., Lasserre, F., Cachier, H., and Zhang, X. Y.: Chemical and optical characterization of aerosols measured in spring 2002 at the ACE-Asia supersite, Zhenbeitai, China, J. Geophys. Res.-Atmos., 108, 8641, https://doi.org/10.1029/2002JD003214, 2003.

Alicke, B., Geyer, A., Hofzumahaus, A., Holland, F., Konrad, S., Patz, H. W., Schafer, J., Stutz, J., Volz-Thomas, A., and Platt, U.: $\mathrm{OH}$ formation by HONO photolysis during the BERLIOZ experiment, J. Geophys. Res.-Atmos., 108, 8247, https://doi.org/8210.1029/2001jd000579, 2003.

Ammann, M. and Pöschl, U.: Kinetic model framework for aerosol and cloud surface chemistry and gas-particle interactions - Part 2: Exemplary practical applications and numerical simulations, Atmos. Chem. Phys., 7, 6025-6045, https://doi.org/10.5194/acp7-6025-2007, 2007.

Ammann, M., Cox, R. A., Crowley, J. N., Jenkin, M. E., Mellouki, A., Rossi, M. J., Troe, J., and Wallington, T. J.: Evaluated kinetic and photochemical data for atmospheric chemistry: Volume VI - heterogeneous reactions with liquid substrates, Atmos. Chem. Phys., 13, 8045-8228, https://doi.org/10.5194/acp13-8045-2013, 2013.

Ammar, R., Monge, M. E., George, C., and D'Anna, B.: Photoenhanced $\mathrm{NO}_{2}$ loss on simulated urban grime, ChemPhysChem, 11, 3956-3961, 2010.

Ao, C. H., Lee, S. C., Yu, J. Z., and Xu, J. H.: Photodegradation of formaldehyde by photocatalyst $\mathrm{TiO}_{2}$ : Effects on the presences of $\mathrm{NO}, \mathrm{SO}_{2}$ and VOCs, Appl. Catal. B-Environ., 54, 41-50, 2004.

Arangio, A. M., Slade, J. H., Berkemeier, T., Poschl, U., Knopf, D. A., and Shiraiwa, M.: Multiphase chemical kinetics of $\mathrm{OH}$ radical uptake by molecular organic markers of biomass burning aerosols: humidity and temperature dependence, surface reaction, and bulk diffusion, J. Phys. Chem. A, 119, 4533-4544, 2015.

Arimoto, R., Kim, Y. J., Kim, Y. P., Quinn, P. K., Bates, T. S., Anderson, T. L., Gong, S., Uno, I., Chin, M., Huebert, B. J., Clarke, A. D., Shinozuka, Y., Weber, R. J., Anderson, J. R., Guazzotti, S. A., Sullivan, R. C., Sodeman, D. A., Prather, K. A., and Sokolik, I. N.: Characterization of Asian Dust during ACE-Asia, Global Planet. Change, 52, 23-56, 2006.

Atkinson, R., Baulch, D. L., Cox, R. A., Crowley, J. N., Hampson, R. F., Hynes, R. G., Jenkin, M. E., Rossi, M. J., and Troe, J.: Evaluated kinetic and photochemical data for atmospheric chemistry: Volume I - gas phase reactions of $\mathrm{O}_{\mathrm{x}}, \mathrm{HO}_{\mathrm{x}}$, $\mathrm{NO}_{\mathrm{x}}$ and $\mathrm{SO}_{\mathrm{x}}$ species, Atmos. Chem. Phys., 4, 1461-1738, https://doi.org/10.5194/acp-4-1461-2004, 2004.

Atkinson, R., Baulch, D. L., Cox, R. A., Crowley, J. N., Hampson, R. F., Hynes, R. G., Jenkin, M. E., Rossi, M. J., Troe, J., and IUPAC Subcommittee: Evaluated kinetic and photochemical data for atmospheric chemistry: Volume II - gas phase reactions of organic species, Atmos. Chem. Phys., 6, 3625-4055, https://doi.org/10.5194/acp-6-3625-2006, 2006.

Baergen, A. M. and Donaldson, D. J.: Formation of reactive nitrogen oxides from urban grime photochemistry, Atmos. Chem. Phys., 16, 6355-6363, https://doi.org/10.5194/acp-166355-2016, 2016.

Balkanski, Y., Schulz, M., Claquin, T., and Guibert, S.: Reevaluation of mineral aerosol radiative forcings suggests a better agreement with satellite and AERONET data, Atmos. Chem. Phys., 7, 81-95, https://doi.org/10.5194/acp-7-81-2007, 2007.

Bauer, S. E., Balkanski, Y., Schulz, M., Hauglustaine, D. A., and Dentener, F.: Global modeling of heterogeneous chemistry on mineral aerosol surfaces: Influence on tropospheric ozone chemistry and comparison to observations, J. Geophys. Res.-Atmos., 109, D02304, https://doi.org/02310.01029/02003JD003868, 2004.

Bedjanian, Y., Romanias, M. N., and El Zein, A.: Uptake of $\mathrm{HO}_{2}$ radicals on Arizona Test Dust, Atmos. Chem. Phys., 13, 64616471, https://doi.org/10.5194/acp-13-6461-2013, 2013a.

Bedjanian, Y., Romanias, M. N., and El Zein, A.: Interaction of $\mathrm{OH}$ radicals with Arizona test dust: uptake and products, J. Phys. Chem. A, 117, 393-400, 2013b.

Berkemeier, T., Huisman, A. J., Ammann, M., Shiraiwa, M., Koop, T., and Pöschl, U.: Kinetic regimes and limiting cases of gas uptake and heterogeneous reactions in atmospheric aerosols and clouds: a general classification scheme, Atmos. Chem. Phys., 13, 6663-6686, https://doi.org/10.5194/acp-13-6663-2013, 2013.

Bertram, A. K., Ivanov, A. V., Hunter, M., Molina, L. T., and Molina, M. J.: The reaction probability of $\mathrm{OH}$ on organic surfaces of tropospheric interest, J. Phys. Chem. A, 105, 9415-9421, 2001.

Bertram, T. H., Thornton, J. A., and Riedel, T. P.: An experimental technique for the direct measurement of $\mathrm{N}_{2} \mathrm{O}_{5}$ reactivity on ambient particles, Atmos. Meas. Tech., 2, 231-242, https://doi.org/10.5194/amt-2-231-2009, 2009a.

Bertram, T. H., Thornton, J. A., Riedel, T. P., Middlebrook, A. M., Bahreini, R., Bates, T. S., Quinn, P. K., and Coffman, D. J.: Direct observations of $\mathrm{N}_{2} \mathrm{O}_{5}$ reactivity on ambient aerosol particles, Geophys. Res. Lett., 36, L19803, https://doi.org/10.1029/2012GL053007, 2009b. 
Bi, J., Huang, J., Holben, B., and Zhang, G.: Comparison of key absorption and optical properties between pure and transported anthropogenic dust over East and Central Asia, Atmos. Chem. Phys., 16, 15501-15516, https://doi.org/10.5194/acp-16-155012016, 2016.

Bi, J., Huang, J., Shi, J., Hu, Z., Zhou, T., Zhang, G., Huang, Z., Wang, X., and Jin, H.: Measurement of scattering and absorption properties of dust aerosol in a Gobi farmland region of northwestern China - a potential anthropogenic influence, Atmos. Chem. Phys., 17, 7775-7792, https://doi.org/10.5194/acp17-7775-2017, 2017.

Bian, H. S. and Zender, C. S.: Mineral dust and global tropospheric chemistry: Relative roles of photolysis and heterogeneous uptake, J. Geophys. Res.-Atmos., 108, 4672, https://doi.org/10.1029/2002JD003143, 2003.

Bogart, K. H. A., Cushing, J. P., and Fisher, E. R.: Effects of plasma processing parameters on the surface reactivity of $\mathrm{OH}(\mathrm{X} 2 \Pi)$ in tetraethoxysilane $/ \mathrm{O}_{2}$ plasmas during deposition of $\mathrm{SiO}_{2}, \mathrm{~J}$. Phys. Chem. B, 101, 10016-10023, 1997.

Boyd, P. W. and Ellwood, M. J.: The biogeochemical cycle of iron in the ocean, Nat. Geosci., 3, 675-682, 2010.

Brauers, T., Hausmann, M., Bister, A., Kraus, A., and Dorn, H.-P.: $\mathrm{OH}$ radicals in the boundary layer of the Atlantic Ocean: 1. Measurements by long-path laser absorption spectroscopy, J. Geophys. Res.-Atmos, 106, 7399-7414, 2001.

Brown, S. S., Ryerson, T. B., Wollny, A. G., Brock, C. A., Peltier, R., Sullivan, A. P., Weber, R. J., Dube, W. P., Trainer, M., Meagher, J. F., Fehsenfeld, F. C., and Ravishankara, A. R.: Variability in nocturnal nitrogen oxide processing and its role in regional air quality, Science, 311, 67-70, 2006.

Brown, S. S., Dube, W. P., Fuchs, H., Ryerson, T. B., Wollny, A. G., Brock, C. A., Bahreini, R., Middlebrook, A. M., Neuman, J. A., Atlas, E., Roberts, J. M., Osthoff, H. D., Trainer, M., Fehsenfeld, F. C., and Ravishankara, A. R.: Reactive uptake coefficients for $\mathrm{N}_{2} \mathrm{O}_{5}$ determined from aircraft measurements during the Second Texas Air Quality Study: comparison to current model parameterizations, J. Geophys. Res.-Atmos., 114, D00F10, https://doi.org/10.1029/2008JD011679, 2009.

Brown, S. S. and Stutz, J.: Nighttime radical observations and chemistry, Chem. Soc. Rev., 41, 6405-6447, 2012.

Brown, S. S., Dube, W. P., Tham, Y. J., Zha, Q. Z., Xue, L. K., Poon, S., Wang, Z., Blake, D. R., Tsui, W., Parrish, D. D., and Wang, T.: Nighttime chemistry at a high altitude site above Hong Kong, J. Geophys. Res.-Atmos., 121, 2457-2475, 2016.

Burkholder, J. B., Sander, S. P., Abbatt, J. P. D., Barker, J. R., Huie, R. E., Kolb, C. E., Kurylo, M. J., Orkin, V. L., Wilmouth, D. M., and Wine, P. H.: Chemical Kinetics and Photochemical Data for Use in Atmospheric Studies, Evaluation No. 18, JPL Publication 15-10, Jet Propulsion Lab., Pasadena, CA, 2015.

Burkholder, J. B., Abbatt, J. P. D., Barnes, I., Roberts, J. M., Melamed, M. L., Ammann, M., Bertram, A. K., Cappa, C. D., Carlton, A. G., Carpenter, L. J., Crowley, J. N., Dubowski, Y., George, C., Heard, D. E., Herrmann, H., Keutsch, F. N., Kroll, J. H., McNeill, V. F., Ng, N. L., Nizkorodov, S. A., Orlando, J. J., Percival, C. J., Picquet-Varrault, B., Rudich, Y., Seakins, P. W., Surratt, J. D., Tanimoto, H., Thornton, J. A., Tong, Z., Tyndall, G. S., Wahner, A., Weschler, C. J., Wilson, K. R., and Ziemann, P. J.: The essential role for labora- tory studies in atmospheric chemistry, Environ. Sci. Technol., 51, 2519-2528, 2017.

Carlos-Cuellar, S., Li, P., Christensen, A. P., Krueger, B. J., Burrichter, C., and Grassian, V. H.: Heterogeneous uptake kinetics of volatile organic compounds on oxide surfaces using a Knudsen cell reactor: adsorption of acetic acid, formaldehyde, and methanol on $\alpha-\mathrm{Fe}_{2} \mathrm{O}_{3}, \alpha-\mathrm{Al}_{2} \mathrm{O}_{3}$, and $\mathrm{SiO}_{2}$, J. Phys. Chem. A, 107, 4250-4261, 2003.

Chang, R. Y. W., Sullivan, R. C., and Abbatt, J. P. D.: Initial uptake of ozone on Saharan dust at atmospheric relative humidities, Geophys. Res. Lett., 32, L14815, https://doi.org/14810.11029/12005GL023317, 2005.

Chang, W. L., Brown, S. S., Stutz, J., Middlebrook, A. M., Bahreini, R., Wagner, N. L., Dubé, W. P., Pollack, I. B., Ryerson, T. B., and Riemer, N.: Evaluating $\mathrm{N}_{2} \mathrm{O}_{5}$ heterogeneous hydrolysis parameterizations for CalNex 2010, J. Geophys. Res.Atmos, 121, 5051-5070, 2016.

Chatani, S., Shimo, N., Matsunaga, S., Kajii, Y., Kato, S., Nakashima, Y., Miyazaki, K., Ishii, K., and Ueno, H.: Sensitivity analyses of $\mathrm{OH}$ missing sinks over Tokyo metropolitan area in the summer of 2007, Atmos. Chem. Phys., 9, 8975-8986, https://doi.org/10.5194/acp-9-8975-2009, 2009.

Chen, Z. M., Jie, C. Y., Li, S., Wang, H. L., Wang, C. X., $\mathrm{Xu}, \mathrm{J} . \mathrm{R}$., and Hua, W.: Heterogeneous reactions of methacrolein and methyl vinyl ketone: kinetics and mechanisms of uptake and ozonolysis on silicon dioxide, J. Geophys. Res.-Atmos, 113, D22303, https://doi.org/22310.21029/22007JD009754, 2008.

Chen, H. H., Navea, J. G., Young, M. A., and Grassian, V. H.: Heterogeneous photochemistry of trace atmospheric gases with components of mineral dust aerosol, J. Phys. Chem. A, 115, 490499, $2011 \mathrm{a}$.

Chen, H. H., Stanier, C. O., Young, M. A., and Grassian, V. H.: A kinetic study of ozone decomposition on illuminated oxide surfaces, J. Phys. Chem. A, 115, 11979-11987, 2011 b.

Chen, H. H., Nanayakkara, C. E., and Grassian, V. H.: Titanium dioxide photocatalysis in atmospheric chemistry, Chem. Rev., 112, 5919-5948, 2012.

Chernoff, D. I. and Bertram, A. K.: Effects of sulfate coatings on the ice nucleation properties of a biological ice nucleus and several typs of minerals, J. Geophys. Res.-Atmos., 115, D20205, https://doi.org/20210.21029/22010JD014254, 2010.

Chou, C., Formenti, P., Maille, M., Ausset, P., Helas, G., Harrison, M., and Osborne, S.: Size distribution, shape, and composition of mineral dust aerosols collected during the African Monsoon Multidisciplinary Analysis Special Observation Period 0: Dust and Biomass-Burning Experiment field campaign in Niger, January 2006, J. Geophys. Res.-Atmos., 113, D00C10, https://doi.org/10.1029/2008jd009897, 2008.

Claquin, T., Schulz, M., and Balkanski, Y. J.: Modeling the mineralogy of atmospheric dust sources, J. Geophys. Res.-Atmos., 104, 22243-22256, 1999.

Creamean, J. M., Suski, K. J., Rosenfeld, D., Cazorla, A., DeMott, P. J., Sullivan, R. C., White, A. B., Ralph, F. M., Minnis, P., Comstock, J. M., Tomlinson, J. M., and Prather, K. A.: Dust and biological aerosols from the Sahara and Asia influence precipitation in the Western US, Science, 339, 1572-1578, 2013.

Crowley, J. N., Ammann, M., Cox, R. A., Hynes, R. G., Jenkin, M. E., Mellouki, A., Rossi, M. J., Troe, J., and Wallington, T. J.: Evaluated kinetic and photochemical data for at- 
mospheric chemistry: Volume $\mathrm{V}$ - heterogeneous reactions on solid substrates, Atmos. Chem. Phys., 10, 9059-9223, https://doi.org/10.5194/acp-10-9059-2010, 2010a.

Crowley, J. N., Schuster, G., Pouvesle, N., Parchatka, U., Fischer, H., Bonn, B., Bingemer, H., and Lelieveld, J.: Nocturnal nitrogen oxides at a rural mountain-site in south-western Germany, Atmos. Chem. Phys., 10, 2795-2812, https://doi.org/10.5194/acp10-2795-2010, 2010b.

Crutzen, P. J.: Albedo enhancement by stratospheric sulfur injections: a contribution to resolve a policy dilemma?, Climatic Change, 77, 211-219, 2006.

Cwiertny, D. M., Young, M. A., and Grassian, V. H.: Chemistry and photochemistry of mineral dust aerosol, Annu. Rev. Phys. Chem., 59, 27-51, 2008.

Cziczo, D. J., Froyd, K. D., Hoose, C., Jensen, E. J., Diao, M., Zondlo, M. A., Smith, J. B., Twohy, C. H., and Murphy, D. M.: Clarifying the dominant sources and mechanisms of cirrus cloud formation, Science, 340, 1320-1324, 2013.

Davidovits, P., Kolb, C. E., Williams, L. R., Jayne, J. T., and Worsnop, D. R.: Update 1 of: Mass accommodation and chemical reactions at gas-liquid interfaces, Chem. Rev., 111, PR76PR109, 2011.

De Laurentiis, E., Socorro, J., Vione, D., Quivet, E., Brigante, M., Mailhot, G., Wortham, H., and Gligorovski, S.: Phototransformation of 4-phenoxyphenol sensitised by 4-carboxybenzophenone: evidence of new photochemical pathways in the bulk aqueous phase and on the surface of aerosol deliquescent particles, Atmos. Environ., 81, 569-578, 2013.

De Longueville, F., Hountondji, Y.-C., Henry, S., and Ozer, P.: What do we know about effects of desert dust on air quality and human health in West Africa compared to other regions?, Sci. Total Environ., 409, 1-8, 2010.

de Longueville, F., Ozer, P., Doumbia, S., and Henry, S.: Desert dust impacts on human health: an alarming worldwide reality and a need for studies in West Africa, Int. J. Biometeorol., 57, 1-19, 2013.

DeMott, P. J., Sassen, K., Poellot, M. R., Baumgardner, D., Rogers, D. C., Brooks, S. D., Prenni, A. J., and Kreidenweis, S. M.: African dust aerosols as atmospheric ice nuclei, Geophys. Res. Lett., 30, 1732, https://doi.org/1710.1029/2003gl017410, 2003.

DeMott, P. J., Prenni, A. J., McMeeking, G. R., Sullivan, R. C., Petters, M. D., Tobo, Y., Niemand, M., Möhler, O., Snider, J. R., Wang, Z., and Kreidenweis, S. M.: Integrating laboratory and field data to quantify the immersion freezing ice nucleation activity of mineral dust particles, Atmos. Chem. Phys., 15, 393-409, https://doi.org/10.5194/acp-15-393-2015, 2015.

Dentener, F. J. and Crutzen, P. J.: Reaction of $\mathrm{N}_{2} \mathrm{O}_{5}$ on tropospheric aerosols: impact on the global distributions of $\mathrm{NO}_{\mathrm{x}}, \mathrm{O}_{3}$, and OH, J. Geophys. Res.-Atmos., 98, 7149-7163, 1993.

Dentener, F. J., Carmichael, G. R., Zhang, Y., Lelieveld, J., and Crutzen, P. J.: Role of mineral aerosol as a reactive surface in the global troposphere, J. Geophys. Res.-Atmos., 101, 2286922889, 1996.

de Reus, M., Dentener, F., Thomas, A., Borrmann, S., Strom, J., and Lelieveld, J.: Airborne observations of dust aerosol over the North Atlantic Ocean during ACE 2: Indications for heterogeneous ozone destruction, J. Geophys. Res.-Atmos., 105, 15263$15275,2000$. de Reus, M., Fischer, H., Sander, R., Gros, V., Kormann, R., Salisbury, G., Van Dingenen, R., Williams, J., Zöllner, M., and Lelieveld, J.: Observations and model calculations of trace gas scavenging in a dense Saharan dust plume during MINATROC, Atmos. Chem. Phys., 5, 1787-1803, https://doi.org/10.5194/acp5-1787-2005, 2005.

Dhandapani, B. and Oyama, S. T.: Gas phase ozone decomposition catalysts, Appl. Catal. B-Environ., 11, 129-166, 1997.

Ding, A. J., Fu, C. B., Yang, X. Q., Sun, J. N., Zheng, L. F., Xie, Y. N., Herrmann, E., Nie, W., Petäjä, T., Kerminen, V.-M., and Kulmala, M.: Ozone and fine particle in the western Yangtze River Delta: an overview of 1 yr data at the SORPES station, Atmos. Chem. Phys., 13, 5813-5830, https://doi.org/10.5194/acp13-5813-2013, 2013.

Donaldson, M. A., Berke, A. E., and Raff, J. D.: Uptake of gas phase nitrous acid onto boundary layer soil surfaces, Environ. Sci. Technol., 48, 375-383, 2014.

Dusanter, S., Vimal, D., Stevens, P. S., Volkamer, R., Molina, L. T., Baker, A., Meinardi, S., Blake, D., Sheehy, P., Merten, A., Zhang, R., Zheng, J., Fortner, E. C., Junkermann, W., Dubey, M., Rahn, T., Eichinger, B., Lewandowski, P., Prueger, J., and Holder, H.: Measurements of $\mathrm{OH}$ and $\mathrm{HO}_{2}$ concentrations during the MCMA-2006 field campaign - Part 2: Model comparison and radical budget, Atmos. Chem. Phys., 9, 6655-6675, https://doi.org/10.5194/acp-9-6655-2009, 2009.

Duvall, R. M., Majestic, B. J., Shafer, M. M., Chuang, P. Y., Simoneit, B. R. T., and Schauer, J. J.: The water-soluble fraction of carbon, sulfur, and crustal elements in Asian aerosols and Asian soils, Atmos. Environ., 42, 5872-5884, 2008.

Edwards, P. M., Brown, S. S., Roberts, J. M., Ahmadov, R., Banta, R. M., deGouw, J. A., Dube, W. P., Field, R. A., Flynn, J. H., Gilman, J. B., Graus, M., Helmig, D., Koss, A., Langford, A. O., Lefer, B. L., Lerner, B. M., Li, R., Li, S.M., McKeen, S. A., Murphy, S. M., Parrish, D. D., Senff, C. J., Soltis, J., Stutz, J., Sweeney, C., Thompson, C. R., Trainer, M. K., Tsai, C., Veres, P. R., Washenfelder, R. A., Warneke, C., Wild, R. J., Young, C. J., Yuan, B., and Zamora, R.: High winter ozone pollution from carbonyl photolysis in an oil and gas basin, Nature, 514, 351-354, 2014.

Ehhalt, D. H.: Photooxidation of trace gases in the troposphere Plenary Lecture, Phys. Chem. Chem. Phys., 1, 5401-5408, 1999.

El Zein, A. and Bedjanian, Y.: Reactive uptake of $\mathrm{HONO}$ to $\mathrm{TiO}_{2}$ surface: "Dark" Reaction, J. Phys. Chem. A, 116, 3665-3672, 2012.

El Zein, A., Bedjanian, Y., and Romanias, M. N.: Kinetics and products of HONO interaction with $\mathrm{TiO}_{2}$ surface under UV irradiation, Atmos. Environ., 67, 203-210, 2013a.

El Zein, A., Romanias, M. N., and Bedjanian, Y.: Kinetics and products of heterogeneous reaction of $\mathrm{HONO}$ with $\mathrm{Fe}_{2} \mathrm{O}_{3}$ and Arizona test dust, Environ. Sci. Technol., 47, 6325-6331, 2013b.

El Zein, A., Romanias, M. N., and Bedjanian, Y.: Heterogeneous interaction of $\mathrm{H}_{2} \mathrm{O}_{2}$ with Arizona test dust, J. Phys. Chem. A, 118, 441-448, 2014.

Evans, M. J. and Jacob, D. J.: Impact of new laboratory studies of $\mathrm{N}_{2} \mathrm{O}_{5}$ hydrolysis on global model budgets of tropospheric nitrogen oxides, ozone, and OH, Geophys. Res. Lett., 32, L09813, https://doi.org/09810.01029/02005GL022469, 2005.

Fitzgerald, E., Ault, A. P., Zauscher, M. D., Mayol-Bracero, O. L., and Prather, K. A.: Comparison of the mixing state of long-range 
transported Asian and African mineral dust, Atmos. Environ., 115, 19-25, 2015.

Formenti, P., Schütz, L., Balkanski, Y., Desboeufs, K., Ebert, M., Kandler, K., Petzold, A., Scheuvens, D., Weinbruch, S., and Zhang, D.: Recent progress in understanding physical and chemical properties of African and Asian mineral dust, Atmos. Chem. Phys., 11, 8231-8256, https://doi.org/10.5194/acp11-8231-2011, 2011.

Formenti, P., Caquineau, S., Desboeufs, K., Klaver, A., Chevaillier, S., Journet, E., and Rajot, J. L.: Mapping the physicochemical properties of mineral dust in western Africa: mineralogical composition, Atmos. Chem. Phys., 14, 10663-10686, https://doi.org/10.5194/acp-14-10663-2014, 2014.

Fuller, E. N., Schettle, P. D., and Giddings, J. C.: A new method for prediction of binary gas-phase diffusion coefficients, Ind. Eng. Chem., 58, 19-27, 1966.

Galy-Lacaux, C., Carmichael, G. R., Song, C. H., Lacaux, J. P., Al Ourabi, H., and Modi, A. I.: Heterogeneous processes involving nitrogenous compounds and Saharan dust inferred from measurements and model calculations, J. Geophys. Res.-Atmos., 106, 12559-12578, 2001.

Gankanda, A. and Grassian, V. H.: Nitrate photochemistry on laboratory proxies of mineral dust aerosol: wavelength dependence and action spectra, J. Phys. Chem. C, 118, 29117-29125, 2014.

Garimella, S., Huang, Y.-W., Seewald, J. S., and Cziczo, D. J.: Cloud condensation nucleus activity comparison of dryand wet-generated mineral dust aerosol: the significance of soluble material, Atmos. Chem. Phys., 14, 6003-6019, https://doi.org/10.5194/acp-14-6003-2014, 2014.

Ge, M. F., Wu, L. Y., Tong, S. R., Liu, Q. F., and Wang, W. G.: Heterogeneous chemistry of trace atmospheric gases on atmospheric aerosols: an overview, Science Foundation China, 23, 62-80, 2015.

Geng, F., Tie, X., Xu, J., Zhou, G., Peng, L., Gao, W., Tang, X., and Zhao, C.: Characterizations of ozone, $\mathrm{NO}_{\mathrm{x}}$, and VOCs measured in Shanghai, China, Atmos. Environ., 42, 6873-6883, 2008.

George, C., Ammann, M., D’Anna, B., Donaldson, D. J., and Nizkorodov, S. A.: Heterogeneous photochemistry in the atmosphere, Chem. Rev., 115, 4218-4258, 2015.

George, C., Beeldens, A., Barmpas, F., Doussin, J.-F., Manganelli, G., Herrmann, H., Kleffmann, J., and Mellouki, A.: Impact of photocatalytic remediation of pollutants on urban air quality, Front. Environ. Sci. En., 10, 1-11, 2016.

Gershenzon, Y. M., Ivanov, A. V., Kucheryavyi, S. I., and Rozenshtein, V. B.: Annihilation of $\mathrm{OH}$ radicals on the surfaces of substances chemically similar to atmospheric aerosol particles, Kinet. Catal.+, 27, 1069-1074, 1986.

Geyer, A., Alicke, B., Konrad, S., Schmitz, T., Stutz, J., and Platt, U.: Chemistry and oxidation capacity of the nitrate radical in the continental boundary layer near Berlin, J. Geophys. Res.-Atmos, 106, 8013-8025, 2001.

Geyer, A., Bachmann, K., Hofzumahaus, A., Holland, F., Konrad, S., Klupfel, T., Patz, H. W., Perner, D., Mihelcic, D., Schafer, H. J., Volz-Thomas, A., and Platt, U.: Nighttime formation of peroxy and hydroxyl radicals during the BERLIOZ campaign: observations and modeling studies, J. Geophys. Res.Atmos., 108, 8249, https://doi.org/8210.1029/2001JD000656, 2003.
Giannadaki, D., Pozzer, A., and Lelieveld, J.: Modeled global effects of airborne desert dust on air quality and premature mortality, Atmos. Chem. Phys., 14, 957-968, https://doi.org/10.5194/acp-14-957-2014, 2014.

Ginoux, P., Prospero, J. M., Gill, T. E., Hsu, N. C., and Zhao, M.: Global-scale attribution of anthropogenic and natural dust sources and their emission rates based on MODIS Deep Blue Aerosol products, Rev. Geophys., 50, RG3005, https://doi.org/3010.1029/2012RG000388, 2012.

Gobbi, G. P., Barnaba, F., Giorgi, R., and Santacasa, A.: Altituderesolved properties of a Saharan dust event over the Mediterranean, Atmos. Environ., 34, 5119-5127, 2000.

Goodman, A. L., Underwood, G. M., and Grassian, V. H.: A laboratory study of the heterogeneous reaction of nitric acid on calcium carbonate particles, J. Geophys. Res.-Atmos., 105, 29053 29064, 2000.

Graedel, T. E., Mandich, M. L., and Weschler, C. J.: Kinetic model studies of atmospheric droplet chemistry: 2. Homogeneous transition metal chemistry in raindrops, J. Geophys. Res.-Atmos, 91, 5205-5221, 1986.

Hall, B. D. and Claiborn, C. S.: Measurements of the dry deposition of peroxides to a Canadian boreal forest, J. Geophys. Res.Atmos, 102, 29343-29353, 1997.

Hanisch, F. and Crowley, J. N.: Heterogeneous reactivity of gaseous nitric acid on $\mathrm{Al}_{2} \mathrm{O}_{3}, \mathrm{CaCO}_{3}$, and atmospheric dust samples: a Knudsen cell study, J. Phys. Chem. A, 105, 3096-3106, 2001.

Hanisch, F. and Crowley, J. N.: Ozone decomposition on Saharan dust: an experimental investigation, Atmos. Chem. Phys., 3, 119130, https://doi.org/10.5194/acp-3-119-2003, 2003a

Hanisch, F. and Crowley, J. N.: Heterogeneous reactivity of NO and $\mathrm{HNO}_{3}$ on mineral dust in the presence of ozone, Phys. Chem. Chem. Phys., 5, 883-887, 2003 b.

Hanning-Lee, M. A., Brady, B. B., Martin, L. R., and Syage, J. A.: Ozone decomposition on alumina: implications for solid rocket motor exhaust, Geophys. Res. Lett., 23, 1961-1964, 1996.

Harris, E., Sinha, B., Foley, S., Crowley, J. N., Borrmann, S., and Hoppe, P.: Sulfur isotope fractionation during heterogeneous oxidation of $\mathrm{SO}_{2}$ on mineral dust, Atmos. Chem. Phys., 12, 48674884, https://doi.org/10.5194/acp-12-4867-2012, 2012.

Harrison, R. M. and Kitto, A. M. N.: Evidence for a surface source of atmospheric nitrous-acid, Atmos. Environ., 28, 1089-1094, 1994.

Harrison, R. M., Peak, J. D., and Collins, G. M.: Tropospheric cycle of nitrous acid, J. Geophys. Res.-Atmos., 101, 14429-14439, 1996.

He, H., Wang, Y., Ma, Q., Ma, J., Chu, B., Ji, D., Tang, G., Liu, C., Zhang, H., and Hao, J.: Mineral dust and $\mathrm{NO}_{\mathrm{x}}$ promote the conversion of $\mathrm{SO}_{2}$ to sulfate in heavy pollution days, Sci. Rep., 4, 4172, https://doi.org/10.1038/srep04172, 2014.

Heard, D. E., Carpenter, L. J., Creasey, D. J., Hopkins, J. R., Lee, J. D., Lewis, A. C., Pilling, M. J., Seakins, P. W., Carslaw, N., and Emmerson, K. M.: High levels of the hydroxyl radical in the winter urban troposphere, Geophys. Res. Lett., 31, L18112, https://doi.org/18110.11029/12004GL020544, 2004.

Highwood, E. and Ryder, C.: Radiative effects of dust, in: Mineral Dust, edited by: Knippertz, P. and Stuut, J.-B. W., Springer, the Netherlands, 267-286, 2014.

Hoffman, R. C., Gebel, M. E., Fox, B. S., and Finlayson-Pitts, B. J.: Knudsen cell studies of the reactions of $\mathrm{N}_{2} \mathrm{O}_{5}$ and $\mathrm{ClONO}_{2}$ with 
$\mathrm{NaCl}$ : development and application of a model for estimating available surface areas and corrected uptake coefficients, Phys. Chem. Chem. Phys., 5, 1780-1789, 2003a.

Hoffman, R. C., Kaleuati, M. A., and Finlayson-Pitts, B. J.: Knudsen cell studies of the reaction of gaseous $\mathrm{HNO}_{3}$ with $\mathrm{NaCl}$ using less than a single layer of particles at $298 \mathrm{~K}$ : a modified mechanism, J. Phys. Chem. A, 107, 7818-7826, 2003 b.

Hofzumahaus, A., Rohrer, F., Lu, K. D., Bohn, B., Brauers, T., Chang, C. C., Fuchs, H., Holland, F., Kita, K., Kondo, Y., Li, X., Lou, S. R., Shao, M., Zeng, L. M., Wahner, A., and Zhang, Y. H.: Amplified trace gas removal in the troposphere, Science, 324, 1702-1704, 2009.

Holland, F., Hofzumahaus, A., Schäfer, J., Kraus, A., and Pätz, H.W.: Measurements of $\mathrm{OH}$ and $\mathrm{HO} 2$ radical concentrations and photolysis frequencies during BERLIOZ, J. Geophys. Res.Atmos, 108, 8246, https://doi.org/8210.1029/2001JD001393, 2003.

Hoose, C. and Möhler, O.: Heterogeneous ice nucleation on atmospheric aerosols: a review of results from laboratory experiments, Atmos. Chem. Phys., 12, 9817-9854, https://doi.org/10.5194/acp-12-9817-2012, 2012.

Hoose, C., Kristjansson, J. E., and Burrows, S. M.: How important is biological ice nucleation in clouds on a global scale?, Environ. Res. Lett., 5, 024009, https://doi.org/10.1088/17489326/5/2/024009, 2010.

Hou, S. Q., Tong, S. R., Zhang, Y., Tan, F., Guo, Y. C., and Ge, M. F.: Heterogeneous uptake of gas-phase acetic acid on $\alpha-\mathrm{Al}_{2} \mathrm{O}_{3}$ particle surface: the impact of temperature, Chem. Asian J., 11, 2749-2755, https://doi.org/10.1002/asia.201600402, 2016.

Hua, W., Chen, Z. M., Jie, C. Y., Kondo, Y., Hofzumahaus, A., Takegawa, N., Chang, C. C., Lu, K. D., Miyazaki, Y., Kita, K., Wang, H. L., Zhang, Y. H., and Hu, M.: Atmospheric hydrogen peroxide and organic hydroperoxides during PRIDE-PRD'06, China: their concentration, formation mechanism and contribution to secondary aerosols, Atmos. Chem. Phys., 8, 6755-6773, https://doi.org/10.5194/acp-8-6755-2008, 2008.

Huang, J. P., Wang, T. H., Wang, W. C., Li, Z. Q., and Yan, H. R.: Climate effects of dust aerosols over East Asian arid and semiarid regions, J. Geophys. Res.-Atmos., 119, 11398-11416, 2014.

Huang, L., Zhao, Y., Li, H., and Chen, Z.: Kinetics of heterogeneous reaction of sulfur dioxide on authentic mineral dust: effects of relative humidity and hydrogen peroxide, Environ. Sci. Technol., 49, 10797-10805, 2015a.

Huang, X., Song, Y., Zhao, C., Cai, X., Zhang, H., and Zhu, T.: Direct radiative effect by multicomponent aerosol over China, J. Climate, 28, 3472-3495, 2015b.

Huang, J., Yu, H., Guan, X., Wang, G., and Guo, R.: Accelerated dryland expansion under climate change, Nat. Clim. Change, 6, 166-171, 2016.

Huff, D. M., Joyce, P. L., Fochesatto, G. J., and Simpson, W. R.: Deposition of dinitrogen pentoxide, $\mathrm{N}_{2} \mathrm{O}_{5}$, to the snowpack at high latitudes, Atmos. Chem. Phys., 11, 4929-4938, https://doi.org/10.5194/acp-11-4929-2011, 2011.

Huneeus, N., Schulz, M., Balkanski, Y., Griesfeller, J., Prospero, J., Kinne, S., Bauer, S., Boucher, O., Chin, M., Dentener, F., Diehl, T., Easter, R., Fillmore, D., Ghan, S., Ginoux, P., Grini, A., Horowitz, L., Koch, D., Krol, M. C., Landing, W., Liu, X., Mahowald, N., Miller, R., Morcrette, J.-J., Myhre, G., Pen- ner, J., Perlwitz, J., Stier, P., Takemura, T., and Zender, C. S.: Global dust model intercomparison in AeroCom phase I, Atmos. Chem. Phys., 11, 7781-7816, https://doi.org/10.5194/acp11-7781-2011, 2011.

Ingham, T., Goddard, A., Whalley, L. K., Furneaux, K. L., Edwards, P. M., Seal, C. P., Self, D. E., Johnson, G. P., Read, K. A., Lee, J. D., and Heard, D. E.: A flow-tube based laser-induced fluorescence instrument to measure $\mathrm{OH}$ reactivity in the troposphere, Atmos. Meas. Tech., 2, 465-477, https://doi.org/10.5194/amt-2465-2009, 2009.

Itahashi, S., Uno, I., Irie, H., Kurokawa, J.-I., and Ohara, T.: Regional modeling of tropospheric $\mathrm{NO}_{2}$ vertical column density over East Asia during the period 2000-2010: comparison with multisatellite observations, Atmos. Chem. Phys., 14, 3623-3635, https://doi.org/10.5194/acp-14-3623-2014, 2014.

Ito, A. and $\mathrm{Xu}, \mathrm{L} .:$ Response of acid mobilization of ironcontaining mineral dust to improvement of air quality projected in the future, Atmos. Chem. Phys., 14, 3441-3459, https://doi.org/10.5194/acp-14-3441-2014, 2014.

Jacob, D. J.: Heterogeneous chemistry and tropospheric ozone, Atmos. Environ., 34, 2131-2159, 2000.

James, A. D., Moon, D. R., Feng, W., Lakey, P. S. J., Frankland, V. L., Heard, D. E., and Plane, J. M. C.: The uptake of $\mathrm{HO}_{2}$ on meteoric smoke analogues, J. Geophys. Res.-Atmos, 122, 554-565, 2017.

Jeong, G. R. and Sokolik, I. N.: Effect of mineral dust aerosols on the photolysis rates in the clean and polluted marine environments, J. Geophys. Res.-Atmos., 112, D21308, https://doi.org/21310.21029/22007jd008442, 2007.

Jeong, G. Y.: Bulk and single-particle mineralogy of Asian dust and a comparison with its source soils, J. Geophys. Res.-Atmos., 113, D02208, https://doi.org/02210.01029/02007jd008606, 2008.

Jickells, T. D., An, Z. S., Andersen, K. K., Baker, A. R., Bergametti, G., Brooks, N., Cao, J. J., Boyd, P. W., Duce, R. A., Hunter, K. A., Kawahata, H., Kubilay, N., laRoche, J., Liss, P. S., Mahowald, N., Prospero, J. M., Ridgwell, A. J., Tegen, I., and Torres, R.: Global iron connections between desert dust, ocean biogeochemistry, and climate, Science, 308, 67-71, 2005.

Jickells, T., Boyd, P., and Hunter, K.: Biogeochemical impacts of dust on the global carbon cycle, in: Mineral Dust, edited by: Knippertz, P. and Stuut, J.-B. W., Springer, the Netherlands, 359384, 2014.

Journet, E., Desboeufs, K. V., Caquineau, S., and Colin, J.-L.: Mineralogy as a critical factor of dust iron solubility, Geophys. Res. Lett., 35, L07805, https://doi.org/10.01029/02007GL031589, 2008.

Journet, E., Balkanski, Y., and Harrison, S. P.: A new data set of soil mineralogy for dust-cycle modeling, Atmos. Chem. Phys., 14, 3801-3816, https://doi.org/10.5194/acp-14-3801-2014, 2014.

Jung, J., Kim, Y. J., Lee, K. Y., -Cayetano, M. G., Batmunkh, T., Koo, J.-H., and Kim, J.: Spectral optical properties of longrange transport Asian dust and pollution aerosols over Northeast Asia in 2007 and 2008, Atmos. Chem. Phys., 10, 5391-5408, https://doi.org/10.5194/acp-10-5391-2010, 2010.

Kaiser, E. W. and Wu, C. H.: A kinetic study of the gas phase formation and decomposition reactions of nitrous acid, J. Phys. Chem., 81, 1701-1706, 1977.

Kanaya, Y., Cao, R., Akimoto, H., Fukuda, M., Komazaki, Y., Yokouchi, Y., Koike, M., Tanimoto, H., Takegawa, N., and Kondo, Y.: 
Urban photochemistry in central Tokyo: 1 . Observed and modeled $\mathrm{OH}$ and $\mathrm{HO}_{2}$ radical concentrations during the winter and summer of 2004, J. Geophys. Res.-Atmos, 112, D21312, https://doi.org/21310.21029/22007JD008670, 2007a.

Kanaya, Y., Cao, R. Q., Akimoto, H., Fukuda, M., Komazaki, Y., Yokouchi, Y., Koike, M., Tanimoto, H., Takegawa, N., and Kondo, Y.: Urban photochemistry in central Tokyo: 1. Observed and modeled $\mathrm{OH}$ and $\mathrm{HO}_{2}$ radical concentrations during the winter and summer of 2004, J. Geophys. Res.-Atmos., 112, D21312, https://doi.org/21310.21029/22007JD008670, 2007b.

Kandler, K., Schutz, L., Deutscher, C., Ebert, M., Hofmann, H., Jackel, S., Jaenicke, R., Knippertz, P., Lieke, K., Massling, A., Petzold, A., Schladitz, A., Weinzierl, B., Wiedensohler, A., Zorn, S., and Weinbruch, S.: Size distribution, mass concentration, chemical and mineralogical composition and derived optical parameters of the boundary layer aerosol at Tinfou, Morocco, during SAMUM 2006, Tellus B, 61, 32-50, 2009.

Karagulian, F. and Rossi, M. J.: The heterogeneous chemical kinetics of $\mathrm{NO}_{3}$ on atmospheric mineral dust surrogates, Phys. Chem. Chem. Phys., 7, 3150-3162, 2005.

Karagulian, F. and Rossi, M. J.: The heterogeneous decomposition of ozone on atmospheric mineral dust surrogates at ambient temperature, Int. J. Chem. Kinet., 38, 407-419, 2006.

Karagulian, F., Santschi, C., and Rossi, M. J.: The heterogeneous chemical kinetics of $\mathrm{N}_{2} \mathrm{O}_{5}$ on $\mathrm{CaCO}_{3}$ and other atmospheric mineral dust surrogates, Atmos. Chem. Phys., 6, 1373-1388, https://doi.org/10.5194/acp-6-1373-2006, 2006.

Keyser, L. F., Moore, S. B., and Leu, M. T.: Surface-reaction and pore diffusion in flow-tube reactors, J. Phys. Chem.-US, 95, 5496-5502, 1991.

Keyser, L. F., Leu, M. T., and Moore, S. B.: Comment on porosities of ice films used to simulate stratospheric cloud surfaces, J. Phys. Chem., 97, 2800-2801, 1993.

Koehler, K. A., Kreidenweis, S. M., DeMott, P. J., Petters, M. D., Prenni, A. J., and Carrico, C. M.: Hygroscopicity and cloud droplet activation of mineral dust aerosol, Geophys. Res. Lett., 36, L08805, https://doi.org/08810.01029/02009g1037348, 2009.

Kok, J. F., Ridley, D. A., Zhou, Q., Miller, R. L., Zhao, C., Heald, C. L., Ward, D. S., Albani, S., and Haustein, K.: Smaller desert dust cooling effect estimated from analysis of dust size and abundance, Nat. Geosci., 10, 274-278, 2017.

Kolb, C. E., Cox, R. A., Abbatt, J. P. D., Ammann, M., Davis, E. J., Donaldson, D. J., Garrett, B. C., George, C., Griffiths, P. T., Hanson, D. R., Kulmala, M., McFiggans, G., Pöschl, U., Riipinen, I., Rossi, M. J., Rudich, Y., Wagner, P. E., Winkler, P. M., Worsnop, D. R., and O' Dowd, C. D.: An overview of current issues in the uptake of atmospheric trace gases by aerosols and clouds, Atmos. Chem. Phys., 10, 10561-10605, https://doi.org/10.5194/acp-1010561-2010, 2010.

Kong, L. D., Zhao, X., Sun, Z. Y., Yang, Y. W., Fu, H. B., Zhang, S. C., Cheng, T. T., Yang, X., Wang, L., and Chen, J. M.: The effects of nitrate on the heterogeneous uptake of sulfur dioxide on hematite, Atmos. Chem. Phys., 14, 9451-9467, https://doi.org/10.5194/acp-14-9451-2014, 2014.

Krieger, U. K., Marcolli, C., and Reid, J. P.: Exploring the complexity of aerosol particle properties and processes using single particle techniques, Chem. Soc. Rev., 41, 6631-6662, 2012.

Krueger, B. J., Grassian, V. H., Iedema, M. J., Cowin, J. P., and Laskin, A.: Probing heterogeneous chemistry of individual atmo- spheric particles using scanning electron microscopy and energydispersive X-ray analysis, Anal. Chem., 75, 5170-5179, $2003 \mathrm{a}$.

Krueger, B. J., Grassian, V. H., Laskin, A., and Cowin, J. P.: The transformation of solid atmospheric particles into liquid droplets through heterogeneous chemistry: laboratory insights into the processing of calcium containing mineral dust aerosol in the troposphere, Geophys. Res. Lett., 30, 1148, https://doi.org/1110.1029/2002g1016563, 2003b.

Kulkarni, G., Zhang, K., Zhao, C., Nandasiri, M., Shutthanandan, V., Liu, X., Fast, J., and Berg, L.: Ice formation on nitric acid coated dust particles: laboratory and modeling studies, J. Geophys. Res.-Atmos, 120, 7682-7698, 2015.

Kumar, P., Sokolik, I. N., and Nenes, A.: Parameterization of cloud droplet formation for global and regional models: including adsorption activation from insoluble CCN, Atmos. Chem. Phys., 9, 2517-2532, https://doi.org/10.5194/acp-9-2517-2009, 2009.

Kumar, R., Barth, M. C., Madronich, S., Naja, M., Carmichael, G. R., Pfister, G. G., Knote, C., Brasseur, G. P., Ojha, N., and Sarangi, T.: Effects of dust aerosols on tropospheric chemistry during a typical pre-monsoon season dust storm in northern India, Atmos. Chem. Phys., 14, 6813-6834, https://doi.org/10.5194/acp-14-6813-2014, 2014.

Ladino Moreno, L. A., Stetzer, O., and Lohmann, U.: Contact freezing: a review of experimental studies, Atmos. Chem. Phys., 13 9745-9769, https://doi.org/10.5194/acp-13-9745-2013, 2013.

Lampimaki, M., Zelenay, V., Krepelova, A., Liu, Z., Chang, R., Bluhm, H., and Ammann, M.: Ozone-induced band bending on metal-oxide surfaces studied under environmental conditions, ChemPhysChem, 14, 2419-2425, 2013.

Langridge, J. M., Gustafsson, R. J., Griffiths, P. T., Cox, R. A., Lambert, R. M., and Jones, R. L.: Solar driven nitrous acid formation on building material surfaces containing titanium dioxide: a concern for air quality in urban areas?, Atmos. Environ., 43, 51285131, 2009.

Laskin, A., Iedema, M. J., Ichkovich, A., Graber, E. R., Taraniuk, I., and Rudich, Y.: Direct observation of completely processed calcium carbonate dust particles, Faraday Discuss., 130, 453-468, 2005a.

Laskin, A., Wietsma, T. W., Krueger, B. J., and Grassian, V. H.: Heterogeneous chemistry of individual mineral dust particles with nitric acid: a combined CCSEM/EDX, ESEM, and ICP-MS study, J. Geophys. Res.-Atmos., 110, D10208, https://doi.org/10.1029/2004JD005206, 2005b.

Laufs, S., Burgeth, G., Duttlinger, W., Kurtenbach, R., Maban, M., Thomas, C., Wiesen, P., and Kleffmann, J.: Conversion of nitrogen oxides on commercial photocatalytic dispersion paints, Atmos. Environ., 44, 2341-2349, 2010.

Lee, A. K. Y. and Chan, C. K.: Heterogeneous reactions of linoleic acid and linolenic acid particles with ozone: reaction pathways and changes in particle mass, hygroscopicity, and morphology, J. Phys. Chem. A, 111, 6285-6295, 2007.

Lee, A. K. Y., Ling, T. Y., and Chan, C. K.: Understanding hygroscopic growth and phase transformation of aerosols using single particle Raman spectroscopy in an electrodynamic balance, Faraday Discuss., 137, 245-263, 2008.

Lelieveld, J., Butler, T. M., Crowley, J. N., Dillon, T. J., Fischer, H., Ganzeveld, L., Harder, H., Lawrence, M. G., Martinez, M., Taraborrelli, D., and Williams, J.: Atmospheric oxidation capacity sustained by a tropical forest, Nature, 452, 737-740, 2008. 
Lemaître, C., Flamant, C., Cuesta, J., Raut, J.-C., Chazette, P., Formenti, P., and Pelon, J.: Radiative heating rates profiles associated with a springtime case of Bodélé and Sudan dust transport over West Africa, Atmos. Chem. Phys., 10, 8131-8150, https://doi.org/10.5194/acp-10-8131-2010, 2010.

Li, W. and Oyama, S. T.: Mechanism of ozone decomposition on a manganese oxide catalyst. 2. Steady-state and transient kinetic studies, J. Am. Chem. Soc., 120, 9047-9052, 1998.

Li, W. J. and Shao, L. Y.: Observation of nitrate coatings on atmospheric mineral dust particles, Atmos. Chem. Phys., 9, 18631871, https://doi.org/10.5194/acp-9-1863-2009, 2009.

Li, W., Gibbs, G. V., and Oyama, S. T.: Mechanism of ozone decomposition on a manganese oxide catalyst. I. In situ Raman spectroscopy and ab initio molecular orbital calculations, J. Am. Chem. Soc., 120, 9041-9046, 1998.

Li, L., Chen, Z. M., Zhang, Y. H., Zhu, T., Li, J. L., and Ding, J.: Kinetics and mechanism of heterogeneous oxidation of sulfur dioxide by ozone on surface of calcium carbonate, Atmos. Chem. Phys., 6, 2453-2464, https://doi.org/10.5194/acp-6-24532006, 2006.

Li, H. J., Zhu, T., Zhao, D. F., Zhang, Z. F., and Chen, Z. M.: Kinetics and mechanisms of heterogeneous reaction of $\mathrm{NO}_{2}$ on $\mathrm{CaCO}_{3}$ surfaces under dry and wet conditions, Atmos. Chem. Phys., 10, 463-474, https://doi.org/10.5194/acp-10-463-2010, 2010.

Li, P., Al-Abadleh, H. A., and Grassian, V. H.: Measuring heterogeneous uptake coefficients of gases on solid particle surfaces with a Knudsen cell reactor: complications due to surface saturation and gas diffusion into underlying layers, J. Phys. Chem. A, 106, 1210-1219, 2002.

Li, X., Brauers, T., Häseler, R., Bohn, B., Fuchs, H., Hofzumahaus, A., Holland, F., Lou, S., Lu, K. D., Rohrer, F., Hu, M., Zeng, L. M., Zhang, Y. H., Garland, R. M., Su, H., Nowak, A., Wiedensohler, A., Takegawa, N., Shao, M., and Wahner, A.: Exploring the atmospheric chemistry of nitrous acid (HONO) at a rural site in Southern China, Atmos. Chem. Phys., 12, 1497-1513, https://doi.org/10.5194/acp-12-1497-2012, 2012.

Li, G., Su, H., Li, X., Kuhn, U., Meusel, H., Hoffmann, T., Ammann, M., Pöschl, U., Shao, M., and Cheng, Y.: Uptake of gaseous formaldehyde by soil surfaces: a combination of adsorption/desorption equilibrium and chemical reactions, Atmos. Chem. Phys., 16, 10299-10311, https://doi.org/10.5194/acp-1610299-2016, 2016.

Liao, H., Yung, Y. L., and Seinfeld, J. H.: Effects of aerosols on tropospheric photolysis rates in clear and cloudy atmospheres, J. Geophys. Res.-Atmos., 104, 23697-23707, 1999.

Liao, J., Huey, L. G., Liu, Z., Tanner, D. J., Cantrell, C. A., Orlando, J. J., Flocke, F. M., Shepson, P. B., Weinheimer, A. J., Hall, S. R., Ullmann, K., Beine, H. J., Wang, Y., Ingall, E. D., Stephens, C. R., Hornbrook, R. S., Apel, E. C., Riemer, D., Fried, A., Mauldin Iii, R. L., Smith, J. N., Staebler, R. M., Neuman, J. A., and Nowak, J. B.: High levels of molecular chlorine in the Arctic atmosphere, Nat. Geosci., 7, 91-94, 2014.

Lipfert, F. W.: Atmospheric damage to calcareous stones: Comparison and reconciliation of recent experimental findings, Atmos. Environ., 23, 415-429, 1989.

Liu, H. M., Lian, Z. W., Ye, X. J., and Shangguan, W. F.: Kinetic analysis of photocatalytic oxidation of gas-phase formaldehyde over titanium dioxide, Chemosphere, 60, 630-635, 2005.
Liu, Y. C., He, H., and Mu, Y. J.: Heterogeneous reactivity of carbonyl sulfide on $\alpha-\mathrm{Al}_{2} \mathrm{O}_{3}$ and $\gamma-\mathrm{Al}_{2} \mathrm{O}_{3}$, Atmos. Environ., 42, 960-969, 2008a.

Liu, Y. J., Zhu, T., Zhao, D. F., and Zhang, Z. F.: Investigation of the hygroscopic properties of $\mathrm{Ca}\left(\mathrm{NO}_{3}\right)_{2}$ and internally mixed $\mathrm{Ca}\left(\mathrm{NO}_{3}\right)_{2} / \mathrm{CaCO}_{3}$ particles by micro-Raman spectrometry, Atmos. Chem. Phys., 8, 7205-7215, https://doi.org/10.5194/acp-87205-2008, 2008b.

Liu, Y., Ma, J., and He, H.: Heterogeneous reactions of carbonyl sulfide on mineral oxides: mechanism and kinetics study, Atmos. Chem. Phys., 10, 10335-10344, https://doi.org/10.5194/acp-1010335-2010, 2010.

Liu, C., Ma, Q., Liu, Y., Ma, J., and He, H.: Synergistic reaction between $\mathrm{SO}_{2}$ and $\mathrm{NO}_{2}$ on mineral oxides: a potential formation pathway of sulfate aerosol, Phys. Chem. Chem. Phys., 14, 16681676, 2012.

Liu, Y., Han, C., Ma, J., Bao, X., and He, H.: Influence of relative humidity on heterogeneous kinetics of $\mathrm{NO}_{2}$ on kaolin and hematite, Phys. Chem. Chem. Phys., 17, 19424-19431, 2015.

Lohmann, U. and Feichter, J.: Global indirect aerosol effects: a review, Atmos. Chem. Phys., 5, 715-737, https://doi.org/10.5194/acp-5-715-2005, 2005.

Lou, S., Holland, F., Rohrer, F., Lu, K., Bohn, B., Brauers, T., Chang, C. C., Fuchs, H., Häseler, R., Kita, K., Kondo, Y., Li, X., Shao, M., Zeng, L., Wahner, A., Zhang, Y., Wang, W., and Hofzumahaus, A.: Atmospheric $\mathrm{OH}$ reactivities in the Pearl River Delta - China in summer 2006: measurement and model results, Atmos. Chem. Phys., 10, 11243-11260, https://doi.org/10.5194/acp-10-11243-2010, 2010.

Lu, K. D., Rohrer, F., Holland, F., Fuchs, H., Bohn, B., Brauers, T., Chang, C. C., Häseler, R., Hu, M., Kita, K., Kondo, Y., Li, X., Lou, S. R., Nehr, S., Shao, M., Zeng, L. M., Wahner, A., Zhang, Y. H., and Hofzumahaus, A.: Observation and modelling of $\mathrm{OH}$ and $\mathrm{HO}_{2}$ concentrations in the Pearl River Delta 2006: a missing $\mathrm{OH}$ source in a VOC rich atmosphere, Atmos. Chem. Phys., 12, 1541-1569, https://doi.org/10.5194/acp-12-1541-2012, 2012.

Lu, K. D., Hofzumahaus, A., Holland, F., Bohn, B., Brauers, T., Fuchs, H., Hu, M., Häseler, R., Kita, K., Kondo, Y., Li, X., Lou, S. R., Oebel, A., Shao, M., Zeng, L. M., Wahner, A., Zhu, T., Zhang, Y. H., and Rohrer, F.: Missing $\mathrm{OH}$ source in a suburban environment near Beijing: observed and modelled $\mathrm{OH}$ and $\mathrm{HO}_{2}$ concentrations in summer 2006, Atmos. Chem. Phys., 13, 10571080, https://doi.org/10.5194/acp-13-1057-2013, 2013.

Lu, K. D., Rohrer, F., Holland, F., Fuchs, H., Brauers, T., Oebel, A., Dlugi, R., Hu, M., Li, X., Lou, S. R., Shao, M., Zhu, T., Wahner, A., Zhang, Y. H., and Hofzumahaus, A.: Nighttime observation and chemistry of $\mathrm{HO}_{\mathrm{x}}$ in the Pearl River Delta and Beijing in summer 2006, Atmos. Chem. Phys., 14, 4979-4999, https://doi.org/10.5194/acp-14-4979-2014, 2014.

Ma, Q. X., Liu, Y. C., Liu, C., and He, H.: Heterogeneous reaction of acetic acid on $\mathrm{MgO}, \alpha-\mathrm{Al}_{2} \mathrm{O}_{3}$, and $\mathrm{CaCO}_{3}$ and the effect on the hygroscopic behavior of these particles, Phys. Chem. Chem. Phys., 14, 8403-8409, 2012.

Macintyre, H. L. and Evans, M. J.: Sensitivity of a global model to the uptake of $\mathrm{N}_{2} \mathrm{O}_{5}$ by tropospheric aerosol, Atmos. Chem. Phys., 10, 7409-7414, https://doi.org/10.5194/acp10-7409-2010, 2010.

Macintyre, H. L. and Evans, M. J.: Parameterisation and impact of aerosol uptake of $\mathrm{HO}_{2}$ on a global tropospheric model, Atmos. 
Chem. Phys., 11, 10965-10974, https://doi.org/10.5194/acp-1110965-2011, 2011.

Mahowald, N.: Aerosol indirect effect on biogeochemical cycles and climate, Science, 334, 794-796, 2011.

Mahowald, N. M., Baker, A. R., Bergametti, G., Brooks, N., Duce, R. A., Jickells, T. D., Kubilay, N., Prospero, J. M., and Tegen, I.: Atmospheric global dust cycle and iron inputs to the ocean, Global Biogeochem. Cy., 19, GB4025, https://doi.org/4010.1029/2004GB002402, 2005.

Mahowald, N. M., Ballantine, J. A., Feddema, J., and Ramankutty, N.: Global trends in visibility: implications for dust sources, Atmos. Chem. Phys., 7, 3309-3339, https://doi.org/10.5194/acp-73309-2007, 2007.

Mahowald, N., Jickells, T. D., Baker, A. R., Artaxo, P., BenitezNelson, C. R., Bergametti, G., Bond, T. C., Chen, Y., Cohen, D. D., Herut, B., Kubilay, N., Losno, R., Luo, C., Maenhaut, W., McGee, K. A., Okin, G. S., Siefert, R. L., and Tsukuda, S.: Global distribution of atmospheric phosphorus sources, concentrations and deposition rates, and anthropogenic impacts, Global Biogeochem. Cy., 22, GB4026, https://doi.org/4010.1029/2008GB003240., 2008.

Mahowald, N., Ward, D. S., Kloster, S., Flanner, M. G., Heald, C. L., Heavens, N. G., Hess, P. G., Lamarque, J.-F., and Chuang, P. Y.: Aerosol impacts on climate and biogeochemistry, Annu. Rev. Env. Resour., 36, 45-74, 2011.

Mao, J., Jacob, D. J., Evans, M. J., Olson, J. R., Ren, X., Brune, W. H., Clair, J. M. St., Crounse, J. D., Spencer, K. M., Beaver, M. R., Wennberg, P. O., Cubison, M. J., Jimenez, J. L., Fried, A., Weibring, P., Walega, J. G., Hall, S. R., Weinheimer, A. J., Cohen, R. C., Chen, G., Crawford, J. H., McNaughton, C., Clarke, A. D., Jaeglé, L., Fisher, J. A., Yantosca, R. M., Le Sager, P., and Carouge, C.: Chemistry of hydrogen oxide radicals $\left(\mathrm{HO}_{\mathrm{X}}\right)$ in the Arctic troposphere in spring, Atmos. Chem. Phys., 10, 58235838, https://doi.org/10.5194/acp-10-5823-2010, 2010a.

Mao, J., Ren, X., Chen, S., Brune, W. H., Chen, Z., Martinez, M., Harder, H., Lefer, B., Rappenglück, B., Flynn, J., and Leuchner, M.: Atmospheric oxidation capacity in the summer of Houston 2006: Comparison with summer measurements in other metropolitan studies, Atmos. Environ., 44, 4107-4115, $2010 \mathrm{~b}$.

Mao, J., Ren, X., Zhang, L., Van Duin, D. M., Cohen, R. C., Park, J.-H., Goldstein, A. H., Paulot, F., Beaver, M. R., Crounse, J. D., Wennberg, P. O., DiGangi, J. P., Henry, S. B., Keutsch, F. N., Park, C., Schade, G. W., Wolfe, G. M., Thornton, J. A., and Brune, W. H.: Insights into hydroxyl measurements and atmospheric oxidation in a California forest, Atmos. Chem. Phys., 12, 8009-8020, https://doi.org/10.5194/acp-12-8009-2012, 2012.

Mao, J., Fan, S., Jacob, D. J., and Travis, K. R.: Radical loss in the atmosphere from $\mathrm{Cu}-\mathrm{Fe}$ redox coupling in aerosols, Atmos. Chem. Phys., 13, 509-519, https://doi.org/10.5194/acp-13-5092013, 2013a.

Mao, J. Q., Paulot, F., Jacob, D. J., Cohen, R. C., Crounse, J. D., Wennberg, P. O., Keller, C. A., Hudman, R. C., Barkley, M. P., and Horowitz, L. W.: Ozone and organic nitrates over the eastern United States: sensitivity to isoprene chemistry, J. Geophys. Res.-Atmos., 118, 11256-11268, 2013b.

Martinez, M., Perner, D., Hackenthal, E. M., Kulzer, S., and Schutz, L.: $\mathrm{NO}_{3}$ at Helgoland during the NORDEX campaign in October 1996, J. Geophys. Res.-Atmos., 105, 22685-22695, 2000 .
Matsuki, A., Iwasaka, Y., Shi, G. Y., Zhang, D. Z., Trochkine, D., Yamada, M., Kim, Y. S., Chen, B., Nagatani, T., Miyazawa, T., Nagatani, M., and Nakata, H.: Morphological and chemical modification of mineral dust: observational insight into the heterogeneous uptake of acidic gases, Geophys. Res. Lett., 32, L22806, https://doi.org/22810.21029/22005gl024176, 2005.

Matthews, P. S. J., Baeza-Romero, M. T., Whalley, L. K., and Heard, D. E.: Uptake of $\mathrm{HO}_{2}$ radicals onto Arizona test dust particles using an aerosol flow tube, Atmos. Chem. Phys., 14, 7397-7408, https://doi.org/10.5194/acp-14-7397-2014, 2014.

Mauldin III, R. L., Berndt, T., Sipila, M., Paasonen, P., Petaja, T., Kim, S., Kurten, T., Stratmann, F., Kerminen, V. M., and Kulmala, M.: A new atmospherically relevant oxidant of sulphur dioxide, Nature, 488, 193-196, 2012.

Meng, Z. and Lu, B.: Dust events as a risk factor for daily hospitalization for respiratory and cardiovascular diseases in Minqin, China, Atmos. Environ., 41, 7048-7058, 2007.

Meskhidze, N., Chameides, W. L., and Nenes, A.: Dust and pollution: a recipe for enhanced ocean fertilization?, J. Geophys. Res.-Atmos., 110, D03301, https://doi.org/03310.01029/02004jd005082, 2005.

Michel, A. E., Usher, C. R., and Grassian, V. H.: Heterogeneous and catalytic uptake of ozone on mineral oxides and dusts: A Knudsen cell investigation, Geophys. Res. Lett., 29, 1665, https://doi.org/10.1029/2002g1014896, 2002.

Michel, A. E., Usher, C. R., and Grassian, V. H.: Reactive uptake of ozone on mineral oxides and mineral dusts, Atmos. Environ., 37, 3201-3211, 2003.

Mihelcic, D., Holland, F., Hofzumahaus, A., Hoppe, L., Konrad, S., Müsgen, P., Pätz, H. W., Schäfer, H. J., Schmitz, T., Volz-Thomas, A., Bächmann, K., Schlomski, S., Platt, U., Geyer, A., Alicke, B., and Moortgat, G. K.: Peroxy radicals during BERLIOZ at Pabstthum: measurements, radical budgets and ozone production, J. Geophys. Res.-Atmos, 108, 8254, https://doi.org/8210.1029/2001JD001014, 2003.

Mogili, P. K., Kleiber, P. D., Young, M. A., and Grassian, V. H.: Heterogeneous uptake of ozone on reactive components of mineral dust aerosol: an environmental aerosol reaction chamber study, J. Phys. Chem. A, 110, 13799-13807, 2006a.

Mogili, P. K., Kleiber, P. D., Young, M. A., and Grassian, V. H.: $\mathrm{N}_{2} \mathrm{O}_{5}$ hydrolysis on the components of mineral dust and sea salt aerosol: comparison study in an environmental aerosol reaction chamber, Atmos. Environ., 40, 7401-7408, 2006b.

Moon, D. R., Taverna, G. S., Anduix-Canto, C., Ingham, T., Chipperfield, M. P., Seakins, P. W., Baeza-Romero, M.-T., and Heard, D. E.: Heterogeneous reaction of $\mathrm{HO}_{2}$ with airborne $\mathrm{TiO}_{2}$ particles and its implication for climate change mitigation strategies, Atmos. Chem. Phys. Discuss., https://doi.org/10.5194/acp-2017439, in review, 2017.

Morgan, W. T., Ouyang, B., Allan, J. D., Aruffo, E., Di Carlo, P., Kennedy, O. J., Lowe, D., Flynn, M. J., Rosenberg, P. D., Williams, P. I., Jones, R., McFiggans, G. B., and Coe, H.: Influence of aerosol chemical composition on $\mathrm{N}_{2} \mathrm{O}_{5}$ uptake: airborne regional measurements in northwestern Europe, Atmos. Chem. Phys., 15, 973-990, https://doi.org/10.5194/acp-15-9732015, 2015.

Morman, S. and Plumlee, G.: Dust and human health, in: Mineral Dust, edited by: Knippertz, P. and Stuut, J.-B. W., Springer, the Netherlands, 385-409, 2014. 
Moteki, N., Adachi, K., Ohata, S., Yoshida, A., Harigaya, T., Koike, M., and Kondo, Y.: Anthropogenic iron oxide aerosols enhance atmospheric heating, Nat. Commun., 8, 15329, https://doi.org/10.1038/ncomms15329, 2017.

Murray, B. J., O’Sullivan, D., Atkinson, J. D., and Webb, M. E.: Ice nucleation by particles immersed in supercooled cloud droplets, Chem. Soc. Rev., 41, 6519-6554, 2012.

Naderi, M.: Chapter Fourteen - Surface area: Brunauer-EmmettTeller (BET) A2 - Tarleton, Steve, in: Progress in Filtration and Separation, Academic Press, Oxford, 585-608, 2015.

Nanayakkara, C. E., Jayaweera, P. M., Rubasinghege, G., Baltrusaitis, J., and Grassian, V. H.: Surface photochemistry of adsorbed nitrate: the role of adsorbed water in the formation of reduced nitrogen species on $\alpha-\mathrm{Fe}_{2} \mathrm{O}_{3}$ particle surfaces, J. Phys. Chem. A, 118, 158-166, 2013.

Nanayakkara, C. E., Dillon, J. K., and Grassian, V. H.: Surface adsorption and photochemistry of gas-phase formic acid on $\mathrm{TiO}_{2}$ nanoparticles: the role of adsorbed water in surface coordination, adsorption kinetics, and rate of photoproduct formation, J. Phys. Chem. C, 118, 25487-25495, 2014.

Ndour, M., Nicolas, M., D’Anna, B., Ka, O., and George, C.: Photoreactivity of $\mathrm{NO}_{2}$ on mineral dusts originating from different locations of the Sahara desert, Phys. Chem. Chem. Phys., 11, 1312-1319, 2009.

Nenes, A., Krom, M. D., Mihalopoulos, N., Van Cappellen, P., Shi, Z., Bougiatioti, A., Zarmpas, P., and Herut, B.: Atmospheric acidification of mineral aerosols: a source of bioavailable phosphorus for the oceans, Atmos. Chem. Phys., 11, 6265-6272, https://doi.org/10.5194/acp-11-6265-2011, 2011.

Net, S., Nieto-Gligorovski, L., Gligorovski, S., TemimeRousell, B., Barbati, S., Lazarou, Y. G., and Wortharn, H.: Heterogeneous light-induced ozone processing on the organic coatings in the atmosphere, Atmos. Environ., 43, 1683-1692, 2009.

Net, S., Gligorovski, S., Pietri, S., and Wortham, H.: Photoenhanced degradation of veratraldehyde upon the heterogeneous ozone reactions, Phys. Chem. Chem. Phys., 12, 7603-7611, 2010a.

Net, S., Gligorovski, S., and Wortham, H.: Light-induced heterogeneous ozone processing on organic coated particles: kinetics and condensed-phase products, Atmos. Environ., 44, 3286-3294, 2010 b.

Net, S., Gomez Alvarez, E., Balzer, N., Wortham, H., Zetzsch, C., and Gligorovski, S.: Photolysis and heterogeneous reaction of coniferyl aldehyde adsorbed on silica particles with ozone, ChemPhysChem, 11, 4019-4027, 2010c.

Net, S., Nieto-Gligorovski, L., Gligorovski, S., and Wortham, H.: Heterogeneous ozonation kinetics of 4-phenoxyphenol in the presence of photosensitizer, Atmos. Chem. Phys., 10, 15451554, https://doi.org/10.5194/acp-10-1545-2010, 2010d.

Net, S., Alvarez, E. G., Gligorovski, S., and Wortham, H.: Heterogeneous reactions of ozone with methoxyphenols, in presence and absence of light, Atmos. Environ., 45, 3007-3014, 2011.

Nickovic, S., Vukovic, A., Vujadinovic, M., Djurdjevic, V., and Pejanovic, G.: Technical Note: High-resolution mineralogical database of dust-productive soils for atmospheric dust modeling, Atmos. Chem. Phys., 12, 845-855, https://doi.org/10.5194/acp12-845-2012, 2012.

Nicolas, M., Ndour, M., Ka, O., D'anna, B., and George, C.: Photochemistry of atmospheric dust: ozone decomposition on illu- minatd titanium dioxide, Environ. Sci. Technol., 43, 7347-7442, 2009.

Nie, W., Ding, A., Wang, T., Kerminen, V.-M., George, C., Xue, L., Wang, W., Zhang, Q., Petaja, T., Qi, X., Gao, X., Wang, X., Yang, X., Fu, C., and Kulmala, M.: Polluted dust promotes new particle formation and growth, Sci. Rep., 4, 6634, https://doi.org/10.1038/srep06634, 2014.

Noguchi, T., Fujishima, A., Sawunyama, P., and Hashimoto, K.: Photocatalytic degradation of gaseous formaldehyde using $\mathrm{TiO}_{2}$ film, Environ. Sci. Technol., 32, 3831-3833, 1998.

Nölscher, A. C., Williams, J., Sinha, V., Custer, T., Song, W., Johnson, A. M., Axinte, R., Bozem, H., Fischer, H., Pouvesle, N., Phillips, G., Crowley, J. N., Rantala, P., Rinne, J., Kulmala, M., Gonzales, D., Valverde-Canossa, J., Vogel, A., Hoffmann, T., Ouwersloot, H. G., Vilà-Guerau de Arellano, J., and Lelieveld, J.: Summertime total $\mathrm{OH}$ reactivity measurements from boreal forest during HUMPPA-COPEC 2010, Atmos. Chem. Phys., 12, 8257-8270, https://doi.org/10.5194/acp-12-8257-2012, 2012.

Obee, T. N. and Brown, R. T.: $\mathrm{TiO}_{2}$ photocatalysis for indoor air applications: effects of humidity and trace contaminant levels on the oxidation rates of formaldehyde, toluene, and 1,3-butadiene, Environ. Sci. Technol., 29, 1223-1231, 1995.

Okada, K., Heintzenberg, J., Kai, K. J., and Qin, Y.: Shape of atmospheric mineral particles collected in three Chinese arid-regions, Geophys. Res. Lett., 28, 3123-3126, 2001.

Osthoff, H. D., Roberts, J. M., Ravishankara, A. R., Williams, E. J., Lerner, B. M., Sommariva, R., Bates, T. S., Coffman, D., Quinn, P. K., Dibb, J. E., Stark, H., Burkholder, J. B., Talukdar, R. K., Meagher, J., Fehsenfeld, F. C., and Brown, S. S.: High levels of nitryl chloride in the polluted subtropical marine boundary layer, Nat. Geosci., 1, 324-328, 2008.

Ouyang, B., McLeod, M. W., Jones, R. L., and Bloss, W. J.: $\mathrm{NO}_{3}$ radical production from the reaction between the Criegee intermediate $\mathrm{CH}_{2} \mathrm{OO}$ and $\mathrm{NO}_{2}$, Phys. Chem. Chem. Phys., 15, 17070-17075, 2013.

Pöschl, U.: Gas-particle interactions of tropospheric aerosols: Kinetic and thermodynamic perspectives of multiphase chemical reactions, amorphous organic substances, and the activation of cloud condensation nuclei, Atmos. Res., 101, 562-573, 2011.

Pöschl, U. and Shiraiwa, M.: Multiphase chemistry at the atmosphere-biosphere interface influencing climate and public health in the anthropocene, Chem. Rev., 115, 4440-4475, 2015.

Park, J.-H., Ivanov, A. V., and Molina, M. J.: Effect of relative humidity on $\mathrm{OH}$ uptake by surfaces of atmospheric importance, J. Phys. Chem. A, 112, 6968-6977, 2008.

Percival, C. J., Welz, O., Eskola, A. J., Savee, J. D., Osborn, D. L., Topping, D. O., Lowe, D., Utembe, S. R., Bacak, A., McFiggans, G., Cooke, M. C., Xiao, P., Archibald, A. T., Jenkin, M. E., Derwent, R. G., Riipinen, I., Mok, D. W. K., Lee, E. P. F., Dyke, J. M., Taatjes, C. A., and Shallcross, D. E.: Regional and global impacts of Criegee intermediates on atmospheric sulphuric acid concentrations and first steps of aerosol formation, Faraday Discuss., 165, 45-73, 2013.

Phillips, G. J., Tang, M. J., Thieser, J., Brickwedde, B., Schuster, G., Bohn, B., Lelieveld, J., and Crowley, J. N.: Significant concentrations of nitryl chloride observed in rural continental Europe associated with the influence of sea salt chloride and anthropogenic emissions, Geophys. Res. Lett., 39, L10811, https://doi.org/10.1029/2012g1051912, 2012. 
Phillips, G. J., Thieser, J., Tang, M., Sobanski, N., Schuster, G., Fachinger, J., Drewnick, F., Borrmann, S., Bingemer, H., Lelieveld, J., and Crowley, J. N.: Estimating N2O5 uptake coefficients using ambient measurements of $\mathrm{NO}_{3}, \mathrm{~N}_{2} \mathrm{O}_{5}, \mathrm{ClNO}_{2}$ and particle-phase nitrate, Atmos. Chem. Phys., 16, 13231-13249, https://doi.org/10.5194/acp-16-13231-2016, 2016.

Pope, F. D., Dennis-Smither, B. J., Griffiths, P. T., Clegg, S. L., and Cox, R. A.: Studies of single aerosol particles containing malonic acid, glutaric acid, and their mixtures with sodium chloride. I. Hygroscopic growth, J. Phys. Chem. A, 114, 5335-5341, 2010.

Pope, F. D., Braesicke, P., Grainger, R. G., Kalberer, M., Watson, I. M., Davidson, P. J., and Cox, R. A.: Stratospheric aerosol particles and solar-radiation management, Nat. Clim. Change, 2, 713-719, 2012.

Pöschl, U., Rudich, Y., and Ammann, M.: Kinetic model framework for aerosol and cloud surface chemistry and gas-particle interactions - Part 1: General equations, parameters, and terminology, Atmos. Chem. Phys., 7, 5989-6023, https://doi.org/10.5194/acp7-5989-2007, 2007.

Pradhan, M., Kalberer, M., Griffiths, P. T., Braban, C. F., Pope, F. D., Cox, R. A., and Lambert, R. M.: Uptake of gaseous hydrogen peroxide by submicrometer titanium dioxide aerosol as a function of relative humidity, Environ. Sci. Technol., 44, 1360-1365, 2010a.

Pradhan, M., Kyriakou, G., Archibald, A. T., Papageorgiou, A. C., Kalberer, M., and Lambert, R. M.: Heterogeneous uptake of gaseous hydrogen peroxide by Gobi and Saharan dust aerosols: a potential missing sink for $\mathrm{H}_{2} \mathrm{O}_{2}$ in the troposphere, Atmos. Chem. Phys., 10, 7127-7136, https://doi.org/10.5194/acp-107127-2010, 2010b.

Prospero, J. M.: Mineral and sea salt aerosol concentrations in various ocean regions, J. Geophys. Res.-Atmos, 84, 725-731, 1979.

Prospero, J. M.: Long-range transport of mineral dust in the global atmosphere: impact of African dust on the environment of the southeastern United States, P. Natl. Acad. Sci. USA, 96, 33963403, 1999.

Raff, J. D., Njegic, B., Chang, W. L., Gordon, M. S., Dabdub, D., Gerber, R. B., and Finlayson-Pitts, B. J.: Chrorine activation indoors and outdoors via surface-mediated reactions of nitrogen oxides with hydrogen chloride, P. Natl. Acad. Sci. USA, 106, 13647-13654, 2009.

Real, E. and Sartelet, K.: Modeling of photolysis rates over Europe: impact on chemical gaseous species and aerosols, Atmos. Chem. Phys., 11, 1711-1727, https://doi.org/10.5194/acp11-1711-2011, 2011.

Ren, X., Harder, H., Martinez, M., Lesher, R. L., Oliger, A., Simpas, J. B., Brune, W. H., Schwab, J. J., Demerjian, K. L., He, Y., Zhou, X., and Gao, H.: $\mathrm{OH}$ and $\mathrm{HO}_{2}$ chemistry in the urban atmosphere of New York City, Atmos. Environ., 37, 3639-3651, 2003.

Rkiouak, L., Tang, M. J., Camp, J. C. J., McGregor, J., Watson, I. M., Cox, R. A., Kalberer, M., Ward, A. D., and Pope, F. D.: Optical trapping and Raman Spectroscopy of solid aerosol particles, Phys. Chem. Chem. Phys., 16, 11426-11434, 2014.

Ro, C. U., Hwang, H., Chun, Y., and Van Grieken, R.: Singleparticle characterization of four "Asian Dust" samples collected in Korea, using low-Z particle electron probe X-ray microanalysis, Environ. Sci. Technol., 39, 1409-1419, 2005.
Rohrer, F., Lu, K. D., Hofzumahaus, A., Bohn, B., Brauers, T., Chang, C. C., Fuchs, H., Haseler, R., Holland, F., Hu, M., Kita, K., Kondo, Y., Li, X., Lou, S. R., Oebel, A., Shao, M., Zeng, L. M., Zhu, T., Zhang, Y. H., and Wahner, A.: Maximum efficiency in the hydroxyl-radical-based self-cleansing of the troposphere, Nat. Geosci., 7, 559-563, 2014.

Romanias, M. N., El Zein, A., and Bedjanian, Y.: Heterogeneous interaction of $\mathrm{H}_{2} \mathrm{O}_{2}$ with $\mathrm{TiO}_{2}$ surface under dark and UV light irradiation conditions, J. Phys. Chem. A, 116, 8191-8200, 2012 a.

Romanias, M. N., El Zein, A., and Bedjanian, Y.: Reactive uptake of HONO on aluminium oxide surface, J. Photoch. Photobio. A, 250, 50-57, 2012b.

Romanias, M. N., El Zein, A., and Bedjanian, Y.: Uptake of hydrogen peroxide on the surface of $\mathrm{Al}_{2} \mathrm{O}_{3}$ and $\mathrm{Fe}_{2} \mathrm{O}_{3}$, Atmos. Environ., 77, 1-8, 2013.

Roscoe, J. M. and Abbatt, J. P. D.: Diffuse reflectance FTIR study of the interaction of alumina surfaces with ozone and water vapor, J. Phys. Chem. A, 109, 9028-9034, 2005.

Rosenfeld, D., Rudich, Y., and Lahav, R.: Desert dust suppressing precipitation: a possible desertification feedback loop, P. Natl. Acad. Sci. USA, 98, 5975-5980, 2001.

Rosenfeld, D., Lohmann, U., Raga, G. B., O’Dowd, C. D., Kulmala, M., Fuzzi, S., Reissell, A., and Andreae, M. O.: Flood or drought: how do aerosols affect precipitation?, Science, 321, 1309-1313, 2008.

Rubasinghege, G. and Grassian, V. H.: Surface-catalyzed chlorine and nitrogen activation: mechanisms for the heterogeneous formation of $\mathrm{ClNO}, \mathrm{NO}, \mathrm{NO}_{2}, \mathrm{HONO}$, and $\mathrm{N}_{2} \mathrm{O}$ from $\mathrm{HNO}_{3}$ and $\mathrm{HCl}$ on aluminum oxide particle surfaces, J. Phys. Chem. A, 116, 5180-5192, 2012.

Rubasinghege, G. and Grassian, V. H.: Role(s) of adsorbed water in the surface chemistry of environmental interfaces, Chem. Commun., 49, 3071-3094, 2013.

Ryder, O. S., Ault, A. P., Cahill, J. F., Guasco, T. L., Riedel, T. P., Cuadra-Rodriguez, L. A., Gaston, C. J., Fitzgerald, E., Lee, C., Prather, K. A., and Bertram, T. H.: On the role of particle inorganic mixing state in the reactive uptake of $\mathrm{N}_{2} \mathrm{O}_{5}$ to ambient aerosol particles, Environ. Sci. Technol., 48, 1618-1627, https://doi.org/10.1021/es4042622, 2014.

Sassine, M., Burel, L., D’Anna, B., and George, C.: Kinetics of the tropospheric formaldehyde loss onto mineral dust and urban surfaces, Atmos. Environ., 44, 5468-5475, 2010.

Scanza, R. A., Mahowald, N., Ghan, S., Zender, C. S., Kok, J. F., Liu, X., Zhang, Y., and Albani, S.: Modeling dust as component minerals in the Community Atmosphere Model: development of framework and impact on radiative forcing, Atmos. Chem. Phys., 15, 537-561, https://doi.org/10.5194/acp-15-537-2015, 2015.

Scheuvens, D., Schütz, L., Kandler, K., Ebert, M., and Weinbruch, S.: Bulk composition of northern African dust and its source sediments - a compilation, Earth-Sci. Rev., 116, 170-194, 2013.

Schulz, M., Prospero, J. M., Baker, A. R., Dentener, F., Ickes, L., Liss, P. S., Mahowald, N. M., Nickovic, S., García-Pando, C. P., Rodríguez, S., Sarin, M., Tegen, I., and Duce, R. A.: Atmospheric transport and deposition of mineral dust to the ocean: implications for research needs, Environ. Sci. Technol., 46, 1039010404, 2012

Seinfeld, J. H., Carmichael, G. R., Arimoto, R., Conant, W. C., Brechtel, F. J., Bates, T. S., Cahill, T. A., Clarke, A. D., Do- 
herty, S. J., Flatau, P. J., Huebert, B. J., Kim, J., Markowicz, K. M., Quinn, P. K., Russell, L. M., Russell, P. B., Shimizu, A., Shinozuka, Y., Song, C. H., Tang, Y., Uno, I., Vogelmann, A. M., Weber, R. J., Woo, J.-H., and Zhang, X. Y.: ACE-ASIA: regional climatic and atmospheric chemical effects of Asian dust and pollution, B. Am. Meteorol. Soc., 85, 367-380, 2004.

Seinfeld, J. H. and Pandis, S. N.: Atmospheric Chemistry and Physics: From Air Pollution to Climate Change, Wiley Interscience, New York, 2006.

Seisel, S., Börensen, C., Vogt, R., and Zellner, R.: Kinetics and mechanism of the uptake of $\mathrm{N}_{2} \mathrm{O}_{5}$ on mineral dust at $298 \mathrm{~K}$, Atmos. Chem. Phys., 5, 3423-3432, https://doi.org/10.5194/acp-53423-2005, 2005.

Seyfioglu, R., Odabasi, M., and Cetin, E.: Wet and dry deposition of formaldehyde in Izmir, Turkey, Sci. Total Environ., 366, 809$818,2006$.

Shao, M., Zhang, Y., Zeng, L., Tang, X., Zhang, J., Zhong, L., and Wang, B.: Ground-level ozone in the Pearl River Delta and the roles of VOC and $\mathrm{NO}_{\mathrm{x}}$ in its production, J. Environ. Manage., 90, 512-518, 2009.

Shen, X., Zhao, Y., Chen, Z., and Huang, D.: Heterogeneous reactions of volatile organic compounds in the atmosphere, Atmos. Environ., 68, 297-314, 2013.

Shi, Z., Zhang, D., Hayashi, M., Ogata, H., Ji, H., and Fujiie, W.: Influences of sulfate and nitrate on the hygroscopic behaviour of coarse dust particles, Atmos. Environ., 42, 822-827, 2008.

Shi, Z. B., Krom, M. D., Jickells, T. D., Bonneville, S., Carslaw, K. S., Mihalopoulos, N., Baker, A. R., and Benning, L. G.: Impacts on iron solubility in the mineral dust by processes in the source region and the atmosphere: a review, Aeolian Res., 5, 21-42, 2012.

Shiraiwa, M., Ammann, M., Koop, T., and Poschl, U.: Gas uptake and chemical aging of semisolid organic aerosol particles, P. Natl. Acad. Sci. USA, 108, 11003-11008, 2011.

Shiraiwa, M., Pfrang, C., Koop, T., and Pöschl, U.: Kinetic multilayer model of gas-particle interactions in aerosols and clouds (KM-GAP): linking condensation, evaporation and chemical reactions of organics, oxidants and water, Atmos. Chem. Phys., 12, 2777-2794, https://doi.org/10.5194/acp-12-2777-2012, 2012.

Shirley, T. R., Brune, W. H., Ren, X., Mao, J., Lesher, R., Cardenas, B., Volkamer, R., Molina, L. T., Molina, M. J., Lamb, B., Velasco, E., Jobson, T., and Alexander, M.: Atmospheric oxidation in the Mexico City Metropolitan Area (MCMA) during April 2003, Atmos. Chem. Phys., 6, 27532765, https://doi.org/10.5194/acp-6-2753-2006, 2006.

Sihvonen, S. K., Schill, G. P., Lyktey, N. A., Veghte, D. P., Tolbert, M. A., and Freedman, M. A.: Chemical and physical transformations of aluminosilicate clay minerals due to acid treatment and consequences for heterogeneous ice nucleation, J. Phys. Chem. A, 118, 8787-8796, 2014.

Simpson, W. R., Brown, S. S., Saiz-Lopez, A., Thornton, J. A., and Glasow, R. V.: Tropospheric halogen chemistry: sources, cycling, and impacts, Chem. Rev., 115, 4035-4062, 2015.

Sing, K. S. W.: 7 - Assessment of surface area by gas adsorption, in: Adsorption by Powders and Porous Solids, 2nd edn., Academic Press, Oxford, 237-268, 2014.

Sinha, V., Williams, J., Crowley, J. N., and Lelieveld, J.: The Comparative Reactivity Method - a new tool to measure total $\mathrm{OH}$
Reactivity in ambient air, Atmos. Chem. Phys., 8, 2213-2227, https://doi.org/10.5194/acp-8-2213-2008, 2008.

Sobanski, N., Tang, M. J., Thieser, J., Schuster, G., Pöhler, D., Fischer, H., Song, W., Sauvage, C., Williams, J., Fachinger, J., Berkes, F., Hoor, P., Platt, U., Lelieveld, J., and Crowley, J. N.: Chemical and meteorological influences on the lifetime of $\mathrm{NO}_{3}$ at a semi-rural mountain site during PARADE, Atmos. Chem. Phys., 16, 4867-4883, https://doi.org/10.5194/acp16-4867-2016, 2016.

Song, C. H., Kim, C. M., Lee, Y. J., Carmichael, G. R., Lee, B. K., and Lee, D. S.: An evaluation of reaction probabilities of sulfate and nitrate precursors onto East Asian dust particles, J. Geophys. Res.-Atmos., 112, D18206, https://doi.org/10.1029/2006jd008092, 2007.

Spicer, C. W., Chapman, E. G., Finlayson-Pitts, B. J., Plastridge, R. A., Hubbe, J. M., Fast, J. D., and Berkowitz, C. M.: Unexpectedly high concentrations of molecular chlorine in coastal air, Nature, 394, 353-356, 1998.

Stockwell, W. R.: On the $\mathrm{HO}_{2}+\mathrm{HO}_{2}$ reaction: its misapplication in atmospheric chemistry models, J. Geophys. Res.-Atmos., 100, 11695-11698, https://doi.org/10.1029/94jd03107, 1995.

Stockwell, W. R., Kirchner, F., Kuhn, M., and Seefeld, S.: A new mechanism for regional atmospheric chemistry modeling, J. Geophys. Res.-Atmos, 102, 25847-25879, 1997.

Stone, D., Whalley, L. K., and Heard, D. E.: Tropospheric OH and $\mathrm{HO}_{2}$ radicals: field measurements and model comparisons, Chem. Soc. Rev., 41, 6348-6404, 2012.

Striegel, M. F., Bede Guin, E., Hallett, K., Sandoval, D., Swingle, R., Knox, K., Best, F., and Fornea, S.: Air pollution, coatings, and cultural resources, Prog. Org. Coat., 48, 281-288, 2003.

Stutz, J., Alicke, B., and Neftel, A.: Nitrous acid formation in the urban atmosphere: gradient measurements of $\mathrm{NO}_{2}$ and $\mathrm{HONO}$ over grass in Milan, Italy, J. Geophys. Res.-Atmos., 107, 8192, https://doi.org/8110.1029/2001jd000390, 2002.

Su, H., Cheng, Y. F., Shao, M., Gao, D. F., Yu, Z. Y., Zeng, L. M., Slanina, J., Zhang, Y. H., and Wiedensohler, A.: Nitrous acid (HONO) and its daytime sources at a rural site during the 2004 PRIDE-PRD experiment in China, J. Geophys. Res.-Atmos., 113, D14312, https://doi.org/14310.11029/12007jd009060, 2008.

Suh, M., Bagus, P. S., Pak, S., Rosynek, M. P., and Lunsford, J. H.: Reactions of hydroxyl radicals on titania, silica, alumina, and gold surfaces, J. Phys. Chem. B, 104, 2736-2742, 2000.

Sullivan, R. C. and Prather, K. A.: Investigations of the diurnal cycle and mixing state of oxalic acid in individual particles in Asian aerosol outflow, Environ. Sci. Technol., 41, 8062-8069, 2007.

Sullivan, R. C., Thornberry, T., and Abbatt, J. P. D.: Ozone decomposition kinetics on alumina: effects of ozone partial pressure, relative humidity and repeated oxidation cycles, Atmos. Chem. Phys., 4, 1301-1310, https://doi.org/10.5194/acp-4-1301-2004, 2004.

Sullivan, R. C., Guazzotti, S. A., Sodeman, D. A., and Prather, K. A.: Direct observations of the atmospheric processing of Asian mineral dust, Atmos. Chem. Phys., 7, 1213-1236, https://doi.org/10.5194/acp-7-1213-2007, 2007.

Sullivan, R. C., Moore, M. J. K., Petters, M. D., Kreidenweis, S. M., Roberts, G. C., and Prather, K. A.: Timescale for hygroscopic conversion of calcite mineral particles through heterogeneous 
reaction with nitric acid, Phys. Chem. Chem. Phys., 11, 78267837, 2009a.

Sullivan, R. C., Moore, M. J. K., Petters, M. D., Kreidenweis, S. M., Roberts, G. C., and Prather, K. A.: Effect of chemical mixing state on the hygroscopicity and cloud nucleation properties of calcium mineral dust particles, Atmos. Chem. Phys., 9, 33033316, https://doi.org/10.5194/acp-9-3303-2009, 2009b.

Sun, S., Ding, J., Bao, J., Gao, C., Qi, Z., and Li, C.: Photocatalytic oxidation of gaseous formaldehyde on $\mathrm{TiO}_{2}$ : an in situ DRIFTS study, Catal. Lett., 137, 239-246, 2010.

Syomin, D. A. and Finlayson-Pitts, B. J.: HONO decomposition on borosilicate glass surfaces: implications for environmental chamber studies and field experiments, Phys. Chem. Chem. Phys., 5, 5236-5242, 2003.

Ta, W. Q., Xiao, Z., Qu, J. J., Yang, G. S., and Wang, T.: Characteristics of dust particles from the desert/Gobi area of northwestern China during dust-storm periods, Environ. Geol., 43, 667-679, 2003

Taatjes, C. A., Welz, O., Eskola, A. J., Savee, J. D., Scheer, A. M., Shallcross, D. E., Rotavera, B., Lee, E. P. F., Dyke, J. M., Mok, D. K. W., Osborn, D. L., and Percival, C. J.: Direct measurements of conformer-dependent reactivity of the Criegee intermediate $\mathrm{CH}_{3} \mathrm{CHOO}$, Science, 340, 177-180, 2013.

Taatjes, C. A., Shallcross, D. E., and Percival, C. J.: Research frontiers in the chemistry of Criegee intermediates and tropospheric ozonolysis, Phys. Chem. Chem. Phys., 16, 1704-1718, 2014.

Tang, M. J., Thieser, J., Schuster, G., and Crowley, J. N.: Uptake of $\mathrm{NO}_{3}$ and $\mathrm{N}_{2} \mathrm{O}_{5}$ to Saharan dust, ambient urban aerosol and soot: a relative rate study, Atmos. Chem. Phys., 10, 2965-2974, https://doi.org/10.5194/acp-10-2965-2010, 2010.

Tang, M. J., Thieser, J., Schuster, G., and Crowley, J. N.: Kinetics and mechanism of the heterogeneous reaction of $\mathrm{N}_{2} \mathrm{O}_{5}$ with mineral dust particles, Phys. Chem. Chem. Phys., 14, 8551-8561, 2012.

Tang, M. J., Camp, J. C. J., Rkiouak, L., McGregor, J., Watson, I. M., Cox, R. A., Kalberer, M., Ward, A. D., and Pope, F. D.: Heterogeneous interaction of $\mathrm{SiO}_{2}$ with $\mathrm{N}_{2} \mathrm{O}_{5}$ : aerosol flow tube and single particle optical levitation-raman spectroscopy studies, J. Phys. Chem. A, 118, 8817-8827, 2014a.

Tang, M. J., Cox, R. A., and Kalberer, M.: Compilation and evaluation of gas phase diffusion coefficients of reactive trace gases in the atmosphere: volume 1. Inorganic compounds, Atmos. Chem. Phys., 14, 9233-9247, https://doi.org/10.5194/acp14-9233-2014, 2014b.

Tang, M. J., Schuster, G., and Crowley, J. N.: Heterogeneous reaction of $\mathrm{N}_{2} \mathrm{O}_{5}$ with illite and Arizona test dust particles, Atmos. Chem. Phys., 14, 245-254, https://doi.org/10.5194/acp-14-2452014, 2014c.

Tang, M. J., Telford, P. J., Pope, F. D., Rkiouak, L., Abraham, N. L., Archibald, A. T., Braesicke, P., Pyle, J. A., McGregor, J., Watson, I. M., Cox, R. A., and Kalberer, M.: Heterogeneous reaction of $\mathrm{N}_{2} \mathrm{O}_{5}$ with airborne $\mathrm{TiO}_{2}$ particles and its implication for stratospheric particle injection, Atmos. Chem. Phys., 14, 6035-6048, https://doi.org/10.5194/acp-14-6035-2014, 2014d.

Tang, M. J., Telford, P. J., Pope, F. D., Rkiouak, L., Abraham, N. L., Archibald, A. T., Braesicke, P., Pyle, J. A., McGregor, J., Watson, I. M., Cox, R. A., and Kalberer, M.: Corrigendum to "Heterogeneous reaction of $\mathrm{N}_{2} \mathrm{O}_{5}$ with airborne $\mathrm{TiO}_{2}$ particles and its implication for stratospheric particle injection" published in Atmos.
Chem. Phys., 14, 6035-6048, 2014, Atmos. Chem. Phys., 14, 8233-8234, https://doi.org/10.5194/acp-14-8233-2014, 2014e.

Tang, M. J., Shiraiwa, M., Pöschl, U., Cox, R. A., and Kalberer, M.: Compilation and evaluation of gas phase diffusion coefficients of reactive trace gases in the atmosphere: Volume 2. Diffusivities of organic compounds, pressure-normalised mean free paths, and average Knudsen numbers for gas uptake calculations, Atmos. Chem. Phys., 15, 5585-5598, https://doi.org/10.5194/acp15-5585-2015, 2015.

Tang, M. J., Cziczo, D. J., and Grassian, V. H.: Interactions of water with mineral dust aerosol: water adsorption, hygroscopicity, cloud condensation and ice nucleation, Chem. Rev., 116, 42054259, $2016 \mathrm{a}$.

Tang, M., Keeble, J., Telford, P. J., Pope, F. D., Braesicke, P., Griffiths, P. T., Abraham, N. L., McGregor, J., Watson, I. M., Cox, R. A., Pyle, J. A., and Kalberer, M.: Heterogeneous reaction of $\mathrm{ClONO}_{2}$ with $\mathrm{TiO}_{2}$ and $\mathrm{SiO}_{2}$ aerosol particles: implications for stratospheric particle injection for climate engineering, Atmos. Chem. Phys., 16, 15397-15412, https://doi.org/10.5194/acp-1615397-2016, 2016b.

Tang, Y., Carmichael, G. R., Kurata, G., Uno, I., Weber, R. J., Song, C. H., Guttikunda, S. K., Woo, J. H., Streets, D. G., Wei, C., Clarke, A. D., Huebert, B., and Anderson, T. L.: Impacts of dust on regional tropospheric chemistry during the ACE-Asia Experiment: a model study with observations, J. Geophys. Res., 109, D19S21, https://doi.org/10.1029/2003jd003806, 2004.

Ten Brink, H. M. and Spoelstra, H.: The dark decay of hono in environmental (SMOG) chambers, Atmos. Environ., 32, 247-251, 1998.

Textor, C., Schulz, M., Guibert, S., Kinne, S., Balkanski, Y., Bauer, S., Berntsen, T., Berglen, T., Boucher, O., Chin, M., Dentener, F., Diehl, T., Easter, R., Feichter, H., Fillmore, D., Ghan, S., Ginoux, P., Gong, S., Grini, A., Hendricks, J., Horowitz, L., Huang, P., Isaksen, I., Iversen, I., Kloster, S., Koch, D., Kirkevåg, A., Kristjansson, J. E., Krol, M., Lauer, A., Lamarque, J. F., Liu, X., Montanaro, V., Myhre, G., Penner, J., Pitari, G., Reddy, S., Seland, Ø., Stier, P., Takemura, T., and Tie, X.: Analysis and quantification of the diversities of aerosol life cycles within AeroCom, Atmos. Chem. Phys., 6, 1777-1813, https://doi.org/10.5194/acp-6-17772006, 2006.

Tham, Y. J., Wang, Z., Li, Q., Yun, H., Wang, W., Wang, X., Xue, L., Lu, K., Ma, N., Bohn, B., Li, X., Kecorius, S., Größ, J., Shao, M., Wiedensohler, A., Zhang, Y., and Wang, T.: Significant concentrations of nitryl chloride sustained in the morning: investigations of the causes and impacts on ozone production in a polluted region of northern China, Atmos. Chem. Phys., 16, 14959-14977, https://doi.org/10.5194/acp-16-14959-2016, 2016.

Thornton, J. and Abbatt, J. P. D.: Measurements of $\mathrm{HO}_{2}$ uptake to aqueous aerosol: mass accommodation coefficients and net reactive loss, J. Geophys. Res.-Atmos, 110, D08309, https://doi.org/08310.01029/02004JD005402, 2005.

Thornton, J. A., Kercher, J. P., Riedel, T. P., Wagner, N. L., Cozic, J., Holloway, J., S., Dube, W. P., Wolfe, G. M., Quinn, P. K., Middlebrook, A. M., Alexander, B., and Brown, S. S.: A large atomic chlorine source inferred from mid-continental reactive nitrogen chemistry, Nature, 464, 271-174, 2010.

Tie, X., Brasseur, G., Emmons, L., Horowitz, L., and Kinnison, D.: Effects of aerosols on tropospheric oxidants: a global model study, J. Geophys. Res.-Atmos., 106, 22931-22964, 2001. 
Tobo, Y., DeMott, P. J., Raddatz, M., Niedermeier, D., Hartmann, S., Kreidenweis, S. M., Stratmann, F., and Wex, H.: Impacts of chemical reactivity on ice nucleation of kaolinite particles: a case study of levoglucosan and sulfuric acid, Geophys. Res. Lett., 39, L19803, https://doi.org/19810.11029/12012g1053007, 2012.

Tong, H.-J., Reid, J. P., Bones, D. L., Luo, B. P., and Krieger, U. K.: Measurements of the timescales for the mass transfer of water in glassy aerosol at low relative humidity and ambient temperature, Atmos. Chem. Phys., 11, 4739-4754, https://doi.org/10.5194/acp-11-4739-2011, 2011.

Tong, S. R., Wu, L. Y., Ge, M. F., Wang, W. G., and Pu, Z. F.: Heterogeneous chemistry of monocarboxylic acids on $\alpha-\mathrm{Al}_{2} \mathrm{O}_{3}$ at different relative humidities, Atmos. Chem. Phys., 10, 75617574, https://doi.org/10.5194/acp-10-7561-2010, 2010.

Twohy, C. H., Kreidenweis, S. M., Eidhammer, T., Browell, E. V., Heymsfield, A. J., Bansemer, A. R., Anderson, B. E., Chen, G., Ismail, S., DeMott, P. J., and Van den Heever, S. C.: Saharan dust particles nucleate droplets in Eastern Atlantic clouds, Geophys. Res. Lett., 36, L01807, https://doi.org/01810.01029/02008g1035846, 2009.

Ullerstam, M., Vogt, R., Langer, S., and Ljungstrom, E.: The kinetics and mechanism of $\mathrm{SO}_{2}$ oxidation by $\mathrm{O}_{3}$ on mineral dust, Phys. Chem. Chem. Phys., 4, 4694-4699, 2002.

Umann, B., Arnold, F., Schaal, C., Hanke, M., Uecker, J., Aufmhoff, H., Balkanski, Y., and Van Dingenen, R.: Interaction of mineral dust with gas phase nitric acid and sulfur dioxide during the MINATROC II field campaign: first estimate of the uptake coefficient gamma $\left(\mathrm{HNO}_{3}\right)$ from atmospheric data, J. Geophys. Res.-Atmos., 110, D22306, https://doi.org/10.1029/2005jd005906, 2005.

Underwood, G. M., Li, P., Usher, C. R., and Grassian, V. H.: Determining accurate kinetic parameters of potentially important heterogeneous atmospheric reactions on solid particle surfaces with a Knudsen cell reactor, J. Phys. Chem. A, 104, 819-829, 2000.

Underwood, G. M., Li, P., Al-Abadleh, H., and Grassian, V. H.: A Knudsen cell study of the heterogeneous reactivity of nitric acid on oxide and mineral dust particles, J. Phys. Chem. A, 105, 6609-6620, 2001.

Uno, I., Eguchi, K., Yumimoto, K., Takemura, T., Shimizu, A., Uematsu, M., Liu, Z., Wang, Z., Hara, Y., and Sugimoto, N.: Asian dust transported one full circuit around the globe, Nat. Geosci., 2, 557-560, 2009.

Usher, C. R., Michel, A. E., and Grassian, V. H.: Reactions on mineral dust, Chem. Rev., 103, 4883-4939, 2003 a.

Usher, C. R., Michel, A. E., Stec, D., and Grassian, V. H.: Laboratory studies of ozone uptake on processed mineral dust, Atmos. Environ., 37, 5337-5347, 2003b.

Vlasenko, A., Sjogren, S., Weingartner, E., Stemmler, K., Gäggeler, H. W., and Ammann, M.: Effect of humidity on nitric acid uptake to mineral dust aerosol particles, Atmos. Chem. Phys., 6, 21472160, https://doi.org/10.5194/acp-6-2147-2006, 2006.

Vlasenko, A., Huthwelker, T., Gaggeler, H. W., and Ammann, M.: Kinetics of the heterogeneous reaction of nitric acid with mineral dust particles: an aerosol flow tube study, Phys. Chem. Chem. Phys., 11, 7921-7930, 2009.

Wagner, C., Hanisch, F., Holmes, N., de Coninck, H., Schuster, G., and Crowley, J. N.: The interaction of $\mathrm{N}_{2} \mathrm{O}_{5}$ with mineral dust: aerosol flow tube and Knudsen reactor studies, Atmos. Chem. Phys., 8, 91-109, https://doi.org/10.5194/acp-8-91-2008, 2008.
Wagner, C., Schuster, G., and Crowley, J. N.: An aerosol flow tube study of the interaction of $\mathrm{N}_{2} \mathrm{O}_{5}$ with calcite, Arizona dust and quartz, Atmos. Environ., 43, 5001-5008, 2009.

Wahner, A., Mentel, T. F., and Sohn, M.: Gas-phase reaction of $\mathrm{N}_{2} \mathrm{O}_{5}$ with water vapor: Importance of heterogeneous hydrolysis of $\mathrm{N}_{2} \mathrm{O}_{5}$ and surface desorption of $\mathrm{HNO}_{3}$ in a large teflon chamber, Geophys. Res. Lett., 25, 2169-2172, 1998.

Walker, R. A., Wilson, K., Lee, A. F., Woodford, J., Grassian, V. H., Baltrusaitis, J., Rubasinghege, G., Cibin, G., and Dent, A.: Preservation of York Minster historic limestone by hydrophobic surface coatings, Sci. Rep., 2, 880, https://doi.org/810.1038/srep00880, 2012.

Wang, Y. H. and Jacob, D. J.: Anthropogenic forcing on tropospheric ozone and $\mathrm{OH}$ since preindustrial times, J. Geophys. Res.-Atmos., 103, 31123-31135, 1998.

Wang, W. G., Ge, M. F., and Sun, Q.: Heterogeneous uptake of hydrogen peroxide on mineral oxides, Chin. J. Chem. Phys., 24, 515-520, 2011.

Wang, K., Zhang, Y., Nenes, A., and Fountoukis, C.: Implementation of dust emission and chemistry into the Community Multiscale Air Quality modeling system and initial application to an Asian dust storm episode, Atmos. Chem. Phys., 12, 1020910237, https://doi.org/10.5194/acp-12-10209-2012, 2012.

Wang, T., Tham, Y. J., Xue, L., Li, Q., Zha, Q., Wang, Z., Poon, S. C. N., Dubé, W. P., Blake, D. R., Louie, P. K. K., Luk, C. W. Y., Tsui, W., and Brown, S. S.: Observations of nitryl chloride and modeling its source and effect on ozone in the planetary boundary layer of southern China, J. Geophys. Res.Atmos, 121, 2476-2489, 2016.

Wayne, R. P., Barnes, I., Biggs, P., Burrows, J. P., Canosamas, C. E., Hjorth, J., Lebras, G., Moortgat, G. K., Perner, D., Poulet, G., Restelli, G., and Sidebottom, H.: The nitrate radical-physics, chemistry, and the atmosphere, Atmos. Environ., 25A, 1-203, 1991.

Webb, A. H., Bawden, R. J., Busby, A. K., and Hopkins, J. N.: Studies on the effects of air pollution on limestone degradation in Great Britain, Atmos. Environ., 26, 165-181, 1992.

Weisenstein, D. K., Keith, D. W., and Dykema, J. A.: Solar geoengineering using solid aerosol in the stratosphere, Atmos. Chem. Phys., 15, 11835-11859, https://doi.org/10.5194/acp-15-118352015, 2015.

Welz, O., Savee, J. D., Osborn, D. L., Vasu, S. S., Percival, C. J., Shallcross, D. E., and Taatjes, C. A.: Direct kinetic measurements of Criegee intermediate $\left(\mathrm{CH}_{2} \mathrm{OO}\right)$ formed by reaction of $\mathrm{CH}_{2} \mathrm{I}$ with $\mathrm{O}_{2}$, Science, 335, 204-207, 2012.

Wesely, M. L. and Hicks, B. B.: A review of the current status of knowledge on dry deposition, Atmos. Environ., 34, 2261-2282, 2000.

Wex, H., DeMott, P. J., Tobo, Y., Hartmann, S., Rösch, M., Clauss, T., Tomsche, L., Niedermeier, D., and Stratmann, F.: Kaolinite particles as ice nuclei: learning from the use of different kaolinite samples and different coatings, Atmos. Chem. Phys., 14, 55295546, https://doi.org/10.5194/acp-14-5529-2014, 2014.

Whalley, L. K., Edwards, P. M., Furneaux, K. L., Goddard, A., Ingham, T., Evans, M. J., Stone, D., Hopkins, J. R., Jones, C. E., Karunaharan, A., Lee, J. D., Lewis, A. C., Monks, P. S., Moller, S. J., and Heard, D. E.: Quantifying the magnitude of a missing hydroxyl radical source in a tropical rainforest, At- 
mos. Chem. Phys., 11, 7223-7233, https://doi.org/10.5194/acp11-7223-2011, 2011.

Wood, E. C., Bertram, T. H., Wooldridge, P. J., and Cohen, R. C.: Measurements of $\mathrm{N}_{2} \mathrm{O}_{5}, \mathrm{NO}_{2}$, and $\mathrm{O}_{3}$ east of the San Francisco Bay, Atmos. Chem. Phys., 5, 483-491, https://doi.org/10.5194/acp-5-483-2005, 2005.

Wu, L.-Y., Tong, S.-R., Zhou, L., Wang, W.-G., and Ge, M.-F.: Synergistic effects between $\mathrm{SO}_{2}$ and $\mathrm{HCOOH}$ on $\alpha-\mathrm{Fe}_{2} \mathrm{O}_{3}$, J. Phys. Chem. A, 117, 3972-3979, $2013 \mathrm{a}$.

Wu, L., Tong, S., and Ge, M.: Heterogeneous reaction of $\mathrm{NO}_{2}$ on $\mathrm{Al}_{2} \mathrm{O}_{3}$ : the effect of temperature on the nitrite and nitrate formation, J. Phys. Chem. A, 117, 4937-4944, 2013b.

Wu, L. Y., Tong, S. R., Wang, W. G., and Ge, M. F.: Effects of temperature on the heterogeneous oxidation of sulfur dioxide by ozone on calcium carbonate, Atmos. Chem. Phys., 11, 65936605, https://doi.org/10.5194/acp-11-6593-2011, 2011.

Xu, B. Y., Zhu, T., Tang, X. Y., Ding, J., and Li, H. J.: Heterogeneous reaction of formaldehyde on surface of $\alpha-\mathrm{Al}_{2} \mathrm{O}_{3}$ particles, Chem. J. Chinese U., 27, 1912-1917, 2006.

Xu, B. Y., Zhu, T., Tang, X. Y., and Shang, J.: Heterogeneous reaction of formaldehyde on the surface of $\mathrm{TiO}_{2}$ particles, Sci. China Chem., 53, 2644-2651, 2010.

Xu, B. Y., Shang, J., Zhu, T., and Tang, X. Y.: Heterogeneous reaction of formaldehyde on the surface of $\gamma-\mathrm{Al}_{2} \mathrm{O}_{3}$ particles, Atmos. Environ., 45, 3569-3575, 2011.

Yang, W. W., He, H., Ma, Q. X., Ma, J. Z., Liu, Y. C., Liu, P. F., and $\mathrm{Mu}$, Y. J.: Synergistic formation of sulfate and ammonium resulting from reaction between $\mathrm{SO}_{2}$ and $\mathrm{NH}_{3}$ on typical mineral dust, Phys. Chem. Chem. Phys., 18, 956-964, 2016a.

Yang, Y., Shao, M., Wang, X., Nölscher, A. C., Kessel, S., Guenther, A., and Williams, J.: Towards a quantitative understanding of total OH reactivity: a review, Atmos. Environ., 134, 147-161, 2016b.

Yang, Y., Russell, L. M., Lou, S., Liao, H., Guo, J., Liu, Y., Singh, B., and Ghan, S. J.: Dust-wind interactions can intensify aerosol pollution over eastern China, Nat. Commun., 8, 15333, https://doi.org/10.1038/ncomms15333, 2017.

Yi, J., Bahrini, C., Schoemaecker, C., Fittschen, C., and Choi, W.: Photocatalytic decomposition of $\mathrm{H}_{2} \mathrm{O}_{2}$ on different $\mathrm{TiO}_{2}$ surfaces along with the concurrent generation of $\mathrm{HO}_{2}$ radicals monitored using cavity ring down spectroscopy, J. Phys. Chem. C, 116, 10090-10097, 2012.

Zhang, Q., Streets, D. G., He, K., Wang, Y., Richter, A., Burrows, J. P., Uno, I., Jang, C. J., Chen, D., Yao, Z., and Lei, Y.: $\mathrm{NO}_{\mathrm{x}}$ emission trends for China, 1995-2004: the view from the ground and the view from space, J. Geophys. Res.-Atmos, 112, D22306, https://doi.org/22310.21029/22007JD008684, 2007.

Zhang, X. L., Wu, G. J., Zhang, C. L., Xu, T. L., and Zhou, Q. $\mathrm{Q}$.: What is the real role of iron oxides in the optical properties of dust aerosols?, Atmos. Chem. Phys., 15, 12159-12177, https://doi.org/10.5194/acp-15-12159-2015, 2015.

Zhang, X. Y., Gong, S. L., Shen, Z. X., Mei, F. M., Xi, X. X., Liu, L. C., Zhou, Z. J., Wang, D., Wang, Y. Q., and Cheng, Y.: Characterization of soil dust aerosol in China and its transport and distribution during 2001 ACE-Asia: 1. Network observations, J. Geophys. Res.-Atmos., 108, 4206, https://doi.org/4210.1029/2002jd002632, 2003a.

Zhang, X. Y., Gong, S. L., Zhao, T. L., Arimoto, R., Wang, Y. Q., and Zhou, Z. J.: Sources of Asian dust and role of climate change versus desertification in Asian dust emission, Geophys. Res. Lett., 30, 2272, https://doi.org/2210.1029/2003GL018206, 2003b.

Zhang, Y., Young, S. W., Kotamarthi, V., and Carmichael, G. R.: Photochemical oxidant processes in the presence of dust: an evaluation of the impact of dust on particulate nitrate and ozone formation, J. Appl. Meteorol., 33, 813-824, 1994.

Zhao, D. F., Zhu, T., Chen, Q., Liu, Y. J., and Zhang, Z. F.: Raman micro-spectrometry as a technique for investigating heterogeneous reactions on individual atmospheric particles, Sci. China Chem., 54, 154-160, 2011a.

Zhao, Y., Chen, Z. M., Shen, X. L., and Zhang, X. A.: Kinetics and mechanisms of heterogeneous reaction of gaseous hydrogen peroxide on mineral oxide particles, Environ. Sci. Technol., 45, 3317-3324, 2011b.

Zhao, Y., Chen, Z. M., Shen, X. L., and Huang, D.: Heterogeneous reactions of gaseous hydrogen peroxide on pristine and acidic gas-processed calcium carbonate particles: effects of relative humidity and surface coverage of coating, Atmos. Environ., 67, 6372, 2013.

Zhao, Y., Huang, D., Huang, L. B., and Chen, Z. M.: Hydrogen peroxide enhances the oxidation of oxygenated volatile organic compounds on mineral dust particles: a case study of methacrolein, Environ. Sci. Technol., 48, 10614-10623, 2014.

Zhao, X., Kong, L. D., Sun, Z. Y., Ding, X. X., Cheng, T. T., Yang, X., and Chen, J. M.: Interactions between heterogeneous uptake and adsorption of sulfur dioxide and acetaldehyde on hematite, J. Phys. Chem. A, 119, 4001-4008, 2015.

Zhou, L., Wang, W. G., and Ge, M. F.: Temperature dependence of heterogeneous uptake of hydrogen peroxide on silicon dioxide and calcium carbonate, J. Phys. Chem. A, 116, 7959-7964, 2012.

Zhou, L., Wang, W. G., Gai, Y. B., and Ge, M. F.: Knudsen cell and smog chamber study of the heterogeneous uptake of sulfur dioxide on Chinese mineral dust, J. Environ. Sci., 26, 2423-2433, 2014.

Zhou, L., Wang, W. G., Ge, M. F., and Tong, S. R.: Heterogeneous uptake of gaseous hydrogen peroxide on mineral dust, J. Environ. Sci., 28, 44-50, 2016.

Zhu, S., Butler, T., Sander, R., Ma, J., and Lawrence, M. G.: Impact of dust on tropospheric chemistry over polluted regions: a case study of the Beijing megacity, Atmos. Chem. Phys., 10, 38553873, https://doi.org/10.5194/acp-10-3855-2010, 2010.

Zhu, T., Shang, J., and Zhao, D. F.: The roles of heterogeneous chemical processes in the formation of an air pollution complex and gray haze, Sci. China Chem., 54, 145-153, 2011. 